This item was submitted to Loughborough's Research Repository by the author.

Items in Figshare are protected by copyright, with all rights reserved, unless otherwise indicated.

\title{
Pre-emptive game behaviour and the emergence of leadership
}

PLEASE CITE THE PUBLISHED VERSION

PUBLISHER

(C) J.M.D. Kremer

\section{PUBLISHER STATEMENT}

This work is made available according to the conditions of the Creative Commons Attribution-NonCommercialNoDerivatives 2.5 Generic (CC BY-NC-ND 2.5) licence. Full details of this licence are available at: http://creativecommons.org/licenses/by-nc-nd/2.5/

\section{LICENCE}

CC BY-NC-ND 2.5

\section{REPOSITORY RECORD}

Kremer, John M.D.. 2019. "Pre-emptive Game Behaviour and the Emergence of Leadership". figshare. https://hdl.handle.net/2134/27413. 


\section{Loughborough University}

This item was submitted to Loughborough University as a PhD thesis by the author and is made available in the Institutional Repository

(https://dspace.lboro.ac.uk/) under the following Creative Commons Licence conditions.

\section{cc) creative}

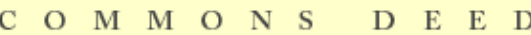

Attribution-NonCommercial-NoDerivs 2.5

You are free:

- to copy, distribute, display, and perform the work

Under the following conditions:

Attribution. You must attribute the work in the manner specified by the author or licensor.

Noncommercial. You may not use this work for commercial purposes.

No Derivative Works. You may not alter, transform, or build upon this work.

- For any reuse or distribution, you must make clear to others the license terms of this work.

- Any of these conditions can be waived if you get permission from the copyright holder.

Your fair use and other rights are in no way affected by the above.

This is a human-readable summary of the Leqal Code (the full license).

Disclaimer 민

For the full text of this licence, please go to: http://creativecommons.org/licenses/by-nc-nd/2.5/ 


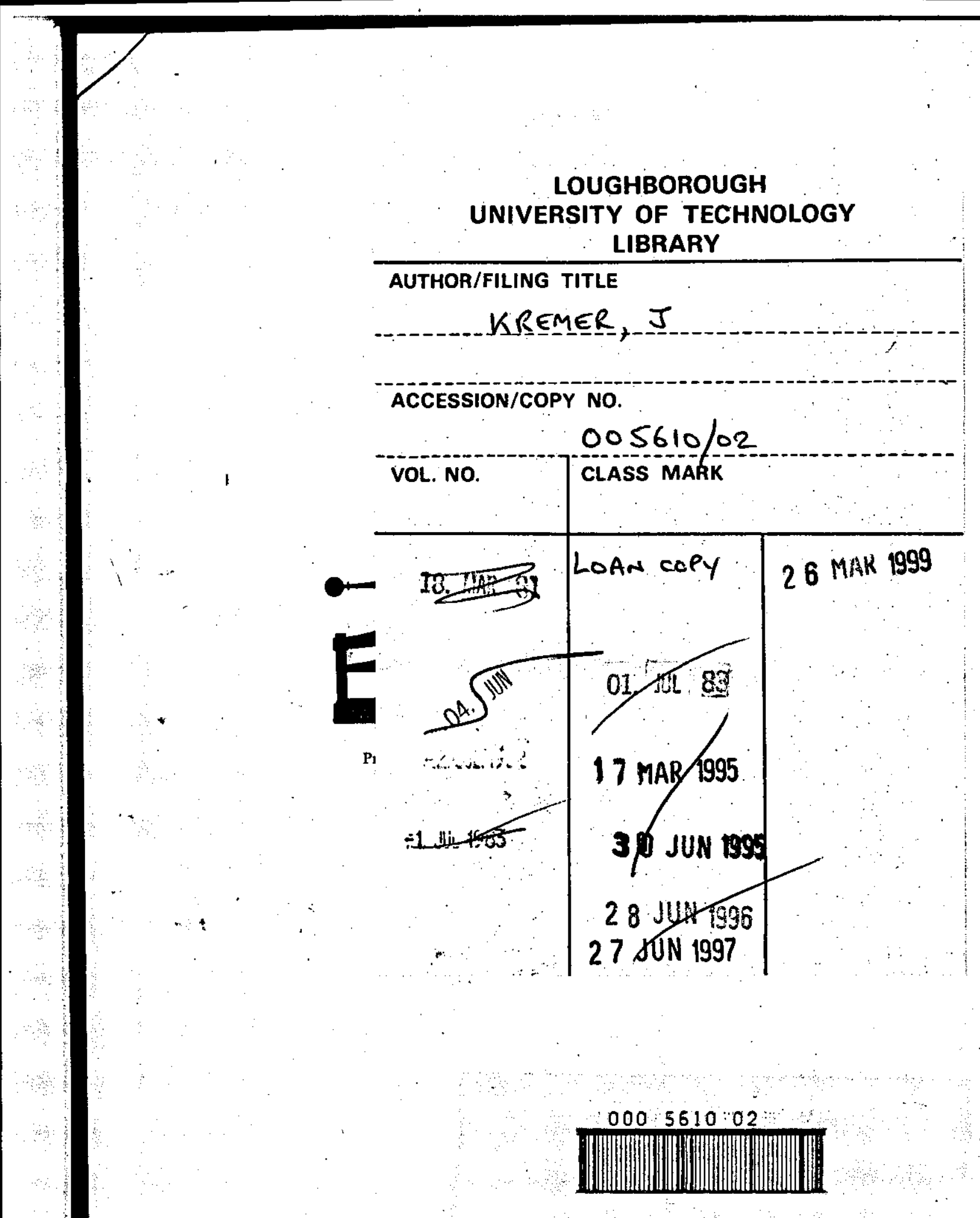


PRE-EMPTIVE GAME BEHAVIOUR AND THE

EMERGENCE OF LEADERSHIP

by

John Michael Dunkley KREMER

A Doctoral Thesis

Submitted in partial fulfilment of the requirements for the award of

Doctor of Philosophy

of the Loughborough University of Technology

(May, 1980)

(C J.M.D. Kremer, 1980

3 


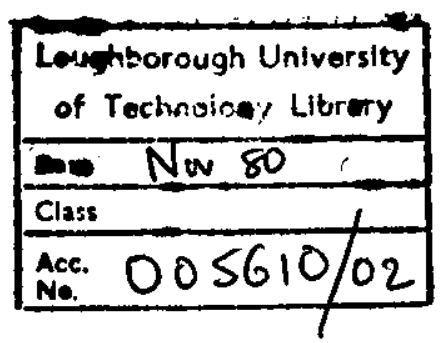




\section{ACKNOWLEDGEMENTS}

I should first of all like to thank Mike Turner for his assistance in the construction and maintenance of the experimental equipment. Also Sarah Gerard for help in the typing, and deciphering, of the project; Jane Crofts for proof reading the final draft; and all the First Year Social Psychology students at Loughborough who cooperated by taking part in the experiments. Lastly, I should especially like to thank David Mack for all his ideas, information and help throughout the duration of my work. 


\section{ABSTRACT}

The project considers the relationship between pre-emptive game behaviour in the mixed-motive game, Leader, and the emergence of leadership roles in unstructured groups. Four investigations are described, each comprising a game and a group situation respectively. In each instance, the game condition is identical." Subjects play one hundred trials of the two-person, non-zero sum game known as Leader against a non-contingent other, whom they believe to be another player of the same sex. In the group condition, five person units of a sexually homogenous nature are employed. Each group setting is characterised by particular task features, which range from complex problem solving exercises to unstructured discussions. A relationship was established between pre-emptive game behaviour of subjects and subsequent nominations for task and socioemotional leadership positions. Socio-emotional leaders were in general noted for low levels of pre-emption. Task leaders were found to have pre-emption rates which were situationalyy dependent. ' On complex tasks requiring innovative leadership, then high pre-emptors emerged as leaders, and on less demanding, general co-ordinating tasks, low pre-emptors rose to prominence. Situational contingencies did not encourage differentiation between role specialists under certain conditions, and sex differences were of importance in the process of role specialisation. Female groups were often less structured, with distinctions less rigidly defined than in male groups. The present results are seen as complementary! to existing findings, and indicate; (i) the relevance of mixed-motive games for identifying individual differences; (ii) features of role differentiation in unstructured single sex groups; (iii) the relationship between pre-emption in the Leader Game and the leadership process itself. 
CONTENTS

Review of Literature

Section One: Leadership

Chapter One: Towards a definition 4

3.1 Towards a definition 5

Chapter Two: Relevant theoretical perspectives 10

2.1 Introduction. 11

2.2 The trait approach 13

2.3 Lewin's differentiation of leadership styles 18

2.4 Ohio State leadership studies 19

2.5 Path-goal thepry of leadership effectiveness 23

2.6 Vroom and Yetton's normative model 24

2.7 Fiedler's contingency model of leadership effectiveness . 26

2.8 Bales's differentiation of leadership roles 33

2.9 Social exchange analyses of leadership 39

Chapter Three: The emergence of leadership 45

3.1 Introduction 46

3.2 Fiedler's least preferred co-worker measure 46

3.3 Participation rate 49

3.4 Role differentiation 58

3.5 Expertise 66

3.6 Social exchange analyses 68

Chapter Four: Sex differences in leadership 71

4.1 Introduction 72

4.2 Sex differences in management styles. 72

4.3 Sex differences in small group leadership 74

4.4 Sex differences in leadership and mixed-motive games 78

Section Two: Mixed-Motive Games 79

Chapter Five: Introduction to mixed-motive games 81

5.1 Mathematical game theory 82

5.2 Zero-sum games 83

5.3 Non zero-sum games 85

5.4 The four archetypal non zero-sum games 86

5.5 Experimental studies of the leader game 94

Chapter Six: Independent variables affecting game behaviour 100

6.1 Manipulation of pay-of matrix 101

6.2 Number of trials 102

6.3 Meaningfulness of reward 103

6.4 Pre-game instructions 104

6.5 Possibilities for communication. . 105

6.6 Strategy of other 106

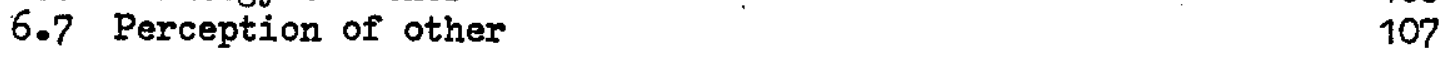

Chapter Seven: Individual differences affecting game behaviour 110

7.1 Organismic dimensions 111

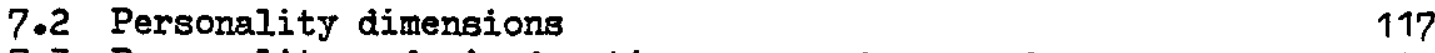

7.3 Personality and mixed-motive games: An overview 125

Chapter Eight: Emergent leadership and mixed-motive games 127

8.1 Emergent leadership and mixed-motive games 128 


\section{CONTENTS}

\section{Investigations and Appendices}

Section Three: The Investigations

Chapter Nine: The Exploratory Investigation 134

9.1 Aim of the investigation 135

9.2 Hypotheses 139

$\begin{array}{ll}9.3 \text { Subjects } & 141\end{array}$

9.4 Apparatus $\quad 142$

9.5 Method 143

9.6 Procedure 143

9.7 Results 150

9.8 Analyses 154

9.9 Summary of results and analyses 156

9.10 Discussion 158

Chapter Ten: Investigation One 164

10.1. Aim of the investigation 165

$\begin{array}{ll}10.2 \text { Hypotheses } & 167\end{array}$

10.3 Subjects 169

$\begin{array}{lll}10.4 & \text { Apparatus } & 169\end{array}$

$\begin{array}{ll}10.5 \text { Method } & 169\end{array}$

10.6 Procedure 170

10.7 Results 171

10.8 Analyses 173

10.9 Summary of results and analyses 175

10.10 Discussion $\quad 175$

Chapter Eleven: Investigation Two 178

11.1 Aim of the investigation 179

$\begin{array}{ll}11.2 \text { Hypotheses : } 180 & 189\end{array}$

$\begin{array}{lll}11.3 & \text { Subjects } \quad \therefore \quad & 181\end{array}$

11.4 Apparatus 182

11.5 Method 182

11.6 Procedure $\quad 182$

11.7 Results 183

$\begin{array}{ll}11.8 \text { Analyses } & 185\end{array}$

11.9 Summary of results and analyses. 186

$\begin{array}{ll}11.10 \text { Discussion } & 187\end{array}$

Chapter Twelve: Investigation Three 189

12.1 Aim of the investigation 190

12.2 Hypotheses 190

$\begin{array}{ll}12.3 \text { Subjects } & 191\end{array}$

12.4 Apparatus 192

12.5 Method 192

12.6 Procedure 193

12.7 Results 193

12.8 Analyses 195

12.9 Summary of results and analyses 196

$\begin{array}{ll}12.10 \text { Discussion } & 197\end{array}$

Chapter Thirteen: Discussion of the investigations 198

Chapter Fourteen: Conclusions 213

$\begin{array}{ll}\text { References } & 216\end{array}$

$\begin{array}{ll}\text { Appendices } & 231\end{array}$ 
REVIEW OF LITERATURE 
SECTION ONE:

IUEADERSHIP 


\section{SUMMARY}

Leadership research of particular concern to the present investigations is considered. The section begins with an appraisal of current trends in the definition of leadership behaviour. A growing awareness of the complexity of leadership roles is noted. Relevant theoretical perspectives, many of which rely upon a dichotomy of leadership styles are then looked at, and the review then identifies specific aspects of the emergent situation, and details research findings concerning role differentiation. These point to the potential of experimental games in this field. The final chapter considers the relevance of sex differences in leadership styles, but notes the paucity of research in this area. 
SUMMARY

The chapter describes the development of leadership definitions, predominantly over the last 30 years. The literature highlights differences in the mode of leadership across situations, and distinguishes between roles such as emergent, elected and appointed leaders. Whilst there still exists considerable divergence with regards the definition of the leadership process, the trend has been for greater emphasis to be placed on the complexity of group functioning and the interactive nature of leadership. This shift in emphasis is taken as a useful index for gauging contemporary attitudes within leadership research. Classifications of leadership behaviour by a number of authors are given, and the inherent difficulties in attempting to.identify these forms of behaviour is emphasised. 


\subsection{TOWARDS A DEFINITION}

A major concern with leadership definition became apparent in the $1950^{\prime} \mathrm{s}$ with the growing realisation of the complexity of leadership functioning. A number of authors at that time proposed definitions which are of interest as they throw light on then-future developments in leadership research.

\footnotetext{
"Leadership is the process of influencing group activities towards goal setting and goal achievement. (Stodgill, 1950)

"The leader is the one who initiates and facilitates member interaction". (Bales \& Strodtbeck, 1951)

"Leadership is the exercise of authority and the making of decisions". (Dubin, 1951)

"The leader is the person who creates the most effective change in group performance". (Cattell, 1953)

"Leadership is the initiation of acts which results in a consistent pattern of group interaction directed toward the solution of a mutual problem". (Hemphill, 1954)

"The leader is the man who comes closest to realising the norms the group values highest; this conformity gives him his high rank which attracts people and implies the right to assume control of the group". (Homans, 1950)
}

Gibb (1954) has provided an extensive review of leadership definitions, and draws conclusions, later echoed by Fiedler (1967). Gibb sees the leader. in terms of six distinct categories:

a) The individual in a given office.

b) The focus for the behaviour of the group members.

c) The sociometric choice.

d) The individual who exercises influence over others.

e) The individual who exercises influence apon syntality.

f) The individual who engages in leadership activities.

a) The individual in a given office

Whosoever occupies a leader's office is accordingly labelled a leader. This category is not applicable in situations where no formal hierarchy is evident, nor does it take into account the actual relevance and power of the particular position. 
b) The focus for the behaviour of the group members.

Gibb bases this category on the work of Redl (1942), who identifies the leadership relationship as characterised by love of the members for the central person. The concept is largely Freudian in that the relationship entails the incorporation of the leader into the ego ideal of the followers. The definition is of limited value, but important in so far as the emotional relationship between the leader and other group members is stressed.

c) The sociometric choice

The leader is defined by reference to the nominations which the group give for the individual who exerts the most influence upon them, or simply who they consider to be the leader. The correlations which are reported between this measure and observer ratings of leadership are consistently high (Gibb, 1950; Stein et al., 1973). The specific nature of the question asked to group members is of importance in the ability to define leadership utilising this method.

d) The individual who exerts influence over others

The leader is defined in terms of his/her influence within the group. Gibb sees it as important to differentiate within this category between leadership and headship. Headship is evidenced by a unilateral flow of influence, whereas leadership is characterised by influence that is voluntarily accepted or in a shared direction. The distinction is quite obviously relevant in terms of the analysis of situations, but unfortunately contemporary research often fails to highlight the important differences.

e) The individual who exerts influence upon syntality Cattell (1951) argues that the existence of a leader is detectable 
from either an examination of internal group relations (i.e., structure) or from the effectiveness of total performance of the group as a group (i.e., syntality). He defines a leader in terms of syntality, but qualifies this statement by reference to the direction of influence:
"There are certain putative dimensions such as integration, cohesiveness, viscidity, which must reach acceptable values for the group to function and survive as a group at all, and presumably any leader who can increase these is good ..... Apart from these possible exceptions, it is perfectly safe to speak of a leader as being good or bad for some specific performance".

Unfortunately this definition is unable to discriminate between headship and leadership, between leader and follower relationships or between those individuals whose influence on group syntality is adjudged to be specifically towards the goals set down by the group.

\section{f) The individual who engages in leadership activities}

Leaders are identified by the frequency with which they engage in acts which are seen by others as being in pursuance of the goals of the group. This formulation recognises that groups develop leadership hierarchies and that differentiation between successive levels is in terms of frequency of leading. For example, Hemphill (1954) suggests that:

"To lead is to engage in an act which initiates a structure in the interaction of others as part of the iprocess of solving a mutual problem".

Gibb concludes his survey by noting the change in emphasis away from the study of leaders per se, and towards the study of leadership behaviour among all group processes: 
"Whose behaviour shall we observe in drawing up role prescriptions of leadership? If we observe all the behaviour of all the members, as seems best to do, by what criteria should we differentiate leaders? Or perhaps the concept of the leader will be of no further value to us when we have differentiated such roles as those of the initiator, energizer, harmoniser, expediter and the like. To shift the problem of definition from that of defining the leader to that of defining leader behaviour or leadership acts has advantages for particular researches and for particular systematic psychologies, but it offers no solution to the definitional problem. Whether we couch our definitions in terms of the leader or the leadership act, it is of course leader behaviour with which the psychologist is concerned".

Stodgill (1974) presents a categorisation of leadership definitions

which follows on from the work of Gibb. The main area of study switches from the leader in an individual context towards the differentiation of leadership acts. Eleven definitional categories of leadership are listed as:
a) A focus of group processes.
b) Personality and its effects.
c) The art of inducing compliance.
d) The exercise of influence.
e) Act or behaviour.
f) A form of persuasion.
g) A power relation.
h) An instrument of goal achievement.
i) An effect of interaction.
j) A differentiated role.
k) The initiation of structure.

Stodgill traces the development of definition in terms of a progression of thought. The earliest approaches identified leadership as a focus of group process and movement. Later definitions considered it as the art of inducing compliance and more recently the trend has been towards conceiving of this factor in terms of power differentials, role differentiation and initiation of structure. Stodgill analyses this trend in terms of increasing concern not only for the process of the emergence of a leader but also the ongoing leadership process within groups - the maintenance and continuance of leadership. 
Hollander and Julian (1969) have also made reference to the development of leadership research, with an increasing concern for the complexity of leadership within the context of group relationships. They summarise the changing emphasis in four points:
a) the realisation of a distinction between the leader and the intergroup process of leadership;
b) . the importance of the exchange or transition between leaders and followers, in which each side give and receive;
c) the multitude of tasks or functions attached to being a leader;
d) the effect of leadership styles on group achievements and desired outputs.

This approach is taken as representative of the direction of contemporary research, whereby the leadership process is seen squarely within the context of other group processes, and "offers a clear alternative to the older concern with what the leader did or did not do". 
CHAPTER TWO: RETEVANT THEORETICAL PERSPECTIVES

\section{SUMMARY}

The chapter considers in some detail those theoretical positions which are pertinent to the present investigation, as well as offering criticism of particular stances. Beginning with the earliest debate on leadership (Great Man vs. Zeitgeist), the chapter goes on to describe other important historical perspectives, and particularly the trait approach, before looking at contemporary theories. The trait approach is covered in some detail, as it reveals interesting aspects of leadership behaviour. The more contemporary approaches include the work of Lewin, Hemphill, House, Fiedler, Vroom and Yetton, Bales and various social exchange analyses. All are noted for the manner in which they dichotomise leadership styles. These dichotomies are along similar dimension in all cases, but no over-riding dimension is discernible. The task/socioemotional distinction offered by Bales is seen as important in the context of group functioning. 
2.1. INTRODUCTION

Whilst present research centres around aspects of group functioning, and is largely the concern of social psychology, the earliest debate concerning leadership ranged over a multitude of disciplines. This debate (Zeitgeist vs. Great Man) looked at the historical influence of leaders on the development of cultures and societies.

The Great Man theory maintains that major events in world affairs both national and international - are influenced by men who hold leadership positions, and that "all factors in history, save great men, are inconsequential". (Hook, 1955). The eighteenth century rationalists believed that the personal characteristics of significant figures, coupled with chance, determined the course of history. An outstanding exponent of the Great Man theory was Thomas Carlyle, who held that genius would come to have an influence in whatever situation it was found. To William James, mutation or drastic change within society was due to Great Men who initiated movement and hindered others from leading societies in other directions. Winston Churchill's histories can be described as a study of the impact of Great Men on nations and countries. (For example, the rise of National Socialism in pre-war Germany was taken by Churchill as solely a reflection of the influence of Adolf Hitler).

Wood (1913) carried out an exhaustive study of 386 rulers in Western Europe. Each was classified as strong, mediocre or weak on the basis of his intellectual and personal characteristics. Wood found a high relationship between the strength of the monarch and the condition of the country. However, despite statistical errors, the study fails to determine if strong economies produce strong monarchs or vice-versa. Indeed, it may be that a third set of variables need to be introduced to explain how the monarch came to power originally. 
The Zeitgeist approach has received greater attention in philosophical circles over the centaries. "Zeitgeist" is translated as "spirit or temper of the times". According to this perspective, leaders' temperaments, motives or abilities have little influence on a given situation - leaders are merely expressions, instruments or consequences of historical laws. For Hegel, the Great Man was an expression of the needs of his times. What he did was automatically correct since he fulfilled the needs of his period. The Great Man could not control his own destiny or that of others as he was simply an instrument of his historical environment. According to Thomas Spencer, societies evolved in a uniform, gradual, progressive manner. In Buckles analysis, Great Men were puppets of no historical significance. The development of a history of science evidences the scant importance of Great Men in scientific discoveries. Theoretical innovations are rarely found in isolation from other work but are the culmination of previous research.

Social psychologists with a strong sociological orientation have emphasised the social determinism viewpoint. Analyses such as those offered by Mumford, Persons, Zillig, Cottrell and Spiller stress situational factors as important in determining who is likely to emerge in a given situation. In a critical analysis of the biographies of Great Men, Spiller (1929) inferred that the personalities and abilities of the Great Men had little importance in determining their stature and effects on society, or as he says:

"If a sweeping survey of the field of human progress were made, perhaps $95 \%$ of the advance would be found unconnected with the Great Men".

According to Spiller, the Great Man appears at a critically important advancement of a socially valued cause and devotes himself to it, profiting from the many previous contributions of others. As Bass (1960) states: 


\begin{abstract}
"Hook (1955) effectively took apart the position of the extreme environmentalists without overemphasising the significance of the individual personality. There is some restriction in the range of traits permitted the person in a high status position, e.g., no negro will be the governor of South Carolina for a very long time to come. But within this range, a wide variety of possibilities can occur and give rise to different historical effects".
\end{abstract}

Hook concludes from his analysis that:

"Heroic action can count decisively only where the historical situation permits of major alternative paths of development".

Thus it is apparent that a single analysis is inadequate. A combination of factors from the situation and the individuals involved would seem to play a part in the determination of history.

\title{
2.2. THE TRAIT APPROACH
}

Undoubtedly the earliest experimental approach to the study of leadership was concerned with the individual characteristics of those in positions of authority. The trait approach has been in gradual decline over the last two decades, but nevertheless reviews of trait research reveal certain interesting characteristics of those who are either nominated or elected to leadership positions. Unquestionably the largest drawback in utilising the data relates to the lack of knowledge of situational factors which characterise each study.

A number of extensive reviews of personality and leadership have been undertaken (Bass, 1960; Bird, 1940; Gibb, 1969; Mann, 1959; Stodgill, 1948, 1974) but overall, little consistent pattern is discernible. Bird (1940) identified seventy nine traits that distinguished leaders from non-leaders, but found little overlap from one study to another. 
of the seventy nine traits, fifty one were mentioned only once, but as Wrightsman (1972) points out, this may have been the result of using different, yet synonymous terms in each study. (For example, two studies reported leaders to be more "reliable" while another study found leaders more "accurate in work"). In the twenty studies Bird investigated, intelligence was found most frequently (50\%) with initiative being mentioned in six studies. Overall, Bird identified four general traits of leadership-intelligence, initiative, sense of humour and extroversion (Bird, 1940, p.380).

Stodgill carried out an exhaustive survey of leadership traits in 1948, (and supplemented this was a further review in 1974). The primary methods employed in the studies he reviewed up to 1948 were;

(i) observation and time sampling of behaviour in group situations; (ii) choice of associates (roting, naming, ranking, sociometrics); (iii) nomination by qualified observer; (iv) selection of persons occupying positions of leadership; $(v)$ analysis of biographical and case history data; ( $v i$ ) listing of traits considered essential to leadership; (vii) various supplementary measures, e.g. intelligence and personality tests.

The range of studies covered is diverse, and consequently, any conclusions must be general in order to be applicable to a spectrum of situations of power differences within groups.

Stodgill's survey was based upon factors which had been investigated on at least three separate occasions. These factors are summarised in Table 1: 


\begin{tabular}{|c|c|c|c|}
\hline \multirow[b]{2}{*}{ FACTOR } & \multicolumn{3}{|c|}{ NO. OF STUDIES REIATING FACTOR TO LEADERSHIP } \\
\hline & $\begin{array}{c}\text { POSITIVE } \\
\text { RETATIONSHIP }\end{array}$ & $\begin{array}{c}\text { NEGATIVE } \\
\text { RELATIONSHIP }\end{array}$ & $\begin{array}{c}\text { NO } \\
\text { SIGNIFICANT } \\
\text { FINDING }\end{array}$ \\
\hline $\begin{array}{l}\text { Chronological Age } \\
\text { Height } \\
\text { Weight } \\
\text { Physique, Energy, Health } \\
\text { Appearance } \\
\text { Fluency of Speech } \\
\text { Intelligence } \\
\text { Scholarship } \\
\text { Knowledge } \\
\text { Judgement \& Decision } \\
\text { Insight } \\
\text { Originality } \\
\text { Adaptability } \\
\text { Extroversion } \\
\text { Dominance } \\
\text { Initiative, Persistence, } \\
\text { Ambition } \\
\text { Responsibility } \\
\text { Emotional Control } \\
\text { Self Confidence } \\
\text { Mood Control, Mood Optimism } \\
\text { Social \& Economic Status } \\
\text { Social Activity \& Mobility } \\
\text { Bio-Social Activity } \\
\text { Social Skills } \\
\text { Popularity \& Prestige } \\
\text { Co-operation }\end{array}$ & $\begin{array}{r}6 \\
9 \\
7 \\
21 \\
11 \\
13 \\
23 \\
21 \\
11 \\
9 \\
25 \\
7 \\
10 \\
5 \\
11 \\
24 \\
17 \\
11 \\
17 \\
14 \\
15 \\
26 \\
22 \\
22 \\
10 \\
19\end{array}$ & $\begin{array}{r}10 \\
2 \\
2 \\
- \\
- \\
- \\
- \\
- \\
- \\
- \\
- \\
- \\
2 \\
4 \\
- \\
- \\
5 \\
- \\
4 \\
- \\
- \\
- \\
- \\
-\end{array}$ & $\begin{array}{l}- \\
2 \\
2 \\
- \\
1 \\
\overline{5} \\
- \\
- \\
- \\
- \\
- \\
- \\
2 \\
- \\
- \\
- \\
- \\
- \\
- \\
- \\
- \\
- \\
- \\
- \\
-\end{array}$ \\
\hline
\end{tabular}

TABLE 1: A Summary of Stodgill's Survey

On the basis of his review, Stodgill concluded that:

a) The average person who occupies a position of leadership exceeds the average member of his group in the following respects; (i) intelligence; (ii) scholarship; (iii) dependability; (iv) activity and social participation; (v) socio-economic status.

b) The qualities, characteristics and skills required in a leader are determined to a large extent by the demands of the situation in which he is to function as a leader. 
Stodgill accordingly acknowledges the important role of the situation

in determining the emergence of a leader:

"A person does not become a leader by virtue of the possession of some combination of traits, but the pattern of personal characteristics of the leader must bear some relevant relationship to the characteristics, activities and goals of the followers ..... It becomes clear that an adequate analysis of leadership involves not only a study of leaders but also of situations".

Unfortunately, the lack of information as to situational variables in the 124 references given by Stodgill does not enable the reader to look closely at the relationship between the leader and the situation. As McDavid and Harari (1969) state:

"Comprehensive reviews of research in this area have particularly criticised the failure of investigators to recognise the importance of specific group activities and specific membership characteristics in determining emergent leadership".

Additionally, the relationships, although positive, were in many instances very weak, or as Fiedler and Chemers (1974) note:

"It should be stressed that the findings were so tenuous that there is no real hope of using them (traits) to identify or to predict leaders in any practical situation".

Stodgill's 1974 survey is based upon a further 163 references, but no new revelations were forthcoming. The author concludes his later research by remarking:

"The leader is characterised by a strong drive for responsibility and task completion, vigour and persistence in pursuit of goals, venturesomeness and originality in problem solving, drive to exercise initiative in social situations, self-confidence and sense of personal identity, willingness to accept consequences of decision and action, readiness to absorb interpersonal stress, willingness to tolerate frustration and delay, ability to influence other persons' behaviour and capacity to structure social interaction systems to the purpose at hand". 
A. review of the literature by Mann (1959) concluded that a number of relationships between an individual's personality and his leadership status in groups appeared to be well established. Table 2 indicates the relationship between personality factors and leadership:

\begin{tabular}{|c|c|c|c|c|c|c|c|c|}
\hline \multirow[b]{2}{*}{$\begin{array}{c}\text { Personality } \\
\text { Factors }\end{array}$} & \multirow[b]{2}{*}{$\begin{array}{l}\text { No. of } \\
\text { Studies }\end{array}$} & \multirow[b]{2}{*}{$\begin{array}{l}\text { No. of } \\
\text { Results }\end{array}$} & \multicolumn{2}{|c|}{ Positive } & \multicolumn{4}{|c|}{ Negative } \\
\hline & & & Sig. & N.S. & $\begin{array}{c} \\
\text { Untested }\end{array}$ & Sig. & N.S. & ested \\
\hline $\begin{array}{l}\text { Intelligence } \\
\text { Adjustment } \\
\text { Extroversion } \\
\text { Dominance } \\
\text { Masculinity } \\
\text { Conservatism } \\
\text { Sensitivity }\end{array}$ & $\begin{array}{r}28 \\
22 \\
22 \\
12 \\
9 \\
17 \\
15\end{array}$ & $\begin{array}{r}196 \\
164 \\
119 \\
39 \\
70 \\
62 \\
101\end{array}$ & $\begin{array}{l}91 \\
50 \\
37 \\
15 \\
11 \\
3 \\
15\end{array}$ & $\begin{array}{r}68 \\
55 \\
38 \\
9 \\
37 \\
18 \\
55\end{array}$ & $\begin{array}{r}14 \\
14 \\
6 \\
3 \\
0 \\
0 \\
3\end{array}$ & $\begin{array}{r}1 \\
2 \\
6 \\
6 \\
1 \\
17 \\
1\end{array}$ & $\begin{array}{r}22 \\
28 \\
23 \\
4 \\
19 \\
21 \\
25\end{array}$ & $\begin{array}{l}0 \\
0 \\
3 \\
0 \\
0 \\
3 \\
0\end{array}$ \\
\hline
\end{tabular}

TABLE 2: The Relationship between Personality Factors and Leadership

What this fails to indicate is the low significance of these relationships. Intelligence is the most consistently related trait to leadership, and yet "no correlation reported exceeds 0.50 and the medium $r$ is roughly $0.25^{\prime \prime}$. (Mann, 1959, p.248)

Reviewing his own search for leadership traits, Gibb (1969) concluded that:

"There are indications that certain traits such as surgency, intelligence, dominance, self-confidence and social participation are frequently found to characterise leaders of various types in various situations. But, in every instance, the relation of the trait to the leadership role is more meaningful if consideration is given to the detailed nature of the role. A person does not become a leader by virtue of his possession of any one particular pattern of personality traits, but the pattern of personal characteristics of the leader must bear some relevant relationship to the present characteristics, activities and goals of the group of which he is Ieader". 


\subsection{LEWIN'S DIFFERENTIATION OF LEADERSHIP STYLES}

One of the earliest set of investigations concerned primarily with leadership style was those performed by Lewin; Lippitt and White in the 1930's and 1940's. Taking groups of elementary school age boys, leaders were assigned to the groups who had been trained in different leadership styles. Lewin et al. (1939) set up three leadership situations;

(i) the autocratic style, where all decisions were made by the leader and the boys were required to follow prescribed procedures under strict discipline with heavy censureship; (ii) the democratic style, where group decisions were made by majority vote, equal participation was encouraged and criticism and punishment were minimal; (iii) the laissezfaire style, in which the leadership activity of the group leader was kept to a minimum, allowing the boys to work and play almost totally without supervision.

The different styles were alternated within the groups. Six week periods were studied with distinct styles being predominant in each period. It was noted that different leadership styles clearly had an effect upon group behaviour.

Under democratic leaders, group members were more open-minded, more friendly, more efficient in their work and more individualistic.

Under the autocratic climate, a great deal of hostility and aggression was observed, particularly when group members were not being watched by the autocratic leader, The subjects demanded more attention, attached more blame to the inadequacies of others, were submissive and obedient and were relatively inefficient in their work. The products of the autocratic group were inferior to the products of the democratic group. Group members also held their leader in greater regard in the democratic situation. 
Under laissez-faire leadership, the group rapidly deteriorated-the boys did very little work and group activities centred around play and non-goal related behaviour.

The most important conclusions that can be drawn from this early work by Lewin and his co-workers relate to the influence on group atmosphere and performance of overt differences in leadership style. Differences were noted in terms of atmosphere for individual development and growth. Democratic groups showed more initiative, were more likely to develop their own policies and showed more overall individuality. However, although the data supports distinctions between styles, there is no conclusive evidence suggesting that any style is more efficient in terms of group performance. Research indicated that democratic leadership promoted individual and group health, but not necessarily greater productivity.

Within a historical context, the investigations are of importance in that they mark the genesis of experimental work identifying a dichotomy between leadership styles.

\subsection{OHIO STAFE LEADERSHIP STUDIES}

These researches were initiated over twenty-five years ago at Ohio State University, and although the centre of criticism over the years (e.g. Korman, 1966), in general the work continues to generate positive interest.

The primary concern of the studies was the empirical measurement of leader behaviour. To this end, in 1950 Hemphill and his co-workers began generating statements descriptive of a wide range of supervisory behaviours. From a subsequent list of over 1800 statements, ten 
categories of leader behaviour were developed, namely Initiation;

Representation; Fraternisation; Organisation; Domination; Recognition;

Production Emphasis; Integration; Communication-down and Communicationup. Using these ten dimensions as a basis, the original IBBD (Leader Behaviour Description Questionnaire) was drawn up. The questionnaire was administered to subordinates who described their supervisors in a wide variety of different kinds of group leadership situations.

Employing a factor analysis to look at this data (Halpin and Winer, 1952), it was found that two major clusters emerged. These were centred around the factors "Consideration' and Initiating Structure. The two terms are defined below:

a) Consideration: Leader behaviour indicates friendship, mutual trust and respect, with warmth and rapport between the supervisor and his group. Tolerance for two-way communication is seen as an important component, with behaviour related essentially to the maintenance and strengthening of the group itself.

b) Initiating Structure: Leader behaviour involves acts which imply that the leader organises and defines the relationships in the group. He tends to establish well defined patterns and channels of communication, and ways of ensuring the task completion.

These two dimensions are taken as being independent, and not opposite ends of a continuum. Hence, a leader may be high on both, or have any combination of the two.

Of the two measures, 'Consideration' has systematically been found to have a positive relationship with satisfaction and performance of subordinates (the two criteria which are used to identify the effects of the leader behavioural dimensions). "Initiating Structure has 
been found at various times to have significantly positive, significantly negative and insignificant relationships with subordinate satisfaction and performance.

Korman (1966) came to rather negative conclusions regarding the value and usefulness of Initiating Structure to the study of leader behaviour in his review of previous work. Kerr, Schriesheim, Murphy and Stodgill (1974) were more optimistic in their appraisal of previous research.

From their work, the authors saw fit to develop a contingency theory of leadership based upon "Consideration" and Initiating Structure, and the dependant variables satisfaction, morale and performance, with situational elements which included subordinate, supervisor and task considerations. Utilising these, Kerr et al. present ten propositions pertaining to the situational variability of leadership (pp. 73-74). Whilst acknowledging the lack of research upon which to base their model, the authors nevertheless see it as valuable. Two general postulates are taken from their ten propostions. These postulates, given below, are søen as "useful in synthesising much of the Consideration - Initiating Structure literature":

a) The more that subordinates are dependant upon the leader for provision of valued orcieeded services, the higher the positive relationships will be between leader behaviour measures and subordinate satisfaction and performance.

b) The more the leader is able to provide subordinates with valued, needed or expected services, the higher the positive relationships will be between leader behaviour measures and subordinate satisfaction and performance. 
Schriesheim, House and Kerr (1976) present an analysis of the Leader Initiating Structure research which indicates that some of the confusion surrounding the use of the term may orginate in the variety of measures which have been employed to identify leaders' behaviour. Four scales have been used at various times; (i) the Supervisory Behaviour Description Questionnaire (SBDQ); (ii) the early and (iii) revised Leader Behaviour Description Questionnaire (LBDQ); and (iv) the Leadership Opinion Questionnaire (LOQ). Inconsistencies are evident regarding the definition of Initiating Structure across the four scales, and this has resulted in:

"A myriad of definitions, working definitions and operationalisations having taken their place in the research literature". (Schriesheim et al., 1976)

The authors concluded that a closer check must be made on the information gleaned from research in order to understand the nature of the differences among scale versions, and the likely effects of such differences upon the measurement of leader behaviour.

Fleishman (in Fleishman \& Hunt, 1973) concludes from his review of the work on 'Consideration' and Initiating Structure over the last twenty years that although in some instances the evidence is a little weak, in general research points to certain relationships between Initiating Structure', 'consideration and leadership. Firstly, a high-Initiating Structure, high-Consideration pattern optimises more different effectiveness criteria. Secondly, a low-Consideration, low-Structure pattern most often appears the least desirable. Thirdly, results from the two factors show that there is some relationship between these and variables such as risk taking behaviour (Rim, 1965), empathy (Fleishman \& Salter, 1963) and sociometric choice. Fourthly, Fleishman sees a link between Consideration', 'Initiating Structure' and organisational effectiveness. 
In this way it was hoped to develop the Ohio State Studies to a position where not only would stability in leaders' behaviour in particular situations be identified, but also the predictability of leadership effectiveness over a range of situations.

The Ohio State Studies, despite their internal debates and schisms, again present an appraisal of leaders' behaviour which centres around two variables (Initiating Structure and Consideration). In this respect, the studies are of interest to the present investigation.

\subsection{PATH - GOAL THEORY OF LEADERSHIP EFFECTIVENESS}

The Path - Goal theory of leadership developed by House (1971), was an attempt to situationally define the relationship between leader behaviour and subordinate performance and work attitudes, and was endeavouring to reconcile the discrepant findings regarding Consideration and Initiating Structure. House proposed that the motivational functions of a supervisor are to; (i) assure the subordinates personal rewards for accomplishing work goals, by facilitating their reaching those rewards; and (ii) improve the opportunities for work satisfaction by showing consideration and support for the subordinates. Hence in the words of Downey, Sheridan and Slocum (1976):

"The subordinates motivation to work hard is dependant on the leader's ability to enhance valences and expectancies as the basis of his influence".

The assertation is also made that the effectiveness of performing either of these motivational functions is contingent upon the structure of the work tasks. In situations where the tasks are unstructured, an effective superior will initiate structure in the work environment to aid subordinates in successful task accomplishment, and clarify the extent to which their performance will be rewarded. 
House and Mitchell (1974) conducted a large scale review of existing research on the Path - Goal theory. According to their evidence, a degree of contradiction surrounds the theory. Two studies confirmed that leader Initiating Structure had been found to have a positive correlation with subordinate satisfaction, when subordinates were engaged in highly structured tasks, yet four studies failed to substantiate this hypothesis. Likewise, the theory points out that there would be a positive relationship between leader Initiating structure and subordinate performance when subordinates are performing ambiguous tasks. Three studies failed to support the theory in terms of performance. One hypothesis which does receive support is that which states that supportive leader behaviour will have a positive relationship with subordinate performance expectancies and satisfaction when subordinates are performing highly structured tasks.

Downey et al. (1976) provide an appraisal of the Path - Goal theory which answers many of the perplexities in research findings to date. From their analysis of the model, they conclude that it is perhaps too simplistic - that additional moderator variables over and above task structure may be important, and hence:

"Future research must concentrate on more comprehensive models of the Path - Goal theory if it is to discern causal paths in what appear to be highly interactive relationships between leadership style and subordinate performance and job attitudes".

\subsection{VROOM AND YETTON'S NORMATIVE MODEL}

Vroom and Yetton's model has developed largely in response to the problem of participative decision making, and essentially whether autocratic or participative leadership is the most effective style. Vroom (1976) states that past research has produced equivocal results, with situational variability being of importance. 
Vroom and Yetton's (1973) theoretical position is founded on the premise that whenever a leadership decision is made, the leader must be concerned with both the quality of the decision, and subordinate acceptance of the decision. Decision quality refers to the objective or impersonal aspects of the decision, whereas decision acceptance refers to the degree of subordinate commitment that is necessary to effectively implement the decision. In certain instances, subordinate compliance rather than acceptance, is sufficient to implement the decision. However, when the implementation of the decision requires initiative, judgement or creativity from subordinates, it is important for the leader's decision to be consistent with subordinate preferences.

Four basic management decision styles which Vroom and Yetton utilise to describe managerial behaviour are labelled autocratic (A); consultative (C); group (G); and delegative (D). Within each category, Roman numerals: are used to symbolise variants on that process. Basically the model has been devised as a guide for managers to regulate their choices among decision styles, in order to maximise the effectiveness of their decision. The actual effectiveness of a decision is taken as being dependent on a number of dimensions, including quality requirement, leader and subordinate information, problem structure, likelihood and importance of subordinate acceptance, goal congruency, conflict and numbers of subordinates involved (Vroom \& Yetton 1973). These situation dimensions or problem attributes are related to the selection of a management decision style by a set of ten rules that are designed to ensure both the quality and acceptance of the decisions. Commonly, these rules are expressed in the form of a decision tree where the response to question one predetermines subsequent questions to be answered (Vroom \& Jago, 1974 ). When a terminal node is reached at the end of a particular branch, the leader is able to determine that decision style which is suitable for that 
situation. In later work, the number of problem attributes has varied, but in general seren stages are seen as the most popular (Hill and Schmitt, 1977).

The Path - Goal model represents a practical application of the dichotomy between autocratic and participative leadership, in order for leaders (and particularly industrial leaders) to optimise effectiveness. To date, the limited research utilising this model has tended to validate the original formulations (Hill and Schmitt, 1977), but further research is necessary before the theory becomes of major significance.

\subsection{FIEDLER'S CONTINGENCY MODEL OF LEADERSHIP EEFECTIVENESS}

Fiedler's model has developed over nearly 30 years of research, begun at the University of IIlinois in 1951. The major exposition of the theory is found in Fiedler's own book, A Theory of Leadership Effectiveness (1967), although numerous reviews of the available research have also been published (e.g., Chemers \& Rice, 1974; Fiedler, 1971; Graen et al., 1970). Early enthusiasm for the model has been somewhat tempered in the last decade, following a series of critiques questioning the plausibility of the theory (e.g., Ashour, 1973; Graen et al., 1970; McMahon, 1969). These criticisms will be reviewed later, following an initial outline of the theory and some research implications.

The core of Fiedler's model is his Least Preferred Co-worker, or LPC scale. An individual who completes the IPC scale is asked to think of all the people with whom he has ever worked and to focus on the one person with whom he had the most difficult experience in completing a task, i.e. his least preferred co-worker. The rater is then asked to describe the individual using a series of sixteen bipolar, 8-point 
descriptive adjective scales, such as pleasant-unpleasant, tenserelaxed, boring-interesting, cold-warm.

The LPC score is simply the sum of all individual scale scores ( 1 to 8 ). In order to determine the high and low IPC persons, the scores are divided into extreme groups on the basis of a median split.

Prior to the formal presentation of the model in 1964, data relating IPC to group performance was collected from over 1000 groups, including such diverse types as infantry squads, basketball teams, B-29 bomber crews; company managers, church groups, university groups in the U.S.A. and Holland, sales display teams, etc. Although some early relationships between LPC and group productivity were found, it was not until Fiedler attempted to relate LPC to situational variables in a contingency approach that a coherent pattern of results emerged.

Fiedler identified three major variables which contribute to the leader's influence and control or situational favourableness. These three determinants are; (i) interpersonal relations between the leader and his followers; (ii) task structure, or the degree to which the group's task is clear cut and unambiguous with verifiable goals and specified procedures for reaching the goal; (iii) the leader's formal power of position. That is, his ability to reward or punish the group members. In empirical work with the contingency model, each of the three variables is dichotomised to yield an eight celled model of situational favourableness, (see Table 3). 


\begin{tabular}{|c|c|c|c|}
\hline & $\begin{array}{l}\text { Leader's personal } \\
\text { relations with } \\
\text { members }\end{array}$ & Task structure & Position power \\
\hline $\begin{array}{l}\text { I } \\
\text { II } \\
\text { III } \\
\text { IV } \\
\text { V } \\
\text { VI } \\
\text { VII } \\
\text { VIII } \\
\text { VIII-A }\end{array}$ & $\begin{array}{l}\text { Good } \\
\text { Good } \\
\text { Good } \\
\text { Good } \\
\text { Moderately poor } \\
\text { Moderately poor } \\
\text { Moderately poor } \\
\text { Moderately poor } \\
\text { Very poor }\end{array}$ & $\begin{array}{l}\text { Clear, or structured } \\
\text { Clear } \\
\text { Unclear, or unstructured } \\
\text { Unclear } \\
\text { Clear } \\
\text { Clear } \\
\text { Unclear } \\
\text { Unclear } \\
\text { Clear }\end{array}$ & $\begin{array}{l}\text { Strong } \\
\text { Weak } \\
\text { Strong } \\
\text { Weak } \\
\text { Strong } \\
\text { Weak } \\
\text { Strong } \\
\text { Weak } \\
\text { Strong }\end{array}$ \\
\hline
\end{tabular}

TABLE 3: Classification of Group-Task Situations on the Basis of 3 Factors

Octant $I$ is the most favourable and octant VIII the least. As can be discerned from the data, low leader IPC scores are associated with high productivity in the very favourable and very unfavourable portions of the dimensions (octants, I, II, III and VIII) whereas high leader IPC scores are associated with high group productivity in the moderately favourable zone (octants IV, V and VII).

Chemers and Rice (1974) note certain assumptions which underlie the theory. Firstly, the model acknowledges that there is a best way to lead in a given situation. Secondly, the theory maintains that certain leader attributes are stable and enduring and that these attributes must be considered with situational factors in order to predict leadership effectiveness. Thirdly (and this assumption is seen as unique and separate from other contingency theories), is the notion that certain specifiable variables will affect leader potential for influence and control. (Although the three dimensions offered are not taken by Fiedler as the only variables, they are seen as having an important influence on leadership.) Fourthly, the number of variables may be altered to include items such as stress, cultural and linguistic 
heterogeneity, training and experience and leadership legitimation. Finally, assumptions are made that situational favourableness, or potential influence and control, is a general and widely encompassing dimension. It is assumed that almost all variables which affect the leadership position can be subsumed into the favourableness dimension.

Turning to areas of dispute, some serious limitations are evident in Fiedler's model of leadership effectiveness.

In the first instance, to date research has failed to find out exactly what it is the IPC scale measures. It was considered appropriate to continue work utilising the measure only in so far as it predicted leadership effectiveness, but with little understanding of why. More recently, three interpretations of the LPC scale have been offered, two of which rely on a motivational factor and the third on cognitive direction.

The earliest interpretation of the LPC is the one still most often presented in introductory texts. Quite simply, low LPC leaders, who were intolerant of an incompetent co-worker, were thought to be primarily motivated toward successful task achievement. It was assumed that this relatively stable orientation would be manifested behaviourally in terms of high levels of task related or structuring acts. High LPC leaders were considered to be oriented toward, and motivated by, good personal relations. Consequently, high levels of considerate socio-enotional behaviour would be found. This outlook is underpinned by the belief that although the leader's behaviour is constant across situations, the situational leadership demands vary.

Thus low LPC leaders are successful in the situations which require strong and directive leadership, that is very good or very bad situations. 
The high IPC leader is better equipped to deal with situations requiring more subtle handling of relationships, in moderately favourable situations.

This approach came under scrutiny when it was discovered that existing data failed to tie in with the analyses, (Bass, Fiedler \& Kruger, 1964; Bishop, 1964; Fiedler, O'Brien \& IIgen, 1969). Under certain conditions, low IPC persons were found to report a greater interest in interpersonal than in task concerns, while the opposite was true for high LPC persons. In addition, it was shown that both high LPC and Iow LPC leaders deviated from their characteristic forms of leader behaviour. (Rice \& Chemers, 1973).

Fiedler (1972) later offered a new motivational interpretation of the IPC scale. The basic assumption of the motivational hierarchy analysis is that each individual maintains a hierarchy of personal needs or goals. It is assumed that high and low IPC persons possess divergent need hierarchies. The primary goal of low IPC persons is task achievement, and their secondary goal is good interpersonal relations. The primary goal of high IPC persons is good interpersonal relations and their secondary goal is prominence and self-enhancement. Additionally, this motivational hierarchy states that an individual will seek to satisfy as many of his goals as the situation permits. This assumption leads to the hypothesis that situational changes will lead to changes in leaders' behaviour. In very favourable situations, where attainment of one's primary goal is virtually assured or already accomplished, the leader will direct his attention toward satisfaction of his secondary goal.

This analysis is at variance with the earlier model on one important.issue. Behaviour of both high and low IPC leaders is dependent upon the particular situation, and hence role differentation is introduced to the contingency model. 
A third interpretation of IPC has been offered (Foa, Mitchell and Fiedler, 1971) and this relies on differences in cognitive complexity. Using a modification of Scott's (1962) measure of cognitive complexity, . which requires subjects to sort and categorise various types of groups, Mitchell (1969) found that there was a moderate correlation (.50) between complexity and the IPC score. In an extension to his work, Mitchell found that high IPC subjects utilised more information and a more complex procedure for evaluating favourableness than did low LPC * subjects. In this way, IPC is taken as a measure of the individual's degree of differentiation in task situations. A high LPC leader, when asked to rate an individual with whom he had difficulty in getting a job done (i.e. his LPC), differentiates between this individual's task performance and personal attributes. The high IPC person is seen as capable of rating his LPC positively on interpersonal attributes even though he is a poor co-worker. On the other hand, the low IPC person, who gives his IPC uniformly low ratings on both task and interpersonal dimensions, is taken as having a lower degree of differentiation. Rice and Chemers (1975) conclude from their work that, "the complexitydifferentiation hypothesis appears to be the most fruitful avenue for future investigation", but to date, as much of this evidence is based upon post hoc analyses, the issue of what the IPC scale is actually measuring remains unclear.

Turning to general critiques of the contingency modelss validity, Graen, Alvares, Orris and Mortella (1970) and Ashour (1973) both offer interestins criticisms of the model. Basic conclusions which they reach are concerned with the predictive validity of the model. Graen et al. base their criticisms around three points; (i) they maintain that the specification of situational favourableness has been so vague and variable across studies that any pattern of results could be produced by the 
careful ordering of the data; (ii) they criticise the use of nonsignificant directional results as support for the theory. The wealth of data available compensates for the lack of consistent significant findings; (iii) the authors present data from two experiments of their own which fail to support the theory.

Fiedler (1971) has replied to this attack, and retaliated largely by pointing out the inadequacies in the experimental design of Graen et al.'s work. However, Fiedler does not fully answer the problems of specification and analysis in contingency model research. Chemers and Skrzynek (1972) attempted to offer additional support for the model. Employing a design which included all octants of Fiedler's favourableness dimension, the authors discovered a close concordance between their results and the predicted curve. Unfortunately, however, none of the correlations for the octants was significant. In a later study, Rice and Chemers (1973) found weaker evidence in favour of the model, and what they described as "general support".

Mitchell, Biglon, Onchen and Fiedler (1970) point to other weaknesses in the structure of the model, namely the inadequacies in the specification of the situational favourableness dimension. For two of the three controlling factors, task structure and position power, there exists reasonably objective means of differentiation (Fiedler, 1967, p. 24, 28, 269, 281-291), but for the third, leader - member relations, these are usually assessed after the test session by means of the Group Atmosphere Scale. Quite obviously, scores on this measure are likely to be influenced by the performance of the group, and hence the variable is dependent upon the effectiveness of the leader. The group atmosphere is likely to be determined by their effectiveness, which is affected. in turn by the style of leadership. 
An additional criticism of the model is concerned with the size and anchoring of the situational favourableness dimension. Each of the three variables which determine favourableness is dichotomised into two levels. This results in an arbitrary split into eight different combinations as opposed to a continuum of conditions. Chemers and Rice (1974) point out that this type of division may group together essentially distinct units. The three dimensions of task structure, leader-member relations, and leader position power may in essence be continuous dimensions, rather than ordinal dichotomies, which may consequently falsely simplify a complex phenomenon.

A further problem deals with situational variables which are not included in the favourableness dimension. Several variables which have been looked at but not established in the formal specification include, "stress, linguistic or cultural heterogeneity, training experience, leader status and organisational climate". (Chemers and Rice, 1974, p. 107).

A review of these other variables, in conjunction with the criticisms previously detailed, would seem to indicate that a reappraisal of the current model may be beneficial.

\subsection{BALES'S DIFFERENTIATION OF LEADERSHIP ROLES}

Bales's development of role types is founded upon his technique of Interaction Process Analysis. Using this technique, group members' behaviour is categorised into one of twelve types - seems friendly, dramatises, agrees, gives suggestion, gives opinion, gives information, asks for information, asks for opinion, asks for suggestion, disagrees, shows tension and seems unfriendly. Bales (1958) had presumed that 
in small group situations as many as five different role types may be discerned by formulating around three factors - task ability, activity and likeability.

Of primary interest to leadership research are three role types given below:

a) Task specialist - High on activity and task ability but lower on likeability.

b) Social specialist - High on likeability but lower on the others.

c) Great man - High on all three factors.

Bales and Slater (1955) identify the emergence of these role types within their dynamic analysis of group interaction, with the factors being identified by post session questionnaires as well as the I.P.A. Although there is no cast iron rule that any one or combination of these roles will emerge, where this is the case the most complementary combination is that of the task and social specialists, producing "good group leadership".

Slater (1955) determined that the degree of consensus within the group would be important in the development of these roles. In high consensus groups, role differentiation seemed to result in an active task specialist and $a$ best liked other person. In low consensus groups, there tended to be three role types - an active participator, a more passive task specialist and a most liked member who was not necessarily active nor high on task ability. The actual rates of participation were not automatically related to liking, but the differentiation was more in terms of interaction type. Best liked men initiated more activity in the general area of positive reactions to others, while idea men engaged in more problem solving attempts. Bales and Slater (1955) also point 
to the important relationship between the best liked man and the idea man. They found that the interaction between these two specialists was directly related to the degree of status consensus within the group. In groups with high status consensus, the highest interaction levels were found between the two specialists, and this was generally of a supportive nature. In groups with low status consensus the pattern was less distinct, which may be an indication of a less clearly defined hierarchy.

The authors discovered differences between the specialists in terms of their rate of interaction. Generally, the social specialist was lower in activity rate than the task specialist. The high average talking rank for the task specialist (1.6, Bales and Slater, 1955, p. 266) is likely to set him/her up early in the status competition as a strong contender for high status. In high status consensus groups, this person will be encouraged to specialise in the task area and consequently have a substantial percentage of the total participation time. Bales and Slater speculate that this continued high participation may lead to a degree of ambivalence towards him/her by other members. This ambivalence may lead to the withdrawal of liking from the task specialist, and growing liking for some other person who is less active and is able to reciprocate positive actions. In this manner, a differentiation of roles takes place over time, whereby the task specialist comes to represent the task values of the members and the socio-emotional specialist represents other values and attitudes which tend to be disturbed, de-emphasised, threatened or repressed by the requirements of the emerging task situation.

This dynamic change is evidenced by the coincidence of top idea ranking with top liking ranking over a period of sessions. Bales (1958) found that the probability of the same person being identified as a task and socio-emotional specialist was $56.5 \%$ in the first meeting of a group, 
but as shown in Table 4, this percentage dropped considerably in subsequent meetings:

\section{SESSIONS}

\begin{tabular}{|c|c|c|c|}
\hline & 2 & 3 & 4 \\
\hline 56.5 & 12.0 & 20.0 & 8.5 \\
\hline
\end{tabular}

TABLE 4: Percentage of cases where one man held top position on idea and liking ranking.

Subsequent research has indicated that the emergence of the task and socio-emotional roles may well be a natural consequence of the group's evaluation of the functions performed in reference to the attainment of group goals. Hence, the nature of the goals will be of extreme importance in role differentiation. Shelley (1960) suggests that one key variable may be the actual function of the interaction. When group interaction is a means to the attainment of group goals rather than an end in itself, and when motivation levels are low, leadership can be conceived in terms of administrative convenience, i.e. group goals can best be accomplished with a highly differentiated role structure and an early focus of leadership. In this situation, the task specialist would emerge quickly and the status hierarchy would develop without substantial competition. Indeed, the need for a social specialist would not be inherent in such a situation and so this role may not emerge. Alternatively, when the group interaction is an end in itself, there probably will be a strong competition for status and a positive relationship between the participation of group members and liking for the group by the members. This may result in low status consensus, because of competition within the group for position and this in turn may necessitate the emergence of a social specialist.

Marwell (1968) discovered similar trends in his work. Employing medium sized discussion groups, the author found that a crystallisation of role 
behaviour did occur with regard to task specialisation but not with social specialisation. This was seen as being due to the heavy concentration by group members on instrumental behaviour. Hence the task oriented behaviours of the task specialists were seen as legitimate and not a source of tension.

Gustafson (1973) likewise suggests that the nature of the task is the most important determinant of role differentiation and acceptability. Where there is a high task requirement, it is feasible to imagine that the task leader may be the most popular group member even though there is another individual providing socio-emotional support.

With regard to personality characteristics of role specialists, Bales and Slater (1955) administered the California F-scale to all subjects in their study. High scores on this scale are thought to indicate one kind of rigidity and absolutism, associated with the authoritarian personality. In a comparison of scores between ideas specialists, best liked men, most active participators and those nominated as leaders, some interesting differences emerged. In groups with high status consensus, idea men had lower F-scores than best liked men, but in general top men in high status consensus groups tend to be more flexible than those in low status consensus groups. Overall they concluded that:

"Individuals with more specialised characteristics (i.e. task and socio-emotional leaders) are less flexible than individuals with more generalised characteristics".

A further investigation was made into subjects' ratings of other group members. Comparing the incidence of undifferentiated choices of liking, the authors found that $42 \%$ of the best liked men fail to differentiate as compared to $20 \%$ of top men on ideas. The best liked men apparently 
like everyone, and in conjunction with their high F-scores:

"This suggests the possibility of a certain rigidity in the attitudes of best liked men towards interpersonal relationships".

Moment and Zaleznik (1963) offer an alternative analysis of predisposition for role taking. The four general conclusions they reach are:

a) Individual performances addressed to task and group maintenance problems are required in group problem solving. Task problems tend to demand aggressive and disruptive behaviours, while social maintenance problems tend to demand more passive, nurturant and integrative behaviours. b) The life expectations of an individual (his prior social learning together with the personal needs he reflects in his own behaviour) determine his role enactment predispositions.

c) The interaction between external role requirements, posed by the group's task and its environment and internal predispositions determine an individual's actual behaviour in a specific group activity. Within limits, interaction between external demands and internal predispositions will produce behaviour of four extreme types - technical specialisation, social specialisation, role fusion or self-oriented behaviours.

d) The actial pattern of predispositions for role taking displayed by an individual at a given time and place will lie somewhere between those predispositions appropriate to his current stage of development that represent inappropriate defences in the face of current realities.

Three of the roles which they envisage were taken as serving ego defensive functions. For example, the technical specialist was thought to be such not only because of the intrinsic rewards of the task performance alone, but also because concentration on the properties of the task protects the individual to some extent from the requirement for socio-emotional interaction with other group members. The social specialist, through his 
relatively undifferentiated socio-emotional behaviour, is seen as protecting himself from the tensions which result from a requirement to initiate task activity and from possible rejection by other group members. The authors indicate that only the individual who is able to combine both kinds of roles in a flexible manner is able to react in an undefensive way within the group.

Accordingly, the conclusions Moment and Zaleznick reach regarding task and socio-emotional specialists behaviour mirror quite closely those of Bales. The analyses differ as to why these behaviours should come into play.

On the one hand, Moment and Zaleznick argue that the inflexibility of these specialists is a consequence of defensive behaviour toward other group members, while on the other hand, Bales and his co-workers see this behaviour as an interplay between the needs of the group for efficient functioning and the individual characteristics of the specialists.

\subsection{SOCIAI EXCHANGE ANALYSES OF IEEADERSHIP}

Exchange theory, as presented by Homans (1958), Thibaut and Kelley (1959) and Gergen (1969), suggests that whether a person assumes a leadership function depends upon the reward-cost outcomes experienced by him and his followers. The rewards and costs are taken as being a function of the requirement of the situation, i.e. the nature of the task; the characteristics, needs and skills of the person and his followers; his position in the power and communication structures; and in some instances, his position in the affect structure. 
According to a theory of social exchange, the rewards of leadership are in two categories. Firstly, the satisfactions to be gained from successful task accomplishment, and secondly, the rewards gained from leadership activity itself. These include satisfaction of needs for achievement and dominance as well as other socio-emotional considerations. Persons who assume leadership also incur a number of costs. In addition to the effort directly expended in goal related activities, the leader experiences costs in the form of strains stemming from the necessity of serving as a model for group behaviour. Other costs include anxiety imposed by the ever present possibility of failure, rebuffs in his attempts to lead with consequent loss of stature and blame as well as guilt when his decisions are wrong. Finally, since his behaviour is apt to affect adversely the reward-cost outcomes of other members, he faces the cost of losing their friendship. He risks not only his status but also his popularity. Closely related is the cost of Ioneiness. The leader is often avoided not only because he may have incurred hostility, but also because of his power. Others regard interaction with him/her as risky in terms of adverse rewardcost outcomes.

The rewards and costs associated with leader and follower behaviours are in part a function of situationally imposed requirements. A number of studies suggest that if the costs of inaction in the face of situational demands are great enough, group members will respond with appropriate behaviour. Thus in initially leaderless groups situated in the laboratory, or in groups studied in a natural setting where established leaders fail to carry out leadership functions, certain members will rise to the occasion. (Bales and Slater, 1955). 
Hollander and Julian (1969) viewed the legitimacy of leadership in terms of social exchange. The process by which the leader's role is legitimised is seen as operating within an exchange of rewards, whereby these exchanges signal the acceptance of his position and influence. The theory is important in its ability to appreciate the reciprocal nature of the leadership process, as the authors say:

"In social exchange terms, the person in the role of leader who fulfills expectations and achieves group goals, provides rewards for others, which are reciprocated in the form of status, esteem and heightened influence. Because leadership embodies a 2-way influence relationship, recipients of influence assertions may respond by asserting influence in return, that is, by making demands upon the leader".

Homans (1961) encapsulates the sentiment by stating:

"Influence over others is purchased at the price of allowing one's self to be influenced by others".

Hollander (1958) introduces a concept which he links to social exchange, that of idiosyncratic credit. This refers to status as a summative consequence of being perceived by others as contributing to the group's task and conforming to expectancies of members. The credits are positively disposed impressions of a person held by others which provide the basis for influence assertion and its acceptance. At a later stage, the leader is able to behave in a more deviant fashion and is better able to divert the course of group action, on the basis of having received credit in the first place. The dynamic nature of this concept is seen as important in demonstrating how a new leader is legitimised in the perceptions of his peers, and how he is able to behave within his role over a period of time, particularly with regards innovation. Jacobs (1971) criticises this notion of idiosyncratic credit on the basis of experimental evidence (Wiggins, Dill and Schwartz, 1965; 
Alvarez, 1968). This work demonstrates that a group will tolerate a leader's peculiarities and idiosyncracies only as long as they themselves do not suffer a loss. The model is applicable to successful groups, but is not so appropriate under conditions of group failure. Jacobs (1971) goes on to develop a critique of the idiosyncratic credit hypothesis, in that the group's failure may be attributed by its members to the failure of the leader to conform. This leads to a substantial negative reaction against the leader which is in proportion to the benefits they gave him/her, such as esteem and status, and which the leader failed to reciprocate. Non-conformity in effect can be taken as a means for the individual to further his own ends ahead of those of the group. In the case of deviance in successful groups, this is seen as acceptable so long as the members continue to receive rewards and so the leader has kept his part of the bargain. Jacobs therefore sees that judgements of group members about their leaders are made in terms of the criterion of successful accomplishment of group goals, weighted by their estimate of the value of those goals to themselves, and secondarily by the degree of status the leader actually presumed for himself/herself in relation to other members of the group.

A list of ten principles can be derived from the work of Jacobs, which provide a succinct account of a social exchange analysis of leadership behaviour and its origin:

a) Social exchange behaviour is derived from the fundamental learned need to experience the presence of others and to obtain their approval. b) The most basic form of social exchange behaviour consists of behaviours that reward others in some way, and the most basic of these are behaviours that indicate approval.

c) Derived from the exchange process is the expectation that rewards will accme from benefits provided. That is, that benefits or favours will be reciprocated. 
d) There is a principle of marginal return, in which a little of a scarce benefit will affect a lot of a benefit which is not scarce, and in which providing more of a type of benefit of which a lot already exists is not very rewarding.

e) There is a strong tendency to get the most one can for the benefits he/she provides in return, that is to maximise the benefits/cost ratio. f) A superior bargaining position, particularly stemming from the ability to command scarce or uniquely desirable resources, is fundamental to the concept of power and the ability to influence others. g) While power over others can be obtained by coercion, it is not stable and does not satisfy the same needs as that obtained by positive means, and this fact tends to be learned during the socialisation process. h) Stable group leadership consists of an established social exchange process between leader and group members in which the leader makes unique and valuable contributions to the attainment of group goals, and in turn, is accorded unique status and esteem by group members. This is an exchange which is viewed by both sides as equitable. However, in order for these unique assets to produce a leadership status, four conditions must be met; (i) the group members cannot easily do without the benefits the leader provides; (ii) they cannot obtain it elsewhere or from someone else; (iii) they cannot force the leader to provide the benefit; (iv) they cannot reciprocate equally "in kind".

i) Stable group leadership cannot exist in the absence of agreed upon group goals, because lacking such goals, it is difficult to conceive how a group member could contribute uniquely to the group. Popularity can be achieved under such conditions, but popularity and leadership are not synonymous.

j) Group success is a crucial factor in determining whether the leader will retain his influence within the group, because facilitating attainment of group goals is the leader's main reason for existing and 
the main benefit he can offer the group in exchange for the status they give him. Under conditions of group failure, leader rejection is highly likely when he is seen either as not having tried to satisfy his responsibility to the group, or as having tried to use his position to satisfy his own personal needs at the cost of satisfaction of the group needs.

With regard to the characteristics which the leader exhibits, Jacobs argues that the functional utility of roles such as analysed by Bales (1958) is likely to lead to the establishment of members of the group with specific task or socio-emotional abilities. Burke (1967) discovered that when the group saw that task activity was necessary and desirable, then task specialists' behaviour was not related to tension and dislike. Where task legitimacy was low, high task participation by task specialists and competition over who would have the role of task leader were associated with a reduction in social participation by those task leader contenders. A social specialist role then emerged as a consequence of the competition and associated tension between task specialists for the task leadership role. Therefore, Jacobs sees role specialisation as important in the smooth functioning of the group. Group effectiveness is increased by the development of specialised roles and because there are generally two important objectives for the group (task accomplishment and group maintenance), there is a strong tendency for both task specialists and social specialists to appear as role types. The nature of the group goals will influence whether both or either type emerge. 


\section{SOMMARY}

The chapter is concerned with the process of leadership emergence from initially undifferentiated groups. The theoretical base is found to be weaker than that underlying analysis of existing hierarchies. A number of factors influencing emergence are identified, including participation rate, expertise and individual factors in role differentiation. The evidence relating participation rate to leadership is found to be somewhat inconsistent, and it would appear that group members utilise other cues in determining status. The emergence of leadership roles, and particularly task and socio-emotional roles, is well documented, but no data is available identifying predictive devices for selecting potential role players. The incidence of either or both roles is seen to be dependent on the particular task at hand. Limited evidence suggests that role specialists may exhibit inflexible behaviour in some instances. 


\subsection{INTRODUCTION}

The concern of the present investigation is specifically with "the actual display of role behaviour that involves effective power and influence over others". (McDavid and Harari, 1969, p. 349). That is, with emergent leadership in originally unranked groups.

As has already been described, this type of leadership may not correspond with formal or titular positions of authority, which have been the main concern of much contemporary research. The major theoretical advances have been made in the analysis of leadership styles in existing hierarchies (e.g. Fiedler's Contingency Model; the Ohio State University Studies). A perusal of work on the emergence of leadership reveals less distinct trends, and less consistency than theoretical positions built on post hoc analyses. Gibb (1969) points to certain reasons why this is so. Firstly, the emergence of leadership is not easily studied in real groups. Secondly, emergence "seemed to be set off by what may have been thought to be a small and insignificant variable", (e.g. liking) and thirdly, a degree of irrationality is assumed in the emergent process, in that very few factors have consistently been found to have any relationship with the phenomenon.

Nevertheless, as researchers in the field of leadership style and leaders' behaviour have come to a realisation that situational variables are of paramount importance in their analyses, so too it would seem that these same variables are likely to become of greater concern in the future work on leadership emergence.

\subsection{FIEDLER'S IEAST PREFERRED CO-WORKER MEASURE}

The majority of work employing the Least Preferred Co-worker (IPC) measure has concentrated on the relationship between group effectiveness 
and IPC scores. Two studies alone have been identified which look at situations in which leaders emerged without having been previously appointed or designated (Rice and Chemers, 1973; Schneier, 1978). Both these works attempted to define the usefulness of the LPC as a predictive device, but neither was totally successful.

Rice and Chemers (1973) assigned 18 four-man groups to one of two tasks, being either structured or unstructured. Each member was previously scored on the LPC scale, with 2 high and 2 low LPC subjects being allocated to each group. Emergent leaders were assessed from sociometric nominations in a post-experimental questionnaire. Rice and Chemers saw their experimental design as providing replications of two of Fiedler's octants of favourability - VI (low leader acceptance, high task structure, Iow position power) and VIII (Iow leader acceptance, low task structure, low position power). These interpretations are at odds with those of Schneier, as will be explained later. Nevertheless, the authors found no difference in the number of high or low IPC emergent leaders within or across conditions. However, correlations between emergent leader IPC and group productivity were generally in accord with those predicted by the contingency model.

Schneier (1978) looked at the relationships between LPC, sex, cognitive complexity and other characteristics of emergent leaders' behaviour. Forty two groups were employed, 27 male and 15 female, to work on ten experiential learning exercises over a period of fifteen weeks. The conditions were taken by the author as sufficient to warrant labelling the study a field study rather than a laboratory experiment, although this classification is somewhat debatable. 
Schneier defines the situation as falling into octant II of Fiedler's categorisation (high leader acceptance, high task structure, low position power). Fiedler (1967) maintains that all emergent leadership situations, almost by definition, imply low levels of leader acceptance and position power, because group members are competing with one another for leadership positions. Hence, it would seem that Schneier's work falls into octant VI, not II.

The author found that those people who emerged as leaders of their groups had LPC scores significantly lower than non-leaders ( $p<001$ ) and had the lowest LPC scores in $74 \%$ of the groups. He found no distinction between the LPC scores of male and female leaders and cites his research as being, "the lone statistically significant correlation between IPC and group performance in octant II of the contingency model, including developmental and antecedent research". In fact, Schneier determined that leader-member relations were high by employing the Group Atmosphere Scale (Fiedler, 1967). As has been demonstrated previously, the unreliable nature of this device may have had an influence on his interpretation.

Schneier also investigated the cognitive style and behaviour of different emergent leaders, by employing measures such as Bales's Interaction Process Analysis (I.P.A.), various subscales of the California Psychozogical Inventory (Gough, 1957), and two separate measures of cognitive complexity -

Firstly, the I.P.A. revealed that leaders engaged in task/instrumental behaviours to a significantly higher degree than socio-emotional behaviours, but no differentiation was noted between leaders and other group members. Secondly, LPC scores correlated positively with the 
C.P.I. subscale Flexibility, and negatively with the subscales Dominance and Achievement via Independence. Thirdly, the author found that, "low IPC leaders are relatively cognitively simple", (p. 233). Hence low LPC emergent leaders were seen as task oriented, inflexible, having a high capacity for status, a high interest in achievement and being cognitively simple.

With regard to the present investigation, the relationship between emergent leadership, IPC and flexibility is seen as important, despite other limitations of the experimental design.

\subsection{PARTICIPATION RATE}

Some of the earliest consistent findings regarding emergent leadership, are those relating the phenomenon to the rate of participation of group members. Sorrentino and Boutillier (1975) came to the conclusion that:

"The experimental literature describing the emergent leadership process yields the enigmatic proposition that the group member who talks a lot is quite likely to emerge as leader of the group, independent of what he has to say".

A review of the available literature does not indicate that the relationship is quite as strong as was originally believed. Bales (1953) established that in the early stages of group formation, the individual who provided the largest contribution, i.e. the highest participator, was most likely to be nominated by the other members of the group as leader, but the relationship was by no means absolute.

One intervening variable which early work in particular neglected was whether or not group members anticipated future interaction, or whether the meeting was only one in isolation. This omission, as well as 
scant detail in general regarding situational variables, devalues much of the early work. Hence heavier concentration will be placed on more contemporary studies.

Kirscht, Lodahl and Haire (1959) followed in the style of earlier writers (Bass, 1949; Peterman, 1950; Crockett, 1955; Carter, Haythorn, Shriver, Beatrice and Lanzetta, 1951) in attempting to relate factors such as participation rate and frequency of task and group oriented interaction, with the emergence of leadership. Using 66 subjects in 3-person groups, measures were made of amount of talking time and type of interaction over a 20 minute period. To this end, a modified version of Bales's I.P.A. was employed, with a system of 8 categories. The most important category was seen as that which defined group oriented, organisational types of interaction. Regarding participation rate and subsequent evaluations of leadership, the authors discovered that those members who were chosen as leaders talked an average of $44.8 \%$ of the time, whereas non-leaders averaged only $27.6 \%(t:=5.2, p<.001)$. However, their subsequent discussion reveals a less monolithic concept of small groups, in that variance between groups was large. Of the twenty two groups studied, $64 \%$ had their highest participants as leaders, but only if the level of participation was high enough to exclude other competitors (i.e. talked over $50 \%$ of the time) was leadership nomination assured.

Morris and Hackman (1969) analysed transcripts from 108 three-man groups, where the subjects worked on three different types of task (production, discussion and problem solving). From their analyses, the authors found little differentiation between behavioural patterns of leaders and non-leaders, apart from overall participation. However, high participation was not necessarily a sufficient condition for perceived leadership. 
Often high participators who were found to emphasise activities detrimental to group creativity and to de-emphasise facilitative activities, did not emerge in leadership roles. An extraneous variable which may have had some effect on the results was unfortunately present, in that nominal leadership assignments were made by the experimenters prior to the study being undertaken. These assignments were on occasions unaffected when the appointed member failed to provide any real contribution to the group. In addition, Morris and Hackman's definition of a high participator was merely an individual who was above the average in terms of talking. Of 154 subjects with above average participation, only 101 were perceived as leaders and only $25 \%$ of leadership rating variance. was accounted for by participation rate.

Regula and Julian (1973) examined the relationship between talkativeness and person perception in two person interactions. The authors noted that previous research had failed to take into account "the obvious contamination of how frequently people talk with what they have to say, i.e. they have confounded the quantity with the quality of task contributions". (p. 116). This aspect of the contribution formed the basis for the investigation. Ninety four subjects were employed, each watching 2 confederates engage in an interaction where quality and quantity of ideas were varied. The subjects were divided into: pools, each pool observing a quantity, quality-quantity and quality condition respectively. Following their observations, subjects rated the confederates on a variety of measures.

The results indicated that the individual who contributed the most frequently was perceived as more able than one who contributed less frequently. However, the only two significant results found with regard to quantity were; (i) a relationship with greater creativity 
( $p<.01)$; and (ii) influence over others $(p<.05)$. The authors found that in the quality-quantity condition, it was quantity of interaction that had the greatest influence in each condition where significant results were found.

Regula and Julian conclude that quantity rather than quality is the major criterion for judging others. This summation is reached from consideration of two person interactions only, along a number of dimensions which although allied to leadership behaviour, cannot be taken as providing concrete evidence for a link between talkativeness and leadership per se.

Stang (1973) directly manipulated the rate of interaction in order to determine its influence on leadership and liking ratings. The subjects were 30 undergraduate women who listened to a short dialogue between three confederates. The confederates read from scripts, which each contained equal amounts of information but varied in length by a ratio of $3: 2: 1$.

After hearing the dialogues, the subjects rated each of the three speakers on scales measuring liking and leadership. No cues were available apart from the taped discussion, and subjects were unable to distinguish between confederates on voice pattern or other idiosyncratic characteristics. Stang found that leadership rating had a positive relationship with length of script. He sees this as an indication that in the act of speaking, the subject momentarily exerts leadership, "thus overall leadership ratings would be proportional to the overall interaction rate". Jacobs (1971) sees this relationship as indicative of the competitive process early in a group's existence. The individual who wishes to attain the position of leadership must aim to dominate the interaction with large amounts of participation, so excluding his competitors and guaranteeing his position. 
Whilst the analysis provides a simplistic answer to the question of emergent leadership, as has been demonstrated, and will be described (e.g. Bales and Slater, 1955; Stein, 1975; Sorrentino and Boutillier, 1975), it leaves aside many factors which may be of equal importance and hence falls short of an all pervasive solution.

Stein (1973, 1975) addressed himself to this problem whilst comparing the criteria used by observers to differentiate leaders from nonleaders, and the emergent leadership hierarchies described by participants in various situations. Stein hypothesised that the subject/observers criteria for discriminating were not only similar to those used by actual group members, but were also based upon cues of both verbal and non-verbal communication. These cues were seen as not necessarily dependent upon participation rate alone.

Stein (1975) videotaped meetings of 4 small leaderless task groups, of eight or nine mixed-sex composition. The groups met on a number of occasions over the year, but only the first meeting was taped. Four conditions were employed: full information (verbal, non-verbal and visual playback), script (verbal playback), filtered speech (full visual but only rocal quality not information) and no-sound (visual playback). Subjects viewed the tapes and then completed a leadership questionnaire which ranked the members of the group on four leadership functions - harmony, liking, co-ordination and participation. An analysis of the data revealed that in each of the 4 stimuli conditions, subjects were able to match the actual leadership hierarchies closely. Additionally, "both verbal and non-verbal behaviours in small groups provide cues of the group members emergent leadership statures, independent of their relative participation rates". This statement is obviously at odds with previous research (Morris and 
Hackman, 1969 ; Stang, 1973) which stresses the importance of participation rates. Stein addresses himself to this previous work by. specifically offering a critique of the work of Morris and Hackman, and particularly their data analysis. He concludes from an overview of the work that; (i) participation rates per se are probably much less useful in making leadership selections than the failure to identify other leader/non-leader differences might suggest; and (ii) the importance of participation rates may be highly dependent upon the leadership function under consideration.

This concept of the distinction between leaders' and non-leaders' behaviour being fluid is quite obviously allied to current developments in contingency models of leadership style, and particularly within a social exchange analysis. The individual who fulfills the role most appropriate to the task function rated high on leadership in that situation, is likely to be nominated as the emergent leader. Stein sees his work as suggesting a reorientation of research, in order to look at the selection techniques which group members employ for choosing their leader in each situation.

Sorrentino and Boutillier (1975) conducted an investigation again designed to investigate the influence of quality and quantity of interaction, but with important variations. Sixteen four-member male groups engaged in a problem solving situation, with one member of each group varying his quantity and quality of verbal interaction in order to determine their influence on nomination for leadership positions. After the session, subjects rated themselves and other members of the group with regard to task and socio-emotional leadership ability, as well as other measures related to leadership emergence - influence on others, contributions to the group's goal, competence and interest. 
Their results indicated that quantity of interaction had an effect on ratings of competence, confidence, interest, influence, task leadership ability and socio-emotional leadership ability. Quality had an effect on competence, influence and contribution, and a significant interaction effect was noted between quantity and quality with regard to ratings of socio-emotional leadership ability. The confederate received the highest rating when he was high in both quantity and quality of interaction, but the lowest rating when he was high in quality but low in quantity. Sorrentino and Boutillier provide an interesting analysis of their data. Quantity is taken as representing motivation, whereas quality is a reflection of competence. The individual who is high in quality but low in quantity is seen as lacking motivation and would not be perceived as much a group member as someone who tried hard but was not as able, or even someone who tries less hard because he is unable.

The relationships between high quantity/high quality, low quantity/ high quality and socio-emotional leadership are interpretable in this light. This type of leadership stresses positive relationships between members, whereas task leadership does not stress interpersonal relationships. Group members were not as rejecting of the low quantity/high quality confederate who was seen as contributing specifically to the attainment of group goals. The authors conclude by stating:

"The amount of verbal interaction may predict emergent leadership because it is a clear indication of the group members' intentions, whereas quality of verbal interaction is contingent upon other relevant information". (p. 409).

This analysis goes some way towards a synthesis of the work of Stein and earlier work on talkativeness (e.g. Regula, 1967; Burroughs and Jaffee, 1969; Jaffee and Iucas, 1969) in that participation rates alone are not of primary importance, but rather they are picked up by 
other group members as an indication of greater motivation and involvement on the individual's part - indeed a willingness to lead. It is therefore likely that non-verbal as well as verbal cues will be discernible by others, and hence participation rates per se cannot be taken as reliable predictors of emergent leadership. The competent person must show a willingness to share his resources with other group members and must be perceived to be trying seriously to contribute to the goals of the group. This attempt may be discernible through an intense quantity of participation, and likewise a high degree of competition in the race for leadership.

Strickland, Guild, Barefoot and Paterson (1978), in their work on medium of communication and leadership differentiation, attempt to develop a model of leader emergence. Their model describes the development of leadership through five stages, with apparently quantity of contribution being all important in the early stages, and later quality. What the mechanisms of emergence are in groups which do not have the opportunity to pass through these phases, i.e. those which only meet once, or for $\because$ short periods, the model fails to predict.

Additionally, and as has already been demonstrated, the analysis linking quantity of contribution to leadership emergence may be somewhat simplistic, and an alternative perspective taking into account motivational and nonverbal influences is called for.

The study was designed to determine whether video mediated groups would have less dramatic leadership emergence than would face to face groups, in that eye contact was taken as being important in the emergence process (Burroughs, Schultz and Autrey, 1973). Their results indicated that in the video groups, where contact was via video conferencing networks, 
the role differentiation was sharply curtailed and no true stability in the hierarchy was found. The authors concluded that the mediated communication reduced the interpersonal cues, both verbal and non-verbal, to the extent that individuality of each member was de-emphasised, and accordingly the subtle interaction processes which lead to the evaluation of leadership were interfered with.

The authors' conclusions are somewhat at odds with their own emergence model, for they acknowledge the importance of non-verbal factors, and not simply quality or quantity of verbal contribution. Stein and Heller (1980) conducted an empirical analysis of the correlations between leadership status and participation rates in the literature. Three explanations of the leadership/participation rate relationship were supported by the data. Namely; (i) task leadership behaviours are a major component of total participation; (ii) those with superior task ability make more task related contributions to the group, which increases their participation; (iii) males are permitted both greater influence and higher participation rates in mixed sex groups. The authors see that these explanations may be integrated if:

"The performance of task leadership behaviours is viewed as the major source of the variance common to leadership status and participation rates".

They also found that the relationship between leadership and participation was lower when the leadership judgements were not made by observers, but by group members.

By way of a summary to the work on participation and leader emergence, research indicates that participation rate alone may be an unreliable predictor of leadership. Insofar as it demonstrates a willingness to aid the group in the attainment of goals, and competence in the task at 
hand, then quantity of contribution may be useful. However, to assume that an individual who talks the most will automatically rise to a position of authority (Bass, 1949, 1954, 1955; French, 1950; Hurwitz, Zander and Hymovitch, 1953; Regula, 1967, Burroughs and Jaffee, 1969; Morris and Hackman, 1969; Burke, 1974; Regula and Julian, 1973) may be a non sequitor.

\subsection{ROLE DIFFERENTIATION}

Undoubtedly, the most important contribution to role differentiation in leadership came from the work of Robert Bales in the 1950's. The essential components of Bales's work have been presented earlier, but additional information highlighting the emergent leadership process is given below.

Bales and his co-workers typically analysed the responses of group members over a series of meetings (Bales and Slater, 1955; Bales, 1953). The major finding over these sessions concerned the differentiation of roles following the initial encounter. When asked after the first meeting to nominate members who held top positions on liking or ideas, subjects found it difficult to distinguish between these individuals. In over $50 \%$ of cases the same individual was put forward. In subsequent meetings, the coincidence fell rapidly to just above $10 \%$. Linked with the increase in discrimination by group members was a further differentiation of the overt behaviour of the two leaders, or as Bales states (1958, p. 441-442):

"The general picture is thus one of specialisation and complexity, with the idea man concentrating on the task and playing a more aggressive role, while the best liked man concentrates more on social emotional problems, giving rewards and playing a more passive role". 
Regarding rate of participation, the influence on leadership nominations of quantity of contribution seems to decline over a series of meetings, but is taken as important in the early stages of group formation. Bales sees the frequency of communicative acts as being dependent upon a number of factors; (i) the nature of the task involved; (ii) the type of leadership being exhibited; and (iii) the activity of the leader's co-workers. Bates (1952), Bass (1954), Borgatta (1954), Berkowitz (1956) and Riecken (1958) add to this analysis by reporting that the group member who is likely to emerge as a leader in these early stages is likely to exhibit a high rate of activity specifically in initiating structure, and in directing the activities of others.

Carter, Haythorn, Shriver and Lanzetta (1951) conducted a comprehensive investigation into the differences between behaviour of emergent leaders and non-leaders. Taking 40 students, 5 groups were formed and each were given 3 tasks to perform, involving reasoning, mechanical assembly and discussion problems. On the basis of leadership ratings caleulated from their performances, each group was split into sub-groups of 4 , with approximately equal distribution of "leadership ability". These groups then worked on 3 similar tasks. Observers rated the members of these groups on leadership ability, and those individuals with the highest score were labelled the leaders. The same observers also categorised the subjects' behaviour on no less than fifty three categories. 324 comparisons were possible between leaders and non-leaders behaviour and of these, 165 were made. Forty two comparisons were significant at the $5 \%$ level. The : categories which showed consistent differentiation between leaders and non-leaders were, "diagnoses situation makes interpretation", and "gives information on carrying out action".

The authors conclude that leaders are characteristically concerned with gaining insight or analysing the situation, and with initiating 
the action required. The task on which the group was working was seen as important, with more task oriented behaviour being found in the reasoning and mechanical assembly situations, and a more laissezfaire approach in the discussion task. Regarding the amount of work performed, leaders and non-leaders were undifferentiated except in the discussion task.

Kirscht, Lodahl and Haire (1959), apart from looking at participation rates in three-person groups, also identified differences in the types of interaction. Employing Bales's Interaction Process Analysis, the authors found that leaders differed from non-leaders on 'DEF': scores, i.e. those scores which measure group oriented, organisational kinds of interaction.

Crockett (1955) attempted to discover the contribution made by emergent leaders in small decision making groups with designated heads. Seventy two conferences in business, government and industrial organisations were observed over a period of two years, and measurements were made of individual contributions to the decision making process. Behaviour of subjects was coded into eleven categories, including items such as goal setting, problem proposing, information seeking, development seeking, solution proposing and summarising. The leader was defined as:

"A group member who directs the group's behaviour. He generally sets the group's goals, summarises contributions of others and seeks out contribution of others".

Following the interaction, observers rated the subjects on this measure. Of the 72 conferences, 44 were characterised by the emergence of one or more leaders in addition to the designated head. One emergent leader was nominated in 31 groups, two in 12 groups and three leaders in one. 
Crockett found that "emergent leaders had a far higher participation rate than members in general", but a more detailed analysis revealed interesting differences between high participators and leaders. of the 57 emergent leaders, 33 were high participators whilst another 47 individuals were high participators but were not identified by the observers as emergent leaders. An analysis was undertaken of the forms of behaviour performed by these leaders and other high participators, where it was discovered that emergent leaders engaged in significantly more acts in the categories of problem proposing and information seeking, and significantly less development giving.

With regard to the interplay between designated and emergent leaders, Crockett found that in situations where the designated chairman performed relatively few acts in the areas of goal setting, information seeking, development seeking, solution proposing and problem proposing, then informal leaders emerged more frequently. Additionally, these leaders were noted as being high in rank and expertness in the larger organisation, had higher personal motivation and were judged as being needed more than their fellow group members.

Crockett's analysis ties in closely with later social exchange work, in that he sees the emergence process as being dependent upon the functions required by the situation, and particularly the task at hand. To the extent that the official leader fails to fulfill these functions, so those individuals best suited to adopt the roles required, and motivated to do so, will emerge.

Geier (1967) specifically examined the relevance of certain factors in the behaviour of leaders which set them apart from others. The author looked at the responses of group members in order to determine their 
perceptions of the leadership process. Sixteen groups of five subjects were used over a series of four sessions. The leader was defined as:

"That member who was perceived by a consensus of fellow members as having made the most successful attempts to influence the group". (Geier, 1967)

An analysis of the perceptions of his subjects revealed to the author a similar pattern of leadership emergence across all 16 groups. This pattern was characterised by two stages:

a) There was an elimination of leader contenders who possessed "negative characteristics". In the situation Geier describes, a nonstructured, academically oriented group meeting, then those who were uninformed, non-participants or extremely rigid tended to be eliminated. No time limit was set on this first stage, as the rejection depended on how long it took other members to perceive the negative traits. of the negative traits looked at, ignorance of the facts was the most important factor limiting leadership ascendancy, followed by non-participation and finally extreme rigidity.

b) The author describes an intense struggle developing for the leadership role. In this stage, each contender engages in overt attempts at leadership and tries to engage the support of likely deputies. The second stage is also a scenario for further elimination of contenders, with authoritative members being rejected in favour of more democratic contenders. Where this was not the case, was in groups which appeared to have extremely inferior members.

As already noted by Bales (1953), participation in later stages may have an adverse effect on Ieadership nomination. Geier found that incessant talking at the second stage was offensive to group members, and served to discredit the potential leader. 
Schultz (1974, 1978) has developed a schemata which she sees as useful in the prediction of emergent leadership. In her original study (Schultz, 1974), the author set out to identify those particular qualities of an emergent leader which set $\mathrm{him} / \mathrm{her}$ apart from the rest of the group. To this end, 19 variables were extracted from previous research on leadership and each member of the group ( $n=64$ ) scored each other on these variables, as well as identifying who they considered the emergent leader. The group met for 5 sessions of 45 minutes each, and the subjects rated each other at the end of each session. The 19 variables she isolated were co-operative/unco-operative; seeks information/does not seek information; self assured/hesitant; formulates goals/does not formulate goals; cheerful/gloomy; objective/biased; harmonious/quarrelsome; gives directions/does not give directions; enthusiastic/unenthusiastic; summarises/ does not summarise; supportive/ hostile; interesting/boring; informative/uninformative; goal oriented/ directionless; assertive/defensive; interesting/uninteresting; precise/unclear; imaginative/dull; and sensible/non-sensible.

The problems which the groups worked on were of a social or political concern, and each group $(n=9)$ was expected to reach a consensus solution which later would be presented to the class.

Jsing a multi-variate Q-factor analysis, Schultz found that the number of variables which distinguished leaders was small, numbering 4 positive factors across the" sessions (self-assured, formulates goals, gives direction and summarises). Negative variables were identified as gloomy, quarrelsome and not sensible. In the first session, the most important variable was identified as "gives direction". Schultz concluded from this study that: 
"While other studies have focused on the wide dispersal, variety and contingency of leadership functions, the present study suggests that a leader is differentiated on the basis of a few functions, regardless of the group's needs or the leader's personality attributes". (p. 272).

Schultz (1978) provided further support for this statement, whereby a few characteristics associated with competence in communication were the sole differentiation between leaders and non-leaders.

In this later work, Schultz again asked her subjects to rate group members on the 19 variables. On this occasion, leaders were predicted on the basis of these ratings. After the fifth session, subjects were asked to nominate a leader. The author predicted 15 leaders from their communication ratings, and of these 15 , eleven were actually nominated.

It may be misplaced to set too much store by these results, as certain difficulties are evident with regard to the experimental design. Specifically, the problem concerns the fact that the relationship between emergent leadership and communication variables is based upon ratings from the same source - the group members themselves. In this respect, the issue of causality becomes important, for do the subjects nominate leaders on the basis of these variables, or are the variables merely a manifestation of a wider construct which the group members hold as to who they perceive as a leader. It may be that the emergence of a status hierarchy precedes the subjects' ratings of communicative variables, and so will influence individual's scores. It would seem prudent to conduct further investigations, perhaps where observers rank group members on the various factors, in order to determine the precise nature of the relationship. 
Stein (1973; 1975) has conducted some interesting enquiries into the relationship between verbal and non-verbal communications, and the emergence of leadership roles. In their study of 1973, Stein, Geis and Domain were specifically looking at the accuracy of observer ratings of emergent leadership roles. As a basis for evaluation, six small groups ( $n=8$ to 10 ) worked on a project, of which the first three meetings were videotaped. These recordings were subsequently combined into a 60 minute tape which included $45 \%$ of the total interactions. 149 subjects viewed the tapes, and were asked to rank the group members on five leadership test items - coordination, influence, participation, harmony and liking. These rankings were compared with those made by the participators in the groups themselves. Stein et al. found that there was a correlation of .82 with measures of agreement among the stimulus group members' ranking of each other, and perhaps more importantly, that the perception of task and socio-emotional leadership was - independent:
"Subjects were generally more accurate in perceiving member participation and the task leadership dimension (coordination and influence), and were relatively less accurate in perceiving the socio-emotional dimension (harmony and liking). However, it cannot be concluded that participation, coordination and influence are easier to perceive than harmony and liking ....... the correlations between subjects accuracy and a measure of agreement among the taped groups members in their rankings of each other accounts for a very large portion of the variance. This variance indicates that it may be easy to perceive one aspect of leadership in a particular group but difficult to perceive other aspects in the same group". (Stein et al., 1973).

The authors do not see the relative lack of agreement on socio-emotional considerations as indicative of a lack of differentiation on this dimension, but only that in this specific situation are task oriented behaviours more important and hence likely to be more prominent. With regard to participation rates, Stein et al. note: 
"The group members participation rates seem to be an extremely strong cue for the observers in perceiving both task and socio-emotional leader behaviours. But the data also indicated that some cues unrelated to participation were used by the subjects in perceiving the leadership statuses of the group members. The approach of having experts analyse the content of the groups' verbal interaction has failed to reveal the criteria used to select emergent leaders other than participation rates".

In a later study, Stein (1975) attempted to identify those cues which group members and observers employ to make their selections. By controlling for participation rate, verbal and non-verbal cues, he discovered that cues from both verbal and non-verbal behaviour were used in the selection of leaders. Stein concluded that a reorientation was required in leadership research, with more emphasis to be placed upon, "examining the selection criteria members use, their interpretations and attributions concerning one anothers behaviour and their decision making processes". He suggests that the emergence of leadership should be considered from the perspective of group members making selections, or permitting a member to assume a leadership role rather than leaders engaging in particular forms of behaviour.

\subsection{EXPERTISE}

The relationship between emergent leadership and the group member with the greatest ability regarding the task at hand, has been investigated on a number of occasions.

In an early investigation, Carter and Nixon (1949) found that scores on mechanical tests were related to leadership status in groups performing mechanical tasks, and word fluency and clerical aptitude was related to emergence in clerical tasks. Hollander (1964) found that in a small group situation, a deviant member will be more likely to receive leadership nomination if he is perceived as being knowledgable in the task at hand. 
Stires (1970) informed members of experimental groups that they differed in ability, while other groups were told that they did not differ. Leaders with confidence in their ability attempted to gain leadership through modesty, whereas those who were uncertain of their ability attempted to gain respect through self enhancement. Korman (1971) discovered that high expectancies of competence by others had an influence on the performance of the individual. Hence, if the individual is aware of his potential, then it is likely that he will make attempts to share his knowledge with the group. This process will be reflected in the attainment of a higher status position.

Hemphill, Pepinsky, Shevitz, Jaynes and Christner (1956) provide validation for this proposal. Certain individuals within their experimental groups were provided with information which would give them an advantage in the solution of the group problem. Those provided with information scored significantly higher in attempts to lead in assembly and constructive tasks, but not in discussion tasks. Shevitz (1956) found that the exclusive possession of information by a group member resulted in: (i) his making a greater number of attempts to lead; (ii) a differentiation of his position from that of other members; and (iii) a consolidation of his leadership role.

Shaw (1963) found that too much discrepancy between the individual's knowledge and that of the group could have a negative effect. One member of each group was provided with either one, two or six units of information. The informed member entered the discussion earlier and initiated more task oriented communication than uninformed members in the two-unit condition, but this difference was reversed in the six-unit condition. The informed members' suggestions were accepted more frequently and he was named more often as a leader in the two-unit but not in the six-unit condition. 
Rudraswamy (1964) also found that subjects possessing task relevant information exhibit a significantly higher rate of leadership attempts than uninformed subjects.

Results of the above studies indicate that superior knowledge in a particular area is likely to increase the chances of higher status, but that if the individual is too far removed from the group norm then he/she is likely to face rejection.

\subsection{SOCIAL EXCHANGE ANALYSES}

The basic tenet of exchange theorists (e.g. Homans, 1950; Thibaut and Kelley, 1959) that individuals who attain leadership in groups are those who provide rewarding interactions for group members, by reacting appropriately to them, lends itself to analysis of emergent leadership situations. Hollander (1964) has argued that the individual who attains status requires two characteristics in order to take up the role social perceptiveness and modifiable behaviour. Therefore, the leader is not marked by a particular set of abilities or skills, but by the capacity to gauge the needs of a situation and subsequently adjust his behaviour. Hollander (1958) notes that:

"Insofar as the incipient status person is attuned to the altering group expectancies and is capable of reacting appropriately to them, his status will very likely move upward".

Stodgill (1974) provides a detailed review of the links between social insight and leadership. Numerous studies (Williams and Leavitt, 1947; Green, 1948; Lansing, 1957; Gallo and McClintock, 1962) support this link, but as many fail to substantiate it (see Stodgill, 1974, p. 101-102). Stodgill concludes by stating: 
"Clearly the findings indicate that leaders excel followers in factual knowledge about persons and events. However, this is not synonymous with insight and empathy. The hypothesis that leaders are better able than followers to diagnose social situations is not well supported by research results".

This appraisal perhaps indicates that this ability or capacity is useful only in certain situations. Indeed the capacity may be a hindrance in situations where the iron hand is called for and where autocratic rule is appropriate.

With regard to modifiable behaviour, research demonstrates that if anything, task and socio-emotional specialists are characterised by inflexible behaviour (Bales, 1953; Bales and Slater, 1955; Stein, 1975; Scheier, 1978; Stodgill, 1974). Hence, there is (at least with regards male subjects) little substantiation for Hollander's assertion.

Garland and Beard (1979) looked at the relationship between leader emergence and Snyder's Self Monitoring Scale, (Snyder, 1974). The scale was designed to measure not only an individual's motivation to respond to situational information, but also his or her ability to respond. Snyder argues that the scale measures concern for the social appropriateness of one's behaviour, attentiveness to social comparison, information, ability to control behaviour and self expression, and the extent to which behaviour is cross-situationally variable. High self monitors are seen as socially perceptive and adaptable, and were therefore hypothesised as being more likely to emerge as leaders in situations where member task competence was important. The authors saw that in situations where solutions were unique and verifiable, the best performer would be likely to emerge as leader, and hence no relationship was predicted in this situation. 
The experiment was conducted using single sex, three-person groups ( $n=48)$ and subjects were engaged for a total of one hour. Two experimental conditions were employed - one using a brainstorming task and the second an anagram task. This second condition was taken as being more reliant upon group member competence. An additional variable in this study was sex of group. The only significant result with regard to self monitoring and leadership emergence was found in the female brainstorming group. In this situation, the relationship between high self monitors and leader emergence was significant $(p<-01)$, and what is more, the relationship was completely independent of participation rate (correlation of -.12). In the male group, the majority of leaders were found in the middle of self-monitoring rank, according to Garland and Beard indicating that:

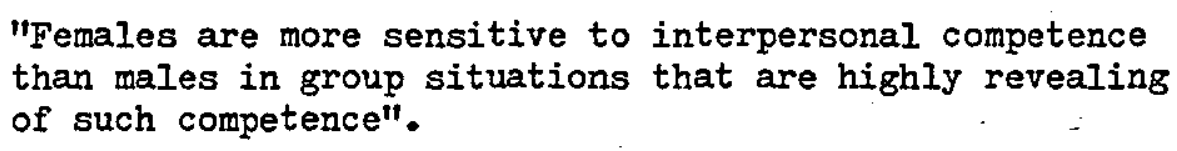

Therefore, the investigation revealed no link between social awareness and leader behaviour in male groups. However, and this may be of importance, this link was established in female groups.

In summary, social exchange analyses which imply that social perceptiveness and modifiable behaviour are necessary prerequisites for the emergence of leadership, are not substantiated by the limited research available. Hollander (1964) perhaps fails to account for the diversity of roles which the leader must adopt in order to achieve his status. If one of these roles is related to intransigent and rigid behaviour, then it is unlikely that the relationship previously detailed will be found. 


\section{SUMMARY}

The chapter considers evidence of sex differences in leadership style. The literature is described as being dominated by work on male, or mixed-sex groups. In mixed-sex situations, a consistent finding is that male members are likely to assume positions of authority regardless of ability. Cultural factors are taken as important in the current sexist orientation of leadership research. Limited research comparing sexually homogenous groups indicates that male and female leaders may exhibit differential behaviour. Male leaders typically act in a more authoritarian manner. Female leaders are noted for greater flexibility on similar tasks to their male counterparts. Additionally, the status hierarchy in male groups may be more rigid than in female group situations. 


\subsection{INTRODUCTION}

Without doubt, an area of leadership research which suffers from a paucity of research findings is that concerned with sex differences. Denmark ( 1977) notes:

"Most leadership studies have been and are concerned with males, at least male leaders. Gender, as an important aspect of the situation, has rarely been studied".

Eskilson and Wiley (1976) reach similar conclusions, stating that:

"Historically, leadership analysis has focused only on male leaders".

The reasons for this bias in the research are seen as being largely due to cultural reasons, whereby leadership is taken as a male perogative. The Harvard Business Review (1965) in a survey of 2000 executives, found that $41 \%$ of the males in their sample were against women being executives. Many felt women were unsuitable in this role, and that opportunities for advancement were limited by gender. With the current trends in women's movement in the last decade, it would appear that this male preserve is being questioned, but to date the change is not evidenced in the available literature (Schneier, 1978).

\subsection{SEX DIFFERENCES IN MANAGEMENT STYLES}

The literature indicates that with regard to effective management styles, the established male sex role is seen as the most efficient (Petty and Miles, 1966; Rosen and Jerdee, 1974). The work of Schein (1973; 1975) show that middle managers are perceived by both male and female managers as having characteristics more similar to those ascribed to men than to those ascribed to women. Although the female managers viewed women as being more similar to men than did the male managers, the results still imply that women managers are as likely as men to make placement and promotion decisions in favour of men. The male managers are reported as 
seeing themselves as more likely to be leaders than females (Megargee, 1969) and to possess traits associated with leadership ascendancy (Schein, 1975).

Kanter (1975) found that within business organisations, women were absent from positions of influence and prestige. This the author notes, may be due to a conscious decision not to strive for promotion because of the risk of losing their peer relationships within a group of women. The women already in management may not seek promotion into a higher level job because of the difficulties faced in establishing new relationships as well as the threat of interactional isolation.

Lyle and Ross (1973) conducted a large scale study of employment patterns of women in industrial and non-industrial firms. Women managers tended to be older, have longer service with the firm and have lower wages. They relied on four management styles (as determined by field research based on interviews with the sample of managers and their subordinates); (i) one third used a: productive but somewhat over-controlling task oriented approach; (ii) another third dealt with subordinates in a submissive manner. They were well liked and received praise as managers from subordinates; ( $i i i)$ one sixth were described as detached, aloof and under-controlling in their staff relations; (iv) one sixth attempted to use their job as a stepping stone to a better one and used an exploitative style. These managers blamed their subordinates for failure, but attributed success to themselves.

The male sample Lyle and Ross studied was more homogenous. $75 \%$ used the exploitative, self-seeking style, while $25 \%$ used the productive, over-controlling style. Both groups of men and women were reported to display most of the traits associated with management success (desire 
for achievement, fear of failure, drive for upward mobility, assertiveness and decisiveness).

Bartol and Butterfield (1976) administered one of two versions of a questionnaire to 225 male and 57 female students. The questionnaire contained four stories, each depicting a leadership style based upon initiating structure, consideration, production emphasis and tolerance for freedom." Names were altered in the two versions to indicate that it either referred to a male or female manager. Eight evaluative questions were asked for each of the leadership styles, and it emerged that sex had an effect on the evaluations of managerial behaviour. Female managers were perceived as being more active on the consideration dimension, while initiating structure behaviour was valued more highly when engaged in by male managers. Hence, the sex of the manager influences the perception of that person's behaviour. Female managers were seen as more considerate and males more able to initiate structure.

\subsection{SEX DIFFERENCES IN SMAIL GROUP LEADERSHIP}

The majority of work in this sub-section has looked at groups which are heterogenous with regard to sex. In these groups, the usual pattern is for male members to assume positions of responsibility (Megargee, 1969), but whether or not they make more effective leaders, and consequently more efficient groups, is debatable (Day and Stodgill, 1972; Bigoness, 1976; Hamer, Kim, Baird and Bigoness, 1974).

Megargee (1969) paired groups of two subjects, consisting of one person high on the Californian Psychological Inventory Dominance scale, and one person low. The subjects were not aware of the basis for pairing, but had to decide which one would be the leader and which one the follower. 
Groups were either homo- or heterogenous with regard to sex, and hence four types of group were formed:- high Do female $v$ low Do female; high .Do female $v$ low Do male; high Do male $v$ low Do male; high Do male $\checkmark$ low Do female. When groups were either all male or all female, in $70 \%$ of cases the individual with the high Do score became the leader. In female-male groups with male dominant, $90 \%$ of the males were selected as leader. In female-male groups with the female as dominant, only - $20 \%$ of the females became the leader. Ironically, it was the high dominant female who made the decision to have the male serve as leader.

Jacobson and Effertz (1974) used college students to form three-person groups. Half of the groups were either all male or all female, with a leader randomly selected. The other groups consisted of either two females and one male, or two males and one female. In the former situation the male was designated as the leader, and in the latter, the female. The subjects were led to believe that the selection was random. The task given to all groups was to arrange dominoes according to a prepared pattern. However, the arrangement was so complex that every group experienced failure by being unable to solve the problem.' In both same and mixed-sex groups that had a male leader, the leader's performance was rated significantly worse than when the leader was a female. The ratings of the followers by the leaders was the exact reverse (i.e. male followers were rated significantly higher than female followers by both male and female leaders).

McKenna and Denmark (1976) set out to investigate whether an individual who behaves in a high status manner will be identified as a leader on the basis of non-verbal cues, or on the basis of sex. Subjects were asked to make judgements about pairs of actors based on their non-verbal behaviour. Pairs were either same sex or mixed sex, and the actors behaved non-verbally in either high or low status styles. 
Results indicated that high status females were seen as more potent than high status males, and generally, that non-verbal cues served to identify status rather than sex. Those of high status (both male and female) were rated less positively (impolite, unpleasant and distant) than those of lower status. Females of high status were seen as more responsive than males regardless of with whom they interacted. The authors conclude that:

"Despite same sex-by-status interactions, and contrary to
what might have been predicted, non-verbal behaviour rather
than sex was basic to the determination of status (or
leadership) evaluations. The implications of this study
are clear. If women (as well as men) behave in a certain
way, they will be perceived in a high status or leadership
position vis-a-vis their interactant, regardless of whether
the latter is male or female".

Denmark, McKenna, Juran and Greenberg (1976) looked at the non-verbal interactions of female and male subjects, over a wide range of differing statuses in a university setting. Despite the fact that the status of the other was either higher or lower, or the other was male or female, no overall differences were noted between male and female subjects on any of the clies measured.

Chapman (1975) looked at the relationship between the sex of the leader and their IPC scores. Using appointed leaders for comparison, he found no significant différences in males and females' IPC scores.

Schneier (1978) attempted to relate LPC scores of emergent leaders to leaders' sex. - Of the 42 emergent leaders, 26 were male and 16 female from his sexually heterogenous groups. No differences were found between LPC scores of male and female leaders.

Turning to the styles of leaders in sexually homogenous groups, little research is available to date. Aries (1976) looked at the interaction 
patterns and themes in male and female groups, and at the development of the leadership role within these groups. Defining leadership as the rank order of subjects initiating interaction, he found that there was a greater variation in this ranking across sessions in the female as compared to male groups. On the basis of the previous review, it may be that there is greater flexibility on the part of the female groups to adapt the status hierarchy to the needs of the situation. This is further evidenced by the fact that the male leaders spent less time talking to individual members, and more time addressing the group as a whole. The work of Garland and Beard (1979) cited earlier also indicates that female leaders in single sex groups may be more adaptable and socially perceptive than their male counterparts.

Denmark and Diggory (1966) found differences between the leadership styles of males and females. They noted that male leaders exhibit and find approval from followers for more authoritarian behaviour than do female leaders.

The limited literature available therefore indicates that there may exist differences in the process of leadership within male and female groups. Male groups seem to rely on a more rigid, structured pattern, with authoritarian behaviour from the leader being more acceptable than in female groups. In these, the situation is apparently more flexible, with the status hierarchy adapting to the needs of the situation, and presumably the leader herself exhibiting greater adaptability. Additionally, the status differentiation in male groups seems to be more definite. 
4.4. SEX DIFFERENCES IN LEADERSHIP AND MIXED-MOTIVE GAMES

One of the better substantiated variables affecting game behaviour is that of sex (Harris, 1971; Terhune, 1970). The different styles of play are seen as representing different approaches to game interaction by male and female players. The limited research on sex differences in leadership styles indicates that similar variables may be influential in the emergence of roles in sexually homogenous groups. Additionally, the review of research on emergent leadership indicates that the capacity to take up particular roles will be dependent on interaction style. It is therefore seen as appropriate to determine how useful behraviour in experimental games might be in the context of establishing individuals' predisposition for leadership.

The following section endeavours to look at the potential of experimental games in this respect. 
SECTION TWO: MIXED-MOTIVE GAMES 
The section is concerned with the potential relevance of experimental mixed-motive games in identifying individual differences. Chapter Five provides a general introduction to Game Theory, before moving on to consider specific characteristics of two-person, non zero-sum games. Although superficially similar, these games are taken as bringing distinctly different psychological pressures to bear on the players involved. The experimental evidence obtained from the Leader game is noted. Chapter Six looks at independent variables influencing game behaviour. A number of variables are isolated, all of which have a direct influence on game behaviour. Chapter Seven considers individual differences affecting behaviour, and notes that various authors suggest closer control must be kept over experimental variables if individual differences are to be isolated clearly. The section concludes by looking at the possibility of utilising mixed-motive games in the context of identifying leadership potential. Given the control of variables which influence players' behaviour, it is argued that Leader game may hold this potential. 
CHAPTER FIVE: INTRODUCTION TO MIXED-MOTIVE GAMES

SUMMARY

The chapter details the development of Game Theory over the last 35 years and the growth of research into non zero-sum games. The specific features of non zero-sum games are identified, as well as important classifications of games. The 4 archetypal games are given and comparisons made between them. Problems associated with Prisoner's Dilemma as a research tool are noted. Evidence of research utilising the Leader Game is given, and the features of the game which enhance its stance for further development are listed. Of major importance in this respect is the lack of bias towards any one strategy, and the potential for pre-emption by one player. 


\subsection{MATHEMATICAL GAME THEORY}

The foundations of Game Theory were laid more than 35 years ago. With the publication of "Theory of Games and Economic Behaviour" in 1944, Von Neumann and Morganstern were attempting to forge a bond between mathematics and decision making processes other than those based on the mechanics of chance. As compared to probability theory, Game Theory was designed to extend the use of mathematics to encompass the analysis of decisions where the outcome of each of the decision maker's possible choice is dependent upon the decisions of another person. The other person has preferences of his own, and in turn the outcome of his choices are dependent on the former decision maker.

The essence of Game Theory lies in the fact that the decision makers have conflicting goals or objectives whose fates are intertwined. Shubik (1964) proposes certain basic elements of any game situation. The player is taken as an autonomous decision making unit and he or they operate towards gaining some objective. This objective will determine the selections of the player who is in possession of a set of resources, be they pecuniary, military, imaginary or whatever. However, the ability of the player to utilise these resources depends upon the limitations imposed on behaviour by the rules of the game. The player is able to manipulate his resources only within the confines of these prescribed rules. The outcome of the game will depend upon the strategies adopted by the players and this outcome will be evaluated as preferable or otherwise. It is assumed that an individual has a valuating scheme whereby he can measure the worth of any prospect with which he is confronted. The outcome of a game presents a prospect which must be evaluated. It results in an allocation of resources and the values attached by the players to these prospects are known as pay-offs. The two major classifications of games are zero and 
non zero-sum. The former applies to situations where the gains of one player mirror the losses of the other, whilst in the latter, the outcomes for each are not diametrically opposed.

\subsection{ZERO-SUM GAMES}

In this type of game the essential feature is pure opposition; the gains of one player are mirrored exactly in the losses of the other. Von Neumann and Morganstern hypothesised that the rational way to play in this type of game is for each player to adopt a strategy which guarantees that each will obtain the "max-min" pay-offs, or the best of the worst possible outcomes. The rational player realises that the desires of his competitor are diametrically opposed to his own and by examining the least preferred outcomes, on the assumption that his actions will be countered by a hostile other, he then proceeds to select the strategy which minimises the damage that the other can inflict upon him.

The concept of rationality is essential to zero-sum games. Von Neumann and Morganstern developed their theory along normative assumptions based on the concept of a "rational individual". Indeed, Schloss (1959) found that of 1,228 listed references on Game Theory, 1,198 of these were based on mathematical analysis raticer than empirical evidence. The theory has tended to limit itself to the normative rather than descriptive and Shubik (1964) sees this as:

"Pessimistic in the extreme inasmuch as it implies that not only is the opponent out to render him as much damage as possible but also that he is intelligent and fully understands how to take advantage of any situation. If it were known in advance that the opponent had a bias, made errors or was generally somewhat stupid, then this normative theory would not necessarily be the best one to follow". 
However, the limited empirical evidence available tends to quash these doubts. Only a few studies (e.g. Kaufman and Becker, 1961; Kilgard, 1966) were necessary to indicate that the presribed strategies are followed by naive subjects. Ziebenman (1960) administered a $3 \times 3$ two-person zero-sum game to fifteen pairs of subjects, giving 200 trials to each pair. He found that overall, $50 \%$ of subjects conformed to the "rational prediction" although this increased to $90 \%$ in the final ten trials. It would therefore appear that the players in a zero-sum game have little difficulty in learning that the rational choice is that one which ultimately produces the more favourable results.

Rapoport and Chammah (1965) identified two types of two-person zero-sum games - those with saddle points and those without. The former are identifiable as having an entry which is the most favourable strategy for both players involved, i.e. the saddle point (so named after the corresponding point on a saddle which is lowest with respect to the horse's longitudinal plane and highest with respect to the vertical plane). The latter have no single best strategy, but a best mixture of strategies. That is, a way of randomising strategies on successive plays such that each strategy is chosen with a given relative frequency. If both players choose their best mixed strategies, each will ensure for himself an expected pay-off which is the largest he can receive under the circumstances.

In both types of zero-sum game, there exists a notion of rational play, if it is accepted that a rational decision is represented by the principle of measuring expected utility gain.

Once one departs from the zero-sum game, then the concept of rationality becomes less clear cut and Game Theory loses a degree of its prescriptive power. 


\subsection{NON ZERO-SUM GAMES}

The non zero-sum game differs substantially from the zero-sum game in that there exists the possibility for mutual co-operation as well as competition. Von Neumann and Morganstern believed that the same principles which applied to zero-sum games could be transferred to the non zero-sum situation. That is, to find a situation where the player maximises his own gain.

Since that time, doubt has been cast on this supposition (O'Connor, Baker and Wrightsman, 1970), as the problem of defining rationality now becomes complex, involving a conflict between individual and group activity (Rapoport, 1966).

The $2 \times 2$ situation presents the simplest game of the non zero-sum type. Rapoport and Guyer (1966) identified 78 types of two-person games having a strongly stable equilibrium outcome which is deficient (i.e. less than optimal) in pay-off to both players. of these 78 , Rapoport identified twelve symmetrical games (those with identical payoff matrices for both players), and of these twelve, eight were "trivial" (the same outcome is the most preferred by both players and hence there is no conflict of interest). The remaining four are seen by Rapoport (1967) as bringing out four distinct types of psychological pressure to operate on each player. These four non zero-sum, non trivial games are labelled Martyr (Prisoner's Dilemma), Exploiter (Chicken), Hero and Leader. The four games have received relatively unequal treatment, by far the greatest amount of attention being afforded to the Martyr Game, otherwise known as Prisoner's Dilemma. 
a) Prisoner's Dilemma Game

This game takes its name from an anecdote, attributed by Luce and Raiffa (1957) to A.W. Tucker:

"Two suspects are taken into custody and separated. The district attorney is certain that they are guilty of a specific crime, but he does not have adequate evidence to convict them at a trial. He points out to each prisoner that each has two alternatives: to confess to the crime the police are sure they have done or not to confess. If they both do not confess, then the D.A. states he will book them on some very minor trumped-up charge, and they will both receive minor punishment; if they both confess they will be prosecuted, but he will recommend less than the most severe sentence; but if one confesses and the other does not, then the confessor will receive lenient treatment for turning state's evidence whereas the latter will get the book slapped at him. In terms of years in a penitentiary, the strategic problem might reduce to:

Prisoner 2:

\begin{tabular}{|c|c|c|c|}
\hline & & Not Confess & Confess \\
\hline \multirow{2}{*}{ Prisoner 1: } & Not Confess & $1 \mathrm{yr}$ each & {$\left[\begin{array}{l}10 \text { yrs. for } 1 \\
3 \text { mths. for } ?\end{array}\right.$} \\
\hline & Confess & $\begin{array}{l}3 \text { mths. for } 1 \\
\text { to yrs. for } 2\end{array}$ & 8 yrs. each. \\
\hline
\end{tabular}

( Years in prison are regarded as negative values in the matrix.) Application of the logical axiom of Game Theory - the principle of rationality - reveals that from either prisoner's point of view, his best chance, irrespective of what he believes his partner will do, is to confess. If he is convinced that his partner vill not confess, then he himself should confess, since he will thereby avoid a long sentence. If he is convinced that his partner will confess then again his only rational alternative is to confess in order to hold his sentence to eight jears. Paradoxically, two rational prisoners faced with this situation fare worse (eight years) than do two persons who are so irrational as to refuse to confess (one year). This situation may be represented diatramatically as below, with $C$ referring to the cooperative choice (not corfess), and $D$ the defective choice (confess).

PRISONER 2:

C2 D2

PRISONER 1:

01

D1

\begin{tabular}{|c|c|}
\hline $\mathrm{R}, \mathrm{R}$ & $\mathrm{S}, \mathrm{T}$ \\
\hline $\mathrm{T}, \mathrm{S}$ & $\mathrm{P}, \mathrm{P}$ \\
\hline
\end{tabular}


The letters are representative of the pay-offs available to the two subjects. In Rapoport's notation, $R=$ reward; $S=$ sucker's pay-off; $T=$ temptation; and $P=$ punishment (Rapoport, 1966). Of the 2 choices of strategy available, $C$ equals the co-operative strategy and $D$ the defective one.

By applying certain limitations to the pay-off values, it is possible to devise a rule system equivalent to the anecdote previously mentioned (Rapoport and Chammah, 1965).

RULE 1: $\quad T>R>P>S$

When a player receives the sucker's pay-off, he must be motivated to switch to the defectory strategy so as to get at least $P$. If he receives the co-operator's pay-off $R$, he must be motivated to defect so as to receive still more, T. If he receives the defector's punishment $P$, he may wish there were a way or receiving $R$, but this is possible only if the other defector will switch to the co-operative strategy together with him.

RULE 2: $\quad 2 \mathrm{R}>\mathrm{S}+\mathrm{T}>2 \mathrm{P}$

If $S+T$ were equal to or greater than $2 R$, the players would have more than one form of tacit collusion available. That is, they may alternate between $C D$ and $D C$ as well as agreeing to lock in on CC.

RULE 3: $\quad S=-T$

The game is thereby made symmetrical and reduces the number of individual parameters to three.

Given these rules it would seem appropriate to discover some rational solution to the game. According to Game Theory, the rational way of playing is to acquire as much as possible in terms of utilities or pay-offs. When faced with two risky choices, the choice of greater pay-off or utility is always preferred. By the mathematical definition 
of rationality the only choice is $D, D$, the equilibrium point (by equilibrium is meant that the $D$ strategy is preferable whether the other player chooses C or D).

If both players employ individual rationality, then both will lose in the game situation. A conflict therefore exists between individual and collective rationality. Rapoport (1966) has attempted to include the mutual perception of the other's rationality within a framework of individual strategy:
"The best outcome for both of us is C, C. However, if player 2 assumes that I shall choose $C$, he may well play $D$ to win the largest pay-off. To protect myself I will also play D. But this makes for a loss for both of us. 2 rational players certainly deserve the outcome $C, C$. I am rational and by the fundamental notion of Game Theory, I must assume that player 2 is also rational. If I have come to the conclusion that $C$ is the rational choice, he too must have come to the same conclusion. Now, knowing that he will play C, what shall I play? Shall I not play $D$ to receive the greatest pay-off? But if I have come to this conclusion, he has also probably done so. Again we end up with $D, D$. To ensure that he does not come to the conclusion that he should play D, I had better avoid it also. For if $I$ avoid it and am rational, he too will avoid it if he is rational. On the other hand, if rationality prescribes $D$, then it must also prescribe $D$ for him. At any rate, because of the symmetry of the game, rationality must prescribe the same choice to both. But if both choose the same, then $C, C$ and $D, D$ are the only possible outcomes. Of these $C, C$ is clearly the better. Therefore, I choose C".

This finding is at odds to the expected result applying the standard minimax strategy, which Luce and Raiffa (1957) maintain is the only "rational" solution in a single trial version of the game (i.e. D, D). Over a series of trials, however, they maintain that a tacit agreement will arise to both remain in $C, C$, even though this is an inherently unstable base (as unilateral defection from this agreement will increase the pay-off of the defector). 
Both Flood. (1958), and also: Scodel et al. (1959) indicated that subjects tended to choose the $D$ strategy predominantly and this choice increased rather than decreased over time (Gallo and McClintock, 1965; Halpin and Pilisuk, 1970). Whilst these findings collaborate the Game Theorists' notion of individual rationality, much work has been devoted to explaining why subjects fail to co-operate, rather than why any co-operative responses are observed at all. Amnon Rapoport (1967) notes that in the Prisoner's Dilemma Game, unconditional competitive responding is still optimal against any non-contingent strategy (e.g• random choice of $C$ on $0,10,20,80$ or 100 per cent of the trials) on the other player's part. Mack (1972) also notes that the Prisoner's Dilemma Game contains a definite bias towards one of the two alternatives available to each player on any play of the game. The D strategy clearly dominates the C strategy - the pay-offs afforded by the $D$ choice to either player being better than the corresponding pay-offs under alternative $C$, regardless of which alternative the other player might choose on any given play of the game. Knapp and Podell (1968) also note that in order to minimise losses when playing against a competitive other, the player must respond competitively.

This double bias of the Prisoner's Dilemma Game (P.D.G.) has led many researchers to look elsewhere for games capable of correlating behaviour in the mixed-motive situation to individual characteristics of players and situations.

\section{b) Chicken Game}

The second most frequently studied game of Rapoport's four archetypes is that known as Chicken or Exploiter. As compared with Prisoner's Dilemma, superficially Chicken is very similar. However, certain variations in the rules governing the game give Chicken distinctive 
characteristics. Formally, $T>R>S=P$. This effectively switches the risky response from the co-operative choice $C$, to the competitive choice D. Further, and perhaps most importantly, the non-co-operative response is no longer dominant. Moreover, non-matching choices are much more stable in Chicken than in Prisoner's Dilemma, in that the rational reaction for a person who finds himself in the cell in which he receives $S$ and his partner receives $T$ is to continue to choose $C$ in subsequent trials, rather than risking a decrease in pay-off from $S$ to $P$.

\section{c) Hero Game}

This game is analogous to an anecdote in which two persons who insulted each other the previous night while dead drunk now meet each other again. Best for either would be for the other to apologise while remaining silent himself; next preferred would be if he apologised while the other remained silent; next preferred would be if neither apologised; and worst of all would be if both blurted out their apologies (the game has alternatively been labelled Apology). Formally; the game is governed by the rule $S \backslash \bar{T}>\mathrm{R}>\mathrm{P}$ although as Harris (1971) points out, the connotations associated with these letters no longer apply.

\section{d) Leader Game}

Leader is closely related to an anecdote labelled Battle of the Sexes (Rapoport and Guyer, 1966). In this, a husband and wife are involved in a dilemma. One of them wishes to visit the opera, whilst the other prefers the entertainment of a wrestling match. Each prefers going to his or her non-preferred activity together with spouse rather than attending the preferred activity without this companionship. The least preferred outcome for each player is to stick obstinately to his/ her preferred activity and thereby have his bluff called. Formally 
the game is identified by the rule $T>S>R>P$.

In matrix form, the 4 games are as shown (Rapoport, 1967): 
EXPJJOITER (CHICKEN)

$\mathrm{C}$

\begin{tabular}{|c|c|}
\hline 1,1 & $-1,2$ \\
$R, R$ & $S, T$ \\
\hline $2,-1$ & $-2,-2$ \\
$T, S$ & $P, P$ \\
\hline
\end{tabular}

LEADER

C D

(

\begin{tabular}{|c|c|}
\hline$-1,-1$ & 1,2 \\
$R, R$ & $S, T$ \\
\hline 2,1 & $-2,-2$ \\
$T, S$ & $P, P$ \\
\hline
\end{tabular}

HERO

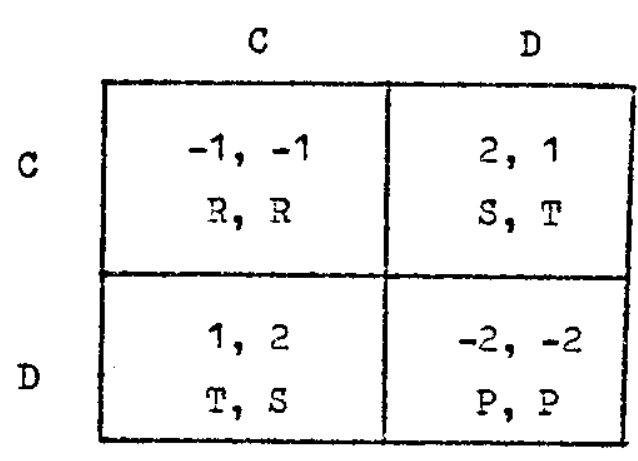

MARTYR

(PRISONER'S DILEMMA)

$\mathrm{C}$

\begin{tabular}{|c|c|}
\hline$-1,-1$ & $2,-2$ \\
$P, P$ & $T, S$ \\
\hline$-2,2$ & 1,1 \\
$S, T$ & $R, R$ \\
\hline
\end{tabular}

Although matrix values are denoted by $S, I, R, P$, it must be remembered that these symbols are only meaningful within the context of Prisoner's Dilema.

Similarly, strategy choices are referred to as cooperative or defective (C or D), although these torms do not apply to all the matrices. In the following pases, the $C$ strategy is equivalent to Ris choice or $L$ as appropriate, and the $D$ strategy is equivalent to BLJE choice or $R$, in reference to the Leader Game. 
In terms of "maxmin" (minimising losses if the player should suffer a loss), the upper lefthand corner represents the natural outcome of the game. In Chicken, Leader and Hero this is not an equilibrium outcome as either player is motivated to switch from the natural outcome. By switching, each would receive a larger pay-off. If both switch, however, both are likely to harm each other by incurring the worst pay-off $(-2)$. In these three games there is only the capacity for one "exploiter", "leader" or "hero" respectively, whereas Prisoner's Dilemma or Martyr has the potential to allow for 2 "martyrs".

Leader and Chicken differ substantially from the other two games in that they contain the potential for pre-emption. If one player succeeds in switching from the natural outcome before the other has had the chance, he will receive not only the largest pay-off, but will ensure that pay-off for himself since the other player can now by switching only impair his own pay-off. Thus a switch from the natural outcome by a single player results in an equilibrium outcome. There are 2 equilibria, and the player who switches first secures the equilibrium with the largest pay-off for himself. However, this pressure is tempered by the thought that the other player may switch at the same time, thus incurring a loss for both.

Unlike Chicken, Leader and Hero are characterised by the fact that the only strategy which could provide equal and moderately satisfactory per trial pay-offs over a number of trials is an alternating strategy between either of the unequal outcomes. (Co-operation in these games is measured by the Co-operation Index; which measures the frequency of occurence of the Pareto outcomes and the extent to which these joint pay-offs are equitably distributed). 
In this respect, Leader Game does not contain any particular bias towards either response. Hence, it is likely to be of value as a vehicle which not only simulates the elements of a mixed-motive situation but which is also sufficiently unbiased as to allow each player a real freedom of choice.

\subsection{EXPERIMENTAL STUDIES OF THE LEADER GAME}

AIthough Rapoport identified the elements of Leader in 1967, only a very few studies have adopted the game into an experimental situation.

Hurst et al. (1969) looked at the effect of mood active drugs (Damphetamine and amorbarbital) on choice behaviour in the four archetypal games identified by Rapoport (1967). The drugs administered are known to affect mood, and they attempted to demonstrate that certain strategies would become more prevalent under the influence of the drugs. To this end, a table was devised which correlated indices such as caution with total number of minimax choices, co-ordination with total successive alternators in Leader and Hero games, etc. The results indicated that styles of play were affected by the drugs' influences, and so it may be implied that the games are responsive to changes in mood. These changes in mood did not necessarily produce changes in choice in the predicted direction and some produced diametrically opposed outcomes.

Guyer and Rapoport (1969) undertook an investigation which analysed the effects of information of the other's pay-off on the type of interaction which develops between players. Initially, the authors lamented the lack of research into Leader and Hero and accordingly redress the balance by employing these two games. As a measure of co-operation in the games, they devised an index based on the frequency of alternation 
between the two Pareto outcomes, $L R$ and RL (see Matrix 1 and Matrix 2 below).

LEADER: MATRIX 1

$\mathrm{L}_{2} \quad \mathrm{R}_{2}$

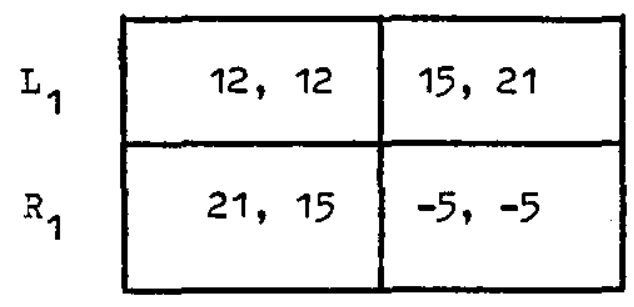

HERO: MATRIX 2

$\mathrm{I}_{2} \quad \mathrm{R}_{2}$

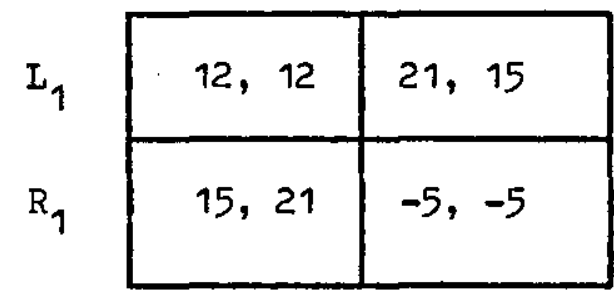

Co-operative Index (C.I.) $=\%\left(R_{1} I_{2}+I_{1} R_{2}\right)-\left|\%_{1} I_{2}-\% I_{1} R_{2}\right|$

The authors used 10 pairs of subjects, playing 300 trials of the Leader and Hero games with the above matrices. Analysis of the time course (series of trials) for each of the 4 conditions (Leader with partial information or complete information, Hero likewise) indicated differences between the two games. Hero was characterised by an overall increase in C.I., whereas Leader produced a relatively stable C.I. Ip to the 100 th trial, C.I. increased in all 4 conditions. Further analysis of the results indicated that the number of Pareto outcomes was similar for both games, but the distribution of these outcomes was more equal in Hero than Leader. Further, the number of $R R$ responses was greater in Leader than Hero. Examining the differences between the information and non-information conditions, Rapoport (1976) in a later analysis distinguishes between two components of the Co-operative Index - the asymmetry component $\left(R_{1} I_{2}+L_{1} R_{2}\right)$ and the dominance component $\left(R_{1} I_{2}-I_{1} R_{2}\right)$. He concludes that "the entire effect of information on the amount of co-operation in these games is via the dominance component" (p. 302). With little information, each player is likely to attempt domination, although this pressure is felt most strongly in Leader, by the nature of the differences in pay-off matrices. 
In order to examine the way in which a subject's response on a trial is related to the outcome of the previous trial, individual probabilities were defined:

a) $x_{1}=p\left(R_{1} / L_{1} L_{2}\right)$ : the conditional probability of player one choosing his R strategy on trial : A given he and the other player chose their L strategies in the preceding trial.

b) $y_{1}=p\left(R_{1} / L_{1} R_{2}\right)$ : the conditional probability of player one choosing $R$ on trial $A$ following a trial in which he chose $I$ and the other chose R.

c) $z_{1}=p\left(R_{1} / R_{1} I_{2}\right)$ : the conditional probability of player one choosing $R$ on trial A following a trial in which he chose $R$ and the other chose I.

d) $w_{1}=p\left(R_{1} / R_{1} R_{2}\right)$ : the conditional probability of player one choosing $R$ on trial A following a trial in which he and the other player chose R.

For all these conditions, the authors found that the probabilities for a player in Leader to pre-empt were above those in Hero. The most significant probability differences between Leader and Hero with complete information was found in $x_{1}$. The authors summarised their findings as follows:

"Players in Hero are reluctant to pre-empt; players in Leader readily attempt pre-emption. The probability of a player switching to the pre-empting response following a trial on which neither player pre-empted is small in Hero. (Mean probability across subjects of $(\mathrm{R} / \mathrm{LL})=.13$, while in Leader $p(R / L L)=.50)$. In addition, there is also a large difference between these games in the propensity to persist in pre-emption following an outcome in which both players were punished for joint pre-emption $(p(R / R R)=.45$ in Hero; $p(R / R R)=.67$ in Leader".

Mack (1972) investigated the mechanics of Leader game by examining the choices made by male and female subjects playing 100 trials of the game in single sex dyads. Employing the matrix illustrated below 
and with perfect information, Mack discovered that the level of cooperation (as measured by the Index of Co-operation) remained at a constant level for both groups over the series of trials (male $\approx 42$, female $\approx 48$ ). The female dyads were generally more co-operative than the male dyads although the results failed to reach significance. Guyer and Rapoport (1969) did not employ male and female groups but the levels of co-operation which they found over 100 trials were similar to those in Mack's investigation.

THE PAY-OHF MATRIX

\begin{tabular}{ccc}
$C$ & $C$ & $D$ \\
$C$ & 0,0 & 1,2 \\
\hline & & \\
\hline & 2,1 & $-1,-1$ \\
\hline
\end{tabular}

The stability of co-operative response over a series of trials in this experiment, in conjunction with the results of Guyer and Rapoport, led Mack to believe that the Leader Game was not subject to the learning effect evident in Prisoner's Dilemma (in which DD responses increase over a series of trials) and that the game contains no inherent bias toward a particular outcome. In leader, the optimal method of play is to choose the strategy opposite to that chosen by the other player. The stability of response over a series of trials may be an indication that the game itself is perceived as constant over time. That is, each trial is played as a game with a value equal to all other trials in a series. In contrast, Prisoner's Dilemma Game may be looked upon as a series of different games, the strategy of each trial depending upon the relative value of pay-offs, i.e. the utility value. Mack outlines his arguments in favour of the use of Leader as opposed to Prisoner's Dilemma:

"If we elect to use a dilemma situation to produce differential responding by different types of people, and the question to be asked is of the sort, "What 
types of people make what sort of choices?", then it would seem logical to avoid any situation which is indirectly biased towards one form of behaviour (viz. the D strategy in Prisoner's Dilemma) thus discouraging differential responding and causing changes in behaviour over time, regardless of the type of player involved .. ..... it is suggested that by virtue of its stability and the absence of a learning effect, the Leader Game deserves further consideration as a vehicle for the experimental investigation of player characteristics in mixed-motive situations".

Flint and Harris (1970 a \& b) undertook an investigation into the interrelationship between seven different experimental games, including the 4. games classified by Rapoport (1967) as "psychologically interesting". Each of 35 subjects played these games, and the between game correlations of each pair's scores were based on the measure $C D-D C$ (i.e. the number of trials on which the raw player received a lower pay-off than the column player, minus the number of trials in which he received a higher pay-off). These correlations ranged from .035 to .792 with a medium of .500. 15 of these 18 correlations exceeded the .33 value needed for significance at the .05 level. With regard to the Leader Game, Flint and Harris assumed that players different in submissiveness and/or in willingness to tolerate inequitable outcomes would produce a negative correlation between heroism and leadership, and hence a negative correlation between being the unilateral shifter in Leader (the preemptor) and the same tendency in Hero. They found a correlation of $-.792(p<.01)$ between these two games, with respect to an index of this behaviour (i.e. $C D-D C$ ).

Harris (1971) has suggested an alternative hypothesis to that which presupposes individual differences between players produces these impressive inter-correlations between the seven games:

"Since each subject played all seven games with the same partner, which member of each pair would be dominant (receive more points than his partner) may have been determined in the first game played by the pair, by 
purely chance factors with both players accepting this verdict throughout all seven games. To test this hypothesis, a second study was conducted in which each of 160 subjects played 100 trials of each four games. Half of the subjects (the Fixed Group) played all 4 games with the same partner while the other half (the Mixed Group) played each game with a different partner. The games employed were a Prisoner's Dilemma, Chicken, Leader and Hero. The overall magnitude of the CD - DC inter-correlations is statistically significant for the Fixed Group but not under lfixed Group conditions; and the difference between the two groups in overall magnitude of inter-correlations is statistically significant. Failure of the between-game correlations to reach statistical significance under Mixed conditions leaves the hypothesis of purely random determination of dominance in the first game played by a pair still tenable".

In an attempt to specify if there were in fact certain differences inherent in each player which led to the individual differences in behaviour within the game situation, Flint and Harris (1970b) conducted a further survey. The medium absolute magnitude of the 56 correlations calculated between raw player's or column player's CD - DC score, and his scores on McReynolds and Guevara's (1967) Success-Failure Inventory, Christie and Merton's (1958) Machiavellianism scale and two of the subscales of Wrightsman's (1964) Philosophies of Human Nature scale, was only .057 .

In a later study, Flint and Harris (1970b) computed the multiple correlation between the 16 subscales of Edward's Personal Preference Schedule, and each of eight dependent measures for each of the four games and each of the four experimental groups. Only four of these 128 regression analyses yielded statistically significant $(p<.05)$ multiple correlations. 
CHAPTER SIX: INDEPENDENT VARIABLES AFFECTING GAME BEHAVIOUR

\section{SUMMARY}

The chapter identifies those variables which have been shown to influence game behaviour. These include pay-off values, number of trials, meaningfulness of reward, type of instruction, possibilities for communication, strategy of other and perception of other. The review concentrates on data obtained from the Prisoner's Dilemma Game, as this is the mixedmotive situation used predominantly in contemporary research. The data reveals the importance of experimental variables in determining the types of responses given by subjects. 


\subsection{MANIPULATION OF PAY-OFF MATRIX}

Manipulations of the pay-off matrix have taken many forms. The differences between the pay-offs afforded to the two players can be altered within limitations imposed by the rules of the game (e.g. in the Prisoner's Dilemma Game this is when $2 R>T+S>2 P$ ). Rapoport and Orwant (1962) have proposed that an Index of Competitive Advantage can be obtained by subtracting the $S$ pay-off from the $T$ pay-off. As this index becomes larger, so the percentage of competitive responses increases (Scodel, Minas, Ratoosh and Lipetz, 1959). It may also be anticipated that a similar increase in the index $S-T$ in Leader Game would be likely to cause a greater frequency of competitive play, although this assumption is qualified by the fact that joint pre-emption is detrimental to the payoff of both. Minas, Scodel, Marlow and Rawson (1960) relaxed the rules of Prisoner's Dilemma by ensuring that the worst pay-off was in the case of joint defection from co-operation (as in Leader) and also the individual advantage to be gained by a unilateral defection was eliminated. Both variations produced less competitive behaviour than in a standard Prisoner's Dilemma Game, but the number of competitive choices still exceeded the number of co-operative choices and tended to increase over a series of trials.

Rapoport and Chamman (1965) examined the effects of manipulating the values of pay-offs, whilst maintaining the Prisoner's Dilemna rule $\mathrm{T}>\mathrm{R}>\mathrm{P}>\mathrm{S}$. Seven matrices were employed, and 10 pairs played each of the games 300 times. The authors hypothesised; (i) that of 3 games where $S, T$ and $P$ were constant and $R$ increased from 1 to 5 to 9 respectively, the number of co-operative responses would increase correspondingly; (ii) that of 3 games where $R$ and $P$ were constant, while the magnitude of both $S$ and $T$ increased from 2 to 10 to 50 respectively, the number of co-operative responses would decrease; (iii) that in 3 
games where $R, S$ and $T$ were kept constant whilst the magnitude of $P$ increased from 1 to 5 to 9 respectively, the number of co-operative responses would increase. All the hypotheses were substantiated by their results. Of the seven matrices, Rapoport and Chamman discovered that the least biased toward either $C$ or $D$ was one where $R=5, S=-10$, $T=10$ and $P=-1$

With regard to Leader Game, the matrices of fered by Mack (1972) and Guyer and Rapoport (1969) differed in terms of values. The former study allowed for equal average score for $C$ or $D$ when playing a random other, $(R+S=T+P)$, whereas the latter favoured the $C$ response $(R+S>T+P)$. This disparity may explain slight differences in the results over a series of trials, where greater consistency is noted in the study by Mack.

\subsection{NUMBER OF TRIALS}

The majority of studies incorporating reiterated mixed-motive games have employed under 100 trials. Rapoport (1966) has compiled evidence from experiments where the subjects played from 300 to 700 trials. In general he found similar results to experiments conducted with fewer trials, but certain differences appear between trials 50 and 150 . When male subjects play one another, the usual decline in co-operative behaviour is observed in the early trials but a reversal tends to occur after trial 50, and this upward trend continues to an asymptote of well over $50 \%$ of co-operative responses. In addition, this upward trend is strong enough to bring the total percentage of co-operative responses to above $50 \%$ for the entire game. Rairs of female subjects also show this reversal but it occurs later in the game and arises more slowly. Overall, pairs of female subjects produce only about half as many 
co-operative responses as pairs of male subjects. When mixed sex dyads are employed, there is virtually no difference in the performance of males and females. The mixed sex pairs tend to play more cooperatively than pairs of female subjects but less co-operatively than pairs of male subjects.

\subsection{MEANINGFULNESS OF REWARD}

An aspect of the game situation which would seem likely to influence behaviour is the meaningfulness of the rewards. Most of the experiments conducted in Game Theory involve rewards in the form of real or imaginary money (tangible rewards), although Gallo (1966) lists other rewards such as achievement and self-esteem (symbolic rewards) which may be as important. Gallo (1963) conducted one of the very few studies into the effects of real versus imaginary tangible rewards on behaviour in non zero-sum games. Using a game developed by Deutsch and Krauss (1960), Gallo found that subjects playing for imaginary money lost an average of $\$ 38.20$ per dyad over 20 trials, while subjects playing for large amounts of real money won on average $\$ 9.92$ per dyad. Thus game behaviour was much different and much more co-operative when real money was involved.

Evans (1964) assessed the value of the matrix entries in the Prisoner's Dilemma Game by using imaginary money in one condition and points to be added to the subject's examination score in the other condition. Over the six trials no significant differences in the number of co-operative responses between conditions were found. Evans concluded that:

"Tentatively it is safe to generalise from game situations in which the rewards are small or imaginary to situations where the pay-off of an outcome is of a moderate value". 
Wrightsman (1966) took 28 subjects and had them play two trials of the Prisoner's Dilemma Game. In the first trial, the subjects were offered monetary reward and in the second the subjects were informed that they were playing for fun. In both experiments, Wrightsman found that the type of reward did not affect behaviour and hence supports Evan's findings.

In contrast, Gallo's findings are substantiated by the work of Oskamp and Perlman (1965) and Lave (1962, 1965) who both found that the possibility of real gain led to greater co-operation. Therefore, to date the research presents somewhat contradictory evidence.

\subsection{PRE-GAME INSTRUCTIONS}

Most studies fail to specify in detail the extent of pre-game instructions, or the training given to the subjects. Wrightsman, Davis et al. (1972) speculated that many subjects were confused about the implications of their choices, because instructions had not been sufficiently explicit.

A subsequent study (Wrightsman, Bruininks et al., 1972) systematically varied the nature of the other player's response on the first twenty trials to see if this influenced the extent of co-operation on later trials. Furthermore, all subjects received rather extensive instructions about the implications of their choices and were required to complete successfully a set of questions about the pay-off of various choice combinations before game trials began. There was no significant effect on level of co-operation from systematically varying the nature of the other's response. Wrightsman, Lucker et al. (1972) reviewed copies of instructions used in several studies and components common to these studies were identified. 
The authors proceeded to produce three sets of instructions which varied in their completeness. They hypothesised that the more nearly the ideal instructions were approached, the greater would be the extent of co-operation. The results indicated that the minimum level of instructions produced the smallest number of co-operative choices and that the greatest number of co-operative responses were produced by the middle level of instructions, which included basic instructions and illustrated examples.

\subsection{POSSIBILITIES FOR COMMUNICATION}

Loomis (1959) studied the effects of communication on frequency of cooperative play. Half of his subjects sent, and the other half received, standardised notes expressing expectation, intention, retaliation and/or absolution. Five levels of communication were used, from expectation alone to all of them in combination. Perceived trust was positively related to level of communication, and co-operation was positively related to perceived trust. Note receivers were somewhat more co-operative than note senders, but both groups averaged over $50 \%$ co-operative play. Deutsch (1958) also reported increased co-operation when communication was allowed. However, this was true only when the subjects had been given an individualistic motivational set and did not hold when the subjects had been given co-operative or competitive instructions. Scodel, Minas, Ratoosh and Lipetz (1959) reported an increase in joint co-operative responses as a function of communication but noted that joint competitive responses still predominated. Garner and Deutsch (1974) also indicate that post-game communication may have an influence on behaviour in that if subjects anticipate interaction with the other player then the level of competition decreases. 


\title{
6.6. STRATEGY OF OTHER
}

Oskamp (1971) saw the strategy of other as one of the most important variables in the game situation:

\begin{abstract}
"Studying the effects of strategy variations is one of the major ways to answer questions concerning the resolution or avoidance of conflict, the maximisation of participants' outcomes and similar issues which have important consequences in real world situations".
\end{abstract}

The strategy of other may be manipulated by either employing a confederate or a pre-planned programme of scores, so its effects may be evaluated separately from any non-manipulable characteristics of the situation, or from any perceived qualities of the participants. For these reasons, strategy has been one of the most extensively studied topics in games of conflict and bargaining. In their review of mixed-motive games, Gallo and McClintock (1965) listed strategy as one of the four most often studied independent variables, the others being pay-off matrix, communication opportunities and personality.

Oskamp (1971) has produced an extensive review of the effects of programmed strategies on co-operation in mixed-motive games. A central thesis of the review is the differentiation between results obtained from Prisoner's Dilemma and other mixed-motive situations. The review is limited to cover only Prisoner's Dilemma, Chicken, matrix games based on Prisoner's Dilemima and non-matrix Prisoner's Dilemma.games. The author concluded from his work that subjects who; (i) experience a CC outcome on the first trial of the game; (ii) receive only a high level of co-operation; (iii) give only a high level of co-operation and receive co-operative. choices in response; (iv) "lock in" on CC outcomes, all become highly co-operative towards the end of the game. 
In reviewing literature on the delayed effects of programmed strategies on co-operation in the game situation, he found that; (i) an abrupt change from a $\%$ co-operative strategy to a $100 \%$ co-operative strategy produces greater delayed co-operation than does a consistent $100 \%$ cooperative strategy; (ii) abrupt strategy changes have a delayed effect which displays major shifts in both direction (even if the mean cooperative scores are unaffected); (iii) programmed strategies often interact with other variables (i.e. number of trials, length of initial strategy series, matrix values and subjects' diagnostic classification) to produce delayed effects on co-operation.

In conclusion, Oskamp states that:

"One of the major theoretical implications stemming from the results of strategy studies with simple matrix games is that the organisation or patterning of programmed input is much more important than the overall level of reinforcement in determining subjects' responses. This suggests, for instance, that abrupt changes in strategy are more likely to affect subjects' co-operation than are more gradual shifts".

The author also concluded that:

"There is clear evidence that contingent strategies produce higher co-operation than non-contingent strategies with the same level of reinforcement".

\subsection{PERCEPTION OF OTHER}

The characteristics which are ascribed to the other player have been shown to have an influence on game behaviour on a number of occasions.

Racial differences in game behaviour have been noted by a number of authors. Sampson and Kardush (1965) found that negro dyads exhibited less competitive behaviour than white dyads in the Prisoner's Dilemma Game, as did Berger and Tedeschi (1969). Wilson and Wong (1968) compared levels of co- 
operation between Japanese and American dyads, and found greater cooperation in the former. However, other research has demonstrated that the perception of racial differences has no effect on game behaviour (Wrightsman, Davis, Lucker, Bruininks, Evans, Wilde, Paulson and Clark, 1972; Baxter, 1969), or the opposite effect (Knight and Mack, 1973).

Information concerning the other's past behaviour has been shown to influence game behaviour. Baxter (1969) found that information concerning the other person's co-operative nature led to significantly more co-operation than did information about their competitive nature. Garner and Deutsch (1974) also found prior information was of importance to levels of cooperation. Braver and Rohrer (1975) gave information to subjects as to the previous game behaviour of the other player. When the Other was perceived as trustworthy, co-operative plays increased and when the other was perceived as exploitative, these plays decreased. Grant and Sermat (1969) manipulated the relative power. "status of the subject by having the Other appear either superior, equal or inferior to the subject on a test which was designed to reflect knowledge and skill in the game playing task. The authors found no clear link between status and behaviour. Mack (1976) found that in a situation where the Other was directly perceived as having different status within a university structure, status did affect game behaviour. In the equal status condition, there was more competition than in either the higher or lower status Other conditions. The perceptions of the Other as either a human or a machine has been investigated. Abric, Faucheux and Moscovici (1967) found that subjects knowingly playing a machine other adopted a defensive style of play. Orcutt and Anderson (1974) attempted to describe differentials between "human-human" relationships and "human-computer" relationships in the game situation. Subjects were seen to have difficulty in taking the role of the other in the latter condition and hence co-ordination 
suffered. Generally, however, their subjects' attitudes failed to discriminate between human-human and human-computer relationships. Mack, Williams and Kremer (1979) looked at subjects' perceptions of a computer Other, and found that game behaviour could best be analysed by viewing the computer in terms of male characteristics. That is, both male and female subjects played against the computer as they would against a male opponent. The results indicated that the subjects ascribed sex-related characteristics to the computer. The research on sex differences as a variable affecting game behaviour will be considered in detail in the following section. 
CHAPTER SEVEN: INDIVIDUAL DIFFERENCES AFFECTING GAME BEHAVIOUR

\section{SUMMARY}

The chapter describes work linking individual characteristics to aspects of game behaviour. The individual differences are divided into two categories, those concerned with organismic dimensions and those with personality dimensions. Of the organismic category, sex differences are seen as having a major influence. A number of analyses of sex related behaviour are presented, many of which rely on traditional sex role orientation. No one analysis is seen as adequate, as many of the. research findings are contradictory. Personality dimensions are considered, and a lack of consistency in results is again evident. It is suggested that a closer control over experimental contingencies may aid in utilising games as research tools. The work on dominance, as a personality trait, indicates that this dimension may have an influence on game behaviour. 


\subsection{ORGANISMIC DIMENSIONS}

a) Sex Differences

The research undertaken into the role of sex differences in game playing behaviour has produced little consistency to date. Up until 1972, Wrightsman (1972) reports over 90 studies having been undertaken. A large number report no statistically significant differences (e.g. Iutzker,1961; Marlowe, 1959; Bixenstine, Potash and Wilson, 1963; Komorita \&.. Mechling, 1967; Miller, 1967; Wilson and Kayatani, 1968; Evans and Crumbauch, $1966 \therefore$ ). The following review will concentrate on those studies which have identified differences between male and female players.

Bixenstine, Chambers and Wilson (1964) found that females playing a nonsymmetrical game against a programme of $80 \%$ matching of a subject's response on that trial, were more co-operative than were males. Halpin and Pilisuk (1967) however, found that employing a Restricted Prisoner's Dilemma, in which the subject had the additional task of predicting what response his partner would make on the next trial, males were:

"more liable to realise that the optimal strategy was to predict $C$ on all trials ....... (and) more liable to play the game as though the Other was always going to choose C".

A more detailed report of this study (Halpin and Pilisuk, 1970) indicates that the subjects played against a pre-programmed non-contingent strategy of $70 \%$ co-operative choices, and that males showed a more rapid decline than did females in futile attempts to communicate with the partner through co-operative responses on trials on which the subject predicted non-co-operation from the partner, and a more rapid increase in exploitative choices of $D$ on trials where a $C$ response was expected from the partner. 
This tendency of males to respond more competitively than females when playing Prisoner's Dilemma against a non-contingent strategy (under which circumstances the optimal strategy is $100 \% \mathrm{D}$ ) was also noted by; (i) Pilisuk, Skolnick and Overstreet (1968) in a 5 alternative version of a Restricted Prisoner's Dilemma Game; (ii) by Tedeschi, Lesnick and Gahayan (1968) for the first 2, 5 and 10 trials of a Restricted Prisoner's Dilemma Game; and (iii) by Tedeschi, Bonoma and Iindskold (1970). These latter authors also found that females were less likely than males to take advantage of possession of a threat option by competing on trials on which they threatened the partner with a large loss of points should they fail to choose $C$.

Grant and Sermat (1969) found in a study involving a Chicken Game that males were more likely than females to co-operate on a trial on which they predicted that their partner would compete, and less likely to co-operate when they expected co-operation from their partner.

Many reviewsiof sex differences in game behaviour (Harris, 1971; Terhune, 1970) imply greater rationality to male play than female. Harris (1971) found only one exception to this general rule, that being a study by Marwell, Ratcliff and Schmidt (1969). The study involved subjects initially playing games which either forced equal or unequal outcomes, and then switching to a Maximising Differences Game $(R>T>P=S)$, where theoretically there is no conflict as $R(C, C)$ is the optimum strategy for both players. In the equal condition, female subjects were much less competitive than males and hence more rational. In the condition of inequality, males were slightly less competitive than under equity, while females were much more competitive. These results are consistent with the assumption that males assign a slightly negative weight to their partners' outcomes and are quite responsive to structural factors 
which alter the optimality of various courses of action for maximising this weighted average. Female subjects, alternatively, seem relatively unresponsive to structural factors (Bedell and Sistrunk, 1973).

This type of analysis is reflected in many studies which posit a greater emotional component to female play than their more "rational" male counterparts. Bixenstine and O'Reilly (1966) found that females reacted in a much more retaliatory fashion than males to being punished by their partner. Rapoport and Dale (1966) indicate that women react more positively than do men to being double-crossed in the Prisoner's Dilemma Game. Terhune (1970) concludes from his review of sex differences in game behaviour that; (i) women are generally less co-operative in mixed-motive games, where there is interpersonal challenge and where strategic coping is necessary. In such situations, they are seen as "becoming involved in mutually punishing conflict deadlocks and are less repentant for their conflictive behaviour"; (ii) women prefer straightforward accommodative solutions in conflict of interest problems. They seek to compromise and will avoid competition; (iii) when placed in a vulnerable position, women react with greater retaliation and apparent vindictiveness than do men; (iv) men tend to use a tit-for-tat strategy more, and tend to be more co-operative in response to a tit-for-tat strategy. Women are more co-operative, if presented with co-operation, but once crossed, they are less responsive to co-operative gestures. Males, when presented with a co-operative other, tend to exploit him; (v) "Women have difficulty in comprehending strategic situations, often failing to recognise the optimal or rational strategy".

This type of analysis is reflected in much of the research, and is taken as a reflection of sex role stereotyping within the game situation. 
Mack, Auburn and Knight (1971) investigated the effects of playing partners of either the same or opposite sex on behaviour in Prisoner's Dilemma. They found that in single sex dyads, females were more cooperative than males, and that single sex dyads were generally more competitive than subjects playing in mixed sex dyads. In addition, an overall analysis of the results led the authors to believe that differences between the strategies adopted by male and female subjects were interpretable in terms of "achievement motivation" and its relation to sex role identification. Uesugi and Vinacke (1963) analysed the differences between their subjects in terms of styles of play. The typical masculine style was termed exploitable and involved competitive bargaining and striving to win, whereas the typical feminine strategy was described as accommodative. Females were described as more interested in the social interaction and discussion aspects of the situation than in bargaining. To them, the objective appeared to be not a matter of winning, but more directed to maintaining a fair, satisfying outcome for all players.

As mentioned previously, the question of "rational behaviour" in the game situation is a complex one. In terms of "maxmin", then individual rationality, with no regard to the characteristics or play of the Other, is most efficient. However, the game situation also allows for the player to accrue more points if the aforementioned considerations of the other are taken into account. Hence, the socio-emotional aspects of female play which Terhune, Harris and others consider to be irrational, may provide females with a greater capacity to maximise pay-offs against a contingent other. Steele and Tedeschi (1967) in a study involving 42 interval symmetrical games of widely different types, each played by a different single sex dyad, found that the probability of a co-operative response following a trial in which the subject had co-operated and their partner had co-operated was higher for males than females. Mack, 
WiIliams and Kremer (1979) found that in a game situation where the Other was known to be a computer, male players still attempted "exploitation", whereas the female subjects adopted their style of play to account for the assumed rationality of her opponent.

Several recent investigations demonstrate that differential orientation within the male and female populations will be reflected in game behaviour. Ingram and Berger (1977) found that those women who were identified as rejecting the traditional sex role stereotype, displayed less competitive behaviour in single sex dyads. Cardi (1972) found that women whose expectations of people were not based on sex stereotypes competed more against men than women in a Prisoner's Dilemma game, and more traditionally oriented women competed more against women than men (as the analyses of Terhune and Harris would suggest).

Baefsky and Berger (1974) looked at the differences in game behaviour between career oriented women and traditionally oriented women. They found that the latter subjects were less inclined to compete, and more willing to opt for the self-defeating strategy. Hottes and Kahn (1974) attempted to analyse the traditional differences. in game behaviour by suggesting that women's play is characterised by defensiveness rather than opportunism as a way of avoiding failure, more than seeking success. Thus competition is a defence reaction, for it avoids the possibility of falling for the "sucker's pay-off".

Skotko, Langmeyer and Lundgren (1974) see many of the sex differences in mixed-motive games as a reflection of the sex of the experimenter and hence an experimental axtefact. They discovered that female subjects had higher levels of competition with a male experimenter than a female experimenter. 
In conclusion, the results of research into sex differences in mixedmotive games offer a somehwat confused picture, and with evidence of the decline of traditional sex roles, it is unlikely that this confusion will be clarified in the near future.

\section{b) Age}

Bussey, Marks and Escover (1968) found that the percentage of co-operative responses in a Prisoner's Dilemma - Chicken hybrid game was a decreasing function of age for their samples of pairs of age 8, 12, 16 and 20 years. Sampson and Kardush (1965) obtained a number of complex interactions between age $(7-8$ year olds $\vee 9-11$ year olds), sex, social class and race. Klein and Solomon (1966) found that married patients were more submissive than unmarried ones against a strategy of unconditional nonco-operative responses in a Luce and Raiffa Battle of Sexes Game.

\section{c) Mental State}

It may be anticipated that paranoid individuals would be less co-operative than other players, because of their lower willingness to trust. However, the available data fails to support this hypothesis. Harford and Solomon (1967, 1969) found no differences between college students, paranoid patients and non-paranoid schizophrenics with regard to cooperative responses on the first trial of a restricted Prisoner's Dilemma. Indeed, over 30 trials, the students were less co-operative than the patients. Knapp and Podell (1968) found that the co-operative responses of university students, and patients at a California Mental Hospital were significantly different on the first trial of a Restricted Prisoner's Dilema, but this difference had disappeared by the 100th trial. However, there was an interaction between the population difference and alternative pre-programmed strategies against which the subjects played. The patients were significantly less affected by the differences in programmed 
strategies than the students. A third population, inmates at a California gaol, did not differ from the other populations in the percentage of co-operative responses across the 100 trials, and were unaffected by the difference in programme. Klein and Solomon (1966) found that paranoid patients as compared to non-paranoid patients were less responsive to the other player's change from a $100 \%$ competitive choice to an unconditional alternation strategy across 2 sessions of a Iuce and Raiffa Battle of the Sexes Gane $(T>S>R=P$, alternation is the only co-operative strategy available in this game). Harris (1970a) compared paranoid and non-paranoid patients playing Rapoport's four archetypes of mixed-motive games. He did not find any significant difference between the two populations, and offers the explanation that adjustment to hospital life includes a sense of group identity among the patients and hence greater co-operation. Wallace and Rothaus (1969) using a Restricted Prisoner's Dilemma Game supported this statement when they discovered that subject pairs from the same schizophrenic ward exhibited $88 \%$ co-operative responses, as compared to $39 \%$ comoperation when subjects were selected from different wards.

\subsection{PERSONALITY DIMENSIONS}

\section{a) Massive Surveys}

Several studies have employed a large array of personality measures. Wallace and Rothaus (1969) studied the behaviour of mental patients in a Restricted Prisoner's Dilemma Game played for 10 trials. The authors correlated scores on the Army General Classification Test, 4 subscales of the California Psychological Inventory, an overall co-operation predictor based on a linear combination of these 4 subscales; and the Fundamental Interpersonal Relations Orientation-Behaviour Scale (FIRO-B; Schutz, 1958) with "17 behavioural and attitudinal measures taken for 
both individuals and dyads during the actual play of the game". The authors noted that $6 \%$ and $1 \%$ of the 1700 correlations were significant at the .05 and .01 levels respectively, indicated that analysis of the higher (around .3) correlations revealed no clustering around any single predictor and refrained from further discussion of the personality variables. In the words of Harris (1971):

"Such Spartan refusal to capitalise on chance is rare".

Of other large scale surveys, Klein and Solomon (1966) found 4 of the 66 correlations statistically significant at the .05 level; Pilisuk et al. (1965) analysed the relationship between 5 personality variables and game behaviour in at least 3 different ways and found one statistically significant correlation; McKeown, Gahagan and Tedeschi (1967) obtained five results which were significant at the .09 level or better out of 56 correlations; pilisuk et al. (1968) obtained one significant relationship (for females but not males) after correlating five individual difference measures with five different dependent measures. Marin (1973) looked at two groups of subjects, co-operators: and non-co-operators who were selected on the basis of game behaviour. These subjects were scored on the C.P.R.I. Questionnaire (Eckhardt et al., 1973), but only one scale, Neuroticism, was found to correlate with game behaviour. Wrightsman (1966) attempted to correlate "trusting" behaviour in the Prisoner's Dilemma Game with several personality measures (e.g. Philosophies of Human Nature Scale, Wrightsman, 1964; Personal, Optimism and Anti-Police Attitude Scales, Chein, 1961). The number of attitude and personality variables which related to game behaviour were few and limited to those which were conceptually quite similar to game behaviour, i.e. Philosophies of Human Nature and Political Cynicism Scale, (Agger, Goldstein and Pearl, 1961). 
Mack (1972) had 48 single sex dyads play a version of the Deutsch and Krauss Trucking Game. An analysis of the data provided significant results on the following scales: $C$ (emotional stability) and $Q$ (radicalism/conservation) from the 16 P.F. (Cattell and Eber, 1957); personal relations (factor of the Guilford/Zimmerman (1949) Temperament Survey); Theoretical value (T scale of the Study of Values Test (Richardson, 1965)); exhibition (the 'esh variable of the Edwards (1958) Personal Preference Schedule; and co-operativeness (rule III of the Test of Social Insight (Cassel, 1963)).

Flint and Harris's (1970) study correlated players CD - DC scores with scores on McReynolds and Guevara (1967) Success - Failure Inventory; Christie and Merton's (1958) Machiavellianism Scale and two of the subscales of Wrightsman's (1964) Philosophies of Human Nature Scale, with little success. Similarly, Edwards' Personal Preference Schedule (1953) was found to yield few statistically significant correlations.

\section{b) Specific Dimensions}

Of the specific personality variables identified as possibly having an influence on behaviour within the game situation, several have subsequently proved unsatisfactory predictors of strategy. Baxter (1969, 1972) has made thorough reviews of personality and attitudinal characteristics in two person games, and he indicates that the findings to date are lacking in consistency. However, by reviewing those variables which have provided interesting, if not always significant, results it may be possible to demonstrate that certain personality variables are capable of being identified through game behaviour.

Self-esteem has been noted as having an effect on game behaviour in a number of studies. Three studies (Pepitone, 1964; Faucheux and 
Moscovici, 1968; Pepitone, Faucheux, Moscovici, Cesa-Branchi, Magistretti, Iaconoa, Asprea and Villoni, 1967) employed the same Prisoner's Dilemma Chicken hybrid game, with subjects playing against a pre-programmed noncontingent strategy of $62 \%$ random co-operative choice (the strategy could be exploited most efficiently by choosing the $D$ response continually). As he had predicted on the basis of extensive theoretical and empirical considerations, Pepitone (1964) found that subjects given a success experience (high self-esteem subjects) co-operated significantly more. often than did low self-esteem subjects. Faucheux and Moscovici (1968) found even larger differences between high and low self-esteem subjects when it was made clearer that they were playing with a pre-programmed, and thus exploitable, sequence. More importantly, when chronic selfesteem was used as the variable (i.e. subjects were assigned to high and low self-esteem groups on the basis of a pre-measure), Pepitone's findings of greater competitiveness by high self-esteem subjects was reversed significantly. Pepitone et al. (1967) compared these findings with the results of a study involving Italian subjects which found greater competitiveness by low self-esteem subjects even when self-esteem was manipulated. The authors suggest that this may have been due to an over-representation of chronically low self-esteem subjects as compared to the French and American samples.

Authoritarianism was one of the earliest personality variables to be associated with mixed-motive games. In 1960 , Deutsch reported a positive relationship between authoritarianism (as measured by the California F-scale) and competitiveness in a 2 trial Restricted Prisoner's Dilemma . Game. Subsequently, Gahagan, Horai, Berger and Tedeschi (1967) found no difference between high and low authoritarians in a 100 trial Prisoner's Dilemma Game, but Mckeown et al. (1967), employing a restricted Prisoner's Dilemma in which one player's pay-offs were all positive 
while only $T$ and $R$ were positive for the Other, found that two of the five significant correlations they analysed were involved with authoritarianism. Both of these relationships were significant at beyond the .01 level and despite only 5 of 56 tests proving significant at the .09 level or better, all five results withstood a cross validation test performed by comparing results for subjects run early in the semester with later results. Friedell (1968) found that in an Attack - Retaliation game, closely related to Chicken, authoritarianism increased the propensity to retaliate (i.e. reducing the Other's pay-off from $\$ 1.50$ to 15 cents, but also cutting the player's own pay-off from 15 to 10 cents). In contrast, neither Fry (1965) using a 3 x 3 co-ordination game, nor Wrightsman (1966) using a version of the Prisoner's Dilemma Game, found any significant relationship of behaviour to authoritarianism. Finally, the only significant relationship of a personality variable to behaviour in a 21-alternative Prisoner's Dilemma Game (Pilisuk et al., 1965) was a tendency for pairs of subjects who were both high in "Tolerance for Ambiguity" to become "doves" (i.e. meeting several criteria indicative of a co-operative approach to the game) more often than did subject pairs in which one or both members of the pair had lower Tolerance for Ambiguity scores. Nine of the eighteen items on the Tolerance for Ambiguity Scale have high correlations (presumably negative) with the F-scale.

Another popular personality variable used is the Internationalism Scale, which its deviser Lutzker (1960) found to correlate positively with co-operation in a Chicken Game. McClintock, Gallo and Harrison (1965) in a study involving a game in which one player has no influence on the other's pay-off while the second player has virtually complete control over his partner's outcome, found that Internationalists in the high power role responded more positively than did Isolationists to their 
simulated partner having forced them to lose points in a previous session. However, Pilisuk et al. (1965, 1968) found no difference between Internationalists and Isolationists in game behaviour, even under conditions designed to simulate an arms race as closely as possible.

Christie et al. (1970) found that subjects scoring highly on the Machiavellianism scale (Christie and Merton, 1958) became increasingly more exploitative (as compared with low scoring subjects) over trials in a Restricted Chicken Game, played against a programme of $80 \%$ noncontingent co-operation. Subsequent studies by Daniels (1966), using a seven alternative, turn taking version of the Prisoner's Dilemma Game; Wrightsman (1966), using a Non-Restricted Prisoner's Dilemma Game; and Condry (1967), using a $10 \times 10$ co-ordination game, have failed to detect any significant correlations of game behaviour with Machiavellianism.

Four of the subscales of Wrightsman's (1964) Philosophies of Human Nature scale (P.H.N.) were found by Wrightsman (1966) to distinguish between trusting and distrusting subjects in the first of two experiments involving a two trial Prisoner's Dilemma Game, choosing first on the first trial, second on the second. Two of these subscales (Favourability and Trustworthiness) were related to the classifications in the second experiment involving the same game, although in this case the only difference of any magnitude was between those classified in the "garbage" category of "Others" and the two other classifications.

Tejio and Wrightsman (1967) found that the Altruism, Trustworthiness and Strength of Will scores correlated positively and significantly with level of co-operation in: a Restricted Prisoner's Dilemma Game when the subject knew his partner was Caucasian but correlated negatively and non-significantly with co-operation when the Other was known to be Japanese. 
Wrightsman, Davị, Lucker, Bruininks, Wilde, Paulson and Clark (1972) found a significant relationship between scores on the Altruism scale and behaviour in the $90 \%$ competitive feedback condition of an experiment in which the subject always chose first in what was otherwise a Restricted Prisoner's Dilemma Game, but found no significant relationship for this same scale in another 3 strategy conditions, nor for the other subscales of the P.H.N. in any of the four conditions.

Terhune (1968) compared the game performances of three populations characterised by different mixtures of three needs, as assessed by the Thematic Apperception Tests (these needs being; (i) need for achievement; (ii) need for affiliation; (iii) need for power). The author concluded from his work that; (i) subjects with "need for achievement" were the most trusting and trustworthy regardless of the game matrix; (ii) subjects with "need for affiliation" were highly co-operative in "safe games", but co-operated less in more risky games and became mainly suspicious and defensive; ( $i i i)$ subjects with "need for power" were consistently non co-operative and attempted exploitation of their partners.

\section{c) Dominance}

Four investigations have been identified which attempted to correlate dominance as a personality trait with behaviour in the game situation. Marlowe (1963) using a standard Prisoner's Dilemma matrix, discovered that non co-operative subjects scored higher than co-operative subjects on a dominance measure which was based on the Gough Adjective Check List but the difference failed to reach significance $(p=0.17)$. The subject played a confederate who used unconditionally co-operative. choices for 30 trials. 
Fry (1965) found that pairs of subjects whose scores in the Allport and Allport Ascendance - Submission scale (1939) were not in adjacent quartiles, performed more efficiently in a $3 \times 3$ co-ordination game than those whose scores were more similar.

Sermat (1968) administered the MMPI Dominance scale (Do) to a Iarge population of female students. From the results obtained, he selected twenty highly dominant subjects (score range $42-51$ ) and twenty low dominance subjects (range $22-33$ ). The subjects were allocated to pairs consisting of two high Do, two low Do scores, or one of each, and were led to believe that they were playing a Chicken Game with their partner. In reality they played a predetermined strategy of $60 \%$ cooperative choice for 50 trials followed by $10 \%$ co-operative choice for 60 trials. Sermat discovered that interaction between Do score of the subject, Do score of the partner and trial blocks in the last 60 trials was highly significant $(F=5.19 ;$ d.f. $=5,180 ; p<.001)$. His overall results, based on a combination of two experiments, indicated that the dominant subjects responded more competitively in the last 60 trials than did the submissive subjects. Also, low Do subjects who had met another submissive individual during the pre-game encounter were subsequently less competitive than individuals in the other three subject/ partner combinations. Sermat also indicated that age and sex were not factors affecting behaviour in the game but rather the greater competition on the part of the high Do subjects was due to their dominance alone:

"Subjects who could be classified as dominant, resourceful and used to getting their own way in social situations would attempt either to gain more than the other player or to block the other from getting ahead".

Moore and Mack (1972) had three groups of subjects play a Prisoner's Dilemma Game 300 times against a subject of their own sex. The three experimental groups consisted of high dominance pairs, low dominance pairs and mixed pairs respectively. Dominance was measured by the 
Allport and Allport Ascendance-Submission Reaction Study (1939) and the subjects were chosen from the top and bottom $20 \%$ of the 365 students who undertook the test. It was found that high dominance pairs, but not low dominance pairs locked in sooner than mixed pairs, and that they had a larger proportion of; (i) D responses; (ii) D, D joint responses; and (iii) locks-in on D, D, than either mixed dominance or low dominance pairs. In addition, ascendant subjects initiated D responses more often than submissive subjects.

\subsection{PERSONALITY DIMENSIONS AND MIXED-MOTIVE GAMES: AN OVERVIEW} In general, it would seem that investigations of a relationship between personality and game behaviour are far from consistent, and indeed the majority of studies fail to identify any relationship. A number of authors have sought to outline reasons for these disturbing results. Baxter (1969) has identified six typical reactions:

a) The game situation is seen as being an unsuitable medium through which to investigate individual differences as the interaction between subjects is of such a limited nature.

b) Relationships exist if only suitable variables are identified to measure these relationships.

c) Choice is only truly co-operative if it is accompanied by the belief that the other person will also choose to co-operate. Therefore before each play, subjects must predict the choice of the other if the experimenter is to obtain an accurate estimate of co-operation in the game.

d) It is maintained that role and/or personality characteristics of subjects are interactive with the structure of the conflict situation at first, but soon are washed out by the spiral of conflict. Findings from one or two trial games tend to support this view, as does the 
learning effect found in Prisoner's Dilemma, whereby DD responses increase over a time series.

e) It is suggested that personological factors are complex, and difficult to predict when taken as single and separate variables. f) A final point argues that the simplicity of the game is misleading, and only a deeper analysis will reveal the complexities and dynamic aspects of the game.

Terhune (1970) in a review of personality in mixed-motive situations, indicates that personality dimensions may be influential but that contemporary research often fails to distinguish these factors. The author suggests several areas for improvement; (i) more complex experimental situations; (ii) more attention to incentives; (iii) improved personality measurement; (iv) conceiving personality as configuration; ( $v$ ) use of more specific behavioural indices; and (vi) increased attention to the interaction of personality and situation.

Rapoport (1976) concludes his review of personality variables by stating:

"The impression is unavoidable that direct, enlightening relations between the personality of subjects as assessed by existing personality tests and gaming behaviour are not likely to be established; certainly not if predominantly a single dependent measure, frequency of $\mathrm{C}$ choices, in just one or at most very few $2 \times 2$ games is used as the index of behaviour. Unfortunately, this has been the case in the overwhelming majority of studies. Nevertheless, the few definitive findings relating personality characteristics to game behaviour suggest that the question deserves further exploration".

It is concluded that the mixed-motive situation may hold the potential for identifying individual differences, but to date this potential has not been realised. Perhaps the reliance on only one game, Prisoner's Dilemma, and additionally only simple measures of behaviour within that game have been inhibitory factors in the development of research in this area. 
CHAPTER EIGHT: EMERGENT LEADERSHIP AND MIXED-MOTIVE GAMES

\section{SUMMARY}

The chapter describes the potential of mixed-motive games for identifying leadership roles. In particular, the salient features of the Leader Game are discussed. Research utilising the game is noted. 


\subsection{EMERGENT LEADERSHIP AND MIXED-MOTIVE GAMES}

To date, the author is unaware of any research relating the emergence of leadership to game behaviour. Dominance as a personality trait has been shown to have an influence on behaviour in the Prisoner's. Dilemma situation (Sermat, 1968; Moore and Mack, 1972), but no data exists specifically identifying a relationship between any aspect of game behaviour and leadership itself. This may be seen as a consequence of a number of factors. For example, research relating games and personality has relied heavily on psychological scales of various sorts. As the review of leadership indicates, the phenomenon of emergent leadership has found little by way of relationships with specific attitude or personality measures. However, the literature on emergent leadership does indicate that certain aspects of behaviour may facilitate individuals in emerging as leaders (Jacobs, 1971 ; Stein, 1975; Hollander, 1964; Garland and Beard, 1979). Additionally, the development of task and socio-emotional leadership roles may be dependent on factors other than simply expertise in the particular problem. For example, socio-emotional leaders seem to adopt different interpersonal relationship styles than task leaders (Bales and Slater, 1955). Given the nature of mixed-motive games, where the player is placed in a situation of having to establish co-ordination with another individual, it may be hypothesised that some of the factors which influence the individuals capacity for leadership would be evidenced in styles of play in the game.

of the four archetypal mixed-motive games, Leader would seem to hold the greatest potential. Specifically, the capacity for pre-emption in the game would seem a useful index of certain aspects of behaviour. Whether the player utilises the interactive component of Leader to dominate the other, or whether the player sees the game in terms of an 
individual exercise with little concern for co-ordination will be evidenced by game behaviour.

Certain other features of the game add to its desirability as a research tool. Firstly, there is no evidence of a learning effect over a series of trials - hence presumably the perception of the game by players remains constant over time. Secondly, neither strategy is inherently more productive against a non-contingent other, and thirdly, no significant sex differences have been identified to date, although trends for a greater choice of D response by males are noted. Therefore it would seem that Leader presents an interesting psychological tool for the identification of individual differences.

Mack and Kremer (1977, in press) attempted to define the feasibility of using the Leader game in the context outlined above. Specifically, the experiment investigated the effects of sex differences and dominance on behaviour in the Leader game. Subjects were selected from a first year social psychology course $(n=188)$ and each completed the California Psychological. Inventory (Gough, 1957). From this population, those individuals scoring high or low on the Dominance scale were selected for participation in the game. This consisted of 100 trials of Leader which was played against a non-contingent strategy of $50 \%$ of either choice. Four groups were used ( $n=12$ in each); high dominance males, high dominance females, low dominance males and low dominance females. Subjects were scored on a variety of measures, including the frequency of pre-emption from cell 1 of the matrix.

An analysis of results indicated that dominance did have an effect on choice of strategy, although this failed to reach statistical significance. The pre-emption rates were significantly different $(p<.01)$, in that 
dominant males had a lower propensity to pre-empt than the dominant female subject group. This differential approach to the game by the two groups was taken by the authors as an indication that dominance manifests itself in male play through a persistent, intransigent style, whereas dominance in female play is seen in behaviour with a greater regard to the social intricacies of the game situation.

These results, taken in conjunction with previous findings leads the author to believe that Leader Game may hold potential for the identification of certain aspects of leadership behaviour. The game has therefore been utilised in the present investigations - an account of which follows in the succeeding chapters of this thesis. 
THE INVESTIGATIONS 
SECTION THREE: THE INVESTIGATIONS 
Four investigations are described, each of which considers the relationship between game behaviour and the emergence of leadership in a small group setting. The primary difference between each investigation lies in the nature of the task upon which the group works. The gaming condition" remains constant across all four experiments, with subjects playing 100 trials of the Leader Game gasinst a partner of the same sex. Subjects are than grouped together into 5-person, single sex groups, and work together on a variety of tasks. It was found that pre-emption rates in the Leader Game related to leadership nominations in each of the experiments, although situational variables influenced whether high or low pre-emptors rose to prominence. The investigations provide support for the proposition that Leader holds potential as a device for predicting role emergence in small groups. 
CHAPTER NINE: THE EXPLORATORY INVESTIGATION

\section{SUMMARY}

The investigation considers the relationship between game behaviour, and particularly pre-emption rate, and the emergence of leadership roles in a small group. Subjects played 100 trials of the Leader Game against a non-contingent other, whom they believed to be another student of the same sex. Subjects were then grouped into 5 person units and subsequently worked upon problems derived from mixed-motive situations. The problems were taken as being sufficiently ambiguous as to allow for a variety of approaches to be employed. Following the group session, leadership questionnaires were administered and the highest nominated task and socio-emotional specialists identified. Additionally, participation rate was measured and members' IPC scores. It was found that in both male and female groups, task leaders were differentiated from other subjects in terms of pre-emption rate. In male groups, these leaders had lower levels of pre-emption, whereas in female groups they had higher. The results are interpreted in terms of differences in perception of and approach to the problems by both sexes, and subsequent differences in Ieadership styles, as measured by pre-emption rate. It is concluded that the measure has potential for future research, and particularly with regard to situational variables influencing leadership emergence. 
The investigation is a preliminary enquiry into the relationship between role emergence in small groups, and behaviour in the Leader Game. Given; (i) the lack of research relating role emergence to behaviour in mixed-motive games; and (ii) the situational dependence of particular leadership roles, it was determined that the group's problemsolving task would be in some manner related to a mixed-motive situation. It was presumed that by maintaining some connection between the primary and secondary phases of the experiment (game and group respectively), the likelihood of discovering a relationship would be enhanced. Hence, the tasks upon which groups of subjects worked were derived from anecdotes of mixed-motive games such as the Deutsch and Krauss Trucking Game, Prisoner's Dilemma Game and Leader Game. (Whilst containing the dilemmas. inherent in the matrix games, these problems were described so as to appear unconnected to the game phase of the experiment (see Appendix I)). The task for each group was to reach consensus on the optimum strategy to be employed, the solution being in no way unequivocable.

Mack and Rremer (1977) established a link between dominance, as measured by the California Psychological Inventory Dominance scale (Gough, 1957), and pre-emptive game behaviour in Leader (that is, the willingness of the player to switch from the mutually unrewarding cell of the matrix C, C). This indicated to the authors the potential of Leader for identifying individuals with the propensity to lead in particular situations. Additionally, interesting sex differences were revealed in so far as highly dominant males showed low levels of pre-emption and highly dominant females showed high levels of pre-emption. These findings were taken by the authors as indicative of alternative perceptions of the game situation by dominant subjects of either sex. . It may be that 
these subjects whilst scoring high on the dominance scale may not only be differentiated in terms of game behaviour, but possibly in other interaction settings. Therefore, the game behaviour may be characteristic of alternative styles of interaction.

More positively, the investigation demonstrates that Leader has the capacity for discrimination on the basis of dominance, and so the proposition that the game is useful in identifying individual differences is substantiated.

As outlined in the Review of Literature, Leader Game has certain features which enhance its potential as a research tool. As an experimental game, the control of extraneous variables is relatively straightforward. A number of authors (Terhune, 1970; Harris, 1971; Rapoport 1976) have suggested that games have considerable scope for identifying individual differences, but in the past, a host of confounding variables have detracted from the usefulness of games in this respect. The present investigation was specifically designed to overcome some of these difficulties, for example; (i) by moving away from Prisoner's Dilemma and its associated contradictions and biases; (ii) by using a secondary measure of behaviour (leadership) which is possibly of greater relevance than those extracted from personality inventories; (iii) by utilising more sophisticated measures of game behaviour than simply frequency of either response.

The game was originally dubbed Leader, as pre-emptive play was taken as evidence of initiative in determining the outcome of future trials. As the literature review reveals, there is no data supporting this hypothesis apart from the work of Mack and Kremer, which found dominant females behaved as anticipated, but dominant males pre-empted less than others. 
Intuitively, it may be supposed that the style of play in the game, as demonstrated by rates of pre-emption, may be mirrored in styles of interaction in face-to-face groups. That is, those individuals who play the game with little regard to social facets, and in a generally inflexible style (low pre-emptors) may exhibit similar responses whilst interacting in a group, i.e. behave intransigently. On the other hand, the more adaptable players (high pre-emptors) may give more flexible responses in a group setting. The research literature on leadership styles indicates a differentiation between distinct role types along these general lines. It is anticipated that pre-emption rate may be capable of discriminating between role specialists.

Contemporary research also demonstrates the importance of context in the development of leadership roles. Whilst models purport to distinguish styles of leadership in existing hierarchies, no model has yet developed which is able to predict accurately who is likely to gain prominence in an emergent situation. Factors such as expertise have been shown to have some relevance, but are not sufficiently powerful predictors to warrant rating as determinants of emergent leadership.

The majority of studies into leadership style within existing hierarchies has dichotomised the process (e.g. Least Preferred Co-Worker scale; Autocratic-Democratic styles; Consideration-Initiating Structure). Post hoc analyses of emergent leadership situations have indicated that a worthwhile differentiation can be made between task and socio-emotional specialists (Bales, 1958), particularly after a number of meetings of a group. Social Exchange analyses argue that whichever role is of greatest value to the task at hand will be the one that emerges most forcibly, and indeed if one role is superfluous, then it may not emerge. The characteristics of the two role specialists is not well documented, 
although it may be that the socio-emotional leader displays a somewhat undifferentiated interaction style, as they ascribe similar characteristics to all co-workers. The task specialist is perhaps more specific to the task at hand, although both leaders must be categorised within the particular situation.

Leadership research has tended to concentrate on male or mixed-sex groups, where male dominance is usually found (Megargee, 1969). The limited research comparing sexually homogenous groups indicates that there may be differences between hierarchies in male and female groups. Specifically, male groups tolerate more authoritarian behaviour, and seem to be governed by more rigidly defined role systems. The present investigation intends to look farther at these differences.

The most reliable selectors of leaders within groups have been shown to be group members themselves. Stein (1973) determined that the cues which they pick up, whilst undefined, differ substantially from those which even trained observers employ. Hence, measures of leadership will be determined by members' nominations in this investigation.

As the initial experiment is largely exploratory, it was decided to look at aspects of game behaviour in conjunction with more established leadership measures, in relation to leadership nominations. Hence, Fiedler's Least Preferred Co-Worker Scale was administered to all subjects, along with the Group Atmosphere Scale (Fiedler, 1967). Groups were also videotaped, in order to determine rates of participation by each member. 


\subsection{HYPOTHESE:}

As the investigation is exploratory in nature, hypotheses must necessarily reflect the open-endedness of the work. On the basis of. the literature revieved, four sets of hypotheses vere formulated, concerned with:

a) The relationship between game behaviour and emergent leadership roles;

ib) Sex differences, both in game behaviour and in the group setting;

c) The Least Preferred Co-Horker scale;

d) Participation rate.

a) These hypotheses, considered central to the investigation, are based on the assumption that individuals who emerge as leaders, whether task or socio-emotional, will be distinguishable from other group members in terms of measures of game behaviour. Previous research (Mack and Kremer, 1977) indicates that certain forms of behaviour in the game are useful in determining individual differences. Specifically, the propensity to move away from the mutually unrewarding or punishing cells of the matrix (propensity to change from cell 1 and cell 4 respectively) and the predominant choice of strategy (choice of BLUE or RED over a hundred trials) were shown to be useful indices of behaviour. The following hypotheses vere tested:

1. Those individuals nominated as task leacer will behave differentially from other group members with regard to pre-emption (the provensity to change from cell 1).

2. Those individuals nominated as socio-emotional leader will behave differentially from other group members with regard to pre-emption (the propensity to change from cell 1).

3. Those individuals nominated as task leader will behave differentially from other group members with regard to propensity to change from cell 4.

4. Those indiviouals nominated as socio-emotional leader will behave differentjally from other group members with regard to propensity to change from cell 4 . 
5. Those individuals nominated as task leader will behave differentially from other group members with regard to choice of blue strategy. 6. Those individuals nominated as socio-emotional leader will behave differentially from other group members with regard to choice of blue strategy.

b) Previous research indicates that there is a trend for females to choose blue less often than males in Leader (Mack, 1972), but no precise hypothesis is considered appropriate:

7. Male and female subjects will behave differentially in the game situation.

Previous research also shows that there may be differences in leadership hierarchies between sexually homogenous groups (Denmark, 1977):

8. The emergence of leadership roles will be deperident upon the sex of group.

c) Work on the Least Preferred Co-Worker scale (Fiedler, 1967) indicates that it may have the potential for discriminating between emergent leaders and other group members (Schneier, 1978):

9. Leadership roles will be differentiated by the scores on the Least Preferred Co-Worker scale.

d). Participation rate has been shown to correlate with leadership status on a number of occasions (Stein and Heller, 1980): 10. Leadership roles will be differentiated by rate of participation. 


\subsection{SUBJECTS}

Subjects were selected from the Introductory Social Psychology Course at Loughborough University. 40 male and 45 female subjects were employed, and each was awarded coursework credits for participation.

In the first part of the experiment (trials of the Leader Game), subjects were paired with a partner of the same sex. Subjects were not paired with otheris of close acquaintance.

In the second part (group problem-solving task), subjects were randomly allocated to five person groups, again sexually homogeneous in structure. Hence 17 groups were employed ( 8 male and 9 female). Acquaintance was once again controlled.

Subjects were given a restricted de-briefing after the first part of the experiment. The experimenter ascertained if the subjects; (i) were aware of the aims of the investigation; (ii) were able to understand the instructions. In either instance, if subjects were unaware or unsure, they were not included in the second part of the experiment. (One subject was eliminated as a result of failing to understand the instructions adequately). A more detailed de-briefing was given following the second part of the experiment.

\subsection{APPARATUS}

\section{a) Game Condition}

The apparatus consisted of two identical consoles, located in adjacent sound-proofed cubicles (see DIAGRAM 1). The consoles gave subjects information concerning their total score to date, the outcome of the immediately preceding trial and the values associated with each choice 
(DIAGRAM 2). Subjects indicated their selection on each trial by pressing either the red or blue button. The pay-off matrix (DIAGRAM 3) was taken from Mack (1972), as this version thifies all the rules of the Leader Game, whilst maintaining greater symmetry between the two responses than the matrix originally described by Guyer and Rapoport (1967).

Neither player could communicate either verbally or visually with the other player. In reality, both players played against a probability randomiser which generated 50\% red and 50\% blue responses over the 100 trials. Effectively, two experiments were run simultaneously. Each subject played a non-contingent other, and only an illusion of interaction with the other subject was created. A delay mechanism was incorporated into the apparatus in order that each player could only choose once the other had made a choice, thus reinforcing the illusion of interaction.

Game instructions were tape recorded for uniformity, and relayed to the subjects by headphones via the console.

Subjects' responses were recorded on punch tape to facilitate data analysis.

\section{b) Group Condition}

Subjects were seated around a hexagonal arrangement of tables (DIAGRAM 4), with one table per subject. Colour codes were attached to each table, in order for subjects to identify their co-workers.

The information comprising each task was divided into five segments, and one part was presented randomly to each subject. Task information 
for the next problem was distributed when subjects had reached consensus on the preceding task. On completion of the tasks, a leadership questionnaire was administered (APPENDIX II).

Subjects were observed during the interaction through a one-way vision screen, and were videotaped for future analysis of participation rates.

\subsection{METHOD}

\section{a) Game Condition}

Each subject played 100 trials of the Leader Game against a non-contingent other, their objective being to amass as many points as possible. The subject received feedback after each trial as to the outcome of the previous trial and total score to date.

\section{b) Group Condition}

Each group worked on four problems derived from mixed-motive situations (APPEIDIX I). The problem was divided into five pieces of information, and these were combined by the group members before work on the problem could begin. When consensus was reached as to the optimum solution, then the group moved on to the next problem. Groups were allocated a maximum time of 45 minutes to complete all four problems.

\subsection{PROCEDURE}

All subjects had completed the game before the second stage of the experiment, was begun. Data collected from the Leader Game condition was not analysed until all the investigation was finished, in order to overcome experimenter bias. 


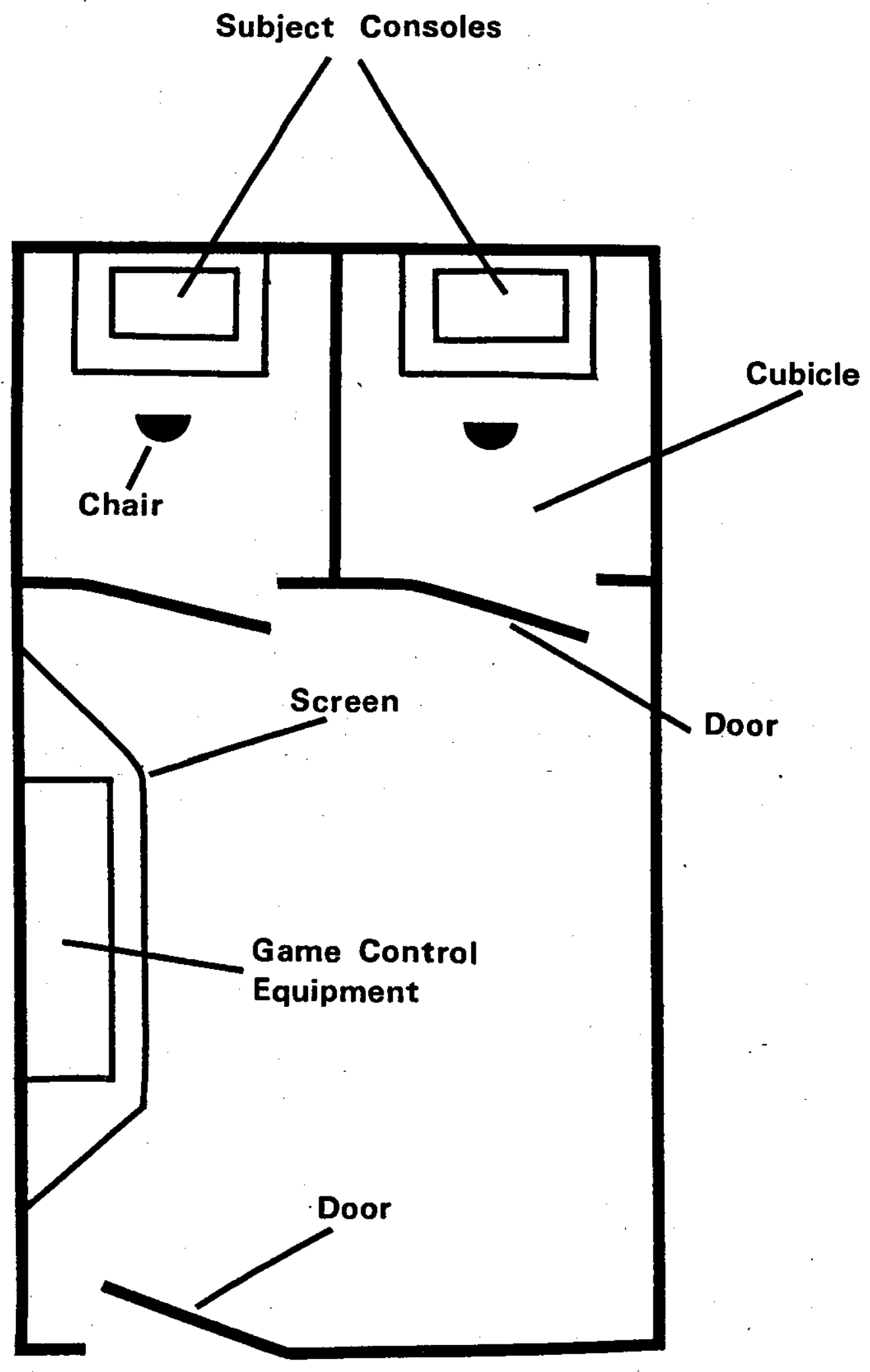

DIAGRAM 1: THE EXPERIMENTAL SITUATION - GAME CONDITION $1+2$ 


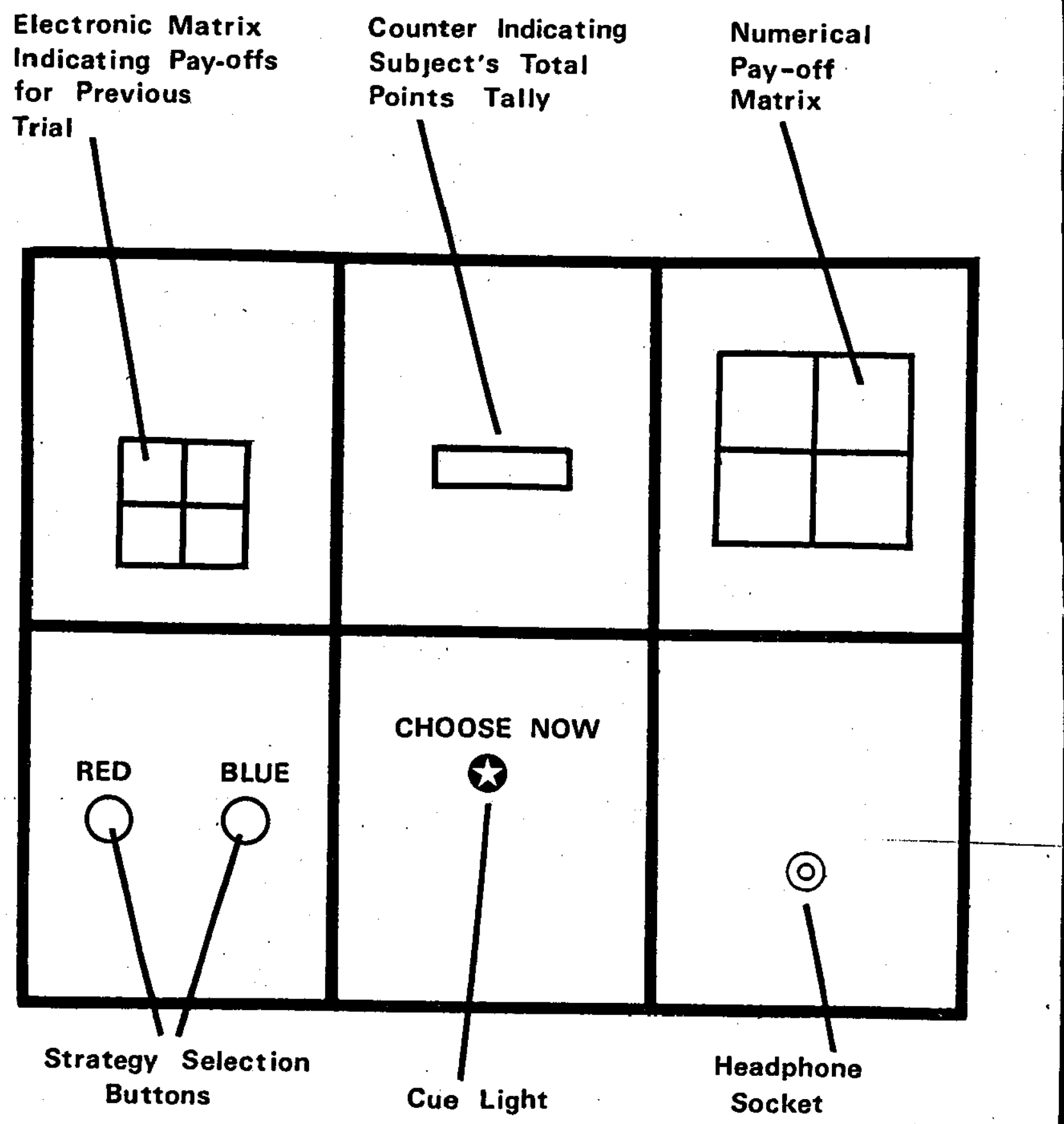

DIAGRAM 2: SUBJECT CONSOLE

3 
PLAYER B
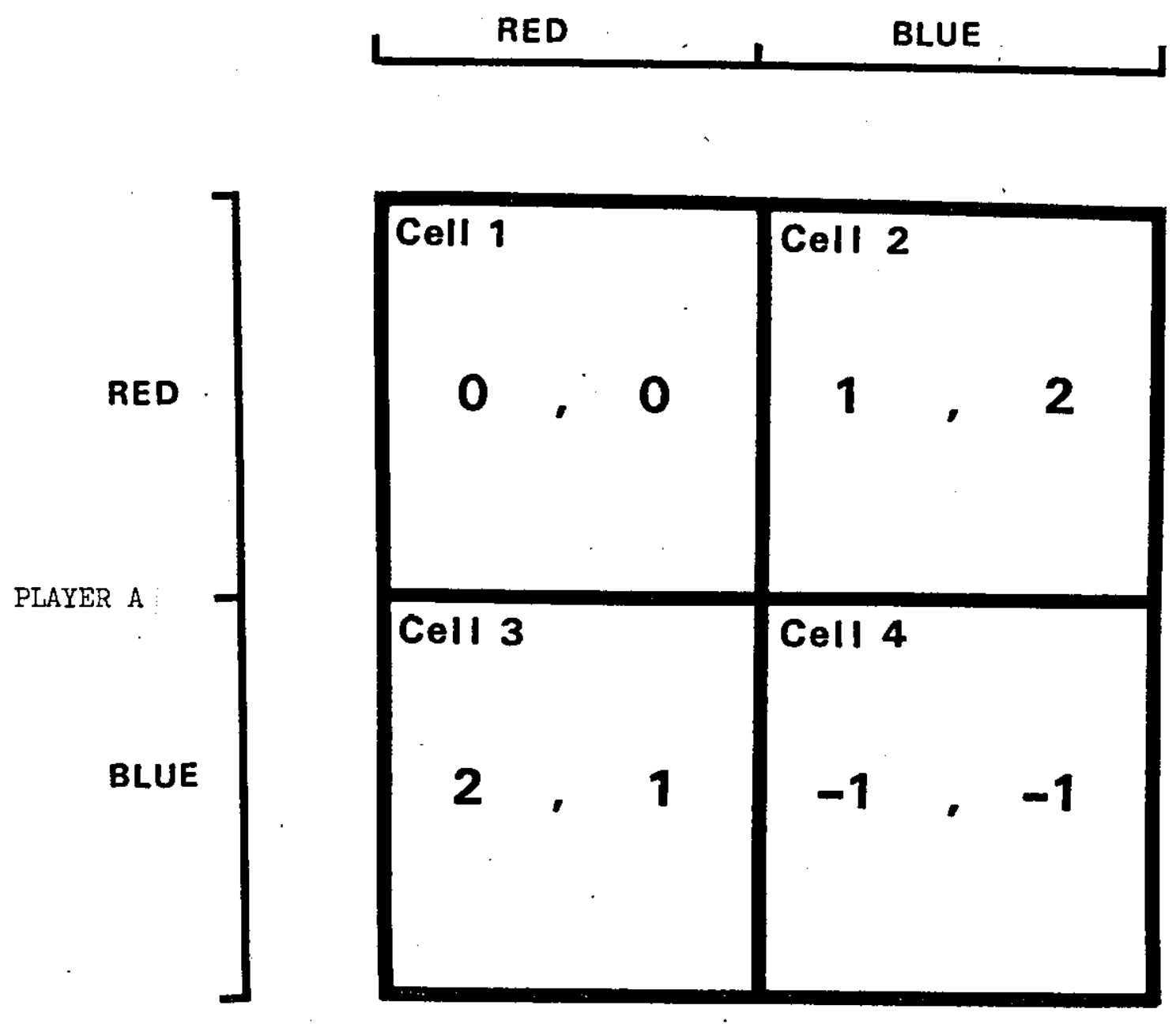

DIAGRAM 3: THE PAY-OFF MATRIX 


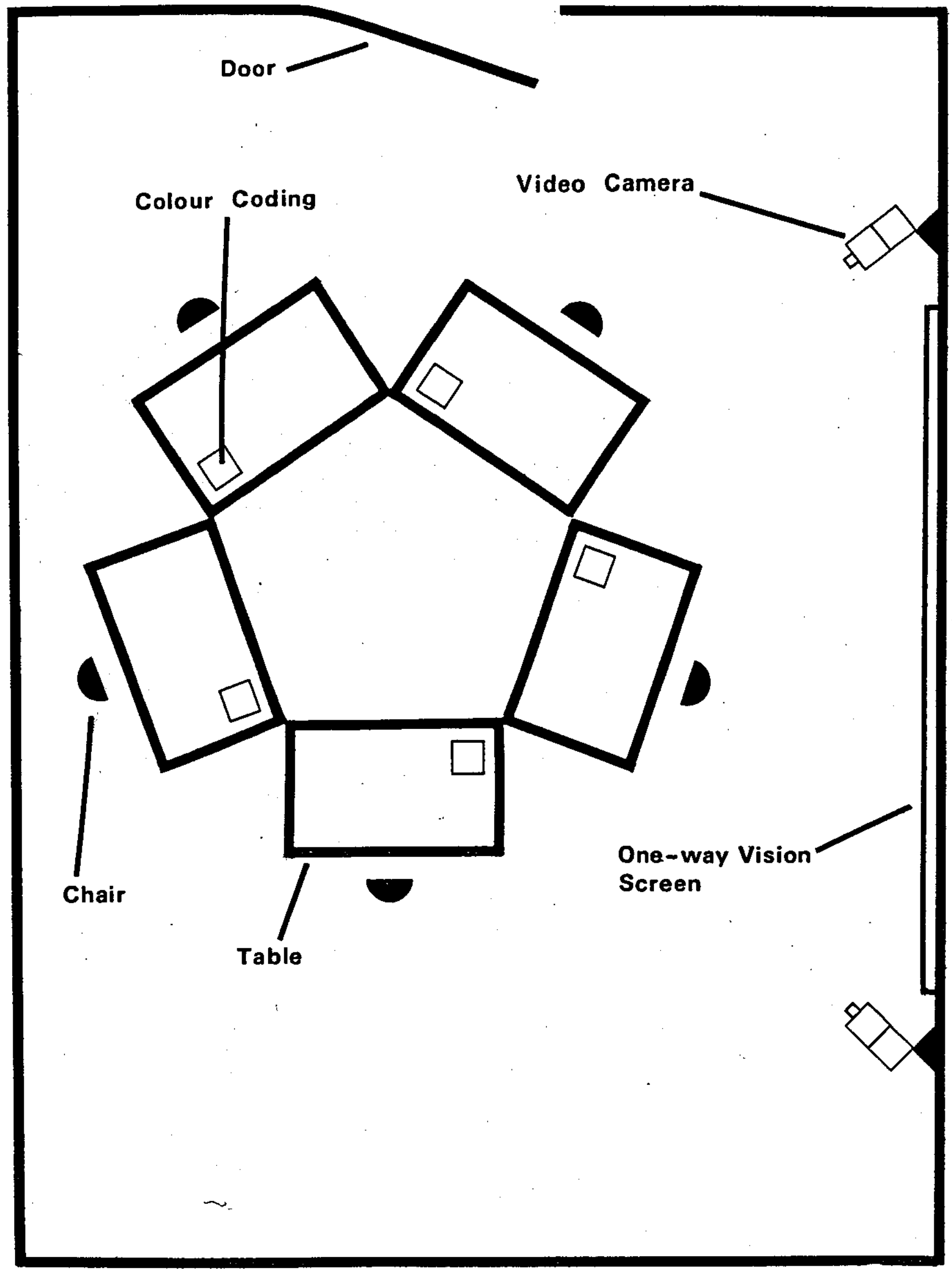

DIAGRAM 4: THE EXPERIMENTAL SITUATION - GROUP CONDITION 
Both subjects were introduced into the experimental room, and ushered into adjoining cubicles. They were instructed to put on the headphones and the following instructions were then relayed 1

"Today I would like you to take part in an experimental game which involves two players, yourself and another person of your own sex. The other player is seated in the adjacent cubicle and has an identical set of apparatus. You are asked to make a simple choice between two colours - you may choose RED, or you may choose BLUE. The other player will be asked to choose between the same two colours at the same time as you make your choice - that is, you both make your choices simultaneously. Depending on your choices, you will each gain a number of points.

The actual number you gain is contained in the pay-off matrix in front of you. It is important that you realise your gain depends not only on the choice you make, but also on the choice made by the other player. You will understand this better if you follow the pay-off matrix while I explain.

You are player $A$ and the other person is player B. You are listed at the left hand side of the matrix, he/she at the top.

If you choose RED you may gain either 0 points or 1 point. If you choose BLUE you may gain either 2 points or lose 1 point. Whether you gain 0 points or 1 point on RED, or whether you gain 2 points or lose 1 point on BLUE, depends on. What the other player has chosen. If you both choose RED, you will gain $O$ points each. If, however, you choose RED and the other person chooses BLUE, then you will gain 1 point while he/she will gain 2. On the other hand, if you choose BLUE and the other player chooses RED, then you will gain 2 points while he/she will gain only 1. If, however, you should both choose BLUE, then you will lose 1 point each. Let me repeat that for you.

You are player $A$ and the other person is player B. You are listed at the left hand side of the matrix, he/she is listed at the top. If you choose RED you may gain either 0 points or 1 point. If you choose BLUE, you may gain 2 points or lose 1 point. Whether you gain $O$ points or 1 point on RED, or whether you gain 2 points or lose 1 point on BLUE, depends on what the other player has chosen. If you both choose RED, you will gain 0 points each. If however, you choose RED and the other person chooses BLUE, then you will gain 1 point while he/she will gain 2. On the other hand, if you choose BLUE and the other player chooses RED, then you will gain 2 points while he/she will gain only 1. If however, you should both choose BLUE, then you will lose 1 point each. 
We will play several trials of the game - that is, you will each make choices several times. After the instructions are finished and when the "choose now light" lights up, I want you to make a choice by pressing the appropriate button. If you want to choose RED, then press the key marked RED. If you want to choose BLUE, then press the key marked BLUE. The scoring counter will automatically add the number of points you have gained.

Finally, I can tell you that the game is absolutely fair for both of you. As you can see from the matrix, the payoff for each choice is equal for both players - if you choose $R E D$ you can gain $O$ points or 1 point; if the other player chooses RED, he/she can gain 0 points or 1 point. Similarly with BLUE, each of you can gain either 2 points or lose 1 point.

While you have been listening to this tape, the other player has received exactly similar instructions to those I have just given you. If you have any questions, please write them on the paper provided.

The object of the game is for you to try to gain as many points as possible. You may begin."

After listening to the instructions, subjects played 100 trials of the game. Following the 100th trial, subjects were thanked for their co-operation, and asked not to discuss any aspect of the experiment with prospective subjects.

\section{b) Group Condition}

Subjects entered the laboratory simultaneously, and seated themselves around the tables. The experimenter then distributed the first problem, with verbal instructions for the group to collect together the five portions of the problem, when they had reached a solution. This served as a cue for the experimenter to distribute the next problem, etcetera. After finishing the fourth problem, a leadership questionnaire was administered to each subject (APPENDIX II). This asked subjects to nominate whom they considered to be the most valuable member of the group with regard to; $(\dot{i})$ : task; and (ii) socio-emotional considerations, on each of the four tasks in turn. Additionally, they were asked to 
nominate whom they considered the person best equipped to lead the group on a number of tasks. Subjects also completed the Least Preferred Co-Worker and Group Atmosphere scales (Fiedler, 1967).

A full de-briefing followed. Subjects were thanked for their cooperation, and again asked to remain silent about the experiment until all subjects had been run.

\subsection{RESULTS}

The results provided data relating to:

a) Game behaviour.

b) Ieadership nominations.

c) The Least Preferred Co-Worker scale.

d) Participation rate.

\section{a) Game Behaviour}

The main measures employed were; (i) the percentage of blue response; (ii) the propensity to change strategy. The Index of Co-operation was considered inappropriate, as this measure relies upon co-ordination between the two players. (In the present investigation, the other played a non-contingent role, hence co-ordination was impossible). (i) The percentage of blue response for each subject was calculated (see APPENDIX III), and the responses were also grouped by sex into ten by ten trial blocks (see APPENDIX IV). The results are shown in Graph 1.

(ii) More sophisticated data was obtained by establishing the propensities of individuals to change strategy. Rapoport and Chammah (1965) defined certain contingent propensities which they took as indices of behaviour less dependent on interaction effects than measures such as frequency of blue or red response. These propensities, given in 


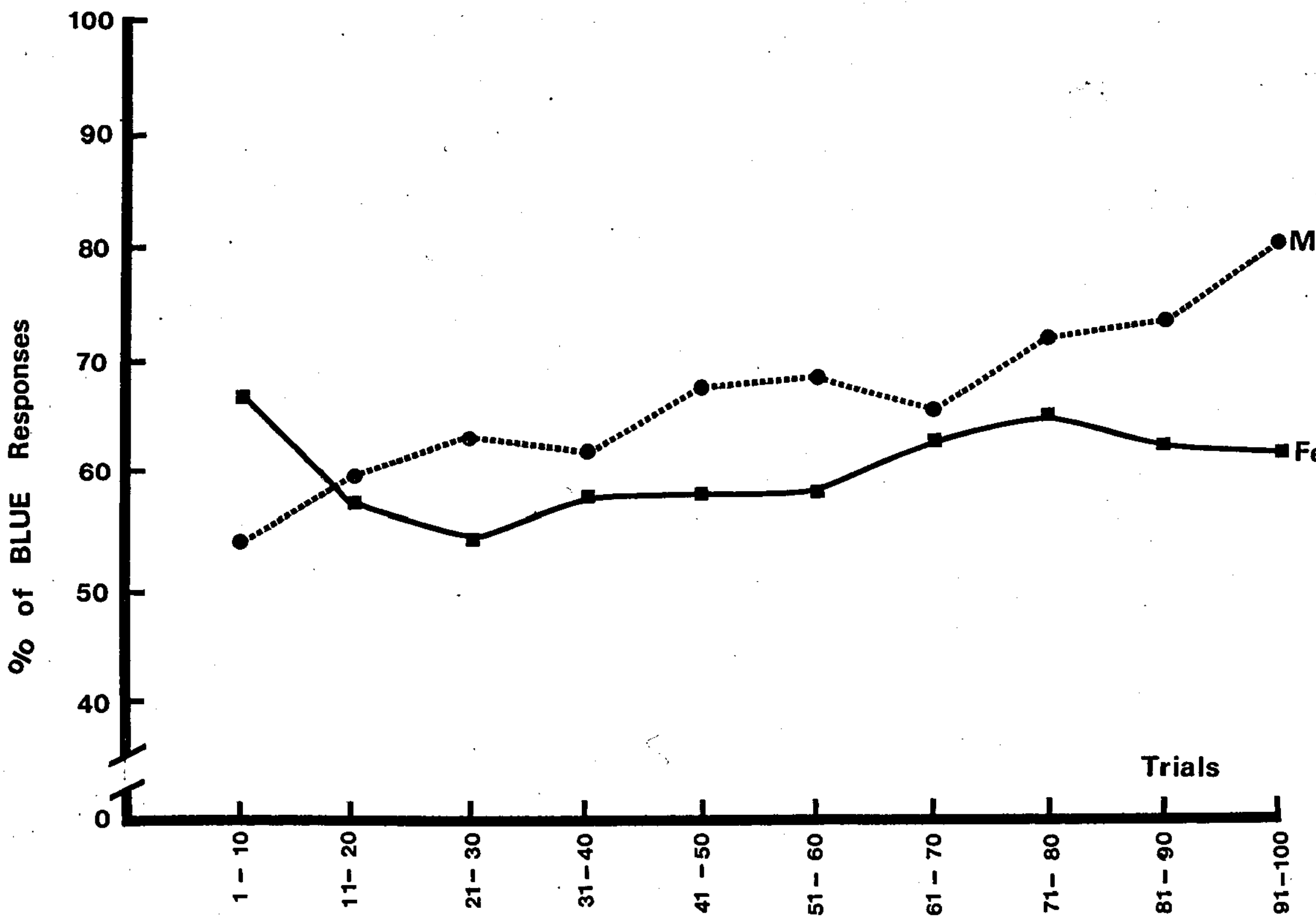

GRAPH 1: PERCENTAGE OF BLUE RESPONSES OVER ONE HUNDRED TRIALS BY TEN-TRIAL BLOCKS 
full on page 96, are the frequency of red responses following a trial where any of the four cells was the outcome.

In the present investigation, the primary concern was with the individual's willingness to adapt his behaviour, and so the propensity to change strategies was used. This modification involves examining the likelihood of a player choosing the alternative strategy to that which he selected in the previous trial. The propensities can be defined as follows:

< : the probability that a player will choose blue following a play on which he chose red, and the other player chose red also.

$\beta$ : the probability that a player will choose blue following a play on which he chose red, and the other player chose blue. $\gamma$ : the probability that a player will choose red, following a play on which he chose blue, and the other player chose red. $\delta$ : the probability that a player will choose red, following a play on which he chose blue, and the other player chose blue also. The mean propensities to change are given below, by sex:

MEAN PROPENSITIES

MALE

FEMAIE

\begin{tabular}{|c|c|c|c|}
\hline$x$ & $\hat{\beta}$ & $x$ & $\zeta$ \\
\hline .502 & .483 & .314 & .319 \\
\hline .503 & .499 & .395 & .4 \\
\hline
\end{tabular}

b) Leadership Nominations

Measures employed were concerned with nominations for; (i) task leader; (ii) socio-emotional leader; and (iii) prolonged leader.

The number of nominations afforded each subject for each role were totalled, and this measure was employed to establish the individual with the highest ranking in each group (APPENDIX V). 
Analyses were subsequently made between those with the highest nominations in each group (the leaders) and all other subjects. In the event of 2 subjects having equal ranking, then both were included in the leader category.

In male groups, there were no ties for task leader, one for socioemotional leader and none for prolonged leader. In female groups, there were 4 ties for task leader, sone for socio-emotional leader and one for prolonged leader.

The overlap between roles was also considered. In male groups, $44 \%$ of task leaders were also highest ranking in the socio-emotional category. In female groups, $38 \%$ of task leaders were highest ranking in socioemotional nominations.

In male groups, all task leaders were also most nominated as prolonged leader, whereas in female groups, $63 \%$ were also prolonged leader.

\section{c) Least Preferred Co-Worker scale}

Subjects were scored on this scale, and their mean response calculated. (APPENDIX VI).

\section{d) Participation Rate}

Videotapes of each group were replayed and the total number of verbal contributions made by each subject noted. Their contribution as a percentage of the group total was calculated. (APPENDIX VII) 


\subsection{ANALYSES}

a) Game Behaviour

Comparisons were made between the game behaviour of male and female subjects, with regard to; (i) choice of strategy; (ii) propensity to change strategies.

(i) A Mann-Whitney U-test was employed to compare percentage of blue response by male and female players. It was found that there was a trend for males to choose the blue response more frequently, although using a two-tailed test, this failed to reach significance $(z \geqslant 1.42, p<.1556) \quad$ (APPENDIX VIII).

(ii) A scan of the data indicated that sex differences did not appear to have a significant influence on propensity to change strategy. The largest difference was evident with regards propensity $\delta$. Employing a two-tailed Mann-Whitney U-test, it was found that there was a trend for males to be more persistent in their choice, although this fell short of significance $(z \geqslant 1.5, p<.1336)$ (APPENDIX IX).

\section{b) Leadership Nominations}

A scan of the data and comparison of group means revealed little differentiation between task, sociomemotional or prolonged leaders and the other group members in terms of; (i) choice of blue response; (ii) propensity $\beta$; (iii) propensity $\gamma$; (iv) propensity $\delta$. Further analysis was therefore considered inappropriate.

With regards propensity $\alpha$ (the primary measure employed) relationships were established as follows:

(i) Male groups. Mann-Whitney U-tests (two-tailed) were employed to compare scores on propensity $\alpha$ between; (i) those most nominated as task, socio-emotional or prolonged leaders respectively, and (ii) other male group members. 
Those with the highest nominations for task leadership in each group were found to have significantly lower levels of pre-emption than other group members $(z \geqslant 2.01, p<.044)$ (APPENDIX X). Prolonged leaders were all highest nominated task leaders, and hence the same levels of significance were found for this measure.

No relationship was found between pre-emption and socio-emotional leadership $(z ; .048, p<.968)$ (APPENDIX XI).

(ii) Female groups. Employing two-tailed Mann-Whitney U-tests, similar comparisons were made as for male groups.

Those individuals with the highest nominations for task leadership in each group were found to have significantly higher levels of pre-emption than other female group members $(z \geqslant 2.33, p<.0198)$ (APPENDIX XII).

Prolonged leader nominations did not relate to pre-emption $(z \geqslant .87$, $p<.3844)$ APPENDIX XIII).

Socio-emotional nominations likewise did not relate to propensity $\alpha$, although there was a trend for those individuals with high socioemotional ranking to pre-empt more often $(z \geqslant 1.55, p<.12)$ (APPENDIX XIV).

c) Least Preferred Co-Worker Scale

(i) Male groups. Analyses were made of the IPC scores of; (i) task; and (ii) socio-emotional leaders, as compared to other group members.

Employing a Mann-Whitney U-test (two-tailed), it was found that male task leaders had a tendency to rate their least preferred co-worker higher $(z \geqslant 1.59, p<.1138)$, although this fell short of significance. (APPENDIX XV:). On the other hand, male socio-emotional leaders had 
a tendency to rate their least preferred co-worker lawer than did ordinary group members $(z ; 1.72, p<.0854)$, although this too fell short of significance. (APPENDIX XVI).

(ii) Female groups. Again employing a Mann-Whitney U-test (two-tailed), the least preferred co-worker scale was found to have no relationship with task leadership ( $z \ddot{y} .513, p \div .610)$, or socio-emotional leadership $(z \geqslant .026, p \lessdot .976)$ (APPENDIX XVII and XVIII respectively).

d) Participation Rate

(i) Male groups. Participation rate related with high leadership nomination. Using a Mann-Whitney U-test, male task leaders were shown to have higher participation rates than other male group members $(z \geqslant 3.53, p<.0004)^{\circ}$ (APPENDIX XIX), and socio-emotional leaders also displayed higher rates of verbalisation $(z \geqslant 3.34, p<.001) \cdot($ APPENDIX XX).

(ii) Female groups. Participation rate also related to high leadership nomination in female groups, with both task leaders ( $z \geqslant 2.96, p(.003$.) and socio-emotional leaders $(z \geqslant 2.27, p<.0232)$ having higher levels of participation than other female group members (APPENDIX XXI and XXII respectively).

9.9. SUMMARY OF RESULTS AND ANALYSIS

With reference to the formal hypotheses quoted earlier, the following results were obtained.

Hypothesis 1: Those individuals nominated as task leader will behave differentially from other group members with regard to propensity to change from cell 1 . 
The hypothesis was substantiated by the data. Male task leaders pre-empted less often, and female task leaders pre-empted more often than other same sex group members.

Hypothesis 2: Those individuals nominated as socio-emotional leader will behave differentially from other group members with regard to propensity to change from cell 1.

No relationship was established for male groups, but in female groups there was a trend for female socio-emotional leaders to pre-empt more often.

Hypotheses 3, 4, 5 and 6, relating other measures of game behaviour (propensity to change from cell 4 and choice of blue strategy) to the emergence of leadership roles, failed to be substantiated by the data.

Hypothesis 7: Male and female subjects will behave differentially in the game situation.

A trend was evident for males to choose blue more frequently, and for them to be more persistent with regard to propensity $\delta$. Neither relationship reached significance.

Hypothesis 8: The emergence of leadership roles will be dependent upon the sex of group.

In so far as differences exist in: (i) game behaviour of emergent leaders; and (ii) role differentiation, then the hypothesis is substantiated. 
Hypothesis 9: Leadership roles will be differentiated by scores on the Least Preferred Co-Worker scale.

Trends were evident that male task leaders made higher evaluations on this scale than other male group members, and socio-emotional leaders made lower evaluations; although both analyses fell short of significance. No relationship was established for female groups.

Hypothesis 10: Leadership roles will be differentiated by rate of participation.

Strong relationships were found between socio-emotional and task leadership nominations and rate of participation, in both male and female groups. Individuals nominated highest for task and socio-emotional roles had higher rates of participation than other same-sex group members.

\subsection{DISCUSSION}

The primary objective of the investigation - to determine whether preemption was related to the emergence of leadership roles, has been substantiated. In male groups, task leaders had low levels of preemption and in female groups, they had high levels of pre-emption, as compared to other same-sex group members.

Apart from this finding, a number of other interesting results emerged relating to; (i) the nature of Leader game itself; (ii) sex differences in role emergence; (iii) the characteristics and perceptions of the task; (iv) the scores on the Least Preferred Co-Worker measure; and (v) the relationship between pre-emption and participation rate. 
As with previous research (Mack, 1972b; Mack and Kremer, 1977), no sex differences in choice of response reached a level of significance. However, as with previous research, the trend was for male subjects to choose blue more often than female subjects. This tendency is seen in certain propensities to change strategy. The propensities to change from cell 1 and cell 2 are virtually identical for male and females, but with propensity to change from cell 3 and cell 4, female subjects tend to be less persistent in their choice.

What is of interest is the remarkable similarity of propensity (pre-emption) for male and female players - mean values of .502 and .503 being found respectively. It can be taken that any differences later established will reflect upon specific variables under consideration.

Of these, the most, striking differences are with regard to the game behaviour of those nominated most often as leaders. These findings mirror those of Mack and Kremer (1977), i.e. Iow pre-empting males and high pre-empting females. The possible explanation for these differences rely upon the capacity of the Ieader Game to measure interaction style, and will be looked at later.

A relationship was established specifically between nominations for task specialist and pre-emption rate. Social exchange analyses (Jacobs, 1971) maintain that the roles most pertinent to the task facing the group will be those which emerge most forcibly. A strong case may be put forward that the features of the present task facilitates the emergence of task leadership as the group's primary concern was with the collection and analysis of data, followed by solution. However, the style of leadership adopted within the broad category of task related is somewhat ambiguous. 
The task involved subjects reaching consensus on four problems. The first objective was to collect together all parts of the problem, and then commence to reach a joint solution. As can be seen from APPENDIX I, the tasks themselves are not particularly complex. What perhaps is more important is that groups are able to reach consensus. In each task, more than one solution is acceptable. Hence, the individual who contributes most to task completion must be able to either; (i) coerce the others to all choose a particular solution which they favour; or (ii) be able to gauge the general feeling of the group, and steer all members in that direction. The former would possibly rely on inflexible behaviour, the latter, more flexible responses. Whilst these hypotheses are purely speculative, the task is taken as being sufficiently ambiguous as to allow a number of approaches to be employed by groups. Relating these speculations to sex differences in leadership styles, previous research (Garland and Beard, 1979; Denmark, 1977) has indicated that there may in fact be alternative leadership styles in male and female groups working on similar problems. Male leaders tend to display more authoritarian, rigid behaviour than their female counterparts. Evidence for this supposition in the present investigation comes from an analysis of participation rates. The mean percentage of group participation by male task leaders was $30.8 \%$, as compared with $24.6 \%$ for female task leaders. Hence there is some indication of freer discussion in the female groups, with less of the time being taken by the leaders' contribution.

The nature of the task at hand is taken as central to an understanding of the appropriateness of a particular leadership style. Because the problem which was studied (detailed previously) allows for a number of approaches to be employed, without implying the superiority of any one style, then it is possible that sex differences may have an overt effect on group structure. 
As mentioned earlier, it is hypothesised that these differences in leadership styles may be identified through an analysis of game behaviour. For the role specialists, Iow pre-emption may be characteristic of an intransigent, inflexible style of interaction, where little regard is given to social niceties. High pre-emption, on the other hand, may be characteristic of a more flexible approach, with a parallel increase in concern for social aspects of domination. (For it must be borne in mind that high pre-emption and low pre-emption are assumed to be styles of game behaviour concerned with domination of the other). Hence it is taken that game behaviour may be a useful predictor of subsequent leadership style. In female groups, high pre-emptors gained prominence. In male groups, low pre-emptors.

Turning to the nature of role specialisation in male and female groups; differences in this process are apparent. In general, the hierarchy established in male groups seems more clearly defined with greater consensus as to who is the most valuable task member. However, both male and female groups show considerable overlap between task and socioemotional nomination. In both cases, approximately $40 \%$ of the highest task nominees were also nominated as socio-emotional leader. This finding complements previous research (Bales, 1957), where there is little differentiation in early meetings of groups with increased speciality later.

In the male groups, all task leaders were also nominated for the position of prolonged leader, indicating the prominence given the task role. In female groups, both task and socio-emotional leaders were nominated for the post of prolonged leader. This may indicate that the differentiation between the two roles is not as clear cut. Perhaps this again reflects differences in the perception of the task by male and female subjects. 
To male subjects, the task was looked at primarily in terms of a simple problem solving exercise, requiring a leadership style which was characterised by an authoritarian, inflexible manner. To female subjects, the problem was perceived in a less monolithic fashion. The leader was presumed to introduce structure to the problem, as well as ensuring that all members were satisfied with the final solution.

The analysis of Least Preferred Co-Worker scores (Fiedler, 1967), indicates that the measure has only a limited capacity to identify differences in styles of emergent leaders. Trends were evident that male task leaders rated their least preferred co-worker higher than did other group members, and socio-emotional leaders rated their least preferred co-worker lower. No differences were found for female groups. These findings stand in contrast to those of Schneier (1978), who found leaders were characterised by low IPC scores.

The author maintains that pre-emption is tapping a different dimension of leadership behaviour than that which the LPC scale measures. It is also maintained that pre-emption has greater predictive validity in both male and female groups than the LPC for identifying emergent leaders.

With regards participation rate, those individuals who emerged as leaders all had higher participation rates than other group members. It may be put forward that pre-emption rates merely relate to participation rates and not actually leadership. However, analyses of pre-emption rates of those with highest participation rates in each group revealed no relationship (APPENDIX XXIII and XXIV). It was found that highest participators were not necessarily leaders, but above average participation characterised those in leadership positions. 
In conclusion, the investigation demonstrates the potential of preemption rate in Leader Game as a measure of emergent leadership. It is hypothesised that the particular task on which the group is working vill be of extreme importance in determining not only role differentiation, but also the style of leadership employed. It is further hypothesised that the task upon which the present groups worked was ambiguous, and this may have highlighted sex differences in the leadership process.

On the basis of the present investigation, and the arguments detailed above, it is proposed to investigate leadership role emergence in situations of a less equivocable nature, where it is hypothesised that the Leader Game will maintain its capacity to differentiate leaders from non-leaders, but where sex differences may be less apparent. 


\section{SUMRARY}

The investigation considers the relationship between pre-emptive game behaviour and leadership emergence within a group context that is characterised by little need for the innovation of structure, and greater concern for socio-emotional aspects of group functioning. The game condition was identical to that employed in the previous investigation. $\quad 35$ male and 55 female subjects played 100 trials of the Leader Game against a non-contingent other, and subsequently were divided into single sex five-person groups. An analysis of leadership nominations revealed that socio-emotional leaders were differentiated from other group members on the basis of pre-emptive game behaviour. In both male and female groups, socio-emotional leaders pre-empted less often than other group members. Additionally female task leaders were noted for low rates of pre-emption. This finding is interpreted in terms of differences in role differentiation between male and female groups. 
10.1. AIM OF THE INVESTIGATION

The second experiment is designed to look further at the relationship between game behaviour and the emergence of leadership roles. The exploratory investigation demonstrated that the Leader Game held a potential for discriminating between different emergent leadership styles. It was also concluded that situational contingencies were likely to be of importance, given previous research. The particular tasks which were worked upon in the first experiment were open to alternative styles of leadership, given alternative perceptions of the nature of the task. Specifically, the analysis of results, coupled with previous research, was interpreted in terms of differences in perception of the task by male and female subjects, with subsequent differences in leadership hierarchies. Male groups were seen as having perceived the tasks as relatively uncomplicated problem.solving exercises, requiring little innovation on the part of the leader. Those in leadership roles reflected the overall orientation of the group - exhibiting inflexible, dogmatic approaches to not only the problem, but also relations with other group members. In female groups, more emphasis may have been placed upon the initiation of structure, and upon the social aspects of group functioning, in what was perceived as a more complex task.

It is suggested that pre-emption in the. Leader Game is a useful index for identifying differences in leadership styles, given the acceptance of the foregoing analysis. The distinction between high and low preemptors is in line with, and in some instances overlapping with, previous dichotomies (such as high LPC/low LPC; consideration/initiating structure; authoritarian/democratic; high self-monitor/low selfmonitor). 
Low pre-emptors are seen as generally intransigent, rigid and unresponsive to social overtures. High pre-emptors are seen as more flexible, innovative and socially aware, but both styles are primarily concerned with the domination of others.

Investigation One does not differ from the first experiment regarding the game phase. Few difficulties were encountered in the design of the gaming condition, and de-briefing revealed that in general, subjects were unaware of the actual aims of the project. However, a small percentage of subjects did remark that they became aware of a certain illogicality on the part of the other over the 100 trials. This awareness may account for the slight increase in blue responses by particularly male subjects over the last 40 trials (Graph 1). This experimental feature: was noted, but was considered unavoidable. The other is by necessity non-contingent, in order to maximise the movement of players around the matrix, and so provide more meaningful data regarding propensity to change strategy.

. In the group condition, it was proposed to employ a task where the capacity to introduce structure was not as important as in the preliminary investigation. The problem was concerned with the development of individual attitudes, together with the pooling of all members' ideas in a joint decision making session. In order to minimise the incidence of divergent ideas, the task was made as straightforward as possible by providing a large block of information.

The task therefore differs markedly. from that employed previously, and it is anticipated that the individual who emerges to co-ordinate a general policy in the present experiment will likewise differ from the previous leaders in terms of interaction style and presumably, game 
behaviour. The individuals in the present context are not required to introduce structure or to ensure that all members have an understanding of a potentially ambiguous task. Instead, they are expected to have the capacity to gather together simple individual profiles, and lead the group towards a common group policy.

As a consequence, it is anticipated that sex differences will not be as apparent in leadership style. All leaders may exhibit low levels of pre-emption given the conditions outlined above.

Regarding the relationship between pre-emption and participation rate, and Least Preferred Co-Worker scores, on the basis of the results from the preliminary investigation, it was considered inappropriate to look further at these other measures, in so far as pre-emption rate appeared to be looking at an unrelated aspect of leadership.

A modification was considered necessary to the leadership questionnaire. In the present investigation, subjects were asked to rank order all members of the group in terms of task and socio-emotional leadership, as this may provide a more clear cut measure of the individual who was most valuable in either respect.

\subsection{HYPOTHESES}

On the basis of previous research, hypotheses concerned with the following were formulated:

a) The relationship between game behaviour and emergent leadership roles;

b) Sex differences in game behaviour;

c) Sex differences in role differentiation. 
a) Game behaviour and emergent leadership roles.

The hypotheses maintain that those individuals who emerge to positions of leadership will be differentiated from other group members on the basis of game behaviour. Previous research has indicated that the measure of game behaviour likely to distinguish leaders is the propensity to change from cell 1. It is anticipated that given the present conditions, leaders will exhibit low levels of pre-emption. It is hypothesised that:

1. Those individuals nominated as task leader will display a lower propensity to change from cell 1 than other group members.

2. Those individuals nominated as socio-emotional leader will display a lower propensity to change from cell 1 than other group members.

b) Sex differences in game behaviour.

Given the previous findings, it is anticipated that male subjects will have a tendency to choose the blue strategy more often than female subjects. This tendency may be revealed in the propensity to change from cells 3 and 4. It is hypothesised that:

3. Male subjects will choose the blue response significantly more often than female subjects.

4. Male subjects will display a lower propensity to change from cell 3 than female subjects.

5. Male subjects will display a lower propensity to change from cell 4 than female subjects.

c) Sex differences in role differentiation.

Given the nature of previous work, it is hypothesised that role differentiation may be dependent upon sex of group:

6. Differentiation of leadership roles will be dependent upon sex of group. 


\subsection{SUBJECTS}

Subjects were selected from the Introductory Social Psychology Course at Loughborough University. 35 male and 55 female subjects were employed, and each was awarded coursework credits for participation.

As with the Exploratory Investigation, subjects in the first part of the experiment were paired with others of the same sex, with attention being paid to control for acquaintance: ' In the group condition, subjects were again randomly allocated to five-person groups of sexually homogenous composition ( 7 male and 11 female groups).

10.4. APPARATUS

a) Game Condition

The apparatus was identical to that employed in the previous investigation (see DIAGRAMS 1,2 and 3).

b) Group Condition

Subjects were seated around a hexagonal arrangement of tables (DIAGRAM 4), with colour codes attached to each table. Information relating to the task was distributed to each subject (APPENDIX XXV) along with paper to write down individual ideas. On completion of the task, a leadership questionnaire was administered (APPENDIX XXVI). Subjects were observed during the experiment through a one-way vision screen.

10.5. METHOD

a) Game Condition

Each subject again played 100 trials of the Leader Game against a noncontingent other, their objective being to amass as many points as 
possible. The subject received feedback after each trial as to the outcome of the previous trial and total score to date.

\section{b) Group Condition}

Each sexually homogenous group worked on an identical problem, which was concerned with drawing up a person profile of an ideal Student Union President for a fictitious university (APPENDIX XXV). Subjects worked on the problem individually for fifteen minutes, before coming together to reach a group decision. A maximum time limit of 45 minutes was allowed for each group.

\subsection{PROCEDURE}

All subjects completed the Leader trials before the second stage of the experiment was embarked upon. Data from the Leader Game was not analysed until the investigation was completed, in order to overcome experimenter bias.

\section{a) Game Condition}

The procedure was identical to that followed in the Exploratory Investigation.

\section{b) Group Condition}

Subjects entered the laboratory simultaneously and seated themselves around the tables. The experimenter then distributed the problem to each subject, together with paper. They were instructed to work on the problem individually. After fifteen minutes, the experimenter re-entered the laboratory and informed subjects to come together as a group. After subjects had reached consensus on the person profile of 
the President, a leadership questionnaire was administered (APPENDIX XXVI). This asked subjects to rank order all members of the group, by colour codes, in terms of; (i) task; and (ii) socio-emotional leadership considerations.

A full de-briefing then followed, in which the aims of the investigation were outlined. Subjects were asked to co-operate by not discussing the experiment until all groups had been run.

\subsection{RESULTS}

The results may be considered in terms of two sections:

a) Game Behaviour

b) Leadership Nominations.

\section{a) Game Behaviour}

The main measures employed were; (i) the percentage of blue response; (ii) the propensity to change strategy.

(i) The total percentage of blue responses was calculated by subject (APPEIDIX XXVII), and the responses were also grouped by sex into ten by ten trial blocks (see APPENDIX XXVIII). These results are shown in Graph 2.

(ii) The individual's propensity to change strategy was established for each cell in turn (APPENDIX XXVII). 'The mean propensities to change were also calculated by sex:

MALE

FEMALE

\begin{tabular}{|c|c|c|c|}
\multicolumn{4}{|c}{ MEAN PROPENSITIES } \\
\hline$\alpha$ & $\beta$ & $\gamma$ & $\varsigma$ \\
\hline .479 & .492 & .315 & .39 \\
\hline .563 & .521 & .262 & .429 \\
\hline
\end{tabular}




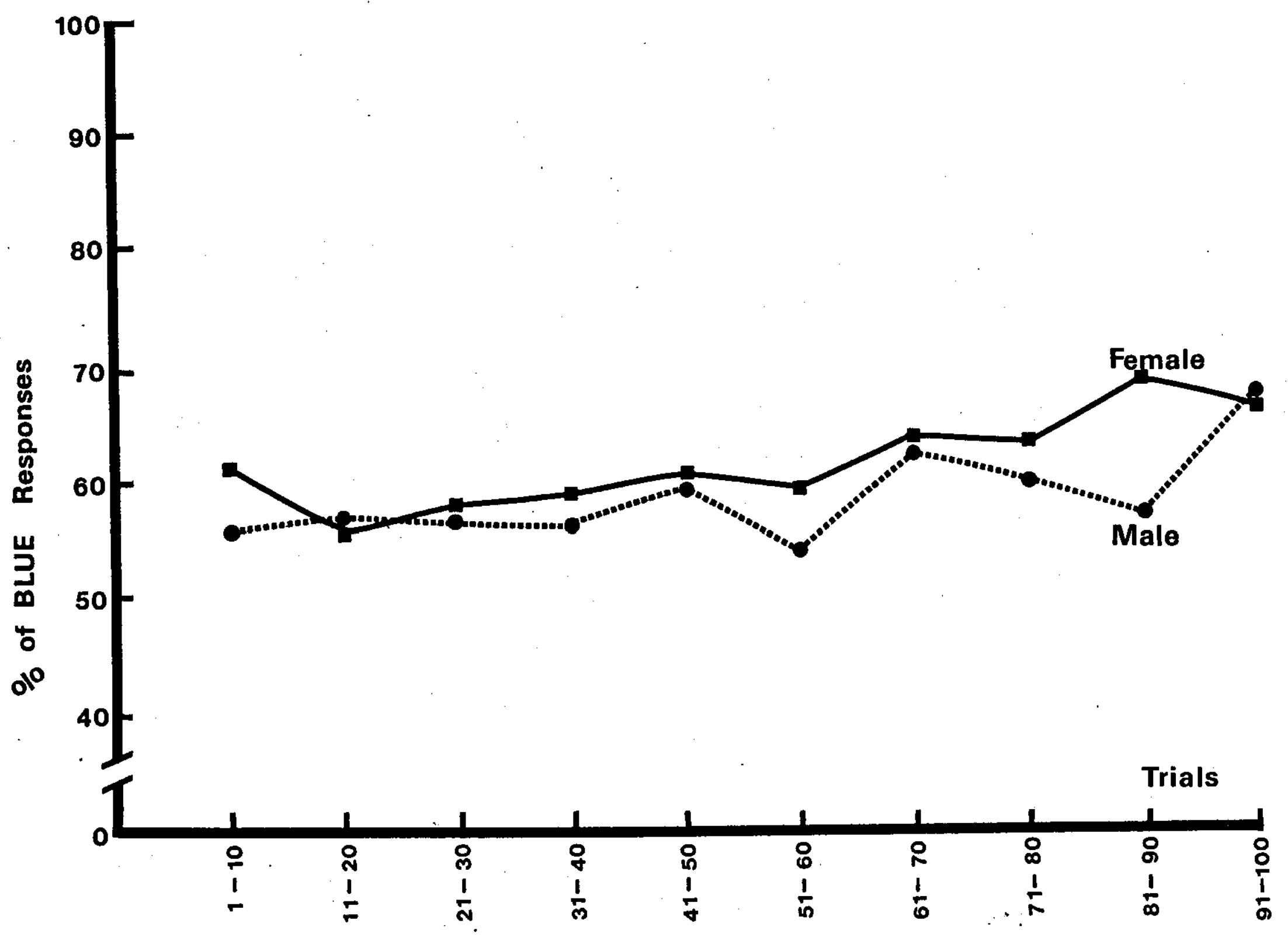

GRAPH 2: PERCENTAGE OF BLUE RESPONSES OVER ONE HUNDRED TRIALS BY TEN-TRIAL BLOCKS 
b) Leadership Nominations

Measures employed were concerned with nominations for; (i) task leader; and (ii) socio-emotional leader.

The individual with the highest overall rank order in each group was taken as the leader of that group (APPENDIX XXIX), and analyses were subsequently made between those individuals and other group members. In the event of two subjects having equal highest overall ranking, then both were included in the leader category.

In male groups, there were no ties for task leader and one for socioemotional leader $(n=7, n=8$ respectively). In female groups, there were no ties for task leader and one tie for socio-emotional leader $(n=11, n=12$ respectively).

The overlap between the two roles was also considered. In male groups, $14 \%$ of task leaders were also highest nominated socio-emotional leader, whereas in female groups, $45 \%$ of task leaders were highest nominated socio-emotional leader.

10.8. ANALYSES

a) Game Behaviour

Comparisons were made between the game behaviour of male and female subjects with regard to; (i) choice of strategy; (ii) propensity to change strategy.

(i) A scan of the data, including Graph 2, indicates little differentiation between subjects' choice of strategy on the basis of sex (male $\bar{x}=59 ;$ female $\bar{x}=62$ ). Indeed, over the 100 trials, male subjects displayed a slightly lower level of blue choices. A subsequent statistical analysis was considered inappropriate. 
(ii) A scan of the data indicates that sex differences alone have little effect on propensity to change strategy. The largest difference is evident with regards propensity *. Imploying a two-tailed HannWhitney U-test, it was found that there was no significant difference between the two populations $(z \geqslant 1.06, p \therefore 299)$ (APPENIDIX XXX).

b) Leadership Nominations

A scan of the data and comparison of means revealed little differentiation between task or socio-emotional leaders and other group members in terms of; (i) choice of blue response; (ii) propensity $\beta$; (iii) propensity

$\because$; (iv) propensity 5 Further analysis was considered inappropriate.

With regards propensity'x, the following relationships were established:

(i) Male groups.

Mann-Whitney U-tests (one-tailed) were employed to compare pre-emption rates between those most nominated as either task or socio-emotional leader and other members of male groups.

Those with the highest nominations for socio-emotional leader were found to have lower levels of pre-emption than other group members, although this fell just short of significance $(z \geqslant 1.55, p<.06)$ (APPENDIX XXXI). No relationship was established between pre-emption and task leadership $(z \geqslant .82, p<.206) \quad($ APPENDIX XXXII).

\section{(ii) Female groups.}

Employing one-tailed Mann-Whitney U-tests, similar comparisons were made.

Those individuals with the highest nominations for socio-emotional leader, by group, were found to have lower levels of pre-emption than other female group members $(z \geqslant 1.946, p<.026)$ (APPENDIX XXXIII). Likewise, those 
individuals with the highest nominations for task leader, by group, were found to have lower levels of pre-emption than other group members, although this fell just short of significance $(z \geqslant 1.53, p \times .063)$ (APPENDIX XXXIV).

10.9. SUMMARY OF RESULTS AND ANALYSES

With reference to the formal hypotheses quoted earlier, the following results were obtained:

Hypothesis 1: Those individuals nominated as task leader will display a lower propensity to change from cell 1 than other group members.

The hypothesis was partially substantiated in female groups, where a strong trend was evident, but not substantiated in male groups.

Hypothesis 2: Those individuals nominated as socioemotional leader will display a lower propensity to change from cell 1 than other group members.

This hypothesis was substantiated in female groups, and a strong trend was evidenced in male groups.

Hypotheses 3, 4 and 5 , concerned with sex differences in game behaviour, were not substantiated. Males and females played the game in a similar fashion.

Hypothesis 6: Differentiation of leadership roles will be dependent upon sex of group.

In so far as female groups show a greater overlap between task and socioemotional leadership, then the hypothesis is substantiated.

10.10 DISCUSSION

The investigation again demonstrates the capacity of Leader game to identify styles of emergent leadership. Additionally, the investigation 
shows that pre-emption is a measure capable of discriminating between styles of leadership in different situations. In the present investigation, the capacities which the leader is likely to exhibit may differ from those in the preliminary enquiry. The leader is not required to innovate, to add structure or to have particular task capabilities beyond those related to the collection of simple data, and the attainment of a joint decision. It may be therefore, that the leadership role which is of greatest concern, and that which will emerge most forcibly, is the socio-emotional specialist.

The strongest relationships established were those between pre-emption and socio-emotional leadership nominations. Previous research has suggested that these specialists may be inflexible in their interaction style (Bales and Slater, 1955), and indeed the present work substantiates this belief. These leaders were noted in both male and female populations for low levels of pre-emption, adding further weight to the supposition that game behaviour is a useful indicator of style of interaction.

Sex differences were once more evident in role differentiation. Male subjects only nominated $14 \%$ of task leaders also as socio-emotional leaders, whereas females had $45 \%$ of leaders highest nominated for both roles. Previous research has detailed greater role specialisation in male groups, and the present investigations bear this out.

of interest is the disappearance of sex differences in pre-emptive behaviour of leaders. This is taken as indicative of the more similar perception of the task by both populations, as compared with the previous problem. However, to suggest that all groups approach the problem identically is not completely evidenced by the data. If the distribution of pre-emption rates of leaders is compared with the overall pre-emption 
distribution, it can be seen that for leaders, there is a degree of polarisation, biased towards that of low pre-emption (APPENDICES XXXI, XXXII, XXXIII and XXXIV). Although the majority of leaders displayed pre-emption rates well below the average, a small percentage had extremely high rates of pre-emption. This had the effect of reducing levels of significance, and may possibly be seen as demonstrating alternative approaches to the problem at hand by groups with high preemptors as leaders. Instead of developing hierarchies which centred around inflexible, dogmatic leadership, those groups may have been led in an alternative style which concentrated on introducing structure and allowed greater scope for individuals' contributions. These arguments will be expanded at a later stage, but it is again apparent that the task at hand is of paramount concern in the development of leadership structure within groups.

The investigation has demonstrated that pre-emption relates to socioemotional leadership, in a situation where that form of role specialisation is likely to be important. The data also indicates that this form of leadership may be characterised by a degree of inflexibility in style of interaction. 
CHAPTER ELEVEN: INVESTIGATION TWO

\section{SUMMARY}

The investigation considers the relationship between pre-emptive game behaviour and leadership emergence within a group context that is characterised by the need for innovation on the part of the leader in a complex problem solving task. The game situation was identical to that employed in the previous investigation. 30 male and 25 female subjects played 100 trials of the Leader Game against a non-contingent other, and were subsequently divided into single sex five-person groups. An analysis of leadership nominations revealed that task leaders in both male and female groups were differentiated from other group members on the basis of pre-emption, by displaying higher rates of pre-emption. Additionally, socio-emotional leaders in male groups were noted by low levels of pre-emption. Differences were once more apparent in the process of role differentiation between male and female groups. 


\subsection{AIM OF THE INVESTIGATION}

The investigation is designed to establish the relationship between pre-emption in the Leader Game and the emergence of leadership roles in a complex problem solving situation.

The previous two experiments had incorporated tasks which were not detailed as being particularly arduous, although it was hypothesised that female subjects in the preliminary enquiry had perhaps perceived the particular problems differentially from male subjects. The leadership structures which emerged were seen as mirroring the orientation of the groups towards task accomplishment. Hence, leaders in the previous experiments were generally not noted for the initiation of group structure, and behaviour which was geared towards the attainment of complex goals.

The present investigation utilises a problem solving task which is taken as being more intricate (APPENDIX XXXV), and it is assumed that the leadership structure which emerges will reflect the nature of the problem. Those in leadership roles will be required to not only co-ordinate the work of all members of the group, but also bring together diverse sections of information, in order to reach a final solution.

The distinction between task and socio-emotional role specialists has been found to be less clear cut in early meetings of groups than in later sessions (Bales and Slater, 1955). However, it is maintained that these roles may emerge in so far as they are necessary for the functioning of the group. In the present investigation, it is hypothesised that given the nature of the task, it may be that two role specialists may emerge (although the previous investigations indicate that the process of differentiation seems more likely to occur in male, rather than female, groups). It is further hypothesised that these roles will be identifiable 
through an analysis of game behaviour. The previous experiments indicate that the socio-emotional leader may be characterised by low rates of pre-emption and the task leader by high rates. The difficulty in clearly differentiating between the two roles in early meetings of the groups makes it unsuitable to offer anything other than speculative arguments at this stage.

\subsection{HYPOTHESES}

On the basis of previous research, hypotheses were formulated concerned with:

a) The relationship between game behaviour and emergent leadership roles;

b) Sex differences in game behaviour;

c) Sex differences in role differentiation.

a) Game behaviour and emergent leadership roles.

The hypotheses maintain that those individuals who emerge to positions of leadership will be differentiated from other group members on the basis of game behaviour, and specifically regarding pre-emption (that is the propensity to change from cell 1). Given the present conaitions, it is taken that task leacers will display high levels of pre-emption and socio-emotional leaders will display low levels of pre-emption. It is hypothesised that:

1. Those individuals nominated as task leaders will disolay a higher rate of pre-erption in the game (propensity to change from cell 4 ) than other group nembers of the same sex.

2. Those individuals nominated as socio-emoticnal leaders will display a lower rate of pre-emption in the game (propensity to change from cell 1) than other group members of the same sex. 
b) Sex differences in game behaviour.

Previous findings have shown little consistency regarding the differences between the two sexes in game behaviour. No differences have yet reached significance, although trends have been evident:

3. Male and female subjects will behave differentially in the game situation.

c) Sex differences in role differentiation.

The previous investigations have revealed differences in the process of role differentiation in male and female groups:

4. Differentiation of leadership roles will be dependent upon sex of group.

\subsection{SUBJECTS}

Subjects were selected from the Introductory Social Psychology Course at Ioughborough University. 30 male and 30 female subjects were employed. Participation in experimental work was a course requirement for all subjects.

As with the previous experiments, subjects in the first part of the investigation were paired with others of the same sex, with attention being paid to control for acquaintance. In the group condition, subjects were allocated to five person groups of the same sex. One group was subsequently found to be composed of four close friends and another subject. These subjects were therefore not included in the final analysis (hence 6 male and only 5 female groups were employed). 
11.4 APPARATUS

a) Game Condition

The apparatus was identical to that employed in the previous investigations.

b) Group Condition

The group arrangement was identical to that employed in the previous investigations. Information relating to the task was distributed to each subject (APPENDIX XXXV), along with paper. On completion of the task, a leadership questionnaire was administered (APPENDIX XXXVI). Subjects were observed through a one-way vision screen.

\subsection{METHOD}

\section{a) Game Condition}

The method was identical to that employed previously.

\section{b) Group Condition}

Each sexually homogenous group worked on an identical probiem, which was concerned with determining the location and relationship of certain objects, on the basis of a variety of inter-related pieces of information (APPENDIX XXXV). Subjects worked together for 40 minutes, and no groups were found to have solved both parts of the problem after this time period.

\subsection{PROCEDURE}

The game condition was completed before any groups were run through the second condition.

a) Game Condition

The procedure was identical to that followed previously. 
b) Group Condition

Subjects entered the laboratory simultaneously and seated themselves around the tables. The problem was then distributed, and subjects were left for 40 minutes. After this time, a leadership questionnaire was administered (APPENDIX XXVI), which was the same as that used in Investigation One.

A full de-briefing then followed.

\subsection{RESULTS}

The results may be considered in terms of two sections:

a) Game Behaviour

b) Leadership Nominations.

a) Game Behaviour

The main measures employed were; (i) the percentage of blue response; (ii) the propensity to change strategy.

(i) The percentage of blue responses, by subject, was calculated (APPENDIX XXXVI), and the responses were also grouped by sex into ten by ten trial blocks (APPENDIX XXXVII). The results are shown in Graph 3. (ii) The propensity to change strategy was calculated for each subject (APPENDIX XXXVI). The mean propensities to change, by sex, are given below:

MEAN PROPENSITY TO CHANGE.

MAIE

FEMALE

\begin{tabular}{|c|c|c|c|}
\hline$\alpha$ & $\sigma$ & $\gamma$ & $\delta$ \\
\hline .536 & .486 & .326 & .333 \\
\hline .547 & .513 & .357 & .279 \\
\hline
\end{tabular}




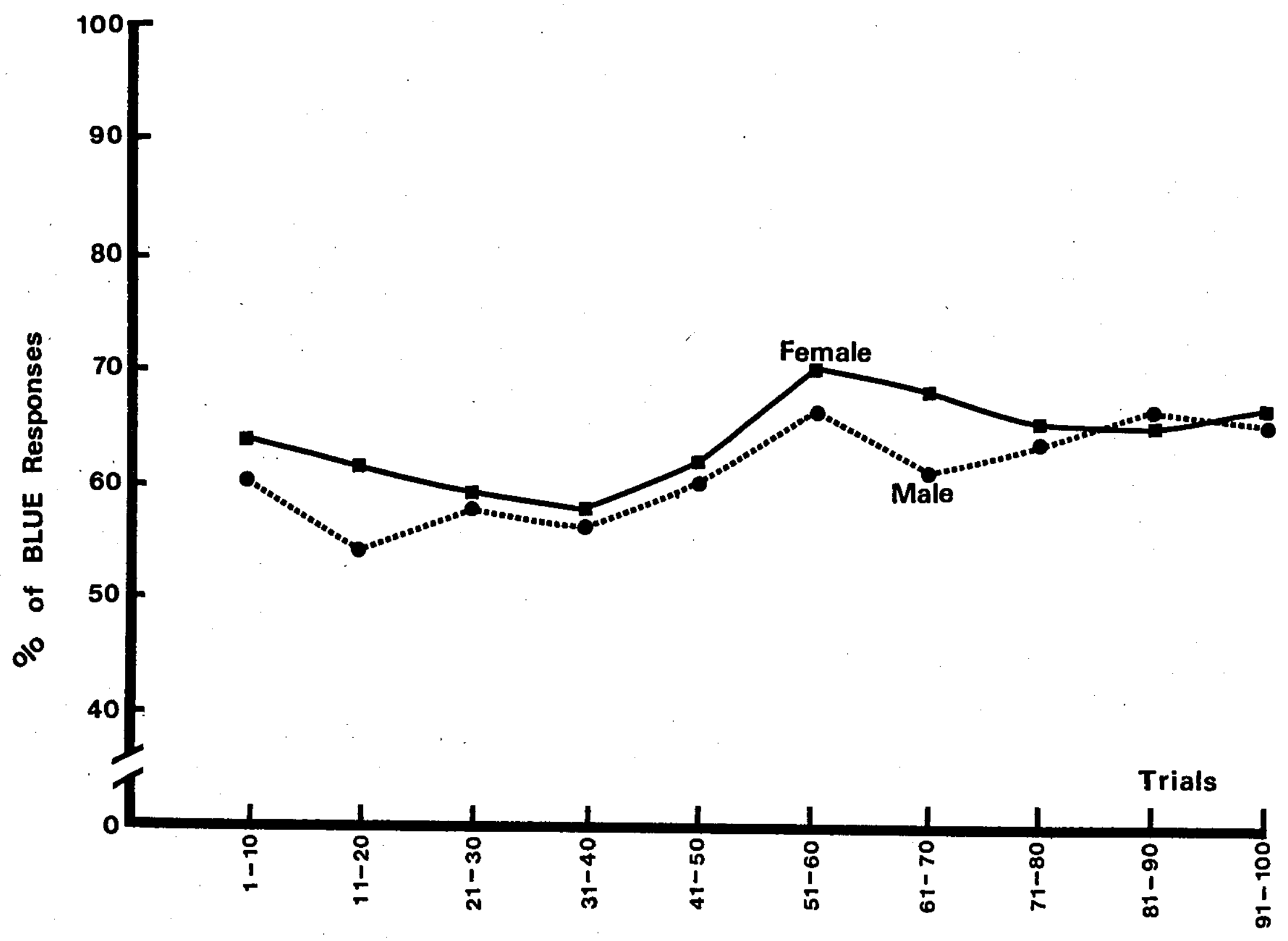

GRAPH 3: PERCENTAGE OF BLUE RESPONSES OVER ONE HUNDRED TRIALS BY TEN-TRIAL BLOCKS 


\section{b) Leadership Nominations}

Measures were concerned with nominations for; (i) task leader; (ii) socio-emotional leader. The individual with the highest ranking on each consideration was taken as the leader. In the event of two subjects having equal ranking, then both were included in the leader category (APPENDIX XXXVIII). Analyses were subsequently made between those with the highest ranking and other group members.

In male groups, there was one tie for task leader and one tie for socioemotional leader. In female groups, there was similarly one tie in each category.

Regarding the overlap between roles, in male groups $14 \%$ of task leaders were also highest nominated socio-emotional leader. In female groups, $33 \%$ of task leaders were also highest nominated in the socio-emotional category.

\subsection{ANALYSES}

a) Game Behaviour

A scan of the data and comparison of means revealed little differentiation between subjects' game behaviour on the basis of sex.

Further analysis was therefore considered inappropriate.

\section{b) Leadership Nominations}

The main concern of the investigation is with the relationship between pre-emption and leadership nomination. 
Male Groups

Mann-Whitney U-tests (one-tailed) revealed that those subjects highest nominated for the role of task leader had higher rates of pre-emption than other male subjects $(z \geqslant 1.32, p<.093)$ (APPENDIX XXXIX). Those individuals highest nominated as socio-emotional leaders had lower rates of pre-emption than other male subjects, although this too fell just short of significance $(z \geqslant 1.57, p<.058)$ (APPESDIX XI).

\section{Female Groups}

Employing similar tests, it was found that female task leaders had a tendency to pre-empt more often than other female subjects, although this fell short of significance $(u=36.5, \alpha(5 \%$ level $)=30)$ (APPENDIX XII). Female socio-emotional leaders were undifferentiated from other group members on the basis of pre-emption $(u=82.5, \alpha(5 \%$ level $)=30)$ (APPENDIX XIII).

\subsection{SUMMARY. OF RESULTS AND ANALYSES}

With reference to the formal hypotheses quoted earlier, the following results were obtained:

Hypothesis 1: Those individuals nominated as task leaders will display a higher propensity to change from cell 1 than other group members of the same sex.

This hypothesis was.in general supported by the data. In male groups, the analysis fell only just short of significance. In female groups, there was a strong trend which also fell short of significance.

Hypothesis 2: Those individuals nominated as socioemotional leaders will display a lower propensity to change from cell 1 than other group members of the same sex.

The hypothesis was substantiated partially in male groups, where there was an extremely strong trend for socio-emotional leaders to pre-empt less often. No relationship was discovered regarding female subjects. 
Hypothesis 3: Male and female subjects will behave differentially in the game situation.

This hypothesis was unsubstantiated by the data.

Hypothesis 4: Differentiation of leadership roles will

be dependent upon sex of group.

In so far as the extent of overlap between roles differs between sexes, as does the game behaviour of socio-emotional leaders, then the hypothesis $\therefore$ is verified.

\subsection{DISCUSSION}

The investigation demonstrates once more that there is a relationship between behaviour in the Leader Game and the emergence of leadership roles.

Additionally, the investigation demonstrates that given particular contingencies, individuals who score both high and low on the pre-emption measure, may complement each other in leadership roles. In male groups, .high pre-emption characterised task leaders, and low pre-emption characterised socio-emotional leaders.

It is taken that this particular problem solving situation is the most suitable of those studied for encouraging the differentiation of roles. The task was sufficiently complex to warrant the emergence of a task specialist, and yet the group had to remain cohesive in order to combine information. Hence, a socio-emotional specialist would also be likely to emerge.

As with the previous investigations, differences are apparent in role differentiation between male and female groups. One third of task 
leaders in the female groups were also highest nominated socio-emotional leader, compared with only $14 \%$ of male task leaders.

This overlap in female groups seems to represent a less clearly defined role system over the short time span that the orroup worked together. (This argument will be expanded later, but the lack of clarity in role definition is likely to have an influence on the capacity of Leader Game to identify particular styles of leadership.)

As with the previous investigations, the distribution of pre-emption scores of leaders appears to be more of a weighted bi-polar nature than the general distribution. This may once more be indicative of alternative approaches to the problem by particular groups, although the present task is seen as less open to different styles than those detailed previously. 
CHAPTER TWELVE: INVESTIGATION THREE

\section{SUMMARY}

The investigation considers the relationship between pre-emptive game behaviour and leadership emergence within a group context that is characterised by a lack of structure and an open-ended task. The game condition is identical to that employed previously. 25 male and 30 female subjects played 100 trials of the Leader Game against a noncontingent other, and subsequently were divided into single sex fiveperson groups. An analysis of leadership nominations revealed no differentiation between leaders and others on the basis of pre-emption, or a differentiation of the task and socio-emotional leadership roles. The results are interpreted in terms of the nature of the particular problem, and the lack of structure within the groups. 


\subsection{AIM OF THE INVESTIGATION}

The investigation is designed to establish the relationship between pre-emption in the Leader Game and the emergence of leadership roles in an unstructured, discussion task. It is taken that different styles of leadership will be appropriate, as compared to those employed in the previous investigations.

Each of the preceding tasks are noted for the manner in which a particular task is laid out in detail, with little opportunity for group members to introduce their own structure to the problem at hand. The present investigation proposes to offer subjects a minimum of information, in order to determine if those individuals who rise to prominence, by presumably initiating structure to the problem, are characterised by particular styles of game behaviour.

In terms of the analysis offered to date, it may be presumed that those individuals will be noted for high rates of pre-emption, but whether the task is such as to necessitate the emergence of two role specialists is debatable. The individual who co-ordinates the group in terms of work on the task may by so doing be ensuring the cohesion of the group as a consequence. That is, the nature of the task may be such that specific role differentiation is not likely to occur.

\subsection{HYPOTHESES}

On the basis of previous research, hypotheses were formulated concerned with:

a) The relationship between game behaviour and emergent leadership roles;

b) Sex differences in game behaviour;

c) Sex differences in role differentiation. 
a) Game behaviour and emergent leadership

These hrpotheses maintain that individuals who emerge to positions of leadership will be differentiated from other group members on the basis of pre-emption rates. Given the present conditions, it would seem that leaders will display high levels of pre-emption as compared with other subjects of the same sex. It is hypothesised that:

1. Those individuals nominated as task leaders will display a higher propensity to change from cell 1 than other same sex group memibers. 2. Those individuals nominated as socio-emotional leaders will display a higher propensity to change from cell 1 than other same sex group members.

b) Sex differences in game behaviour

Previous findings have shown little consistency regarding sex differences in game behaviour:

3. Male and female subjects will behave differentially in the game situation.

c) Sex differences in role differentiation

Previous investigations have detailed differences in the process of role differentiation in male and female groups:

4. Differentiation of leadership roles will be dependent upon the sex of group.

\subsection{SUBJECTS}

Subjects were selected from the Introductory Social Psychology Course at Loughborough University. 25 male and 30 female subjects were employed. Participation in experimental work was a course requirement for all subjects. 
As with the previous experiments, subjects were paired with others of the same sex in the first part of the experiment (the game condition), and allocated to five-person groups of the same sex for the second part (the group condition).

12.4 APPARATUS

a) Game Condition

The apparatus was identical to that employed in the previous investigations.

b) Group Condition

The group arrangement was likewise identical. Information relating to the task was transmitted verbally. A wallboard was provided for the group to put down ideas. On completion of the task, a leadership questionnaire was administered (APPENDIX XXVI). Subjects were observed through a one-way vision screen.

\subsection{METHOD}

a) Game Condition

The method was identical to that employed previously.

b) Group Condition

Each group worked on a problem narrated by the experinenter. The groups were asked to discuss ideas for energy conservation in the 1980's, and jot down these ideas for future reference (APPENDIX XIIII). Subjects worked on the problem for 40 minutes, after which time the experimenter terminated the exercise. 


\subsection{PROCEDURE}

The game condition was completed beiore any groups were run through the second condition.

\section{a) Game Condition}

The procedure was identical to that followed previously.

b) Group Condition

Subjects arranged themselves around the tables before the verbal instructions were given. After subjects had worked on the problem, a leadership questionnaire was administered, as previously. A full debriefing then followed.

\subsection{RESULTS}

The results may be considered in terms of two sections:
a) Game Behaviour
b) Leadership Nominations.

a) Game Behaviour

The main measures employed were; (i) percentage of blue response;

(ii) the propensity to change strategy.

(i) The percentage of blue response, by subject, was calculated (APPENDIX XLIV), and the responses were also grouped by sex into ten by ten trial blocks (APPENDIX XIV). The results are shown in Graph 4.

(ii) The propensity to change strategy was calculated for each subject (APPENDIX XLVI). The mean propensities to change, by sex are given below: 


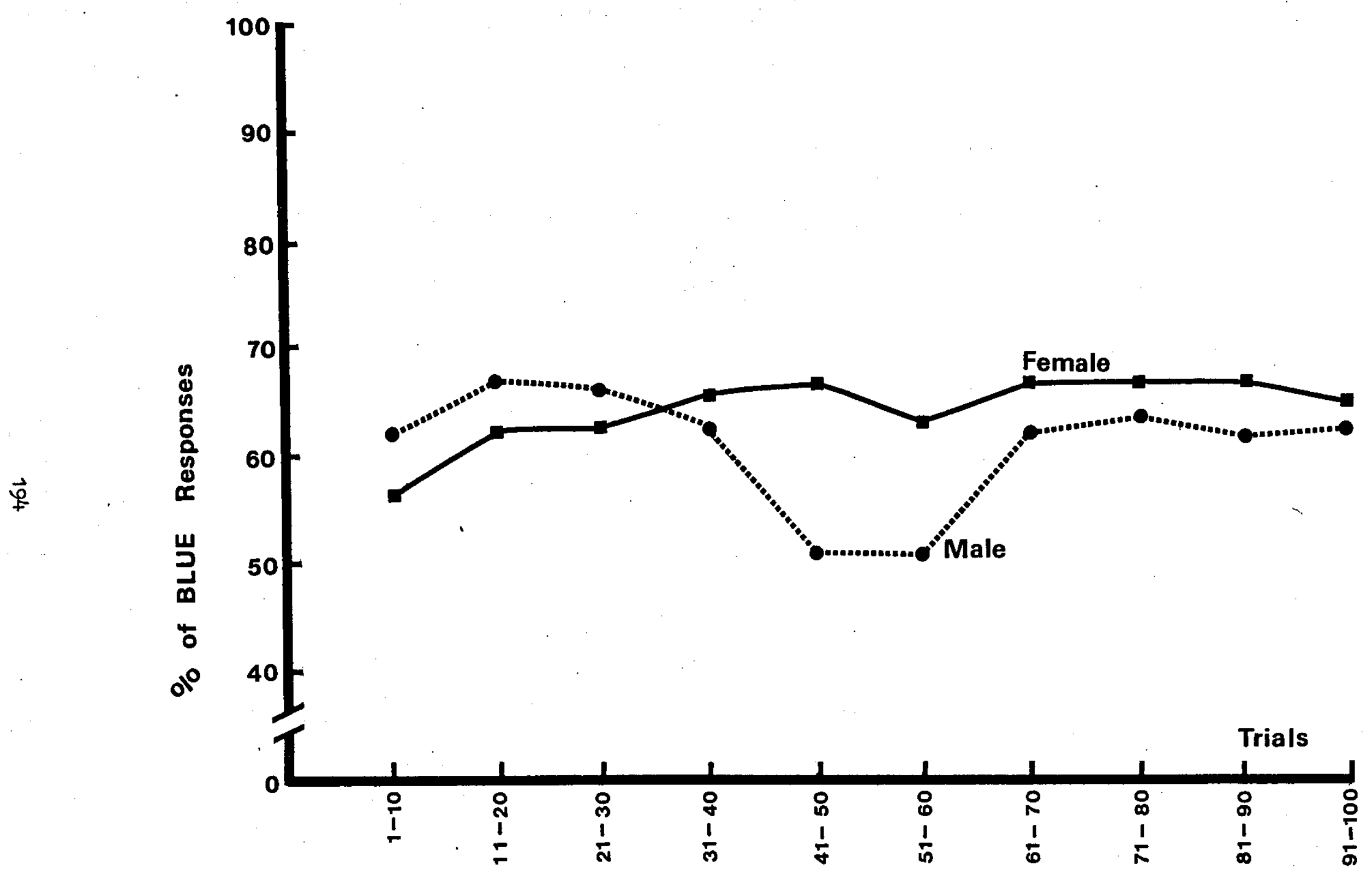

GRAPH 4: PERCENTAGE OF BLUE RESPONSES OVER ONE HUNDRED TRIALS BY TEN-TRIAL BLOCKS 
MEAN PROPENSITY TO CHAI!GE

MALE

FEMAIE

\begin{tabular}{|c|c|c|c|}
\hline .530 & .554 & .326 & .329 \\
\hline .523 & .528 & .313 & .312 \\
\hline
\end{tabular}

\section{b) Leadership Nominations}

Measures were concerned with nominations for; (i) task leader; (ii) socio-emotional leader. The individual with the highest ranking on each consideration was taken as the leader. In the event of two subjects having equal ranking, then both were included in the leader category (APPENDIX XLVI). Analyses were subsequently made between those with the highest ranking and other group members.

In male groups, there were no tied rankings for task or socio-emotional leader. In female groups, there was one tie for task leader and two ties for socio-emotional leader.

Regarding the overlap between roles, in male groups $80 \%$ of task leaders were also highest nominated socio-emotional specialist.

In female groups, $86 \%$ of task leaders were highest nominated in the socio-emotional category.

\subsection{ANALYSES}

\section{a) Game Behaviour}

A scan of the data and comparison of means revealed little differentiation between subjects' game behaviour on the basis of sex.

Further analysis was therefore considered inappropriate. 
b) Leadership Nominations

The main concern of the investigation is with the relationship between pre-emption and leadership nomination.

\section{Male Groups}

Mann-Whitney U-tests (one-tailed) indicated that those subjects highest nominated for the role of task leader were not differentiated from other group members on the basis of pre-emption $(u=39, \alpha(5 \%$ level $)=25)$ (APPENDIX XLVII), nor were socio-emotional leaders $(u=43, \alpha(5 \%$ level $)$ = 25) (APPENDIX XLVIII).

\section{Female Groups}

Employing similar tests, no relationship was found between pre-emption and task leadership $(z \geqslant 1.05, p<.1469)$ (APPENDIX XIIX) or socio-emotional leadership. $(z \geqslant .281, p<.3897)$ (APPENDIX L).

\subsection{SUMMARY OF RESULTS AND ANALYSES}

With reference to the formal hypotheses quoted earlier, the following results were obtained:

Hypotheses 1 and 2 , concerned with the relationships between pre-emption and task and socio-emotional leadership, were unsubstantiated by the data.

Hypothesis 3: Male and female subjects will behave differentially in the game situation.

This hypothesis was not substantiated by the data.

Hypothesis 4: Differentiation of leadership roles will be dependent upon sex of group.

No evidence suggests that this hypothesis is verified. Both male and female groups were noted for a lack of differentiation. 
12.10 DISCUSSION

The results of the present investigation demonstrate little distinction between the task and socio-emotional roles by subjects. No relationships were established between role emergence and rate of pre-emption. In both male and female groups, over $80 \%$ of task leaders were also highest nominated socio-emotional leaders. As with previous investigations, the nature of the task is seen as being central to; (i) the differentiation of leadership roles; (ii) the relationship between pre-emption and leadership.

It would appear that the present task contains certain facets which do not encourage the development of specific roles. The individual who emerges to prominence is ranked high on both task and socio-emotional considerations, and likewise their rates of pre-emption do not reflect one over-riding dimension.

A scan of the pre-emption scores of the leaders again indicates a bi-polar distribution, with the majority of scores being well above the average, but with others being considerably lower. This distribution may reflect upon the differences in approaches to the problem by groups, but as with the preliminary enquiry, these arguments must remain speculative. 
CHAPTER THIRTEEN: DISCUSSION OF THE INVESTIGATIONS

\section{SUMMARY}

The investigations are discussed within the context of previous work. Features of the experimental findings, including the game behaviour of all subjects, role differentiation in single sex groups and classification of tasks is covered, before the relationship between pre-emption and leadership emergence is analysed. 


\subsection{DISCUSSION OF THE INVESTIGATIONS}

The investigations were primarily designed to identify the relationships between pre-emptive behaviour in the Ieader Game and the emergence of leadership roles in small groups. As can be discerned from the foregoing experiments, the work gives general support for the existence of such relationships, and furthermore establishes that the measure preemption is capable of differentiating between particular styles of leadership in specific emergent situations. It may be worthwhile at this point to reconsider the relevant findings.

In the preliminary investigation, leaders who emerged in a group working upon a number of simple mixed-motive problems displayed different rates of pre-emption than other group members. In male groups, task leaders had high levels of pre-emption, and there was a trend for female socioemotional leaders to pre-empt more often than others.

In Investigation One, the groups worked upon a task which was concerned with the collection of individual opinions and the formulation of a group statement. Leaders in both male and female groups were characterised by low levels of pre-emption, and specifically socio-emotional leaders.

Investigation Two utilised a task of a much more complex nature. Groups were required not only to integrate information but also to engage in an exacting problem solving exercise. Task leaders in both male and female groups showed trends of having higher pre-emption rates than the other group members (although certain leaders had rates considerably lower than the average). Socio-emotional leaders in male groups were noted for low levels of pre-emption. 
Investigation Three involved an unstructured discussion task. Groups were noted for little differentiation between task and socio-emotional specialists, and no relationships were found between pre-emption and leadership emergence.

In each investigation, the nature of the task upon which the group engages is taken as central to an understanding of the process of leadership emergence.

Before offering an analysis of the relationship between pre-emption and leadership, other aspects of the investigations merit discussion:

a) Game Behaviour

b) Role Differentiation

c) Classification of Tasks.

\section{a) Game Behaviour}

None of the investigations revealed differences in game behaviour between the sexes, either in terms of choice of strategy or propensity to change strategy. The percentage of blue response remained constant over the four investigations, and more importantly, remained constant over the 100 trials. Graphs 1 to 4 reveal the relative stability of response, as compared to say Prisoner's Dilemma. The latter game is noted for the "learning effect", whereby the percentage of blue responses increases over time as subjects learn that this is the most profitable choice regardless of the choice of the other.

The greater equality between red and blue in Leader, coupled with the greater stability over a time series, indicates the usefulness of the game as a tool for identifying individual differences. Numerous authors (Baxter, 1969; Terhune, 1970; Harris, 1971; Rapoport, 1976) have made reference to the need for control over experimental conditions when 
utilising games in this way. It is argued that the Leader Game goes some way to fulfilling the requirements of experimental conditions that they detail. Rapoport (1976) maintains that measures of game behaviour are often too simple, relying on choice of response alone. The propensity to change strategy would seem to be tapping a measure of personality, or interaction style, which is not detectable through an analysis of choice of response, and so Rapoport's argument seems justified.

Regarding pre-emption as a game measure (i.e. propensity $\alpha$ ), the consistency between the male and female populations is noted in the investigations, with a mean of approximately 0.5 for all groups. However, a scan of scores on this measure reveals that the distribution is weighted away from the mean by subjects with extremely high and extremely low scores, 1 and 0 respectively. These subjects have either pre-empted their opponent on every occasion that they find themselves in cell one of the matrix, or have never done so. In the former case, subjects may have only been in the cell on one occasion, and chosen blue on every succeeding trial. Their high pre-emption score may accordingly not be totally representative of other subjects who score highly on this measure, as their behaviour is generally inflexible rather than modifiable. In the latter case $(\alpha=0)$, subjects may have chosen blue on every occasion, and therefore have had no propensity to change from any strategy. This could be a reflection of any one of a number of reasons (failing to understand the instructions, non-cooperation with the experimenter, or perception of the task). It is argued that these extreme subjects may have an unrepresentative influence on results, but without carrying out a detailed case study into each instance, to establish whether or not that subject's results warrant inclusion, it is deemed impossible to exclude subjects on such an arbitrary basis. Additionally, game results 
were not analysed until after the second part of the experiment, and so subjects could not be discriminated against at that stage on the basis of game behaviour.

Regarding the relevance of experimental games for measuring anything other than artificial behaviour in the laboratory situation, the investigations demonstrate that the Leader game may hold wider potential. The work has established a link between game behaviour and group interactions in the laboratory. It is not a large step to now go on and consider the relevance of game behaviour in more applied settings, where a variety of leadership hierarchies are to be found. Terhune (1970) has suggested that the use of personality inventories may have devalued the potential of games in the past. It may be that by employing measures such as leadership nomination, it will enable experimental games to be developed further as research tools. Basicially, differences in game behaviour are taken as representative of particular styles of interaction in a one to one setting. Leadership is also primarily concerned with interaction styles, and therefore it is likely that there may be a relationship between the two, under a range of conditions.

\section{b) Role Differentiation}

The investigations' capacity to differentiate between leaders and others on the basis of game behaviour will depend not only on the potential of the game in this respect, but also on the actual degree of role specialisation in particular situations. If a specific role does not emerge in a group setting, then it is unlikely that one will be able to establish a relationship between that form of behaviour and any other. Similarly, if the situation does not encourage the diversification of roles, then it is unlikely that the measure of emergent leadership will 
be capable of discrimination along these lines. This section will consider the nature of role differentiation with reference to the present tasks, and will in addition compare role differentiation between male and female groups.

Of initial concern is the method employed for identifying emergent leaders. The literature reveals two consistent findings. Firstly, in groups working on tasks of various sorts, two role specialists are likely to emerge - the task and the socio-emotional leaders. These roles may be filled by one individual, but more normally two persons with complementary attributes are most efficient. Secondly, the most accurate judges of who these specialists actually are, are the group members themselves. The cues which they employ, whilst undefined, differ substantially from those which even trained observers use (Stein, 1975).

Therefore, the most accurate method for gauging leadership hierarchies is likely to be by questionnaire, administered to the interactants themselves. In so far as two leadership roles have a propensity to emerge, then it would seem appropriate to ask group members to rank themselves in terms of the two categories. The degree of overlap between roles may serve as an indication of the degree of role specialisation in the particular situation. A case in point is provided by Investigation Three. Over $80 \%$ of task leaders in this unstructured discussion task were also highest nominated socio-emotional leader, indicating considerable overlap, and hence little differentiation. In comparison, only $14 \%$ of male task leaders in Investigation Two were also highest nominated socio-emotional leaders, in a task which could be interpreted as more complex and more likely to encourage specialism. 
Social exchange theory, as expounded by Jacobs (1971), maintains that the form which role specialisation takes will be dependent upon the contingencies surrounding the meeting of the group. The present investigations support this proposition. In situations where differentiation is necessary for the attainment of particular goals, then that differentiation is more likely to occur, and hence is identifiable by others.

Bales and Slater (1955) found that differentiation was more distinct in later meetings of groups, as compared to first meetings. The present experiments used groups which met only once, as the concern was with the initial structure introduced to a structureless group - uninfluenced by previous experience. The overlap between roles was not found to be as absolute as perhaps Bales and Slater set out, but was relative to the particular group situation. This is reflected in the overlap between nominations for role specialists, and also perhaps in the degree of consensus as to who is the leader. In male groups, greatest consensus was found regarding nomination for task leader in Investigation Two (average nomination $=1.3$ ), although differences in consensus between conditions are not substantial enough to warrant much discussion. In all cases, the task leader seemed to be more easily identifiable than the socio-emotional leader.

Shelley (1960) details the development of particular roles in response to particular task requirements. He maintains that when the group is working towards specific goals then the role structure will develop early, with little competition for status and less emphasis upon socio-emotional components of group functioning. When the aims of the group are less clearly defined, then the socio-emotional role emerges earlier, in response to the competition between other members. . Harwell (1968) and 
Gustafson (1973) echo this appraisal, and Gustafson also notes that in conditions of high task involvement, the task specialist may be the most popular member of the group, because of his contributions towards the successful attainment of goals. These analyses are supported by the present investigations.

Turning to characteristics of those individuals in either of the two roles, Bales and Slater (1955) have noted the inflexibility of behaviour of role specialists. Their scores on the California F-scale indicate a certain rigidity and absolutism associated with the authoritarian personality, and an additional interesting finding is that leaders in groups with lower status consensus had lower F-scores than those in higher status consensus groups. In terms of the analysis outlined so far, it is taken that groups in the present investigation are characterised by relatively low status consensus, given the short time that the groups work upon the problems. Bales and Slater also noted that the best liked men had rigid attitudes towards interpersonal relationships. Referring to Investigation One, a strong trend is evident for socioemotional leaders to rate their Least Preferred Co-Workers lower than is the case for other group members (in male groups), pointing to the rigidity of attitude of these leaders.

The analysis to date has concentrated almost exclusively on male groups, reflecting the orientation of previous research. However, the present results do reveal distinct differences in role differentiation between male and female groups. Wexley and Hunt (1974), Denmark (1977), and Aries (1976) all detail greater flexibility in female groups, and less ridigly defined role systems. Wexley and Hunt noted that female leaders exhibited more release of tension, agreed more often, gave more opinions and asked for more suggestions than did male leaders; Aries 
found greater variation in rankings within female groups; Garland and Beard (1979) noted female leaders to be more adaptable and socially perceptive; and Denmark and Diggory (1966) found less authoritarian behaviour emanating from female leaders. All these studies indicate differences in status hierarchies between the sexes, when engaged on similar problems. The present investigations also point to differences in the process, within the range of situations defined.

Male groups are characterised by a clearer distinction between roles, with two individuals often being isolated in one group condition. Additionally, evidence of differences in participation rate of male and female leaders in the preliminary investigation indicate that the styles which leaders employ may be dissimilar. Male leaders had a tendency to dominate the interaction more than their female counterparts, which evidences a less democratic approach on their part.

The differences in structure between male and female groups is likely to have an effect on the capacity of leadership measures to identify particular styles. The greater overlap between roles in female groups not only indicates less differentiation, but also hinders attempts at analysis of styles. In so far as the literature reveals the potential for marked contrasts in style between male and female leaders in sexually homogenous groups, then this difference is taken as unfortunate.

Concluding the work on role differentiation, three aspects of the process have been highlighted, which bear directly on the present investigations. Firstly, the specialisation of roles is dependent upon characteristics of the situation. In certain instances, particular roles may not emerge, or may not be distinguishable from others. Secondly, role specialists are characterised by particular attributes, 
which are again likely to be situationally dependent. Thirdly, sex differences will have an influence not only on the process of differentiation but also on the appropriateness of any one style of leadership.

\section{c) Classification of Tasks}

Given the considerable importance attached to situational contingencies, it would seem appropriate to classify the four problems. A number of classifications have been employed in the past, usually based on quite arbitrary divisions. For example, the distinctions between structured and unstructured situations, between discussion and problem-solving groups, between groups which meet for specific tasks and those where goals are not detailed, etc. These classifications are all characterised by straightforward dichotomies, but whether such simplistic classification systems are justified is debatable.

Regarding the present investigations, the particular characteristics of each problem are vital to the differentiation of roles. Admittedly, each problem is concerned with the attainment of a goal, whether it be the solution of a problem-solving exercise or the reaching of consensus on an open ended discussion task. However, each situation also contains idiosyncratic features which set it apart from the rest.

The preliminary investigation utilised a number of problems, which had no definitive solutions. The detail of the problem was high, and therefore no structure had to be introduced. The mixed-motive nature of the tasks enabled a number of approaches to be employed. 
The problem detailed in Investigation One involved less of a problem solving component. Subjects worked on individual profiles before coming together to formulate a group policy.

In Investigation Two, subjects worked upon a complex problem solving task, requiring both a commitment to the solution of a difficult puzzle and also the co-ordination of numerous pieces of information from all group members.

The group task in Investigation Three was of an open ended discussion type, with little structure being offered in the instructions.

Each of the tasks is characterised by particular features which set it apart from the others. It was anticipated that these features would facilitate or hinder the emergence of particular role types, but to attempt a classification system on the basis of four situations is not taken as worthwhile. Rather, the combination of factors involved in each situation (e.g. structure, complexity, problem solving component, co-ordination component) will combine to give the situation its particular character.

\footnotetext{
d) Pre-emptive Game Behaviour and the Emergence of Leadership Given the analysis outlined in the previous sections, it is proposed to offer speculative arguments concerning the relationship between game behaviour and leadership emergence.
}

Previous analyses of leadership styles have almost invariably dichotomised the process, beginning with the early work of Lewin and continuing right up to the introduction of measures such as Snyder's self- 
monitoring scale (Garland and Beard, 1979). Each of these dichotomies is originally based upon the measurement of styles of interaction which leaders exhibit. Lewin looked at the distinction between democratic leaders and authoritarian leaders; Hemphill considered the differences between leaders' initiating structure and consideration; Fiedler looked at how leaders perceived (and hence presumably interacted with) their least preferred co-worker. What of pre-emption?

Pre-emption considers the manner in which an individual behaves when placed in an experimentally controlled, one-to-one interaction. The player may respond in one of a number of fashions in order to gain points, and so to dominate the other. It is presumed that the manner in which he/she goes about this task is related to the manner in which he/she would go about interacting with others in a face to face setting. $\mathrm{He} /$ she may respond in the game in a dogmatic, inflexible fashion, dictating play through rigidly following a sequence, regardless of the choices made by the other player. On the other hand, he/she may have a greater awareness of the social complexities of the game, and play in a more adaptable, flexible fashion, whilst still being concerned with domination. Which of these two alternative approaches is predominant can be gauged through an analysis of pre-emption rates.

The links between this leadership measure and existing systems is apparent. Pre-emption too is a measure of interaction style, but rather than utilising questionnaires or post hoc analyses of behaviour in the group setting, it is capable of discriminating between styles of interaction in a controlled laboratory setting, and as importantly, it has the capacity to measure these styles away from the leadership situation itself. In this way the measure is seen as a useful addition to existing research findings on leadership. 
Turnins to the results from the four experiments, it is proposed to analyse the particular relationships in terms of the previous arguments.

In the preliminary investigation, task leaders in male froups had low levels of pre-emption, task and socio-emotional leaders in female groups had high levels of pre-emption. The results are interpreted largely in terms of sex differences in leadership structure, as a response to differences in perception of the task. Hale groups developed a hierarchy which was geared towards the solution of relatively uncomplicated problems, not requiring any large degree of co-ordination between members, and a leadership style characterised by low flexibility and little concern for social facets of group functioning. The task leaders were therefore noted by low levels of pre-emption. Female groups developed hierarchies which were more pre-occupied with the complexity of the task, and the co-ordination of all members' contributions. Leaders were accordingly characterised by high rates of pre-emption, but as is the case with the other female groups, there was little discrimination between the task and socio-emotional roles. This analysis ties in with previous findings and specifically those of Mack and Kremer (1977), and finds support in analyses of participation rates and IPC scores of leaders and others.

In Investigation One, the task was more definitive and less open to alternative approaches. As the problem was concerned with the co-ordination of all the members' contributions, it is likely that the socio-emotional function would be more prominent. In this investigation, male and female socio-emotional leaders were noted for low levels of pre-emption. As with the preliminary enquiry, both female specialists had similar rates of pre-emption, indicating once more a lack of differentiation in female groups. 
The low pre-emption rates of socio-emotional leaders complements previous research findings, which detail a degree of interactional inflexibility on the part of socio-emotional leaders.

Investigation Two involved a far more complex problem solving task, which entailed not only considerable task related behaviour, but also the co-ordination of all the members' contributions. Strong trends were evident for task leaders in both male and female groups to preempt more often than other group members (although certain leaders were also noted for particularly low pre-emption rates). Male socioemotional leaders displayed low levels of pre-emption, as previously.

Investigation Three involved an unstructured discussion task with an open ended solution. Both male and female groups were noted for a lack of role differentiation. Those nominated for leadership roles did not differ significantly from other members in terms of pre-emption, although as with Investigation Two, there was evidence of a bi-polar distribution of scores among leaders.

Over the four investigations, certain interesting features are apparent. Firstly, the emergence of leadership roles which are pertinent to the particular situation are those related to pre-emption rates. Secondly, sex differences are apparent in role differentiation, and hence in relationships with pre-emption. Thirdly, the bi-polar distribution of leaders! pre-emption scores, particularly found in the latter two investigations, indicate that either; ( $i$ ) the game is not capable of differentiating between all leaders and other group members; or (ii) that different leadership hierarchies may have emerged in response to similar problems. This latter explanation seems best able to explain the large sex differences found in the preliminary enquiry. In the 
other three experiments it is by no means certain that only one leadership style will be predominant to the total exclusion of all others. Whether they represent the optimum styles is a totally separate argument, unanswered here as these present investigations have not concerned themselves with efficiency of groups.

The present results are considered to be largely in accord with previous findings, and with previous analyses of leadership behaviour. Leaders have been generally distinguishable from other group members by comparison of pre-emption scores. In those instances where this is not the case, then it is argued that the response of the group structure to the particular task may not have facilitated the identification of specific roles. 
CHAPTER FOURTEEN: CONCLUSIONS 
14.1 CONCLUSIONS

On the basis of the present research, looked at in conjunction with previous findings, a number of conclusions are offered;

a) The development of leadership roles is taken as having a purely functional value. In so far as the goals of the group are specified, then those individuals with the specific capacities necessary for task accomplishment will emerge to positions of leadership.

b) If the task is such that a particular role is superfluous, then that role will be unlikely to emerge and be identified.

c) Sex differences are apparent in role differentiation within single sex groups. In male groups, roles seem more clearly defined and the structure is less flexible than that found in female groups. Male groups are more tolerant of authoritarian leadership, whereas female groups have a greater concern with all members' participation. Differences are evident in the development of male and female role hierarchies for superficially similar tasks, indicating differential perceptions of particular situations.

d) Pre-emptive game behaviour in the mixed-motive game, Leader, has been shown to be related to the emergence of leadership roles. (i) In male groups, socio-emotional leaders are noted by low levels of pre-emption, indicating a rigidity in their interaction style. Task leaders are noted by either high or low pre-emption rates, depending on situational contingencies. In those tasks requiring the initiation of structure and a flexible leadership approach, then the role specialists are characterised by high pre-emption. In less demanding situations, requiring individual effort and only general co-ordinating capacities, then low pre-emptors rise to prominence. 
(ii) In female groups, the lack of clarity regarding role differentiation necessitates less specific conclusions. Leaders in complex problem solving tasks are noted for high levels of pre-emption, whereas those in less structured discussion tasks have lower levels of pre-emption.

e) As regards development of the model, previous leadership research has tended to concentrate on existing hierarchies, where far greater consistency is found than in emergent situations. It would therefore seem appropriate for future research to establish the usefulness of pre-emption as a measure of leadership style in existing, well established leadership settings. 


\section{REFERENCES}

* 1. ABRIC, J•, FAUCHEUX, C., MOSCOVICI, $S_{\bullet}$, \& PION, M. Role de I'image du partenaire sur le cooperation en situation de jeu. Psychologie Francaise, 1967, 12, 267-275.

2. AGGER, R.E., GOLDSTEIN, M•N•, \& PEARL, S.A. Political cynicism: Measurement and meaning. Journal of Politics, 1961, 23, 477-506.

3. ALVAREZ, $R$. Informal reactions to deviance in simulated work organizations: A laboratory experiment. American Sociological Review, 1968, 33, 895-912.

4. ARIES, E. Interaction patterns and themes of male, female, and mixed groups. Small Group Behavior, 1976, 7(10),7-18.

5. ASHOUR, A.S. The contingency model of leadership effectiveness: An evaluation. Organizational Behavior and Human Performance, 1973, 9, 339-355.

BAFFSKY, A., \& BERGER, B. Self sacrifice, cooperation and aggresion in women of varying sex-role orientations. Personality and Social Psychology Bulletin, 1974, 296-298.

7. BALES, R.F. The equilibrium problem in small groups. In T. Parsons, R.F. Bales, \& E.A. Shils (eds.), Working Papers in the Theory of Action. Glencoe, Ill.: Free Press, 1953, p115-134.

8. BALES, R.F. Task roles and social roles in problem solving groups. In E.E. Maccoby, T.M. Newcomb, \& E.I. Hartley (eds.), Readings in Social Psychology. New York: Henry Holt, 1958, p437-446.

9. BALES, R.F., \& SLATER, P.E. Role differentiation in small decision making groups. In T. Parsons \& R. Bales (eds.), Family, Socialization and the Interaction Process. New York: Free Press of Glencoe, 1955.

10. BALES, R.F., \& STRODTBECK, F.I. Phases in group problem solving. Journal of Abnormal and Social Psychology, 1951, 46, 485-495.

11. BARTOL, K.M., \& BUTTERFIELD, D.A. Sex effects in evaluating leaders. Journal of Applied Psychology, 1976, 61(4), $446-454$.

12. BASS, B.M. An analysis of the leaderless group discussion. Journal of Applied Psychology, 1949, 33, 527-533.

13. BASS, B.M. The leaderless group discussion. Psychological Bulletin, $1954,51,465-492$.

14. BASS, B.M. Authoritarianism or acquiescence? Journal of Abnormal and Social Psychology, 1955, 51, 616-623.

15. BASS, B.M. Leadership, Psychology and Organizational Behavior. New York: Harper Row, 1960.

16. BASS, A.R., FIEDIER, F.E., \& KREUGER, S. Personality Correlates of Assumed Similarity (ASo) and Related Scores. (Tech. Rep. No. 19) Urbana, Ill.: Group Effectiveness Research Laboratory, Univ. of Illinois, 1964.

17. BATES, A.P. Some sociometric aspects of social ranking in a small face-to-face group. Sociometry, 1952, 15, 330-342. 
18. BAXTER, G.W. The effects of information about and race of other player upon cooperation in a two-person game. Unpublished $\mathrm{Ph} . \mathrm{D}$. Dissetation, Peabody College, 1969.

19. BAXITER, G.W. Personality and attitudinal characteristics and cooperation in two-person games: A review. In Wrightsman et al., Ref. 250, 1972 .

20. BEDEII, J., \& SISTRUNK, F. Power, opportunity costs and sex in a mixed-motive game. Journal of Personality and Social Psychology, $1973,25,219-226$.

21. BERGER, S.E., \& TEDESCHI, J.T. Aggressive behavior of delinquent, dependant, and normal. white and black boys in social conflicts. Journal of Experimental Social Psychology, 1969, 5, 352-370.

22. BERKOWITZ, I. Personality and group position. Biometry, 1956, 19, 210-222.

23. BIGONESS, W.J. Effect of applicant's sex, race and performance on employers' performance ratings: Some additional findings. Journal of Applied Psychology, 1976, 61, 80-84.

24. BIRD, C. Social Psychology• New York: Appleton-Century-Crofts, 1940.

25. BISHOP, D.W. Relations between task and interpersonal success and group member adjustment. Urbana, Il1.: Group Effectiveness Research Laboratory, Univ. of IIlinois, 1964.

26. BIXENSTINE, V.E., CHAMBERS, N., \& WIISON, K.N. Effect of assymetry of payoff on behavior in a two-person, non-zero-sum game. Journal of Conflict Resolution, 1964, 8, 151-159.

27. BIXFNSTINE, V.E., \& O'REILIY, E.F. Money vs. electric shock as payoff in a Prisoner's Dilema game. Psychological Record, 1966, 16, 251-264.

28. BIXENSTINE, V.E., POTASH, H.M., \& WIISON, K.V. Effects of levels of cooperative choice by the other player on choices in a Prisoner's Dilemma game: Part 1. Journal of Abnormal and Social Psychology, $1963,66,308-313$.

29. BORGATTA, E.F. Analysis of social interaction and sociometric perception. Sociometry, 1954, 17, 7-31.

30. BRAVER, S.I., \& ROHRER, V. When martyrdom pays - The effect of information concerning the opponent's past game behavior. Journal of Conflict Resolution, 1975, 19(4), 652-662.

31. BURKE, P.J. The development of task and socio-emotional role differentiation. Sociometry, 1967, 30, 379-392.

32. BURKE, P.J. Participation and leadership in small groups. American Sociological Review, 1974, 39, 832-842.

33. BURROUGHS, W.A., \& JAFEE, C.I. Verbal participation and leadership voting behavior in the leadership group discussion. The Psychological Record, 1969, 19, 605-610.

34. BURROUGHS, W., SCHULTZ, W., \& AUTREY, S. Quality of argument, leadership votes and eye contact in three-person leaderless groups. Journal of Social Psychology, 1973, 90, 89-93. 
35. BUSSEY, S., MARKS, R., \& ESCOVER, I. The development of cooperation: Child to adult. Tech. Rep. Nonr. 3897(07), Dartmouth College, 1968.

36. CARDI, M.W. The relationship between sex role stereotype and trust among women as measured by cooperation and competition. Unpublished Ph.D. Thesis, Ohio State Univ., 1972.

37. CARTER, L.F., HAYTHORN, W., \& HOWELI, M. A further investigation of the criteria of leadership. Journal of Abnormal and Social Psychology, 1950, 45, 350-358.

38. CARTER, L॰F., HAYTHORN, W., SHRIVER, B॰, \& LANZETTA, J. The behavior of leaders and other group members. Journal of Abnormal and Social Psychology, 1951, 4, 589-595.

39. CARTER, I.F., \& NIXON, M. Ability, perceptual, personality, and interest factors associated with different criteria of leadership. Journal of Psychology, 1949, 27, 377-388.

40. CATTELI, R.B. New concepts for measuring leadership in terms of group syntality. Human Relations, 1951, 4, 161-184.

41. CATTELL, R.B. On the theory of group learning. Journal of Social Psychology, 1953, 37, 27-52.

42. CAIMELI, R.B., \& EBER, H.W. Handbook for the Sixteen P.F.. Champaign, III.: Institute for personality and Ability Testing, 1957.

43. CHAPMAN, J.B. Comparison of male and female leadership styles. Academy of Management Journal, 1975, 18, 645-650.

44. CHEMERS, M.M., \& RICE, R.W. A theoretical and empirical examination of the contingency model of leadership effectiveness. In J.G. Hunt \& I.L. Larsen (eds.), Contingency Approaches to Leadership. Carbondale: Southern Illinois Press, 1974.

45. CHEMERS, M.M., \& SKRYZPEK, G.J. Experimental test of the contingency model of leadership effectiveness. Journal of Personality and Social Psychology, 1972, 24, 172-177.

46. CHRISTIE, R., \& MERTON, R.K. Procedures for the sociological study of the values climate of medical schools. Journal of Medical Education, 1958, 33, 125-153.

47. CHRISTIE, R., GERGEN, K., \& MARIOWE, D. The penng-dollar caper. In R. Christie \& F. Geis (eds.), Studies in Macchiavellianism. New York: Academic Press, 1970, 173-189.

48. CONDRY, J.C. The effects of situational power and personality upon the decision to negotiate or not in a two-person bargaining situation. Dissertation Abstracts, 1967, 27, 2612.

49. CROCKEIT, W.H. Emergent leadership in small, decision-making groups. Journal of Abnormal and Social Psychology, 1955, 51(3), 378-383.

50. DANIELS, V. Communication, incentive and structural variables in interpersonal exchange and negotiation. Journal of Experimental Social Psychology, 1967, 3, 47-74. 
51. DAY, D., \& STODGIIL, R. Leader behavior of male and female supervisors. Personnel Psychology, 1972, 25(2), 353-360.

52. DENMARK, F.I. Styles of leadership. Psychology of Women Quarterly, $1977,2(2), 99-113$.

53. DENMARK, F.I., \& DIGGORY, J.C. Sex differences in attitudes toward leader's display of authoritarian behavior. Psychological Reports, $1966,18,863-872$.

54. DENMARK, F.I., McKENNA, W., JURAN, S., \& GREENBERG, H.M. Status and sex differences in non-verbal behavior. Unpublished research, 1976.

$\forall$ 55. DEUTSCH, M. Trust and suspicion. Journal of Conflict Resolution, $1958,2,265-279$.

* 56. DEUTSCH, M. Trust, trustworthiness, and the F scale. Journal of Abnormal and Social Psychology, 1960, 6!, 138-140.

57. DEUTSCH, M•, \& KRAUSS, R.M. The effect of threat upon interpersonal bargaining. Journal of Abnormal and Social Psychology, 1960, $61,181-189$.

58. DOWNEY, H.K., SHERIDAN, J.E., \& SLOCUM, J.W. The Path-Goal theory of leadership: A longitudinal analysis. Organizational Behavior and Human Performance, 1976, 16, 156-176.

59. DUBIN, R. (ed.) Human Relations in Administration. New York: Prentice-Hall, 1951.

60. ECKHARDT, W., SIOAN, T., \& AZAR, E. The measurement of compassion. Southern Review of Peace Science, 1973.

61. ESKIISON, A॰, \& WIIEY, M.G. Sex composition and leadership in small groups. Sociometry, 1976, 39, 183-194.

62. EVANS, G. Effects of unilateral promise and value of rewards upon cooperation and trust. Journal of Abnormal and Social Psychology, $1964,69,587-590$.

63. EVANS, G., \& CRUMBAUGH, C. Effects of Prisoner's Dilemma format on cooperative behavior. Journal of Personality and Social Psychology, $1966,3,486-488$.

64. FAUCHEUX, C., \& MOSCOVICI, S. Self-esteem and exploitative game behavior in a game against chance and nature. Journal of Personality and Social Psychology, 1968, 8, 83-88.

65. FIEDLER, F.E. A Theory of Leadership Effectiveness. New York: McGraw-HiII, 1967.

66. FIEDLER, F.E. Validation and extension of the contingency model of leadership effectiveness: A review of empirical findings. Psychological Bulletin, 1971, 76, 128-148.

67. FIEDLER, F.E. Personality, motivational systems, and behavior of high and low IPC persons. Human Relations, 1972, 25, 391-412.

68. FIEDIER, F.E., \& CHEMERS, M.M• Leadership and Effective Management. New York: Scott-Foresman, 1974. 
69. FIEDLER, F.E., O'BRIEN, G.E., \& IIGEN, D.R. The effect of leadership style upon the performance and adjustment of volunteer teams operating in a stressful foreign environment. Human Relations, 1966, 22, 503-514.

70. FLEISHMAN, E.A., \& HUNT, J.G. (eds.). Current Developments in the Study of Ieadership. Carbondale: Southern IIlinois Univ. Press, 1973.

71. FLEISHMAN, E.A., \& SLATER, J.A. Relation between the leader's behavior and his empathy toward subordinates. Journal of Industrial Psychology, 1963, 1, 79-84.

* 72. FLINT, R.J., \& HARRIS, R.J. Relative importance of structure and individual differences in two-person games. Unpublished Manuscripts, Univ. of New Mexico, 1970 ( $a$ \& b).

* 73. FLOOD, M.M. Some experimental games. Management Science, 1958, 5, 5-26

74. FOA, U.G., MITCHELL, T.R., \& FIEDLER, F.E. Differentiation matching. Behavioral Science, 1971, 16, 130-142.

75. FRENCH, R.L. Verbal output and leadership status in initially leaderless group discussion groups. American Psychologist, $1950,5,310-311$.

76. FRIEDELI, M.F. Alaboratory experiment in retaliation. Unpublished Doctoral Dissertation, Univ. of Chicago, 1965.

77. FRY, C.I. Personality and acquisition factors in the development of coordination strategy. Journal of Personality and Social Psychology, $1965,2,403-407$.

78. GAHAGAN, J.P., HORAI, J., BERGER, S., \& TEDESCHI, J. Status and authoritarianism in the Prisoner's Dilemma game. Paper presented at the Southeastern Psychological Association convention, Atlanta, 1967.

79. GALIO, P.S. The effects of different motivational orietations in a mixed-motive game. Unpublished Doctoral Dissertation, Univ. of California at Los Angeles, 1963.

80. GALIO, P.S. Effects of increased incentives upon the use of threat in bargaining. Journal of Personality and Social Psychology, 1966, 4 , 14-20.

* 81. GAIIO, P.S., \& MCCIINTOCK, C.G. Cooperative and competitive behavior in mixed-motive games. Journal of Conflict Resolution, 1965, 9, 65-78.

82. GARIAND, H., \& BEARD, J.F. Relationship between self-monitoring and leadership emergence across two task situations. Journal of Applied Psychology, 1979, 64(1), 72-76.

83. GARNER, K., \& DEUTSCH, M. Cooperative behavior in dyads: Effects of dissimilar goal orientations and differing expectations about the partner. Journal of Conflict Resolution, 1974, 18(4), 634-638.

84. GEIER, J.G. A trait approach to the study of leadership in small groups. Journal of Communication, 1967, 17, 316-322.

85. GERGEN, K.J. The Psychology of Behavior Exchange. Reading. Mass.: Addison-Wesley, 1969. 
86. GIBB, C.A. The sociometry of leadership in temporary groups. Sociometry, 1950, 13, 226-243.

87. GIBB, C.A. Leadership. In G. Lindzey (ed.), Handbook of Social Psychology• Reading, Mass.: Adison-Wesley, 1954, p877-921.

88. GIBB, C.A. (ed.) Leadership. London: Penguin, 1969.

89. GOUGH, H.G. Manual for the California Psychological Inventory. Palo Alto, Calif.: Consultancy Psychologists Press, 1957, 1969.

90. GRAEN, G., ALVARES, K., ORRIS, J.B., \& MARTELLA, J.A. Contingency model of leadership effectiveness: Antecedent and evidential results. Psychological Bulletin, 1970, 74(4), 285-296.

91. GRANT, M.J., \& SERMAT, V. Status and sex of others as determinants of behavior in a mixed-motive game. Journal of Personality and Social Psychology, 1969, 12, 151-157.

92. GREEN, G.H. Insight and group adjustment. Journal of Abnormal and Social Psychology, 1948, 43, 49-61.

93. GUSTAFSON, D.H. Task commitment and role differentiation. Human Relations, 1973, 26, 667-679.

X 94. GUYER, M., \& RAPOPORT, A. Information effects in two mixed-motive games. Behavioral Science, 1969, 14, 467-482.

95. HALPIN, S.M., \& PIIISUK, M. Prediction and choice in the Prisoner's Dilemma. Paper 174, Institute for Research in the Behavioral, Economic, and Management Sciences, Purdue Univ., 1967. Also in Behavioral Science, 1970, 15, 141-153.

96. HAIPIN, A.W., \& WINER, B.J. A factorial study of the leader behavior descriptions. Tech. Rep. III. The leadership behavior of the airplane commander. Columbus:'Ohio State Univ. Research Foundation, 1952.

97. HAMNER, W.C., KIM, J.S., BAIRD, L., \& BIGONESS, W.J. Race and sex as determinants of ratings by potential employers in a simulated work sampling task. Journal of Applied Psychology, $1974,59,705-711$.

98. HARFORD, T.C., \& SOLOMON, L. "Reformed sinner" and "lapsed saint" strategies in the Prisoner's Dilemma game. Journal of Conflict Resolution, 1967, 11, 104-109.

99. HARFORD, T., \& SOLOMON, L. Effects of a reformed sinner and a lapsed saint strategy upon trust formation in paranoid and non-paranoid schizophrenic patients. Journal of Abnormal Psychology, 1969, 74, 498-504.

100. HARRIS, R.J. Experimental games as tools for personality research. In P. McReynolds (ed.), Advances in Psychological Assessment, Vol. II. Science and Behavior, 1971.

101. HARVARD BUSINESS REVIEW. Are women executives people? 1965, 43, 14

102. HEMPHIIJ, J.K. Ieader Behavior Description. Columbus: Ohio State Univ. Personnel Research Board, 1954. - 
103. HEMPHIIL, J.K., PEPINSKY, P.N., et al. The effects of reward and expectancy on motivation to lead. American Psychology, 1956, 11,379.

104. HIL, T.E., SCHMITT, N. Individual differences in leadership decision making. Organizational Behaviour and Human Performance,1977 $19,353-367$.

105. HOLLANDER, E.P. Conformity, status, and idiosyncratic credit. Psychological Review, 1958, 65, 117-127.

106. HOLIANDER, E.P. Leaders, Groups, and Influence. New York: Oxford Univ. Press, 1964.

107. HOLLANDER, E.P., \& JULIAN, J.W. Contemporary trends in the analysis of the leadership processes. Psychological Bulletin, 1969, 71, 387-397.

108. HOMANS, G.C. Social behavior as exchange. American Journal of Sociology, 1950, 63, 597-606.

109. HOMANS, G.C. The Human Group. New York: Harcourt, Brace, 1950.

110. HOMANS,G.C. Group factors in worker productivity. In E. Maccoby, T. Newcomb, and E.Hartley (eds), Readings in Social Psychology, New York: Holt, 1958, 546-564.

111. HOMANS, G.C. Social Behaviour: its Elementary Forms. New York: Harcourt Brace, 1961.

112. HOOK, S. The Hero in History. Boston: Beacon Press, 1955.

113. HOTTES, J.A., \& KAHN, A. Sex ifferences in a mixed-motive conflict situation. Journal of Personality, 1974, 42, 260-275.

114. HOUSE, R.J. A path-goal theory of leadership. Administrative science Quarterly, 1971, 16, 321-338.

115. HOUSE, R.J., \& MITCHELL, T.R. Path-goal theory of leadership. Journal of Contemporary Business, 1974,3, 81-93.

* 116. HURST, P.M॰, RADIOW, R., CHUBB, N.C., \& BAGLEY, S.K. Drug effects upon choice behaviour in mixed-motive games. Behavioral science, $1969,14,443-452$.

117. HURWITZ, J.I., ZANDER, A., \& HYMOVITCH, B. Some effects of power on the relations among group members. In D. Cartwright and A. Zander (eds. Group Dynamics: Research and Theory. New York: Harper \& Row, 1953,291-29

118. INGRAM, B.I., \& BERGER, S.E. Sex role orientation, defensiveness and competitiveness in women. Journal of Conflict Resolution, 1977, 21(3), 501-518.

119. JACOBS, T.O. Leadership and Exchange in Formal Organizations. Alexandria, Va.: Human Resources Research Organization, 1971.

120. JACOBSON, M.B., \& EFFERTZ, J. Sex roles and leadership: Perceptions of the leader and the led. Organizational Behaviour and Human Performance, 1974, 12, 383-396.

121. JAFHEE, C.I., \& IDCAS, R.I. Effects of rate of talking and correctness of decisions on leader choice in small groups. Journal of Social Psychology, 1969, 247-254. 
122. KANTER, R.M. Women and the structure of organization: Explanations in theory and behavior. In Millman and Kanter (eds.), Another Voice, New York: Doubleday, 1975.

* 123. KAUFMAN, H., \& BECKER, G.M. The empirical determination of game theoretical strategies. Journal of Experimental Psychology, 1961, $61,464-468$.

124. KERR, S., SCHRIESHEIM, C.A., MURPHY, C.J., \& STODGIII, R.M. Towards a contingency theory of leadership based upon the consideration and initiating structure literature. Organizational Behavior and Human Performance, 1974, 12,62-82.

* 125. KIIGARD, B.J. A comparison of minimax behavior with observed behavior in a two-person zero-sum game interaction. Research report submitted under Nonre. 2794(03), Arizona State Univ., 1966.

126. KIRSCHT, J.P., IODAHL, T.M., \& HAIRE, M. Some factors in the selection of members of small groups. Journal of Abnormal and Social Psychology, '1959, 58, 406-408.

* 127. KLEIN, E.B., \& SOIOMON, L. Agreement response tendency and behavioral submission in schizophrenia.: Psychological Reports, 1966, 18, 499-509.

128. KNAPP, W.M., \& PODELL, J.E. Mental patients, prisoners and students with simulated partners in a mixed-motive game. Journal of Conflict Resolution, 1968, 12, 235-241.

* 129. KNIGHT, G.P., \& MACK, D. Race and behavior in the Prisoner's Dilemma game. The Psychological Record, 1973, 23, 61-64.

KONORITA, S.S., \& MECHIING, J. Betrayal and reconciliation in a two-person game. Journal of Personality and Social Psychology, $1967,6,349-353$.

131. KORMAN, A.K. "Consideration", "Initiating Structure", and organizational criteria - a review. Personnel Psychology, 1966, $19,349-361$.

132. KORMAN, A.K. Organizational achievement, aggression and creativity: Some suggestions toward an integrated theory. Organizational Behavior and Human Performance, 1971, 6, 593-613.

133. LAVE, I.B. An empirical approach to the Prisoner's Dilemma game. Quarterly Journal of Economics, 1962, 424-436.

134. LAVE, L.B. Factors affecting cooperation in the Prisoner's Dilema. Behavioral Science, 1965, 10, 26-38.

135. IEWIN, K.R•, LIPPIMT, R•, \& WHITE, K. Patterns of aggressive behavior in experimentally created social climates. Journal of Social Psychology, 1939, 10, 271-299.

* 136. ILEBERMAN, B. Human behavior in a strictly defined 3 by 3 matrix game. Behavioral Science, 1960, 5, 317-322.

137. LOOMIS, J.L. Communication, the development of trust, and cooperative behavior. Human Relations, 1959, 12, 305-315. 
* 138. LUCE, R.D., \& RAIFFA, H. Games and Decisions. New York: Wiley, 1957.

139. IUTZKER, D.R. Internationalism as a predictor of cooperative game behavior. Journal of Conflict Resolution, 1960, 4, 426-430.

N 140. LUTZKER, D.R. Sex role, cooperation and competition in a two-person non-zero-sum game. Journal of Conflict Resolution, 1961, 5, 366-368.

141. LYIE, J.R., \& ROSS, J.I. Women in Industry• Lexington, Mass.: D.C. Heath and Co., 1973.

142 MACK, D. Personality, pay-off information and behaviour in a twoperson bargaining game. Acta Psychologica, 1972, 36, 125-144.

* 143. MACK, D. Leader, an unbiased mixed-motive game. Psychologische Bietrage, 1972, 14(2), 244-252.

- 144. MACK, D. Status and behavior in the reiterated Prisoner's Dilemma game. The Psychological Record, 1976, 26, 529-532.

145. MACK, D., AUBURN, P.N., \& KNIGHT, G.P. Sex role identification and behavior in a reiterated Prisoner's Dilemma game. Psychonometric Science, 1971, 24(6), 280-282.

146. MACK, D., \& KREMER, J.M.D. Dominance and Pre-Emptive Behaviour in the Mixed-Motive Game Leader. Paper presented at the Annual Conference of the British Psychological Society (Social Section), Durham, 1977.

147. MACK, D., WIIIIAMS, J.G., \& KREMER, J.M.D. Perception of a simulated other player and behavior in the reiterated Prisoner's Dilemma game. The Psychological-Record, 1979, 29, 43-48.

148. MANN, R.D. Areview of the relationships between personality and performance in small groups. Psychological Bulletin, 1959, 56, 241-270.

149. MARIN, G. Cooperation in the Prisoner's Dilemma and personality correlates: A non-existent relationship. Peace Research, 1973, 5(6), 30-32

150. MARLOWE, D. Psychological needs and cooperation-competition in a two-person game. Psychological Reports, 1963, 13, 364.

* 151. MARIOWE, D. Some personality and behavioral correlates of conformity. Unpublished Doctoral Dissertation, Ohio State Univ., 1959.

152. MARWEL, G. Role allocation and differentiation through time in medium sized groups. - Journal of Social Psychology, 1968, 74(2), 225-231.

153. MARWELI, G., RATCLIFF, K., \& SCHMIDI, D. Minimizing differences in a maximising differences game. Journal of Personality and Social Psychology, 1969, 12, 158-163.

154. MCCLINTOCK, C.G., GAIIO, P.S., \& HARRISON, A. Some effects of variation in other strategy upon game behavior. Journal of Personality and Social Psychology, 1965, 1, 319-325.

155. McDAVID, J.W., \& HARARI, H. Social Psychology: Individuals, Groups, Societies. New York: Harper \& Row, 1969.

156. McKENNA, W., \& DENMARK, F.I. The interaction of non-verbal behaviors and sex-role stereotypes in the attribution of status. Unpublished Research, 1976. (cited in Denmark, 1977) 
157. MCKEOWN, C.D., GAHAGAN, J.P., \& TEDESCHI, J.T. The effect of prior power strategy upon behavior after a shift of power. Journal of Experimental Research in Personality, 1967, 2, 226-233.

158. McMAHON, J.T. The contingency theory: Logic and method revisited. Personnel Psychology, 1969, 52, 377-382.

159. MEGARGEE, E.I. Influence of sex-roles on the manifestation of leadership. Journal of Applied Psychology, 1969, 53, 377-382.

f 160. MIIJER, R.R. No-play: A means of conflict resolution. Journal of Personality and Social Psychology, 1967, 6, 150-156.

太 161. MINAS, J.S., SCODEL, A., MARLOWE, D., \& RAWSON, H. Some descriptive aspects of two-person, non-zero-sum games: II. Journal of Conflict Resolution, 1960, 4, 193-197.

162. MITCHELL, T.R. Leader complexity, leadership style and group performance. Unpublished Doctoral Dissertation, Univ. of Illinois, 1969.

163. MITCHEIJ, T.R., BIGLAN, A., ONCKEN, G.R., \& FIEDIER, F.E. The contingency model: Criticism and suggestions. Academy of Management Journal, 1970, 13, 253-267.

164. MOMENT, D., \& ZALEZNIK, A. Role development and Interpersonal Competence. Cambridge, Mass.: Harvard Univ. Press, 1963.

165. MOORE, M.F., \& MACK, D. Dominance-ascendance and behaviour in the re-iterated Prisoner's Dilemma game. Acta Psychologica, 1972, 36, $480-491$.

166. MORRIS, C.G., \& HACKMAN, J.R. Beharioral correlates of perceived leadership. Journal of Personality and Social Psychology, 1969, $13,350-361$.

* 167. O'CONNOR, J., BAKER, N., \& WRIGHTSMAN, L.S. The nature of rationality in mixed-motive games. In Wrightsman et al. (eds.), 1972, p19-30. (ref. 148)

* 168. ORCUTT, J.D., \& ANDERSON, R.E. Human computer relationships:

Interaction and attitudes. Behavior Research Methods and Instrumentation, 1974, 6(2), 219-222.

169. OSKAMP, S. Effects of programmed strategies on cooperation in the Prisoner's Dilemma and other mixed-motive games. Journal of Conflict Resolution, 1971, 15, 198-235.

170. PEPITONE, A. Attraction and Hostility. New York: Atherton Press, 1964.

171. PEPITONE, A., et al. The role of self esteem in competitive choice behavior. International Journal of Psychology, 1967, 2, 147-159.

172. PEILERMAN, J.N. Verbal participation, its relation to decision satisfactio and the leader function in decision making groups. Univ. of Michigan Conference Research Project, 1950. (cited in Kirscht et al., 1959, ref. 12

172. PEITY, M.M. \& MIIES, R.H. Leader sex role stereotyping in a female dominated work culture. Personnel Psychology, 1966, 24, 393-404. 
173. PIIISUK, M., POTTER, P., RAPOPORT, . A., \& WINTER, J.A. War hawks and peace doves: Alternative resolutions of experimental conflicts. Journal of Conflict Resolution, 1965, 9, 491-508.

Y 174. PIIISUK, M., SKOLNICK, P., \& OVERSTREET, E. Predicting cooperation from the two sexes in a conflict simulation. Journal of Personality and Social Psychology, 1968, 10, 35-43.

x 175. RAPOPORT, Amnon. Optimal strategies for the Prisoner's Dilemma. Psychological Review, 1967, 74, 136-148.

$x$ 176. RAPOPORT, A. Two Person Game Theory: The Essential Ideas. Ann Arbor, Mich.: Univ. of Michigan Press, 1966.

$X$ 177. RAPOPORT, A. Exploiter, leader, hero and martry. The four archetypes of the two by two game. Behavioral Science, 1967, 12, 81-84.

Y 178. RAPOPORT, A. The $2 \times 2$ Game. Ann Arbor, Mich.: Univ. of Michigan Press, 1976.

$X$ 179. RAPOPORT, A., \& CHAMMAH, A. Prisoner's Dilema. Ann Arbor, Mich.: Univ. of Michigan Press, 1965.

× 180. RAPOPORT, A., \& CHAMMAH, A. The game of chicken. American Behavioral Scientist, 1966, 10, 10-14, 23-28.

\ 181. RAPOPORT, A., \& DAIE, P.S. The "end" and "start" effects in iterated Prisoner's Dilemma. Journal of Conflict Resolution, 1966, 10, 363-366.

< 182. RAPOPORT, A., \& GUYER, M. A taxonomy of $2 \times 2$ games. General Systems, 1966, 11, 203-214.

( 183. RAPOPORT, A., \& ORWANT, C. Experimental games: A review. Behavioral Science, 1962, 7, 1-37.

184. REDL, F. Groups, emotion and leadership. Psychiatry, 1942, 5, 573-596.

185. RECULA, R.C., \& JULIAN, J.W. The impact of quality and frequency of task contributions on perceived ability. Journal of Social Psychology, 1973, 89, 115-122. (Also appears as Regula, R.C. Techn. Rep. No. 6, 1967, State Univ. of New York at Buffalo, Contract Nonr. 4697, Office of Naval Research.)

186. RICE, R.W., \& CHEMERS, M.M. Predicting the emergence of leaders using Fiedler's coningency model. Journal of Applied Psychology, 1973, 57, 281-287.

187. RICE, R.W., \& CHEMERS, M.M. Personality and situational determinants of leadership. Journal of Applied Psychology, 1975, 60(1), 20-27.

188. RIECKEN, H.W. The effect of talkativeness on ability to influence group solutions to problems. Sociometry, 1958, 21, 309-321.

189. RIM, Y. Leadership attitudes and decisions involving risk. Personnel Psychology, 1965, 18, 423-430.

190. ROSEN, B., \& JERDEE, T.H. The influence of sex-role stereotypes upon evaluation of male and female supervisory behavior. Journal of Applied Psychology, 1974, 59, 9-14. 
191. RUDSWAMY, V. An investigation of the relationships between perceptions of status and leadership attempts. Journal of the Indian Academy of Applied Psychology, 1964, 1(1), 12-19. (abstract)

192. SAMPSON, E.E., \& KARDUSH, M. Age, sex, class, and race differences in response to a two-person non-zero-sum game. Journal of Conflict Resolution, 1965, 9, 212-220.

193. SCHEIN, V.E. The relationship between sex role stereotypes and requisite management characteristics. Journal of Applied Psychology, $1973,57,95-100$.

194. SCHEIN, V.E. Relationships between sex role stereotypes and requisite management characteristics among female managers. Journal of Applied Psychology, 1975, 60, 340-344.

195. SCHNEIER, C.E. The contingency model of leadership: An extension to emergent leadership and leader's sex. Organizational Behavior and Human Performance, 1978, 21, 220-239.

196. SCHRIESHEIM, C.A., HOUSE, R.J., \& KERR, S. Leader initiating structure: A reconciliation of discrepant research findings and some empirical tests. Organizational Behavior and Human Performance, $1976,15(2), 297-321$.

197. SCHULTZ, B. Characteristics of emergent leaders of continuing problem solving groups. Journal of Psychology, 1974, 88, 167-173.

198. SCHUIIZ, B. Predicting emergent leaders: An exploratory study of the salience of communicative functions. Small Group Behavior, $1978,9(1), 109-114$.

* 199. SCODEL, A., MINAS, J.S., RATOOSH, P., \& IIPETZ, M. Some descriptive aspects of two-person non-zero-sum games. Journal of Conflict Resolution, 1959,3,114-119.

200. SCOTT, W.A. Cognitive complexity and cognitive flexibility. Sociometry, 1962, 25, 405-414.

201. SERMAT, V. Dominance-submissiveness and competition in a mixedmotive game. British Journal of Social and Clinical Psychology, $1968,7,35-44$.

202. SHAW, M.E. Some effects of varying amounts of information exclusively possessed by a group member upon his behaviour in a group. Journal of General Psychology, 1963, 68(1), 71-79.

203. SHELIEY, H.P. Focused leadership and cohesiveness in small groups. Sociometry, 1960, 23, 209-216.

204. SHEVITZ, R.N. An investigation of the relationship between exclusive possession of information and attempts to lead in small groups. Dissertation Abstracts, 1956, 16, 806.

* 205. SHUBIK, M. (ed.). Game Theory and Related Approaches to Social Behavior. New York: Wiley, 1964.

206. SKOTKO, V., IANGMEYER, D., \& LUNDGREN, D. Sex differences as artefact in the Prisoner's Dilemma game. Journal of Canflict Resolution, 1974, 18(4), 707-714. 
207. SLATER, P.E. Role differentiation in small groups. American Sociological Review, 1955, 20, 300-310.

208. SNYDER, M. Self-monitoring of expressive behavior. Journal of Personality and Social Psychology, 1974, 30, 526-537.

209. SORRENTINO, R.M., \& BOUTKLIIER, R.G. The effect of quantity and quality of verbal interaction on ratings of leadership ability. Journal of Experimental Social Psychology, 1975, 11, 403-411.

210. SPILLER, G. The dynamics of greatness. Sociological Review, $1929,21,218-232$.

211. STANG, D.J. Effect of interaction rate on ratings of leadership and liking. Journal of Personality and Social Psychology, 1973, $27(3), 405-408$.

212. STEELE, M.W., \& TEDESCHI, J. Matrix indices and strategy choices in mixed-motive games. Journal of Conflict Resolution, 1967, $11,198-205$.

213. STEIN, R.T. Identify emergent leaders with content and noncontent information. Dissertation Abstracts International, 1973, $34,6748 \mathrm{~A}$.

214. STEIN, R.T. Identifying emergent leaders from verbal and nonverbal communications. Journal of Personality and Social Psychology, 1975, 32(1), 125-135.

215. STEIN, R.T. Accuracy of process consultants and untrained observers in perceiving emergent leadership. Journal of Applied Psychology, 1977, 62, 755-759.

216. STEIN, R.T., GEIS, F.I., \& DAMARIN, F. The perception of emergent leadership hierarchies in task groups. Journal of Personality and Social Psychology, 1973, 28, 77-87.

217. STETN, R.T., \& HELLER, T. An empirical analysis of the correlations between leadership status and participation rates reported in the literature. Journal of Personality and Social Psychology, 1980, $37,1993-2002$.

218. STIRES, L.K. Leadership designation and perceived ability as determinants of the tactical use of modesty and self-enhancement. Dissertation Abstracts International, 1970, 30(8-A), 3551.

219. STODGIII, R.M. Personal factors associated with leadership: A survey of the literature. Journal of Psychology, 1948,25, 35-71.

220. STODGILI, R.M. Leadership, membership, and organization. Psychological Bulletin, 1950, 47, 1-14.

221. STODGILL, R.M. Handbook of Leadership. New York: Free Press, 1974

222. STRICKILAND, I.H., GUIID, P.D., BAREFOOT, J.C., \& PATERSON, S.A. Teleconferencing and leadership emergence. Human Relations, 1978, 31(7), 583-596.

223. TEDESCHI, J.T., BONOMA, T., \& IINDSKOLD, S. Threatener's reactions to prior announcement of behavioral compliance or defiance. Behavioral Science, 1970, 15, 171-179. 
224. TEDESCHI, J.T., IESNICK, S., \& GAFAGAN, J. Feedback and 'washout' effects in the Prisoner's Dilemma game. Journal of Personality and Social Psychology, 1968, 10, 31-34.

225. TERHONE, K.W. Motives, situation and interpersonal conflict within the Prisoner's Dilemma. Journal of Personality and Social Psychology, Monograph Supplement, 1968, 8, 1-24.

226. TERHUNE K.W. The effects of personality in cooperation and conflict. In P. Swingle (ed.), The Structure of Conflict. New York, Academic Press, 1970, p193-234.

227. THIBAUT, J.W., \& KELLEY, H.H. The Social Psychology of Groups. New York: Wiley, 1959.

X 228. UESUGI, T.K., \& VINACKE, W.E. Strategy in a feminine game. Sociometry, 1963, 26, 75-88.

229. UEJIO, C.K., \& WRIGETSMAN, L.S. Ethnic group differences in the relationship of trusting attitudes to cooperative behavior. Psychological Reports, 1967, 20, 563-571.

230. VON NEUMANN, J., \& MORGANSTERN, 0 . Theory of Games and Economic Behavior (2nd ed.). Princeton: Princeton Univ. Press, 1947.:

231. VROOM, V.H. Can leaders learn to lead? Organizational Dynamics, 1976, 4, 17-28.

232. VROOM, V.H., \& JAGO, A.G. Decision making as a social process: Normative and descriptive models of leader behavior. Decision Sciences, 1974, 5, 743-769.

233. VROOM, V.H., \& YETTON, P.W. Leadership and Decision Making. Pittsburgh: Univ. of Pittsburgh Press, 1973.

234. WAIIACE, D., \& ROTHAUS, P. Communication, group loyalty, and trust in the P.D. game. Journal of Conflict Resolution, 1969, $13,370-380$.

235. WIGGINS, J., DILI, F., \& SCHWARIZ, R. On status liability• Sociometry, 1965, 28, 197-209.

236. WIILIAMS, S.D., \& IEAVIIT, F.J. Group opinion as a predictor of military leadership. Journal of Consulting Psychology, 1947, $11,283-292$.

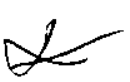

237. WIISON, W., \& KAYATANI, M. Intergroup attitudes and strategies in games between opponents of the same or of a different race. Journal of Personality and Social Psychology, 1968, 9, 24-30.

ॠ 238. WIISON, W., \& WONG, J. Intergroup attitudes towards cooperative vs. competitive opponents in a modified Prisoner's Dilemma game. Perceptual and Motor Skills, 1968, 27(3), 1059-1066.

239. WOOD, F.A. The Influence of Monarchs. New York: MacMillan, 1913.

240. WRIGHISMAN, L.S. Personality and attitudinal correlates of trusting and trustworthy behaviors in a two-person game. Journal of Personality and Social Psychology, 1966, 4, 328-332. 
241. WRIGHTSMAN, I.S. Social Psychology in the Seventies. Monterey, Calif.: Brooks/Cole, 1972.

242: WRIGHTSMAN, I.S., IUCKER, W.G., BRUININKS, R॰H., \& ANDERSON, W. Effect of subject's training and college class and other's strategy upon cooperative behavior in a Prisoner's Dilemma game. In Wrightsman et al., 1972, p126-140. (ref 245)

243. WRIGHTSMAN, L.S. et al: Effects of other persons race and strategy upon cooperative behavior in a Prisoner's Dilemma game. In Wrightsman et al., 1972, p110-125. (ref. 245)

244. WRIGHTSMAN, L.S., LUCKER, W.G., BRUININKS, R.H., \& O'CONNOR, J. Effects of extensiveness of instructions upon cooperation in a Prisoner's Dilemma game. In Wrightsman et al., 1972, p258-268. (ref. 245)

* 245. WRIGHTSMAN, I.S., O'CONNOR, J., \& BAKER, N.J. Cooperation and Competition: Readings in Mixed-Motive Games. Belmont, Calif.: Brooks/Cole, 1972. 


\section{(i) THE PRISONERS' DILEMMA}

1. Imagine that you as a group represent, in a legal capacity, one of two partners in crime, who are being grilled separately by the police.

2. The police carefully explain to your client and the other prisoner (who must choose in isolation from each other) that if neither confesses, they will both receive a one year sentence for a minor crime in which they were both caught red-handed.

3. If both confess, they will each get the standard sentence for the major crime of which they are suspected, five years in prison.

4. If, however, one of them turns state evidence while the other holds out, the person who confesses will be let off with a reprimand from the judge and will in addition have a $\$ 100$ note slipped into his wallet.

5. The holdout will be given the maximum sentence for the crime, twenty years in prison.

Bearing in mind that the other prisoner is also represented legally, what do you advise your client to do?

You must reach your decision without condultation with the other prisoner or his solicitor. 


\section{(ii) HOLIDAY 178}

1. Assuming that you as a group, are either Andy or Flo in the following problem, you are faced with an annual dilemma. 'This concerns where to go for your summer holidays. Last year, you and your spouse were unable to come to any decision as to where to visit, and hence you remained at home. You are determined to reach agreement in 1978 .

2. The problem centres around a basic disagreement - Andy wishes to travel to Ireland, whereas Flo wishes to tour the Lake District. The two week vacation does not allow the couple to visit both places.

3. Each would rather go to their chosen destination with their spouse than to $g^{\circ}$ there alone, and indeed if neither is able to dissuade their partner, they would prefer to go where he or she decides rather than stay at home again.

4. In both their eyes, the worst eventuality would be where they both decided to doggedly stick to their preferred holiday and both therefore travel separately.

5. In fact, although both want to go on holiday, they would rather stay at home than have separate holidays. Imagining that you are either Flo or Andy, what would you do? 


\section{(iii) THE TRUCKING DIIERMA}

1. Imagine that you are the Board of Acme Enterprises Ltd., which is one of two haulage companies, Acme and Bold, which endeavour to transport their loads from one destination to another as quickly as possible. The two companies are not in direct competition as they handle different goods, have different starting points and different destinations.

2. There is however one problem - the fastest route for both converges at one point to a single track road, and the lorries have to travel in opposite directions. The only way both are able to use the road is alternately. If both trucks enter the road simultaneously, neither is able to move until the other has reversed.

3. At the end of this road, Acme has exclusive control to a gate, which could be used to prevent the road from being used. Similarly, at the other end of the road, Bolt has exclusive access to a similar gate.

4. Each company has in addition a private route to their destination. This does not conflict with the other's route, but is considerably longer, slower, and hence economically less viable. The time taken for this alternative is over twice that for the direct route.

5. Bearing in mind that the sole aim of Acme Enterprises Ltd. is to maximise your profit margin, what is your solution to this dilemma? 
1. Imagine yourselves in the position of General Bradley in the following situation. It is 1944, the European War Theatre is a scene of Irenzied activity. The allied forces under your command have just broken out of their beach-head, through a narrow gap by the sea at Avranches. This breakthrough has exposed the Western flank of the German Ninth Army.

2. The German Commander, General von Kluge, has two possible courses of action:

a) to attack towards the west, penetrating to the sea to secure his west flank and cut off the Allied forces south of the gap. b) to withdraw to the east, taking up a more tenable position near the River Seine.

3. You, General Bradley, are overall commanding officer of the First and Third American Armies (part of the allied forces). Your Third Army, under General Patton, has started on its sweep to the west, south and east, slipping through the Avranches gap. The First Army is containing the German Ninth by a frontal attack. Your problem is what to do with the four divisions held in reserve just south of the gap and not yet committed to action (SEE MAP).

4. In surveying the situation, it appears that you have three possible courses of action open to you:
a) order your reserve back to defend the gap;
b) send it eastwards to harass or possibly cut off withdrawal of the German Ninth Army;
c) leave it in position for another day, moving it to the gap if necessary, or to the east if the gap held without reinforcement.

5. As a result of these actions, a number of possible outcomes are likely, depending on the action of General von Kluge:

(i) if the reserves reinforce the gap and the Germans attack, the gap will hold. However, if von Kluge decides to withdraw, he will do so under weak allied pressure.

(ii) if the reserves strike east, they will place the German withdrawal under heavy pressure. However, if von Kluge should then strike towards the gap instead of withdrawing, the gap will be cut. (iii) if the reserves are held in place for a day, they may move to the gap if it is attacked, or to the east should the gap hold without reinforcement. Alternatively, if the Germans withdraw, you could then place them under moderate pressure.

As General Bradley, what strategy would you as a group adopt, bearing in mind the strategies which von Kluge may anticipate. 


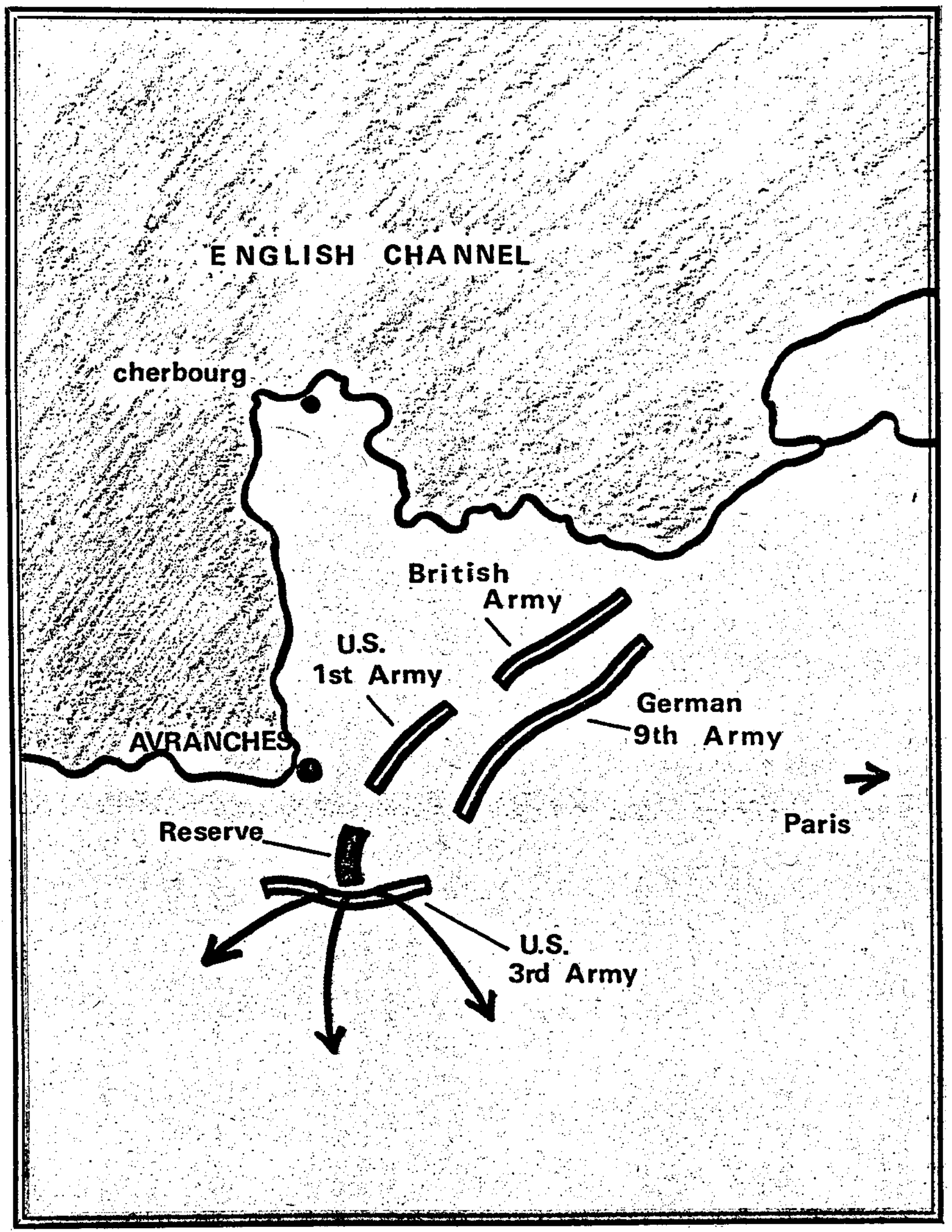


SUBJECT:

The following questions concern Tasks $1,2,3$, and 4 respectively.

(a) Which individual in the group do you consider the most valuable with regard to the initiation of structure, and in the area directly related to the completion of the particular task? (Use colours designated in answering, and include yourself if appropriate.)

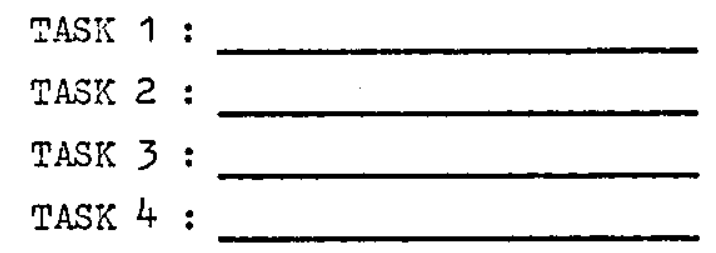

(b) Which individual did you perceive as most valuable with regard to the maintenance of group cohesion and the general social well-being of the group?

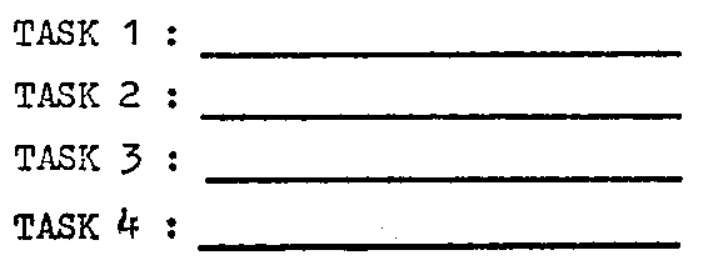

If the group was required to work togethe over a prolonged period of time, on a number of varied tasks, which individual would you nominate for the position of leader? (Again, include yourself if appropriate.)

People differ in the ways they think about those with whom they work. This may be important in working with others. Please give your immediate first reaction to the items below:

Overleaf are pairs of words which are opposite in meaning, such as very Neat and Not Neat. You are asked to describe someone with whom you have worked by placing an "X" in one of the eight spaces on the line between the two words. Each space represents how well the adjective fits the person you are describing, as if it were written:

Very Neat:

\begin{tabular}{|c|c|c|c|c|c|c|c|}
\hline 8 & $\overline{7}$ & 6 & 5 & 4 & 3 & 2 & 1 \\
\hline $\begin{array}{l}\text { Very } \\
\text { Neat }\end{array}$ & $\begin{array}{l}\text { Quite } \\
\text { Neat }\end{array}$ & $\begin{array}{l}\text { Some- } \\
\text { what } \\
\text { Neat }\end{array}$ & $\begin{array}{c}\text { Slight- } \\
\text { ly } \\
\text { Neat }\end{array}$ & $\begin{array}{c}\text { Slight- } \\
\text { ly } \\
\text { Tidy }\end{array}$ & $\begin{array}{l}\text { Some- } \\
\text { what } \\
\text { Untidy }\end{array}$ & $\begin{array}{l}\text { Quite } \\
\text { Tidy }\end{array}$ & $\begin{array}{l}\text { Very } \\
\text { Tidy }\end{array}$ \\
\hline
\end{tabular}
Not Neat 
If you would think of them as beins rery untidy, you would use the space nearest the words Not Neat.

Very Neat:

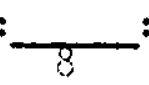
Very
iTeat

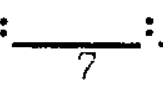

Quite ileat
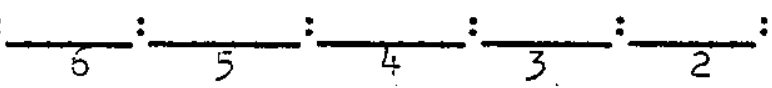

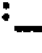

Some-

what

Neat
Slight-Slight- Some- Quite very
$1 y$ Neat Untidy Untidy Not Neat

Look at the words at both ends of the lines before you put in your "X". Please remember that there are no right or wrong answers. Uork rapidly; your first answer is likely to be the best. Please do not omit any items, and mark each item only once.

\section{MPC}

Think of the person with whom you can work best. He may be someone you work with now, or he may be someone you lnew in the past.

He should not necessarily be the person you like best, but should be the person with whom you have been able to work best. Describe this person as he appears to you.

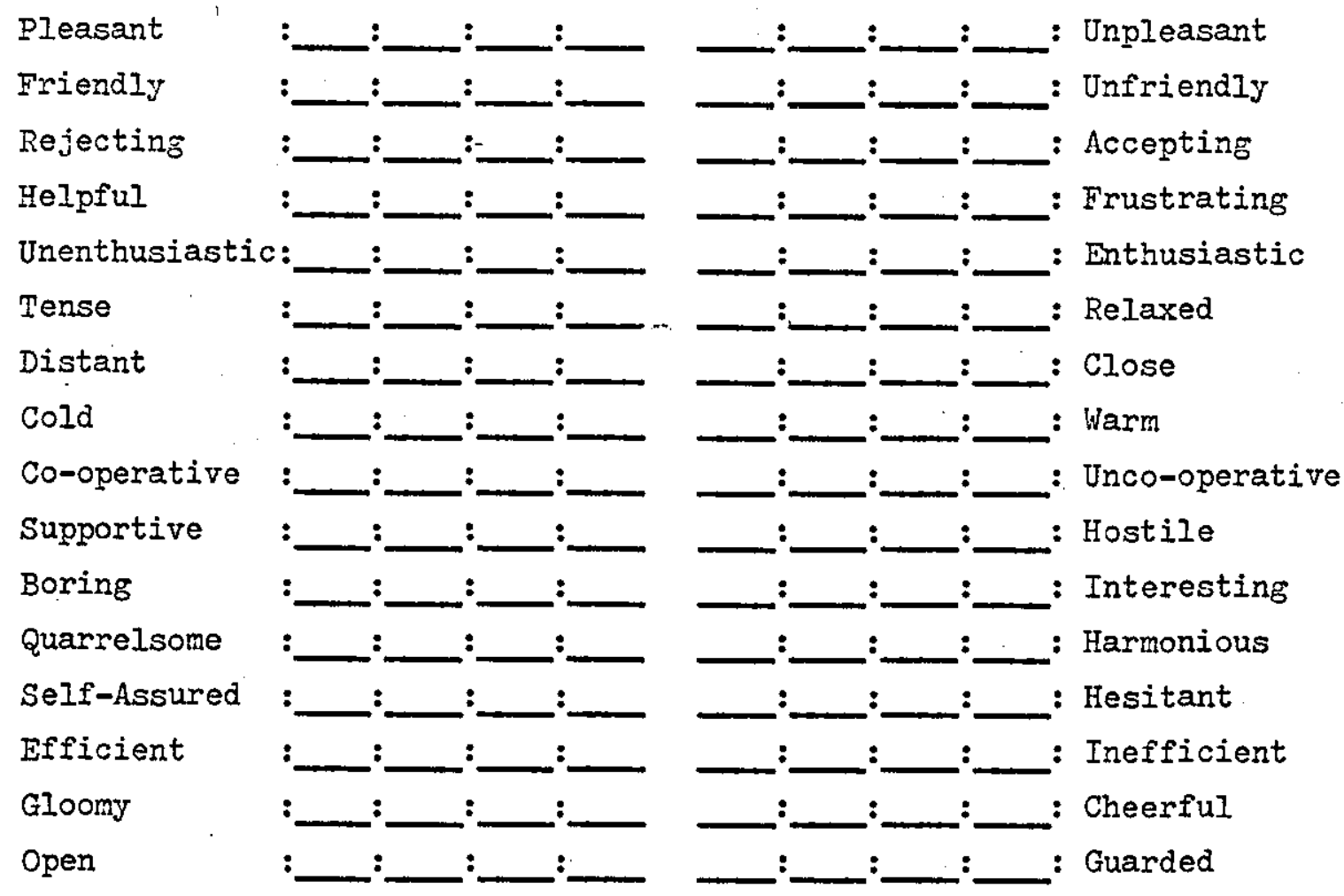


Now, think of the person with whom you can work least well. He may be someone you work with now, or he may be someone you knew in the past.

He does not have to be the person you like least well, but should be the person with whom you had the most difficulty in getting a job done. Describe this person as he appears to you.

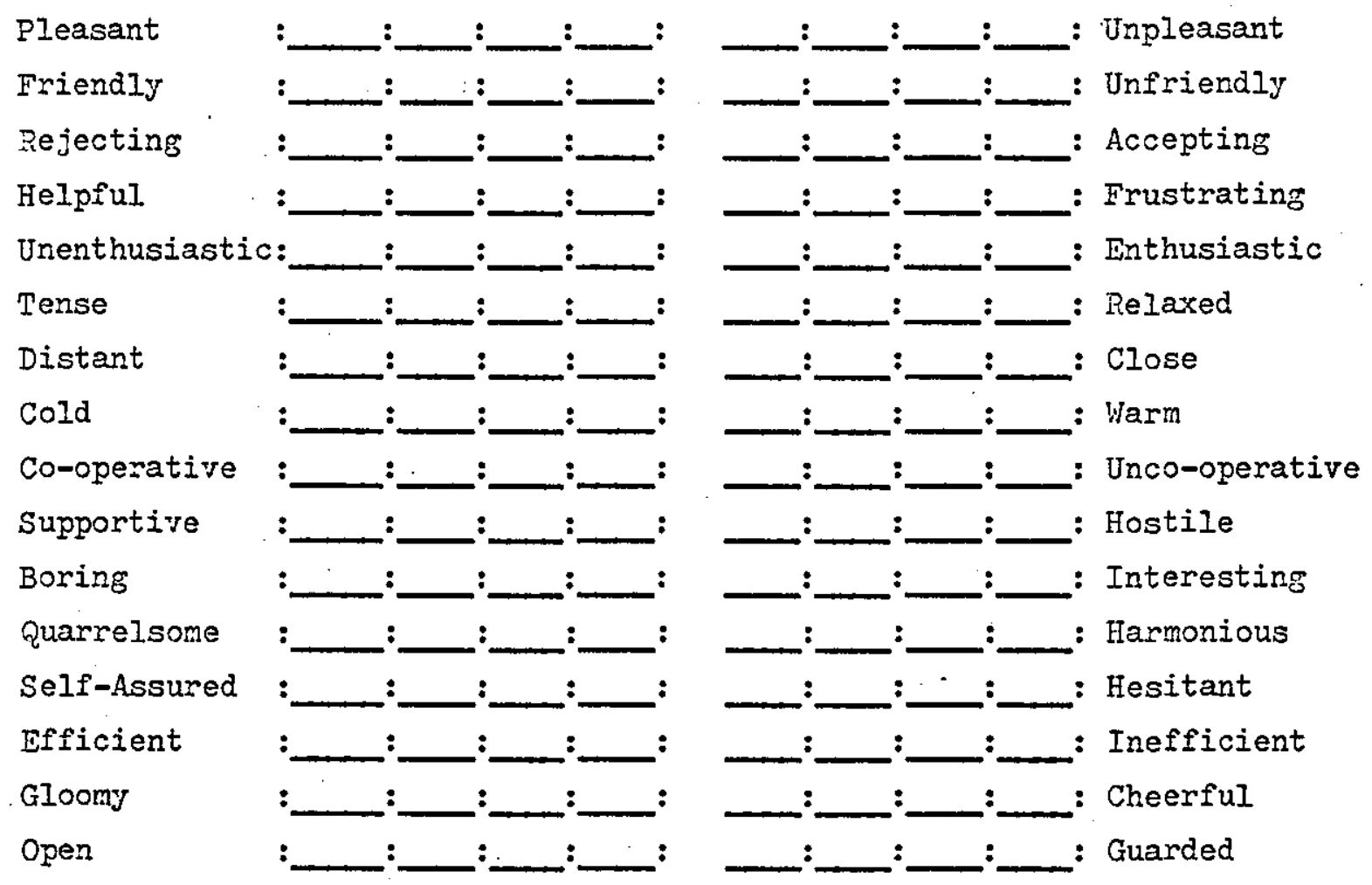

Group Atmosphere Scale

Describe the atmosphere of your group by checking the following items.

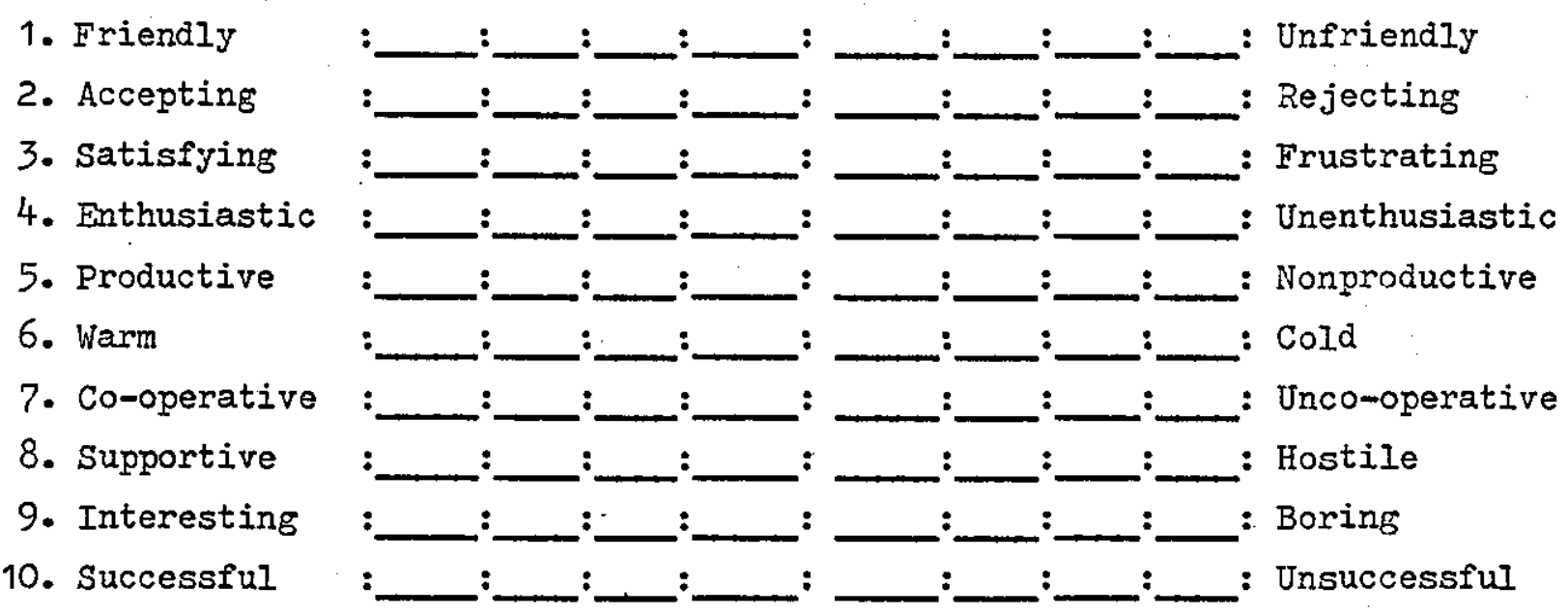


APPENDIX III: (i) Summary of Game Behaviour, by subject (males).

\begin{tabular}{|c|c|c|c|c|c|}
\hline \multirow{2}{*}{ Subjects } & \multicolumn{4}{|c|}{ Propensity to change strategy } & \multirow{2}{*}{ 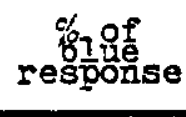 } \\
\hline & $\alpha$ & $\beta$ & $\gamma$ & $\delta$ & \\
\hline $\begin{array}{l}1 \\
2 \\
3 \\
4 \\
5\end{array}$ & $\begin{array}{l}.391 \\
.429 \\
.482 \\
.75 \\
.5\end{array}$ & $\begin{array}{l}.696 \\
.25 \\
.217 \\
0 \\
.56\end{array}$ & $\begin{array}{l}.583 \\
.02 \\
.32 \\
.328 \\
.448\end{array}$ & $\begin{array}{l}.367 \\
.05 \\
.4 \\
0 \\
.321\end{array}$ & $\begin{array}{l}54 \\
89 \\
50 \\
95 \\
57\end{array}$ \\
\hline $\begin{array}{r}6 \\
7 \\
8 \\
9 \\
10\end{array}$ & $\begin{array}{l}.355 \\
0 \\
.8 \\
.391 \\
.682\end{array}$ & $\begin{array}{l}.391 \\
0 \\
.5 \\
.759 \\
.25\end{array}$ & $\begin{array}{c}.25 \\
0 . \\
.189 \\
.821 \\
.261\end{array}$ & $\begin{array}{l}.682 \\
0 \\
.1 \\
.4 \\
.359\end{array}$ & $\begin{array}{r}46 \\
100 \\
76 \\
48 \\
62\end{array}$ \\
\hline $\begin{array}{l}11 \\
12 \\
13 \\
14 \\
15 .\end{array}$ & $\begin{array}{c}.56 \\
.81 \\
1 \\
.348 \\
.926\end{array}$ & $\begin{array}{c}.5 \\
1 \\
.933 \\
.963 \\
1\end{array}$ & $\begin{array}{r}.419 \\
.162 \\
.742 \\
.964 \\
1\end{array}$ & $\begin{array}{r}.321 \\
.875 \\
.552 \\
.273 \\
.941\end{array}$ & $\begin{array}{l}59 \\
67 \\
60 \\
50 \\
49\end{array}$ \\
\hline $\begin{array}{l}16 \\
17 \\
18 \\
19 \\
20\end{array}$ & $\begin{array}{l}.4 \\
.563 \\
.889 \\
.36 \\
.357\end{array}$ & $\begin{array}{l}.706 \\
.546 \\
.6 \\
.5 \\
.739\end{array}$ & $\begin{array}{l}.425 \\
.238 \\
.08 \\
.18 \\
.571\end{array}$ & $\begin{array}{l}.13 \\
.129 \\
.323 \\
.556 \\
.536\end{array}$ & $\begin{array}{l}63 \\
73 \\
81 \\
57 \\
49\end{array}$ \\
\hline $\begin{array}{l}21 \\
22 \\
23 \\
24 \\
25\end{array}$ & $\begin{array}{l}.375 \\
.579 \\
.464 \\
.222 \\
.611\end{array}$ & $\begin{array}{c}.588 \\
.059 \\
.12 \\
0 \\
.9\end{array}$ & $\begin{array}{l}.205 \\
.051 \\
.208 \\
0 \\
.533\end{array}$ & $\begin{array}{l}.25 \\
.44 \\
.478 \\
.073 \\
.406\end{array}$ & $\begin{array}{l}67 \\
64 \\
47 \\
83 \\
62\end{array}$ \\
\hline $\begin{array}{l}26 \\
27 \\
28 \\
29 \\
30\end{array}$ & $\begin{array}{l}.6 \\
.833 \\
.316 \\
.444 \\
.55\end{array}$ & $\begin{array}{l}.5 \\
.556 \\
.294 \\
.5 \\
.625\end{array}$ & $\begin{array}{l}.359 \\
.286 \\
.273 \\
.098 \\
.13\end{array}$ & $\begin{array}{l}.222 \\
0 \\
.44 \\
.094 \\
.385\end{array}$ & $\begin{array}{l}66 \\
79 \\
47 \\
83 \\
72\end{array}$ \\
\hline $\begin{array}{l}31 \\
32 \\
33 \\
34 \\
35\end{array}$ & $\begin{array}{l}.177 \\
.5 \\
.526 \\
.348 \\
.731\end{array}$ & $\begin{array}{r}.097 \\
.375 \\
.714 \\
.333 \\
.588\end{array}$ & $\begin{array}{l}.833 \\
.119 \\
.061 \\
.233 \\
.482\end{array}$ & $\begin{array}{l}.5 \\
.385 \\
.44 \\
.276 \\
.533\end{array}$ & $\begin{array}{l}18 \\
68 \\
74 \\
59 \\
57\end{array}$ \\
\hline $\begin{array}{l}36 \\
37 \\
38 \\
39 \\
40\end{array}$ & $\begin{array}{l}.444 \\
.615 \\
.5 \\
.4 \\
.2\end{array}$ & $\begin{array}{l}.2 \\
.615 \\
.769 \\
0 \\
.385\end{array}$ & $\begin{array}{l}.096 \\
.296 \\
.191 \\
.019 \\
.079\end{array}$ & $\begin{array}{l}.035 \\
.1 \\
.2 \\
.024 \\
.077\end{array}$ & $\begin{array}{l}81 \\
74 \\
77 \\
95 \\
77\end{array}$ \\
\hline
\end{tabular}


APPENDIX III: (ii) Summary of Game Behaviour, by subject (females)

\begin{tabular}{|c|c|c|c|c|c|}
\hline \multirow{2}{*}{ Subjects } & \multicolumn{4}{|c|}{ Propensity to change strategy } & \multirow{2}{*}{$\begin{array}{c}\text { \% of } \\
\text { b1 ữ } \\
\text { response }\end{array}$} \\
\hline & $\alpha$ & $\beta$ & $\bar{x}$ & $\delta$ & \\
\hline $\begin{array}{l}1 \\
2 \\
3 \\
4 \\
5\end{array}$ & $\begin{array}{l}.958 \\
.467 \\
.303 \\
.37 \\
.217\end{array}$ & $\begin{array}{c}1 \\
.28 \\
.238 \\
.655 \\
.154\end{array}$ & $\begin{array}{l}.742 \\
.389 \\
.261 \\
.87 \\
.227\end{array}$ & $\begin{array}{r}.586 \\
.556 \\
.391 \\
.476 \\
.048\end{array}$ & $\begin{array}{l}60 \\
45 \\
46 \\
44 \\
64\end{array}$ \\
\hline $\begin{array}{r}6 \\
7 \\
8 \\
9 \\
10\end{array}$ & $\begin{array}{c}.875 \\
0 \\
1 \\
.325 \\
.235\end{array}$ & $\begin{array}{l}1 \\
.333 \\
1 \\
.29 \\
.1\end{array}$ & $\begin{array}{l}.212 \\
0 \\
0 \\
.75 \\
.026\end{array}$ & $\begin{array}{l}.059 \\
0 \\
.106 \\
.706 \\
.24\end{array}$ & $\begin{array}{l}86 \\
97 \\
95 \\
29 \\
63\end{array}$ \\
\hline $\begin{array}{l}11 \\
12 \\
13 \\
14 \\
15\end{array}$ & $\begin{array}{l}.576 \\
.407 \\
.46 \\
.968 \\
1\end{array}$ & $\begin{array}{l}.857 \\
.436 \\
.269 \\
1 \\
0\end{array}$ & $\begin{array}{c}.963 \\
.688 \\
.727 \\
.909 \\
0\end{array}$ & $\begin{array}{r}.579 \\
.944 \\
.533 \\
.1 \\
.026\end{array}$ & $\begin{array}{l}46 \\
34 \\
37 \\
51 \\
99\end{array}$ \\
\hline $\begin{array}{l}16 \\
17 \\
18 \\
19 \\
20\end{array}$ & $\begin{array}{l}.094 \\
.72 \\
.5 \\
.296 \\
.583\end{array}$ & $\begin{array}{l}.081 \\
.81 \\
.231 \\
.367 \\
.65\end{array}$ & $\begin{array}{l}.667 \\
.731 \\
.023 \\
.546 \\
.655\end{array}$ & $\begin{array}{l}.857 \\
.571 \\
.321 \\
.381 \\
.296\end{array}$ & $\begin{array}{l}10 \\
54 \\
71 \\
43 \\
56\end{array}$ \\
\hline $\begin{array}{l}21 \\
22 \\
23 \\
24 \\
25\end{array}$ & $\begin{array}{l}.818 \\
.571 \\
0 \\
.387 \\
.556\end{array}$ & $\begin{array}{c}.667 \\
.688 \\
0 \\
.368 \\
.571\end{array}$ & $\begin{array}{l}0 \\
.406 \\
0 \\
.393 \\
.064\end{array}$ & $\begin{array}{c}.278 \\
.625 \\
0 \\
.364 \\
.333\end{array}$ & $\begin{array}{r}86 \\
56 \\
100 \\
50 \\
77\end{array}$ \\
\hline $\begin{array}{l}26 \\
27 \\
28 \\
29 \\
30\end{array}$ & $\begin{array}{l}.65 \\
.382 \\
.667 \\
.579 \\
.44\end{array}$ & $\begin{array}{l}.846 \\
.571 \\
1 \\
.591 \\
.8\end{array}$ & $\begin{array}{l}.395 \\
.781 \\
.076 \\
.406 \\
.76\end{array}$ & $\begin{array}{l}.276 \\
.737 \\
.29 \\
.444 \\
.48\end{array}$ & $\begin{array}{l}67 \\
38 \\
84 \\
59 \\
50\end{array}$ \\
\hline $\begin{array}{l}31 \\
32 \\
33 \\
34 \\
35\end{array}$ & $\begin{array}{l}.405 \\
.625 \\
.345 \\
.526 \\
.391\end{array}$ & $\begin{array}{l}.318 \\
0 \\
.259 \\
.524 \\
.125\end{array}$ & $\begin{array}{l}.8 \\
0 \\
.5 \\
.382 \\
.235\end{array}$ & $\begin{array}{l}.286 \\
.333 \\
.346 \\
.346 \\
.074\end{array}$ & $\begin{array}{l}41 \\
77 \\
44 \\
61 \\
61\end{array}$ \\
\hline $\begin{array}{l}36 \\
37 \\
38 \\
39 \\
40\end{array}$ & $\begin{array}{l}.413 \\
0 \\
.8 \\
.607 \\
.188\end{array}$ & $\begin{array}{l}.107 \\
1 \\
.31 \\
.429 \\
.52\end{array}$ & $\begin{array}{c}.812 \\
0 \\
.188 \\
.235 \\
.55\end{array}$ & $\begin{array}{l}.9 \\
.061 \\
.438 \\
.625 \\
.304\end{array}$ & $\begin{array}{l}26 \\
47 \\
64 \\
58 \\
43\end{array}$ \\
\hline $\begin{array}{l}41 \\
42 \\
43 \\
44 \\
45\end{array}$ & $\begin{array}{l}.875 \\
.714 \\
.385 \\
.5 \\
.476\end{array}$ & $\begin{array}{l}.813 \\
.583 \\
.5 \\
.8 \\
.308\end{array}$ & $\begin{array}{l}.243 \\
.044 \\
.353 \\
.441 \\
.321\end{array}$ & $\begin{array}{l}.548 \\
.571 \\
.135 \\
.37 \\
.36\end{array}$ & $\begin{array}{l}68 \\
74 \\
71 \\
61 \\
53\end{array}$ \\
\hline
\end{tabular}


APPENDIX IV: (i) Blue Response over Trial Series, by subject (males)

\begin{tabular}{|c|c|c|c|c|c|c|c|c|c|c|}
\hline Subjects & \multicolumn{10}{|c|}{$\frac{\text { Trials }}{1-50 / 51-60}$} \\
\hline $\begin{array}{l}1 \\
2 \\
3 \\
4 \\
5\end{array}$ & $\begin{array}{l}4 \\
3 \\
6 \\
5 \\
2\end{array}$ & $\begin{array}{r}8 \\
6 \\
3 \\
10 \\
3\end{array}$ & $\begin{array}{r}4 \\
10 \\
5 \\
10 \\
6\end{array}$ & $\begin{array}{r}3 \\
10 \\
5 \\
10 \\
7\end{array}$ & $\begin{array}{r}5 \\
10 \\
3 \\
10 \\
8\end{array}$ & $\begin{array}{r}5 \\
10 \\
2 \\
10 \\
4\end{array}$ & $\begin{array}{r}5 \\
10 \\
3 \\
10 \\
5\end{array}$ & $\begin{array}{r}3 \\
10 \\
7 \\
10 \\
5\end{array}$ & $\begin{array}{r}8 \\
10 \\
7 \\
10 \\
7\end{array}$ & $\begin{array}{r}9 \\
10 \\
9 \\
10 \\
9\end{array}$ \\
\hline $\begin{array}{r}6 \\
7 \\
8 \\
9 \\
10\end{array}$ & $\begin{array}{r}7 \\
10 \\
6 \\
5 \\
6\end{array}$ & $\begin{array}{r}4 \\
10 \\
6 \\
4 \\
6\end{array}$ & $\begin{array}{r}3 \\
10 \\
5 \\
5 \\
8\end{array}$ & $\begin{array}{r}4 \\
10 \\
10 \\
4 \\
4\end{array}$ & $\begin{array}{c}3 \\
10 \\
6 \\
7 \\
8\end{array}$ & $\begin{array}{r}4 \\
10 \\
7 \\
6 \\
6\end{array}$ & $\begin{array}{r}5 \\
10 \\
8 \\
4 \\
3\end{array}$ & $\begin{array}{r}6 \\
10 \\
10 \\
5 \\
7\end{array}$ & $\begin{array}{r}7 \\
10 \\
10 \\
4 \\
4\end{array}$ & $\begin{array}{r}3 \\
10 \\
8 \\
4 \\
5\end{array}$ \\
\hline $\begin{array}{l}11 \\
12 \\
13 \\
14 \\
15\end{array}$ & $\begin{array}{l}4 \\
3 \\
5 \\
4 \\
4\end{array}$ & $\begin{array}{l}3 \\
5 \\
7 \\
4 \\
5\end{array}$ & $\begin{array}{l}6 \\
7 \\
6 \\
5 \\
5\end{array}$ & $\begin{array}{l}6 \\
7 \\
6 \\
6 \\
5\end{array}$ & $\begin{array}{l}7 \\
6 \\
7 \\
3 \\
5\end{array}$ & $\begin{array}{l}7 \\
9 \\
6 \\
5 \\
5\end{array}$ & $\begin{array}{l}2 \\
7 \\
5 \\
5 \\
5\end{array}$ & $\begin{array}{l}6 \\
8 \\
6 \\
7 \\
5\end{array}$ & $\begin{array}{l}8 \\
6 \\
7 \\
5 \\
5\end{array}$ & $\begin{array}{r}10 \\
10 \\
5 \\
6 \\
5\end{array}$ \\
\hline $\begin{array}{l}16 \\
17 \\
18 \\
19 \\
20\end{array}$ & $\begin{array}{l}7 \\
4 \\
8 \\
2 \\
4\end{array}$ & $\begin{array}{l}9 \\
7 \\
8 \\
7 \\
5\end{array}$ & $\begin{array}{l}6 \\
8 \\
9 \\
2 \\
4\end{array}$ & $\begin{array}{l}4 \\
6 \\
9 \\
3 \\
5\end{array}$ & $\begin{array}{l}5 \\
7 \\
8 \\
6 \\
5\end{array}$ & $\begin{array}{r}7 \\
10 \\
8 \\
6 \\
6\end{array}$ & $\begin{array}{l}5 \\
7 \\
8 \\
5 \\
4\end{array}$ & $\begin{array}{l}7 \\
7 \\
8 \\
8 \\
5\end{array}$ & $\begin{array}{l}9 \\
8 \\
7 \\
8 \\
5\end{array}$ & $\begin{array}{r}4 \\
9 \\
8 \\
10 \\
4\end{array}$ \\
\hline $\begin{array}{l}21 \\
22 \\
23 \\
24 \\
25\end{array}$ & $\begin{array}{r}3 \\
10 \\
7 \\
10 \\
6\end{array}$ & $\begin{array}{r}4 \\
7 \\
7 \\
10 \\
6\end{array}$ & $\begin{array}{r}7 \\
5 \\
8 \\
10 \\
5\end{array}$ & $\begin{array}{r}5 \\
5 \\
4 \\
10 \\
6\end{array}$ & $\begin{array}{r}5 \\
6 \\
3 \\
10 \\
5\end{array}$ & $\begin{array}{r}6 \\
7 \\
3 \\
10 \\
8\end{array}$ & $\begin{array}{r}7 \\
9 \\
4 \\
10 \\
6\end{array}$ & $\begin{array}{r}10 \\
9 \\
5 \\
3 \\
6\end{array}$ & $\begin{array}{r}10 \\
3 \\
2 \\
6 \\
4\end{array}$ & $\begin{array}{r}10 \\
3 \\
4 \\
6 \\
8\end{array}$ \\
\hline $\begin{array}{l}26 \\
27 \\
28 \\
29 \\
30\end{array}$ & $\begin{array}{l}5 \\
8 \\
7 \\
8 \\
8\end{array}$ & $\begin{array}{l}6 \\
9 \\
2 \\
7 \\
8\end{array}$ & $\begin{array}{r}7 \\
9 \\
3 \\
5 \\
10\end{array}$ & $\begin{array}{l}5 \\
7 \\
7 \\
5 \\
8\end{array}$ & $\begin{array}{r}5 \\
8 \\
3 \\
10 \\
6\end{array}$ & $\begin{array}{r}9 \\
9 \\
4 \\
10 \\
3\end{array}$ & $\begin{array}{r}5 \\
8 \\
3 \\
10 \\
7\end{array}$ & $\begin{array}{l}9 \\
5 \\
4 \\
9 \\
7\end{array}$ & $\begin{array}{l}8 \\
9 \\
6 \\
9 \\
8\end{array}$ & $\begin{array}{r}7 \\
8 \\
8 \\
10 \\
7\end{array}$ \\
\hline $\begin{array}{l}31 \\
32 \\
33 \\
34 \\
35\end{array}$ & $\begin{array}{r}0 \\
7 \\
3 \\
6 \\
-5\end{array}$ & $\begin{array}{r}1 \\
5 \\
8 \\
-i 1 \\
6\end{array}$ & $\begin{array}{l}0 \\
5 \\
7 \\
0 \\
3\end{array}$ & $\begin{array}{l}3 \\
5 \\
4 \\
6 \\
2\end{array}$ & $\begin{array}{l}1 \\
7 \\
7 \\
9 \\
6\end{array}$ & $\begin{array}{r}3 \\
10 \\
5 \\
8 \\
4\end{array}$ & $\begin{array}{r}1 \\
7 \\
10 \\
6 \\
5\end{array}$ & $\begin{array}{r}3 \\
5 \\
10 \\
8 \\
9\end{array}$ & $\begin{array}{r}2 \\
10 \\
10 \\
8 \\
9\end{array}$ & $\begin{array}{r}4 \\
7 \\
10 \\
7 \\
7\end{array}$ \\
\hline $\begin{array}{l}36 \\
37 \\
38 \\
39 \\
40\end{array}$ & $\begin{array}{l}7 \\
3 \\
8 \\
5 \\
0\end{array}$ & $\begin{array}{r}6 \\
5 \\
8 \\
10 \\
2\end{array}$ & $\begin{array}{r}9 \\
7 \\
8 \\
10 \\
8\end{array}$ & $\begin{array}{r}6 \\
10 \\
7 \\
10 \\
8\end{array}$ & $\begin{array}{r}9 \\
8 \\
8 \\
10 \\
9\end{array}$ & $\begin{array}{r}5 \\
10 \\
7 \\
10 \\
10\end{array}$ & $\begin{array}{r}9 \\
9 \\
6 \\
10 \\
10\end{array}$ & $\begin{array}{r}10 \\
7 \\
9 \\
10 \\
10\end{array}$ & $\begin{array}{r}10 \\
9 \\
6 \\
10 \\
10\end{array}$ & $\begin{array}{r}10 \\
6 \\
10 \\
10 \\
10\end{array}$ \\
\hline & & & & & & & & & & \\
\hline$x$ & 5.42 & 6 & 6.3 & 6.18 & 6.75 & 6.85 & 6.58 & 7.2 & 7.38 & 8 \\
\hline
\end{tabular}


APPEIDIX IV:( $i$ )Blue Pesponse over Trial Series, by subject (females)

\begin{tabular}{|c|c|c|c|c|c|c|c|c|c|c|}
\hline Subjects & $1-10$ & $11-20$ & $21-30$ & $31-40$ & $\frac{T r}{41-50}$ & $\frac{i a l s}{51-60}$ & & $71-80$ & & $91-100$ \\
\hline $\begin{array}{l}1 \\
2 \\
3 \\
4 \\
5\end{array}$ & $\begin{array}{l}7 \\
4 \\
6 \\
6 \\
2\end{array}$ & $\begin{array}{l}5 \\
4 \\
4 \\
6 \\
6\end{array}$ & $\begin{array}{r}6 \\
4 \\
4 \\
4 \\
10\end{array}$ & $\begin{array}{c}6 \\
1 \\
4 \\
4 \\
10\end{array}$ & $\begin{array}{l}5 \\
7 \\
2 \\
4 \\
6\end{array}$ & $\begin{array}{l}5 \\
6 \\
4 \\
4 \\
6\end{array}$ & $\begin{array}{l}6 \\
3 \\
6 \\
3 \\
6\end{array}$ & $\begin{array}{r}7 \\
7 \\
7 \\
4 \\
10\end{array}$ & $\begin{array}{l}7 \\
6 \\
6 \\
4 \\
8\end{array}$ & $\begin{array}{l}6 \\
3 \\
3 \\
5 \\
0\end{array}$ \\
\hline $\begin{array}{r}6 \\
7 \\
8 \\
9 \\
10\end{array}$ & $\begin{array}{r}6 \\
7 \\
10 \\
1 \\
7\end{array}$ & $\begin{array}{r}9 \\
10 \\
8 \\
1 \\
4\end{array}$ & $\begin{array}{r}10 \\
10 \\
10 \\
3 \\
2\end{array}$ & $\begin{array}{r}10 \\
10 \\
10 \\
2 \\
4\end{array}$ & $\begin{array}{r}9 \\
10 \\
10 \\
2 \\
8\end{array}$ & $\begin{array}{r}10 \\
10 \\
9 \\
2 \\
7\end{array}$ & $\begin{array}{r}7 \\
10 \\
9 \\
5 \\
10\end{array}$ & $\begin{array}{r}8 \\
10 \\
10 \\
5 \\
10\end{array}$ & $\begin{array}{r}8 \\
10 \\
9 \\
2 \\
5\end{array}$ & $\begin{array}{r}9 \\
10 \\
10 \\
5 \\
6\end{array}$ \\
\hline $\begin{array}{l}11 \\
12 \\
13 \\
14 \\
15\end{array}$ & $\begin{array}{l}5 \\
5 \\
5 \\
5 \\
9\end{array}$ & $\begin{array}{r}6 \\
3 \\
5 \\
5 \\
10\end{array}$ & $\begin{array}{r}4 \\
3 \\
6 \\
5 \\
10\end{array}$ & $\begin{array}{r}4 \\
4 \\
3 \\
5 \\
10\end{array}$ & $\begin{array}{r}5 \\
4 \\
2 \\
5 \\
10\end{array}$ & $\begin{array}{r}4 \\
1 \\
2 \\
5 \\
10\end{array}$ & $\begin{array}{r}5 \\
3 \\
3 \\
5 \\
10\end{array}$ & $\begin{array}{r}4 \\
5 \\
5 \\
5 \\
10\end{array}$ & $\begin{array}{r}4 \\
3 \\
1 \\
5 \\
10\end{array}$ & $\begin{array}{r}4 \\
4 \\
5 \\
6 \\
10\end{array}$ \\
\hline $\begin{array}{l}16 \\
17 \\
18 \\
19 \\
20\end{array}$ & $\begin{array}{l}2 \\
5 \\
4 \\
6 \\
6\end{array}$ & $\begin{array}{l}2 \\
5 \\
8 \\
6 \\
5\end{array}$ & $\begin{array}{l}0 \\
6 \\
7 \\
1 \\
4\end{array}$ & $\begin{array}{r}0 \\
6 \\
10 \\
4 \\
5\end{array}$ & $\begin{array}{l}2 \\
5 \\
5 \\
3 \\
3\end{array}$ & $\begin{array}{l}2 \\
3 \\
4 \\
5 \\
7\end{array}$ & $\begin{array}{l}1 \\
6 \\
7 \\
5 \\
6\end{array}$ & $\begin{array}{l}0 \\
5 \\
8 \\
3 \\
7\end{array}$ & $\begin{array}{l}1 \\
7 \\
9 \\
5 \\
8\end{array}$ & $\begin{array}{l}0 \\
6 \\
9 \\
5 \\
5\end{array}$ \\
\hline $\begin{array}{l}21 \\
22 \\
23 \\
24 \\
25\end{array}$ & $\begin{array}{r}9 \\
6 \\
10 \\
7 \\
8\end{array}$ & $\begin{array}{r}10 \\
7 \\
10 \\
5 \\
6\end{array}$ & $\begin{array}{r}9 \\
4 \\
10 \\
3 \\
6\end{array}$ & $\begin{array}{r}8 \\
5 \\
10 \\
5 \\
6\end{array}$ & $\begin{array}{r}8 \\
5 \\
10 \\
7 \\
8\end{array}$ & $\begin{array}{r}10 \\
5 \\
10 \\
4 \\
9\end{array}$ & $\begin{array}{r}9 \\
7 \\
10 \\
5 \\
7\end{array}$ & $\begin{array}{r}8 \\
5 \\
10 \\
3 \\
9\end{array}$ & $\begin{array}{r}8 \\
8 \\
10 \\
6 \\
8\end{array}$ & $\begin{array}{c}7 \\
5 \\
10 \\
6 \\
10\end{array}$ \\
\hline $\begin{array}{l}26 \\
27 \\
28 \\
29 \\
30\end{array}$ & $\begin{array}{l}7 \\
2 \\
9 \\
7 \\
5\end{array}$ & $\begin{array}{l}6 \\
3 \\
8 \\
5 \\
5\end{array}$ & $\begin{array}{l}5 \\
5 \\
7 \\
8 \\
5\end{array}$ & $\begin{array}{l}7 \\
6 \\
7 \\
6 \\
5\end{array}$ & $\begin{array}{r}5 \\
4 \\
10 \\
7 \\
5\end{array}$ & $\begin{array}{l}6 \\
4 \\
8 \\
5 \\
6\end{array}$ & $\begin{array}{l}8 \\
3 \\
9 \\
7 \\
3\end{array}$ & $\begin{array}{l}7 \\
3 \\
9 \\
4 \\
5\end{array}$ & $\begin{array}{l}8 \\
3 \\
9 \\
7 \\
7\end{array}$ & $\begin{array}{l}8 \\
3 \\
8 \\
3 \\
4\end{array}$ \\
\hline $\begin{array}{l}31 \\
32 \\
33 \\
34 \\
35\end{array}$ & $\begin{array}{l}7 \\
7 \\
7 \\
6 \\
7\end{array}$ & $\begin{array}{l}4 \\
6 \\
7 \\
7 \\
5\end{array}$ & $\begin{array}{l}3 \\
9 \\
1 \\
2 \\
3\end{array}$ & $\begin{array}{r}4 \\
8 \\
2 \\
6 \\
3\end{array}$ & $\begin{array}{l}3 \\
7 \\
4 \\
7 \\
5\end{array}$ & $\begin{array}{l}4 \\
6 \\
4 \\
8 \\
3\end{array}$ & $\begin{array}{r}4 \\
10 \\
6 \\
6 \\
6\end{array}$ & $\begin{array}{l}4 \\
6 \\
4 \\
7 \\
9\end{array}$ & $\begin{array}{r}4 \\
8 \\
6 \\
5 \\
10\end{array}$ & $\begin{array}{r}4 \\
10 \\
5 \\
5 \\
10\end{array}$ \\
\hline $\begin{array}{l}36 \\
37 \\
38 \\
39 \\
40\end{array}$ & $\begin{array}{r}4 \\
10 \\
6 \\
6 \\
4\end{array}$ & $\begin{array}{l}4 \\
9 \\
4 \\
6 \\
3\end{array}$ & $\begin{array}{r}1 \\
10 \\
5 \\
4 \\
5\end{array}$ & $\begin{array}{l}1 \\
9 \\
6 \\
8 \\
5\end{array}$ & $\begin{array}{r}3 \\
10 \\
6 \\
7 \\
2\end{array}$ & $\begin{array}{r}3 \\
10 \\
8 \\
7 \\
4\end{array}$ & $\begin{array}{r}3 \\
10 \\
6 \\
5 \\
6\end{array}$ & $\begin{array}{r}3 \\
10 \\
7 \\
5 \\
4\end{array}$ & $\begin{array}{l}2 \\
9 \\
8 \\
6 \\
1\end{array}$ & $\begin{array}{r}2 \\
10 \\
8 \\
4 \\
9\end{array}$ \\
\hline $\begin{array}{l}41 \\
42 \\
43 \\
44 \\
45\end{array}$ & $\begin{array}{l}6 \\
6 \\
7 \\
8 \\
6\end{array}$ & $\begin{array}{l}5 \\
4 \\
8 \\
8 \\
2\end{array}$ & $\begin{array}{l}7 \\
7 \\
8 \\
6 \\
4\end{array}$ & $\begin{array}{l}5 \\
9 \\
6 \\
8 \\
3\end{array}$ & $\begin{array}{l}9 \\
7 \\
9 \\
5 \\
3\end{array}$ & $\begin{array}{l}7 \\
7 \\
7 \\
6 \\
5\end{array}$ & $\begin{array}{l}8 \\
9 \\
7 \\
4 \\
7\end{array}$ & $\begin{array}{r}5 \\
9 \\
10 \\
6 \\
8\end{array}$ & $\begin{array}{l}9 \\
9 \\
3 \\
5 \\
5\end{array}$ & $\begin{array}{r}8 \\
7 \\
6 \\
5 \\
10\end{array}$ \\
\hline$x$ & 6.07 & 5.75 & 5.47 & 5.78 & 5.84 & 5.82 & 6.24 & 6.5 & 6.26 & 6.2 \\
\hline
\end{tabular}


APPENDIX V: (i) Leadership Nominations, by subject (males)

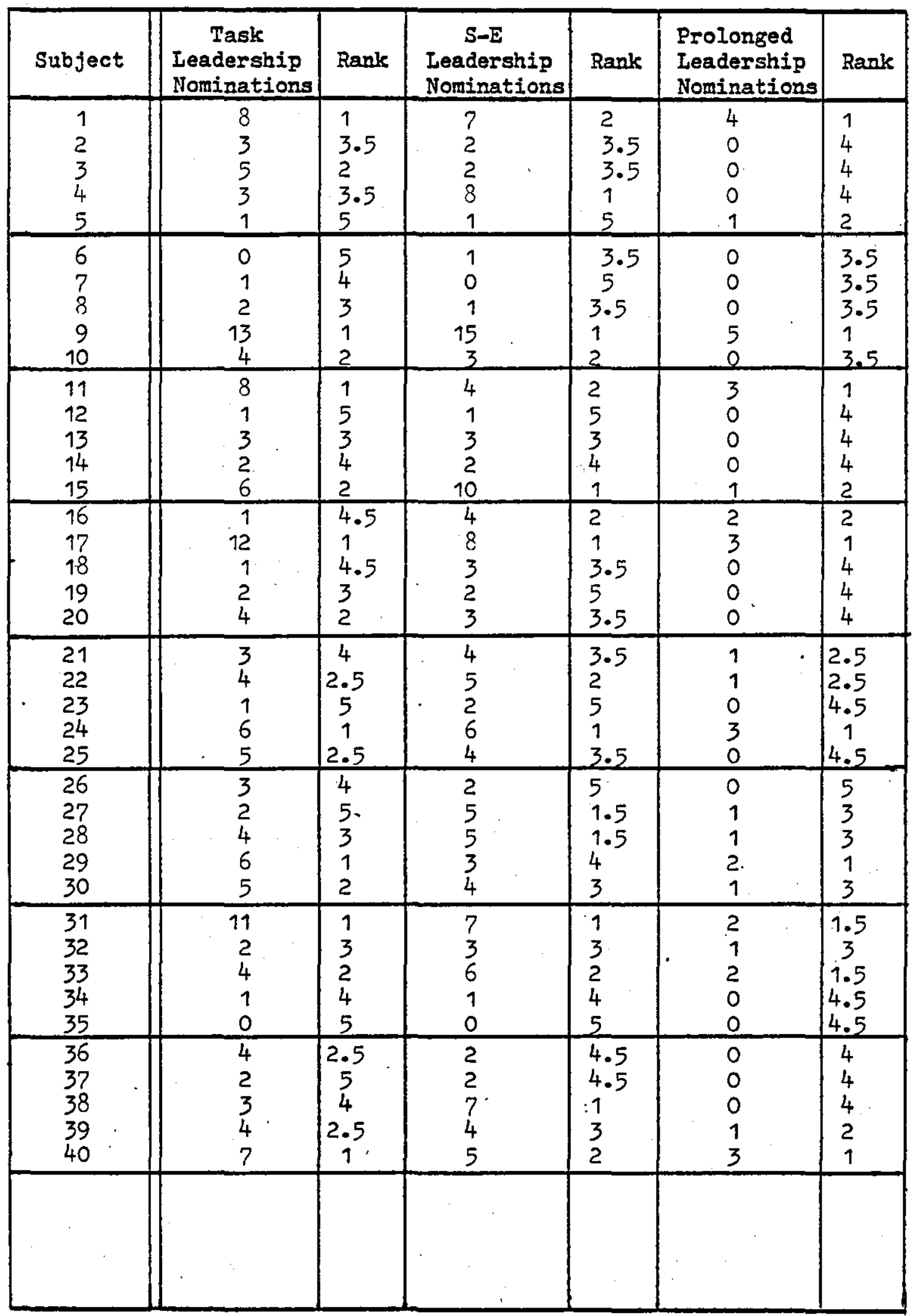


APPENDIX V: (ii) Leadership Nominations, by subject (females)

\begin{tabular}{|c|c|c|c|c|c|c|}
\hline Subject & $\begin{array}{l}\quad \text { Task } \\
\text { Leadership } \\
\text { Nominations }\end{array}$ & Rank & $\begin{array}{l}\quad \text { S-E } \\
\text { Leadership } \\
\text { Nominations }\end{array}$ & Rank & $\begin{array}{l}\text { Prolonged } \\
\text { Leadership } \\
\text { Nominations }\end{array}$ & Rank \\
\hline $\begin{array}{l}1 \\
2 \\
3 \\
4 \\
5\end{array}$ & $\begin{array}{r}0 \\
2 \\
1 \\
10 \\
6\end{array}$ & $\begin{array}{l}5 \\
3 \\
4 \\
1 \\
2\end{array}$ & $\begin{array}{l}1 \\
1 \\
5 \\
5 \\
7\end{array}$ & $\begin{array}{l}4.5 \\
4.5 \\
2.5 \\
2.5 \\
1\end{array}$ & $\begin{array}{l}0 \\
0 \\
1 \\
3 \\
1\end{array}$ & $\begin{array}{l}4.5 \\
4.5 \\
2.5 \\
1 \\
2.5\end{array}$ \\
\hline $\begin{array}{r}6 \\
7 \\
8 \\
9 \\
10\end{array}$ & $\begin{array}{l}7 \\
3 \\
7 \\
1 \\
1\end{array}$ & $\begin{array}{l}1.5 \\
3 \\
1.5 \\
4.5 \\
4.5\end{array}$ & $\begin{array}{l}7 \\
5 \\
5 \\
0 \\
1\end{array}$ & $\begin{array}{l}1 \\
2.5 \\
2.5 \\
5 \\
4\end{array}$ & $\begin{array}{l}0 \\
3 \\
2 \\
0 \\
0\end{array}$ & $\begin{array}{l}4 \\
1 \\
2 \\
4 \\
4\end{array}$ \\
\hline $\begin{array}{l}11 \\
12 \\
13 \\
14 \\
15\end{array}$ & $\begin{array}{l}4 \\
2 \\
0 \\
7 \\
7\end{array}$ & $\begin{array}{l}3 \\
4 \\
5 \\
1.5 \\
1.5\end{array}$ & $\begin{array}{l}3 \\
1 \\
1 \\
9 \\
3\end{array}$ & $\begin{array}{l}2.5 \\
4.5 \\
4.5 \\
1 \\
2.5\end{array}$ & $\begin{array}{l}0 \\
0 \\
0 \\
1 \\
4\end{array}$ & $\begin{array}{l}4 \\
4 \\
4 \\
2 \\
1\end{array}$ \\
\hline $\begin{array}{l}16 \\
17 \\
18 \\
19 \\
20\end{array}$ & $\begin{array}{l}4 \\
3 \\
3 \\
4 \\
6\end{array}$ & $\begin{array}{l}2.5 \\
4.5 \\
4.5 \\
2.5 \\
1\end{array}$ & $\begin{array}{l}2 \\
4 \\
7 \\
2 \\
4\end{array}$ & $\begin{array}{l}4.5 \\
2.5 \\
1 \\
4.5 \\
2.5\end{array}$ & $\begin{array}{l}2 \\
2 \\
0 \\
0 \\
1\end{array}$ & $\begin{array}{l}1.5 \\
1.5 \\
4.5 \\
4.5 \\
3\end{array}$ \\
\hline $\begin{array}{l}21 \\
22 \\
23 \\
24 \\
25\end{array}$ & $\begin{array}{l}2 \\
5 \\
3 \\
1 \\
3\end{array}$ & $\begin{array}{l}4 \\
1 \\
2.5 \\
5 \\
2.5\end{array}$ & $\begin{array}{l}3 \\
4 \\
2 \\
2 \\
3 \\
\end{array}$ & $\begin{array}{l}2.5 \\
1 \\
4.5 \\
4.5 \\
2.5 \\
\end{array}$ & $\begin{array}{l}1 \\
1 \\
0 \\
1 \\
1 \\
\end{array}$ & $\begin{array}{l}2.5 \\
2.5 \\
2.5 \\
5 \\
2.5 \\
\end{array}$ \\
\hline $\begin{array}{l}26 \\
27 \\
28 \\
29 \\
30\end{array}$ & $\begin{array}{l}2 \\
3 \\
3 \\
6 \\
6\end{array}$ & $\begin{array}{l}5 \\
3.5 \\
3.5 \\
1.5 \\
1.5\end{array}$ & $\begin{array}{l}2 \\
3 \\
3 \\
7 \\
5\end{array}$ & $\begin{array}{l}5 \\
3.5 \\
3.5 \\
1 \\
2\end{array}$ & $\begin{array}{l}0 \\
0 \\
1 \\
3 \\
1\end{array}$ & $\begin{array}{l}4.5 \\
4.5 \\
2.5 \\
1 . \\
2.5\end{array}$ \\
\hline $\begin{array}{l}31 \\
32 \\
33 \\
34 \\
35\end{array}$ & $\begin{array}{l}0 \\
5 \\
1 \\
7 \\
7\end{array}$ & $\begin{array}{l}5 \\
3 \\
4 \\
1.5 \\
1.5\end{array}$ & $\begin{array}{l}0 \\
6 \\
6 \\
5 \\
3\end{array}$ & $\begin{array}{l}5 \\
1.5 \\
1.5 \\
3 \\
4 \\
\end{array}$ & $\begin{array}{r}0 \\
1 \\
1 \\
1 \\
2 \\
1\end{array}$ & $\begin{array}{l}5 \\
3 \\
3 \\
1 \\
3\end{array}$ \\
\hline $\begin{array}{l}36 \\
37 \\
38 \\
39 \\
40\end{array}$ & $\begin{array}{l}0 \\
1 \\
4 \\
9 \\
5\end{array}$ & $\begin{array}{r}5 \\
\cdot 4 \\
3 \\
1 \\
2\end{array}$ & $\begin{array}{r}0 \\
6 \\
0 \\
10 \\
4\end{array}$ & $\begin{array}{l}4.5 \\
2 \\
4.5 \\
1 \\
3\end{array}$ & $\begin{array}{l}0 \\
1 \\
0 \\
4 \\
0\end{array}$ & $\begin{array}{l}4 \\
2 \\
4 \\
1 \\
4\end{array}$ \\
\hline $\begin{array}{l}41 \\
42 \\
43 \\
44 \\
45\end{array}$ & $\begin{array}{l}6 \\
2 \\
2 \\
7 \\
3\end{array}$ & $\begin{array}{l}2 \\
4.5 \\
4.5 \\
1 \\
3 \\
\end{array}$ & $\begin{array}{l}5 \\
3 \\
3 \\
4 \\
5\end{array}$ & $\begin{array}{l}1.5 \\
4.5 \\
4.5 \\
3 \\
1.5\end{array}$ & $\begin{array}{l}3 \\
0 \\
0 \\
1 \\
1\end{array}$ & $\begin{array}{c}1 \\
4.5 \\
-4.5 \\
2.5 \\
2.5\end{array}$ \\
\hline
\end{tabular}


APPENDIX.VI: Least Preferred Co-thorker Scores, by subject

\begin{tabular}{|c|c|c|c|c|c|}
\hline $\begin{array}{c}\text { Male } \\
\text { Subjects }\end{array}$ & $\begin{array}{c}\text { IPC } \\
\text { Score }\end{array}$ & Mean & $\begin{array}{c}\text { Female } \\
\text { Subjects }\end{array}$ & $\begin{array}{c}\text { IPC } \\
\text { Score }\end{array}$ & Mean \\
\hline $\begin{array}{l}1 \\
2 \\
3 \\
4 \\
5\end{array}$ & $\begin{array}{l}89 \\
63 \\
92 \\
27 \\
42\end{array}$ & $\begin{array}{l}5.56 \\
3.93 \\
5.75 \\
1.69 \\
2.63\end{array}$ & $\begin{array}{l}1 \\
2 \\
3 \\
4 \\
5\end{array}$ & $\begin{array}{r}79 \\
34 \\
100 \\
95 \\
57\end{array}$ & $\begin{array}{l}4.94 \\
2.13 \\
6.25 \\
5.94 \\
3.56\end{array}$ \\
\hline $\begin{array}{r}6 \\
7 \\
8 \\
9 \\
10\end{array}$ & $\begin{array}{l}84 \\
86 \\
74 \\
60 \\
73\end{array}$ & $\begin{array}{l}5.25 \\
5.38 \\
4.63 \\
3.75 \\
4.56\end{array}$ & $\begin{array}{r}6 \\
7 \\
8 \\
9 \\
10\end{array}$ & $\begin{array}{l}56 \\
74 \\
86 \\
72 \\
61\end{array}$ & $\begin{array}{l}3.5 \\
4.63 \\
5.38 \\
4.5 \\
3.81\end{array}$ \\
\hline $\begin{array}{l}11 \\
12 \\
13 \\
14 . \\
15\end{array}$ & $\begin{array}{l}84 \\
62 \\
56 \\
54 \\
47\end{array}$ & $\begin{array}{l}5.25 \\
3.88 \\
3.5 \\
3.38 \\
2.94\end{array}$ & $\begin{array}{l}11 \\
12 \\
13 \\
14 \\
15\end{array}$ & $\begin{array}{l}42 \\
68 \\
56 \\
21 \\
71\end{array}$ & $\begin{array}{l}2.63 \\
4.25 \\
3.5 \\
1.31 \\
4.44\end{array}$ \\
\hline $\begin{array}{r}16 \\
17 \\
18 \\
19 \\
\quad 20\end{array}$ & $\begin{array}{l}49 \\
43 \\
81 \\
34 \\
63\end{array}$ & $\begin{array}{l}3.06 \\
2.69 \\
5.06 \\
2.13 \\
3.94\end{array}$ & $\begin{array}{l}16 \\
17 \\
18 \\
19 \\
20\end{array}$ & $\begin{array}{l}46 \\
66 \\
80 \\
86 \\
20\end{array}$ & $\begin{array}{l}2.88 \\
4.13 \\
5 \\
5.38 \\
1.25\end{array}$ \\
\hline $\begin{array}{l}21 \\
22 \\
23 \\
24 \\
25\end{array}$ & $\begin{array}{l}27 \\
56 \\
71 \\
76 \\
49\end{array}$ & $\begin{array}{l}1.69 \\
3.5 \\
4.44 \\
4.75 \\
3.06\end{array}$ & $\begin{array}{l}21 \\
22 \\
23 \\
24 \\
25\end{array}$ & $\begin{array}{r}16 \\
77 \\
171 \\
48 \\
84\end{array}$ & $\begin{array}{l}1 \\
4.81 \\
6.94 \\
3 \\
5.25\end{array}$ \\
\hline $\begin{array}{l}26 \\
27 \\
28 \\
29 \\
30\end{array}$ & $\begin{array}{l}65 \\
55 \\
76 \\
72 \\
52\end{array}$ & $\begin{array}{l}4.06 \\
3.44 \\
4.75 \\
4.5 \\
3.25\end{array}$ & $\begin{array}{l}26 \\
27 \\
28 \\
29 \\
30\end{array}$ & $\begin{array}{l}69 \\
50 \\
55 \\
64 \\
76\end{array}$ & $\begin{array}{l}4.31 \\
3.13 \\
3.44 \\
4 \\
4.75\end{array}$ \\
\hline $\begin{array}{l}31 \\
32 \\
33 \\
34 \\
35\end{array}$ & $\begin{array}{l}84 \\
67 \\
89 \\
68 \\
60\end{array}$ & $\begin{array}{l}5.25 \\
4.19 \\
5.56 \\
4.25 \\
3.75\end{array}$ & $\begin{array}{l}31 \\
32 \\
33 \\
34 \\
35\end{array}$ & $\begin{array}{l}81 \\
61 \\
68 \\
85 \\
56\end{array}$ & $\begin{array}{l}5.06 \\
3.81 \\
4.25 \\
5.31 \\
3.5\end{array}$ \\
\hline $\begin{array}{l}36 \\
37 \\
38 \\
39 \\
40\end{array}$ & $\begin{array}{l}62 \\
94 \\
52 \\
53 \\
73\end{array}$ & $\begin{array}{l}3.88 \\
5.88 \\
3.25 \\
3.31 \\
4.56\end{array}$ & $\begin{array}{l}36 \\
37 \\
38 \\
39 \\
40\end{array}$ & $\begin{array}{l}44 \\
83 \\
26 \\
46 \\
34\end{array}$ & $\begin{array}{l}2.92 \\
5.19 \\
1.63 \\
2.88 \\
2.13\end{array}$ \\
\hline & & . & $\begin{array}{l}41 \\
42 \\
43 \\
44 \\
45\end{array}$ & $\begin{array}{l}36 \\
38 \\
30 \\
63 \\
64\end{array}$ & $\begin{array}{l}3.5 \\
2.38 \\
1.88 \\
3.94 \\
4\end{array}$ \\
\hline
\end{tabular}


APPENDIX VII: Participation Rate as Percentage of Group Total, by subject

\begin{tabular}{|c|c|c|c|c|c|}
\hline $\begin{array}{c}\text { Male } \\
\text { Subjects }\end{array}$ & Responses & $\begin{array}{c}\text { Percentage } \\
\text { of Group } \\
\text { Total }\end{array}$ & $\begin{array}{c}\text { Female } \\
\text { Subjects }\end{array}$ & Responses & $\begin{array}{c}\text { Percentage } \\
\text { of Group } \\
\text { Total }\end{array}$ \\
\hline $\begin{array}{r}1 \\
2 \\
3 \\
4 \\
5\end{array}$ & $\begin{array}{l}77 \\
34 \\
57 \\
54 \\
34\end{array}$ & $\begin{array}{l}30 \\
13 \\
22 \\
21 \\
13\end{array}$ & $\begin{array}{l}1 \\
2 \\
3 \\
4 \\
5\end{array}$ & $\begin{array}{l}47 \\
38 \\
45 \\
74 \\
94\end{array}$ & $\begin{array}{l}16 \\
13 \\
15 \\
25 \\
32\end{array}$ \\
\hline $\begin{array}{r}6 \\
7 \\
8 \\
9 \\
10 \\
\end{array}$ & $\begin{array}{r}43 \\
40 \\
50 \\
155 \\
50 \\
\end{array}$ & $\begin{array}{l}13 \\
12 \\
15 \\
46 \\
15 \\
\end{array}$ & $\begin{array}{r}6 \\
7 \\
8 \\
9 \\
10 \\
\end{array}$ & $\begin{array}{r}124 \\
116 \\
125 \\
58 \\
48 \\
\end{array}$ & $\begin{array}{l}26 \\
25 \\
27 \\
12 \\
10 \\
\end{array}$ \\
\hline $\begin{array}{l}11 \\
12 \\
13 \\
14 \\
15 \\
\end{array}$ & $\begin{array}{r}133 \\
93 \\
40 \\
108 \\
260 \\
\end{array}$ & $\begin{array}{r}21 \\
15 \\
6 \\
17 \\
41 \\
\end{array}$ & $\begin{array}{l}11 \\
12 \\
13 \\
14 \\
15 \\
\end{array}$ & $\begin{array}{l}66 \\
37 \\
29 \\
82 \\
77 \\
\end{array}$ & $\begin{array}{l}23 \\
13 \\
10 \\
28 \\
26\end{array}$ \\
\hline $\begin{array}{r}16 \\
17 \\
-18 \\
19 \\
20 \\
\end{array}$ & $\begin{array}{l}20 \\
86 \\
29 \\
25 \\
31\end{array}$ & $\begin{array}{l}10 \\
45 \\
15 \\
13 \\
16\end{array}$ & $\begin{array}{l}16 \\
17 \\
18 \\
19 \\
20\end{array}$ & $\begin{array}{r}72 \\
89 \\
64 \\
105 \\
74 \\
\end{array}$ & $\begin{array}{l}18 \\
22 \\
16 \\
26 \\
18\end{array}$ \\
\hline $\begin{array}{l}21 \\
22 \\
23 \\
24 \\
25\end{array}$ & $\begin{array}{r}116 \\
91 \\
77 \\
94 \\
-118\end{array}$ & $\begin{array}{r}23 \\
.18 \\
16 \\
19 \\
24\end{array}$ & $\begin{array}{l}21 \\
22 \\
23 \\
24 \\
25\end{array}$ & $\begin{array}{l}64 \\
42 \\
74 \\
84 \\
91\end{array}$ & $\begin{array}{l}18 \\
12 \\
21 \\
24 \\
26\end{array}$ \\
\hline $\begin{array}{l}26 \\
27 \\
28 \\
29 \\
30\end{array}$ & $\begin{array}{r}87 \\
155 \\
113 \\
123 \\
89 \\
\end{array}$ & $\begin{array}{l}15 \\
27 \\
20 \\
22 \\
16 \\
\end{array}$ & $\begin{array}{l}26 \\
27 \\
28 \\
29 \\
30\end{array}$ & $\begin{array}{r}59 \\
55 \\
53 \\
86 \\
114 \\
\end{array}$ & $\begin{array}{l}16 \\
15 \\
14 \\
23 \\
31\end{array}$ \\
\hline $\begin{array}{l}31 \\
32 \\
33 \\
34 \\
35\end{array}$ & $\begin{array}{r}153 \\
82 \\
95 \\
54 \\
74 \\
\end{array}$ & $\begin{array}{l}33 \\
18 \\
21 \\
12 \\
16 \\
\end{array}$ & $\begin{array}{l}31 \\
32 \\
33 \\
34 \\
35\end{array}$ & $\begin{array}{l}18 \\
79 \\
54 \\
66 \\
59\end{array}$ & $\begin{array}{r}7 \\
29 \\
20 \\
24 \\
21\end{array}$ \\
\hline $\begin{array}{l}36 \\
37 \\
38 \\
39 \\
40\end{array}$ & $\begin{array}{r}123 \\
96 \\
116 \\
82 \\
180\end{array}$ & $\begin{array}{l}21 \\
16 \\
19 \\
14 \\
30\end{array}$ & $\begin{array}{l}36 \\
37 \\
38 \\
39 \\
40\end{array}$ & $\begin{array}{l}22 \\
22 \\
29 \\
52 \\
31\end{array}$ & $\begin{array}{l}14 \\
14 \\
19 \\
33 \\
20\end{array}$ \\
\hline . & & & $\begin{array}{l}41 \\
42 \\
43 \\
44 \\
45\end{array}$ & $\begin{array}{r}107 \\
71 \\
33 \\
104 \\
83\end{array}$ & $\begin{array}{r}27 \\
18 \\
8 \\
26 \\
21\end{array}$ \\
\hline
\end{tabular}


APPEITDIX VIII: Comparison of Choice of Strategy, by sex

\begin{tabular}{|c|c|c|c|c|c|c|c|c|c|}
\hline $\begin{array}{c}\text { Female } \\
\text { Subjects }\end{array}$ & \begin{tabular}{|c|} 
Blue \\
Respons
\end{tabular} & eRank & $\begin{array}{c}\text { Female } \\
\text { Subjects }\end{array}$ & $\begin{array}{l}\text { Blue } \\
\text { Respons }\end{array}$ & eRank & $\begin{array}{c}\text { Male } \\
\text { Subjects }\end{array}$ & $\begin{array}{c}\text { Blue } \\
\text { Respons }\end{array}$ & $\begin{array}{c}\text { Kale } \\
\text { Subjects }\end{array}$ & $\begin{array}{l}\text { Biue } \\
\text { Respon }\end{array}$ \\
\hline $\begin{array}{l}1 \\
2 \\
3 \\
4 \\
5\end{array}$ & $\begin{array}{l}60 \\
45 \\
46 \\
44 \\
64\end{array}$ & $\begin{array}{l}40 \\
13 \\
15 \\
11 \\
49\end{array}$ & $\begin{array}{l}25 \\
27 \\
28 \\
29 \\
30\end{array}$ & $\begin{array}{l}67 \\
38 \\
84 \\
59 \\
50\end{array}$ & $\begin{array}{c}53 \\
7 \\
74 \\
37 \\
23.5\end{array}$ & $\begin{array}{l}1 \\
2 \\
3 \\
4 \\
5\end{array}$ & $\begin{array}{l}54 \\
89 \\
50 \\
95 \\
57\end{array}$ & $\begin{array}{l}21 \\
22 \\
23 \\
24 \\
25\end{array}$ & $\begin{array}{l}67 \\
64 \\
47 \\
83 \\
62\end{array}$ \\
\hline $\begin{array}{r}6 \\
7 \\
8 \\
9 \\
10\end{array}$ & $\begin{array}{l}36 \\
97 \\
95 \\
29 \\
63\end{array}$ & $\begin{array}{c}75 \\
81 \\
79 \\
4 \\
46.5\end{array}$ & $\begin{array}{l}31 \\
32 \\
33 \\
34 \\
35\end{array}$ & $\begin{array}{l}41 \\
77 \\
44 \\
60 \\
61\end{array}$ & $\begin{array}{l}8 \\
66.5 \\
12 \\
40 \\
43\end{array}$ & $\begin{array}{r}6 \\
7 \\
8 \\
9 \\
10\end{array}$ & $\begin{array}{r}46 \\
100 \\
76 \\
48 \\
62\end{array}$ & $\begin{array}{l}26 \\
27 \\
28 \\
29 \\
30\end{array}$ & $\begin{array}{l}66 \\
79 \\
47 \\
83 \\
72\end{array}$ \\
\hline $\begin{array}{l}11 \\
12 \\
13 \\
14 \\
15\end{array}$ & $\begin{array}{l}46 \\
34 \\
37 \\
51 \\
99\end{array}$ & $\begin{array}{r}15 \\
5 \\
6 \\
26 \\
83\end{array}$ & $\begin{array}{l}36 \\
37 \\
38 \\
39 \\
40\end{array}$ & $\begin{array}{l}26 \\
97 \\
64 \\
58 \\
43\end{array}$ & $\begin{array}{r}3 \\
82 \\
49 \\
35 \\
9\end{array}$ & $\begin{array}{l}11 \\
12 \\
13 \\
14 \\
15\end{array}$ & $\begin{array}{l}59 \\
67 \\
60 \\
50 \\
49\end{array}$ & $\begin{array}{l}31 \\
32 \\
33 \\
34 \\
35\end{array}$ & $\begin{array}{l}18 \\
68 \\
74 \\
59 \\
57\end{array}$ \\
\hline $\begin{array}{l}16 \\
17 \\
18 \\
19 \\
20\end{array}$ & $\begin{array}{l}10 \\
54 \\
71 \\
43 \\
56\end{array}$ & $\begin{array}{l}1 \\
28.5 \\
58 \\
10 \\
30\end{array}$ & $\begin{array}{l}41 \\
42 \\
43 \\
44 \\
45\end{array}$ & $\begin{array}{l}68 \\
74 \\
71 \\
61 \\
53\end{array}$ & $\begin{array}{l}55.5 \\
62 \\
57 \\
42 \\
27\end{array}$ & $\begin{array}{l}16 \\
17 \\
18 \\
19 \\
20\end{array}$ & $\begin{array}{l}63 \\
73 \\
81 \\
57 \\
49\end{array}$ & $\begin{array}{l}36 \\
37 \\
38 \\
39 \\
40\end{array}$ & $\begin{array}{l}81 \\
74 \\
77 \\
95 \\
77\end{array}$ \\
\hline $\begin{array}{l}21 \\
22 \\
23 \\
24 \\
25\end{array}$ & $\begin{array}{r}86 \\
56 \\
100 \\
50 \\
77\end{array}$ & $\begin{array}{l}76 \\
31 \\
84.5 \\
23.5 \\
66.5\end{array}$ & & ? & & & & & \\
\hline & & & $n=$ & & & & & $n_{2}=40$ & \\
\hline
\end{tabular}

Null Hypothesis $\left(\mathbb{H}_{0}\right)$ : Sex does not have an influence on choice of strategy $\left(\mathrm{H}_{1}\right)$ : Sex does have an influence on choice of strategy

Employing a Mann-Whitney $\delta$ test, $U=n_{1} n_{2}+\frac{n_{1}\left(n_{1}+1\right)}{2}-R_{1}=1800+1035-174$ For $n_{2}$ larger than 20, $z=\frac{0-n_{1} n_{2} / 2}{\sqrt{\frac{\left(n_{1}\right)\left(n_{2}\right)\left(n_{1}+n_{2}+1\right)}{12}}}=\frac{162}{113.6}=1.42$

$z \geqslant 0.42$ has a two-tailed probability under $\mathrm{A}_{0}$ of $\mathrm{p}<.156$. Region of refection, p $>.05$.

Therefore $\mathrm{H}_{\mathrm{O}}$ accepted, Sex does not have an influence on choice of strategy. 
APPEIDIX IX: Comparison of Propensity is, by sex

\begin{tabular}{|c|c|c|c|c|c|c|c|c|c|}
\hline $\begin{array}{r}\text { Female } \\
\text { Subjects }\end{array}$ & & Rank & $\begin{array}{c}\text { Female } \\
\text { Subjects }\end{array}$ & & Rank & $\begin{array}{c}\text { Male } \\
\text { Subjects }\end{array}$ & & $\begin{array}{c}\text { Nale } \\
\text { Subjects }\end{array}$ & \\
\hline $\begin{array}{l}1 \\
2 \\
3 \\
4 \\
5\end{array}$ & $\begin{array}{l}.586 \\
.556 \\
.391 \\
.476 \\
.048\end{array}$ & & $\begin{array}{l}26 \\
27 \\
28 \\
29 \\
30\end{array}$ & $\begin{array}{l}.276 \\
.737 \\
.293 \\
.444 \\
.48\end{array}$ & & $\begin{array}{l}1 \\
2 \\
3 \\
4 \\
5\end{array}$ & $\begin{array}{c}.222 \\
0 \\
.44 \\
.094 \\
.385\end{array}$ & $\begin{array}{l}21 \\
22 \\
23 \\
24 \\
25\end{array}$ & $\begin{array}{l}.682 \\
0 \\
.18 \\
.4 \\
.359\end{array}$ \\
\hline $\begin{array}{r}6 \\
7 \\
8 \\
9 \\
10\end{array}$ & $\begin{array}{c}.059 \\
0 \\
.106 \\
.706 \\
.243\end{array}$ & & $\begin{array}{l}31 \\
32 \\
33 \\
34 \\
35\end{array}$ & $\begin{array}{l}.286 \\
.333 \\
.346 \\
.346 \\
.074\end{array}$ & & $\begin{array}{r}6 \\
? \\
8 \\
9 \\
10\end{array}$ & $\begin{array}{l}.5 \\
.385 \\
.44 \\
.276 \\
.533\end{array}$ & $\begin{array}{l}26 \\
27 \\
28 \\
29 \\
30\end{array}$ & $\begin{array}{r}.321 \\
.875 \\
.552 \\
.273 \\
.941\end{array}$ \\
\hline $\begin{array}{l}11 \\
12 \\
13 \\
14 \\
15\end{array}$ & $\begin{array}{c}.579 \\
.944 \\
.533 \\
1 \\
.026\end{array}$ & & $\begin{array}{l}36 \\
37 \\
38 \\
39 \\
40\end{array}$ & $\begin{array}{l}.9 \\
.061 \\
.438 \\
.625 \\
.304\end{array}$ & & $\begin{array}{l}11 \\
12 \\
13 \\
14 \\
15\end{array}$ & $\begin{array}{l}.035 \\
.1 \\
.2 \\
.024 \\
.077\end{array}$ & $\begin{array}{l}31 \\
32 \\
33 \\
34 \\
35\end{array}$ & $\begin{array}{l}.13 \\
.129 \\
.323 \\
.556 \\
.536\end{array}$ \\
\hline $\begin{array}{l}16 \\
17 \\
18 \\
19 \\
20\end{array}$ & $\begin{array}{l}.857 \\
.571 \\
.321 \\
.381 \\
.296\end{array}$ & & $\begin{array}{l}41 \\
42 \\
43 \\
44 \\
45\end{array}$ & $\begin{array}{l}.548 \\
.571 \\
.135 \\
.370 \\
.36\end{array}$ & . & $\begin{array}{l}16 \\
17 \\
18 \\
19 \\
20\end{array}$ & $\begin{array}{l}.367 \\
.05 \\
.4 \\
0 \\
.321\end{array}$ & $\begin{array}{l}36 \\
37 \\
38 \\
39 \\
40\end{array}$ & $\begin{array}{l}.25 \\
.44 \\
.478 \\
.073 \\
.406\end{array}$ \\
\hline $\begin{array}{l}21 \\
22 \\
23 \\
24 \\
25 \\
\end{array}$ & $\begin{array}{c}.278 \\
.625 \\
0 \\
.364 \\
.333 \\
\end{array}$ & & & & & & & & \\
\hline & & & -4 & & & & & $n_{n}=40$ & \\
\hline
\end{tabular}

Null Hypothesis $\left(H_{0}\right)$ : Sex does not have an influence on propensity $\zeta_{3}$ $\left(H_{1}\right)$ : Sex does have an influence on propensity $\hat{\theta}$.

Employing a Mann-Whitney $\delta$ test, $\begin{aligned} U=n_{1} n_{2}+\frac{n_{1}\left(n_{1}+1\right)}{2}-R_{1} & =1800+1035-2105 \\ & =730\end{aligned}$ For $n_{2}$ larger than 20, $z=\frac{0-n_{1} n_{2} / 2}{\frac{\left(n_{1}\right)\left(n_{2}\right)\left(n_{1}+n_{2}+1\right)}{12}} \frac{170}{113.6}=1.5$

$Z \geqslant 1.5$ has a two-tailed probability under $\mathrm{H}_{0}$ of $\mathrm{p}<.134$. Region of rejection, p>.05.

Therefore $\mathrm{H}_{\mathrm{O}}$ accepted, Sex does not have an influence on propensity $\hat{S}$. 


\begin{tabular}{|c|c|c|c|c|}
\hline $\begin{array}{c}\text { Subjects } \\
\text { (1eaders) }\end{array}$ & $\begin{array}{c}\text { Pre-emption } \\
\text { rate }\end{array}$ & Rank & $\begin{array}{l}\text { Subjects } \\
\text { (others) }\end{array}$ & $\begin{array}{l}\text { Pro-emption } \\
\text { rate }\end{array}$ \\
\hline $\begin{array}{r}1 \\
9 \\
11 \\
17 \\
24 \\
29 \\
31 \\
40\end{array}$ & $\begin{array}{l}.391 \\
.391 \\
.56 \\
.563 \\
.222 \\
.444 \\
.177 \\
.2\end{array}$ & $\begin{array}{c}12.5 \\
12.5 \\
26 \\
27 \\
4 \\
17.5 \\
2 \\
3\end{array}$ & $\begin{array}{r}2 \\
3 \\
4 \\
5 \\
6 \\
7 \\
8 \\
10 \\
12 \\
13 \\
14 \\
15 \\
16 \\
18 \\
19 \\
20 \\
21 \\
22 \\
23 \\
25 \\
26 \\
27 \\
28 \\
30 \\
32 \\
33 \\
34 \\
35 \\
36 \\
37 \\
38 \\
39\end{array}$ & $\begin{array}{l}.429 \\
.482 \\
.75 \\
.5 \\
.355 \\
0 \\
.8 \\
.682 \\
.81 \\
1 \\
.348 \\
.926 \\
.4 \\
.889 \\
.36 \\
.357 \\
.375 \\
.579 \\
.464 \\
.611 \\
.6 \\
.833 \\
.316 \\
.55 \\
.5 \\
.526 \\
.348 \\
.731 \\
.444 \\
.615 \\
.55 \\
.4\end{array}$ \\
\hline
\end{tabular}

Null Hypothesis $\left(B_{0}\right)$ : Male task leaders have the same rate of pre-emption as other male subjects.

$\left(H_{1}\right)$ : Male task leaders have different rates of pre-emption than other male subjects.

Employing a Mann-Whitney $U$ test, $\delta=n_{1} n_{2}+\frac{n_{1}\left(n_{1}+1\right)}{2}-R_{1}=256+36-104.5$ For $n_{2}$ larger than 20, $z=\frac{\nabla-n_{1} n_{2} / 2}{\sqrt{\frac{\left(n_{1}\right)\left(n_{2}\right)\left(n_{1}+n_{2}+1\right)}{12}}}=\frac{59.5}{29.57}=2.01$

z) 2.0 Thas a two-tailed probability under $H_{0}$ of $p<.044$. Region of rejection,p $>.0$,

Therefore, $\mathrm{H}_{\mathrm{O}}$ rejected, $\mathrm{H}$ accepted. Male task leaders have lower rates of pre-emption than other male subjects. 


\begin{tabular}{|c|c|c|c|c|}
\hline $\begin{array}{l}\text { Subjects } \\
\text { (Ieaders) }\end{array}$ & $\begin{array}{l}\text { Pre-emption } \\
\text { rate }\end{array}$ & Rank & $\begin{array}{l}\text { Subjects } \\
\text { (others) }\end{array}$ & $\begin{array}{c}\text { Pre-emption } \\
\text { rate }\end{array}$ \\
\hline $\begin{array}{r}4 \\
9 \\
15 \\
17 \\
24 \\
27 \\
28 \\
31 \\
38\end{array}$ & $\begin{array}{l}.75 \\
.391 \\
.926 \\
.563 \\
.222 \\
.833 \\
.316 \\
.177 \\
.5\end{array}$ & $\begin{array}{l}34 \\
12.5 \\
39 \\
26.5 \\
4 \\
37 \\
5 \\
2 \\
23\end{array}$ & $\begin{array}{r}1 \\
2 \\
3 \\
5 \\
6 \\
7 \\
8 \\
10 \\
11 \\
12 \\
13 \\
14 \\
16 \\
18 \\
19 \\
20 \\
21 \\
22 \\
23 \\
25 \\
26 \\
29 \\
30 \\
32 \\
33 \\
34 \\
35 \\
36 \\
37 \\
39 \\
40\end{array}$ & $\begin{array}{l}.391 \\
.429 \\
.482 \\
.5 \\
.355 \\
0 \\
.8 \\
.682 \\
.56 \\
.81 \\
1 \\
.348 \\
.4 \\
.889 \\
.36 \\
.357 \\
.375 \\
.579 \\
.464 \\
.611 \\
.6 \\
.444 \\
.55 \\
.5 \\
.526 \\
.348 \\
.731 \\
.444 \\
.615 \\
.4 \\
.2 \\
.4 \\
.5\end{array}$ \\
\hline$x_{1}=9$ & - & $R_{1}=183$ & $n_{2}=31$ & \\
\hline
\end{tabular}

Null Bypothesis $\left(\mathrm{H}_{0}\right)$ : Male socio-emotional leaders have the same rate of pre-emption as other male subjects.

$\left(\mathrm{H}_{1}\right)$ : Male socio-emotional leaders have different rates of pre-emption than other male subjects.

Employing a Mann-Whitney $\delta$ test, $\quad 0=n_{1} n_{2}+\frac{n_{1}\left(n_{1}+1\right)}{2}-R_{1}=279+45-183$ For $n_{2}$ larger than 20, $z=\frac{\pi-n_{1} n_{2} / 2}{\sqrt{\frac{\left(n_{1}\right)\left(n_{2}\right)\left(n_{1}+n_{2}+1\right)}{12}} \cdot \frac{1.5}{30.87}}=.048$

z) .048 has a two-tailed probability under $\mathrm{H}_{0}$ of $\mathrm{p}\langle .968$. Region of rejection, $\mathrm{p}\rangle .0 \mathrm{~g}$

Therefore, $\mathrm{H}_{0}$ accepted. Male socio-emotional leaders have the same rate of pre-emption as other male subjects. 
APPENDIX XII: Comparison of Pre-Emption Rates: Female Task Leaders and other Group Members

\begin{tabular}{|c|c|c|c|c|}
\hline $\begin{array}{l}\text { Subjects } \\
\text { (1eaders) }\end{array}$ & $\begin{array}{c}\text { Pre-emption } \\
\text { rate }\end{array}$ & Rank & $\begin{array}{l}\text { Subjects } \\
\text { (others) }\end{array}$ & $\begin{array}{c}\text { Pre-eaption } \\
\text { rate }\end{array}$ \\
\hline $\begin{array}{r}4 \\
6 \\
8 \\
14 \\
15 \\
20 \\
22 \\
29 \\
30 \\
34 \\
35 \\
39 \\
44\end{array}$ & $\begin{array}{l}.37 \\
.875 \\
1 \\
.968 \\
1 \\
.583 \\
.571 \\
.579 \\
.44 \\
.526 \\
.391 \\
.607 \\
.5\end{array}$ & $\begin{array}{l}12 \\
40.5 \\
44.5 \\
43 \\
44.5 \\
31 \\
28 \\
30 \\
20 \\
26 \\
16 \\
32 \\
24.5\end{array}$ & $\begin{array}{l}1 \\
2 \\
3 \\
5 \\
7 \\
9 \\
10 \\
11 \\
12 \\
13 \\
16 \\
17 \\
18 \\
19 \\
21 \\
23 \\
24 \\
25 \\
26 \\
27 \\
28 \\
31 \\
32 \\
33 \\
36 \\
37 \\
38 \\
40 \\
41 \\
42 \\
43 \\
45\end{array}$ & 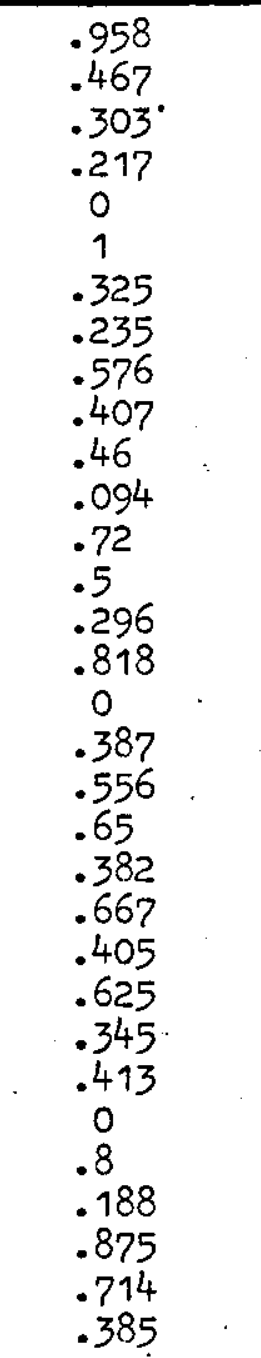 \\
\hline$x_{1}=13$ & & $R_{1}=392$ & $n_{2}=32$ & \\
\hline
\end{tabular}

Null Hypothesis $\left(\mathrm{H}_{\mathrm{O}}\right)$ : Female task leaders have the same rate of pre-emption as other female subjects.

$\left(\mathrm{B}_{1}\right)$ : Female task leaders have different rates of pre-emption female subjects.

Employing a Mann-Whitney $\delta$ test, $\delta=n_{1} n_{2}+\frac{n_{1}\left(n_{1}+1\right)}{2}-R_{1}=416+91-392$

For $n_{2}$ larger than 20, $\quad z=\frac{\delta-n_{1} n_{2} / 2}{\sqrt{\frac{\left(n_{1}\right)\left(n_{2}\right)\left(n_{1}+n_{2}+1\right)}{12}}}=\frac{93}{39.93}=2.33$

z) 2.33 has a two-tailed probability under $H_{0}$ of $p<0.198$. Region of rejection, $\left.p\right\rangle .05$

Therefore, $\mathrm{H}_{\mathrm{O}}$ rejected, $\mathrm{H}_{1}$ accepted. Female task leaders have higher rate of pre-emption than other female subjects. 


\begin{tabular}{|c|c|c|c|c|}
\hline $\begin{array}{l}\text { Subjects } \\
\text { (leaders) }\end{array}$ & $\begin{array}{l}\text { Pro-emption } \\
\text { rate }\end{array}$ & Rank & $\begin{array}{l}\text { Subjects } \\
\text { (others) }\end{array}$ & $\begin{array}{l}\text { Pre-emption } \\
\text { rate }\end{array}$ \\
\hline $\begin{array}{r}4 \\
7 \\
15 \\
16 \\
17 \\
22 \\
29 \\
34 \\
39 \\
41\end{array}$ & $\begin{array}{l}.37 \\
0 \\
1 \\
.094 \\
.72 \\
.571 \\
.579 \\
.526 \\
.607 \\
.875\end{array}$ & $\begin{array}{c}12 \\
2 \\
44.5 \\
4 \\
38 \\
29 \\
31 \\
27 \\
33 \\
41.5\end{array}$ & $\begin{array}{c}1 \\
2 \\
3 \\
5 \\
6 \\
8 \\
9 \\
10 \\
11 \\
12 \\
13 \\
14 \\
18 \\
19 \\
20 \\
21 \\
23 \\
24 \\
25 \\
26 \\
27 \\
28 \\
30 \\
31 \\
32 \\
33 \\
35 \\
36 \\
37 \\
38 \\
40 \\
42 \\
43 \\
.\end{array}$ & $\begin{array}{l}.958 \\
.467 \\
.303 \\
.217 \\
.875 \\
1 \\
.325 \\
.235 \\
.576 \\
.407 \\
.46 \\
.968 \\
.5 \\
.296 \\
.583 \\
.818 \\
0 \\
.387 \\
.556 \\
.65 \\
.382 \\
.667 \\
.44 \\
.405 \\
.625 \\
.345 \\
.391 \\
.413 \\
.0 \\
.8 \\
.188 \\
.714 \\
.385\end{array}$ \\
\hline$x_{1}=10$ & & $R_{1}=262$ & $n_{2}=35$ & \\
\hline
\end{tabular}

Null Hypothesis $\left(\mathbb{H}_{0}\right)$ : Female prolonged leaders have the same rate of pre-emption as other female subjects.

$\left(\mathrm{H}_{1}\right)$ : Female prolonged leaders have different rates of pre-emption than other female subjects.

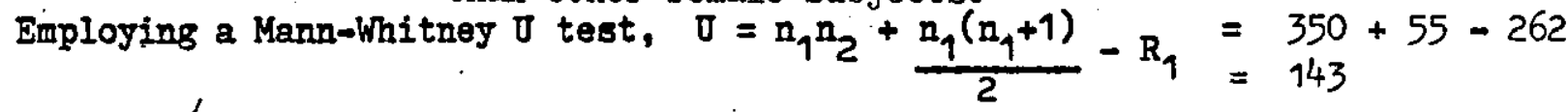
For $n_{2}$ larger than 20, $z=\frac{\delta-n_{1} n_{2} / 2}{\sqrt{\frac{\left(n_{1}\right)\left(n_{2}\right)\left(n_{1}+n_{2}+1\right)}{12}}}=\frac{32}{36.6}=.87$

z) .87 has a twatailed probability under $\mathrm{H}_{0}$ of $\mathrm{p}<.384$. Region of rejection, $\left.\mathrm{p}\right\rangle .05$

Therefore, $\mathrm{H}_{\mathrm{O}}$ accepted. Female prolonged leaders have the same rate of pre-emption as other female subjects. 


\begin{tabular}{|c|c|c|c|c|}
\hline $\begin{array}{l}\text { Subjects } \\
\text { (Ieaders) }\end{array}$ & $\begin{array}{l}\text { Pre-emption } \\
\text { rate }\end{array}$ & Rank & $\begin{array}{l}\text { Subjects } \\
\text { (others) }\end{array}$ & $\begin{array}{l}\text { Pre-emption } \\
\text { rate }\end{array}$ \\
\hline $\begin{array}{c}5 \\
6 \\
14 \\
18 \\
22 \\
29 \\
32 \\
33 \\
39 \\
41 \\
45\end{array}$ & $\begin{array}{l}.217 \\
.875 \\
.968 \\
.5 \\
.571 \\
.579 \\
.625 \\
.345 \\
.607 \\
.875 \\
.476\end{array}$ & $\begin{array}{l}6 \\
41 \\
43 \\
24.5 \\
28 \\
30 \\
33 \\
11 \\
32 \\
40 \\
23\end{array}$ & $\begin{array}{l}1 \\
2 \\
3 \\
4 \\
7 \\
8 \\
9 \\
10 \\
11 \\
12 \\
13 \\
15 \\
16 \\
17 \\
19 \\
20 \\
21 \\
23 \\
24 \\
25 \\
26 \\
27 \\
28 \\
30 \\
31 \\
34 \\
35 \\
36 \\
37 \\
38 \\
40 \\
42 \\
43\end{array}$ & $\begin{array}{l}.958 \\
.467 \\
.303 \\
.44 \\
0 \\
1 \\
.325 \\
.235 \\
.576 \\
.407 \\
.46 \\
.1 \\
.094 \\
.72 \\
.296 \\
.583 \\
.818 \\
0 \\
.387 \\
.556 \\
.65 \\
.382 \\
.667 \\
.44 \\
.405 \\
.526 \\
.391 \\
.413 \\
0 \\
.8 \\
.188 \\
.714 \\
.385 \\
\end{array}$ \\
\hline$n_{1}=11$ & & $1=311$ & $n_{2}=34$ & \\
\hline
\end{tabular}

Null Hypothesis $\left(\mathrm{H}_{\mathrm{O}}\right)$ : Female socio-emotional leaders have the same rate of pre-emption as other female subjects.

$\left(\mathrm{H}_{1}\right)$ : Female socio-emotional leaders have alfferent rates of pre-emption than other female subjects.

Employing a Mann-Whitney $\delta$ test, $\delta=n_{1} n_{2}+\frac{n_{1}\left(n_{1}+1\right)}{2}-R_{1}=374+66-311.5$ For $\mathrm{n}_{2}$ larger than $20, \mathrm{z}=$

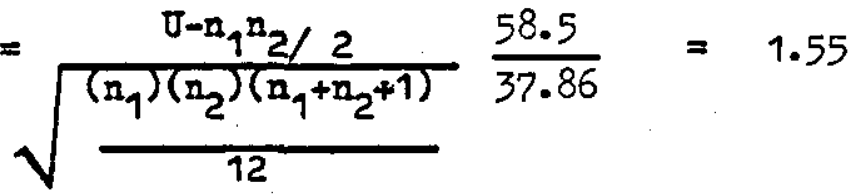

z) 1.55 has a two-tailed probability under $\mathbb{H}_{0}$ of $\mathrm{p}\langle .121$. Region of rejection, $p\rangle .0$.

Therefore, $\mathrm{H}_{\mathrm{O}}$ accepted. Female socio-emotional leaders have the same rate of pre-emption as other female subjects. 


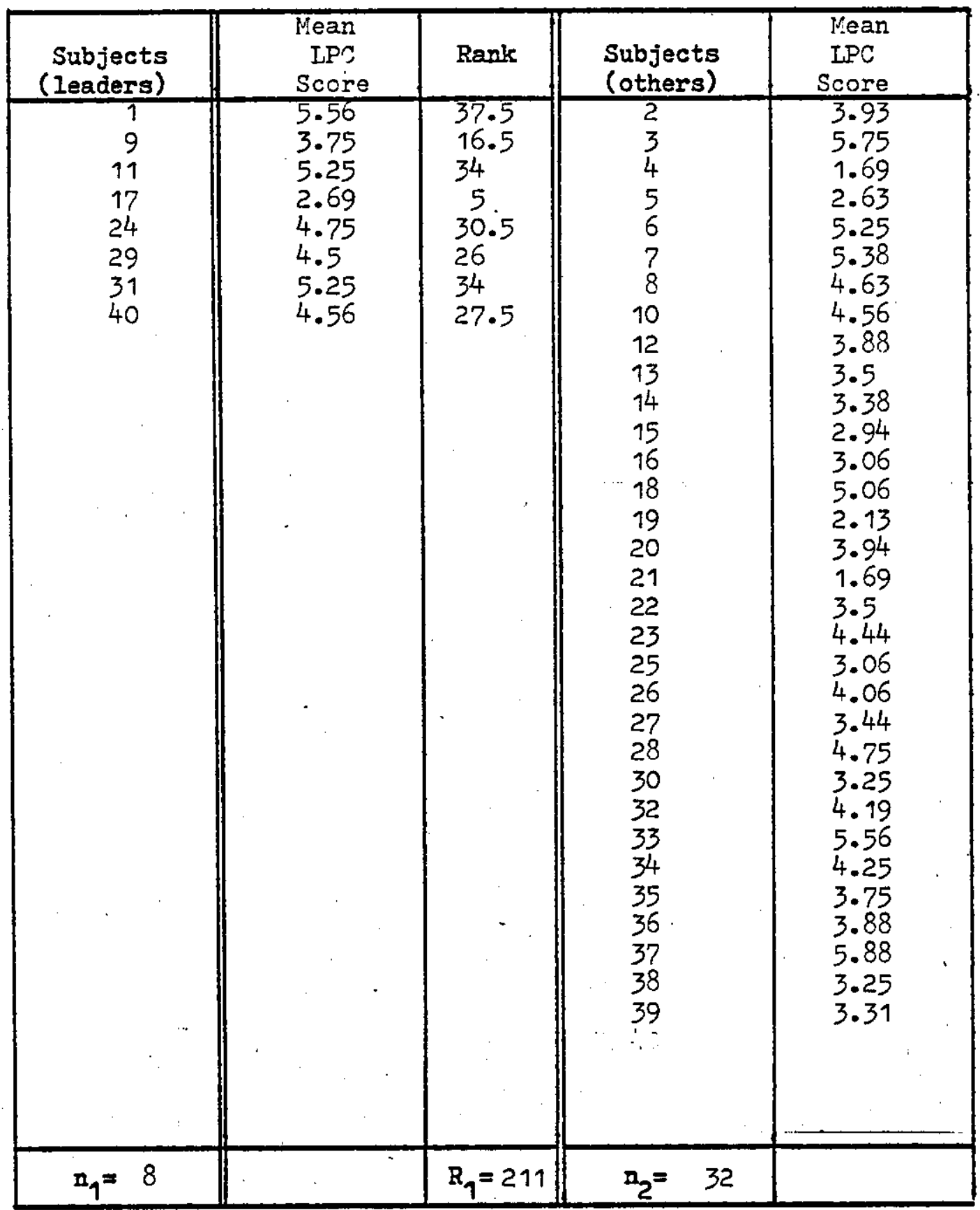

NuIl hypothesis $\left(\mathrm{H}_{0}\right)$ : Male task leaders have the same LPC scores as other male subjects.

$\left(\mathrm{H}_{\mathrm{q}}\right)$ : Male task leaders have different LPC scores than other male subjects.

Employing a Mann-Whitney $\delta$ test, $\quad J=n_{1} n_{2}+\frac{n_{1}\left(n_{1}+1\right)}{2}-R_{1}=\begin{array}{r}256+36-211 \\ 81\end{array}$ For $n_{2}$ larger than 20, $z=\frac{\nabla-n_{1} n_{2} / 2}{\frac{\left(n_{1}\right)\left(n_{2}\right)\left(n_{1}+n_{2}+1\right)}{12}} \frac{47}{29.47}=1.59$

$z \geqslant 1.59$ has a twotailed probability under $E_{0}$ of $p<.1138$ Region of rejection, $\left.p\right\rangle .0$ Therefore $\mathrm{H}$, accepted. Male task leaders have the same IPC scores as other male subjects. 


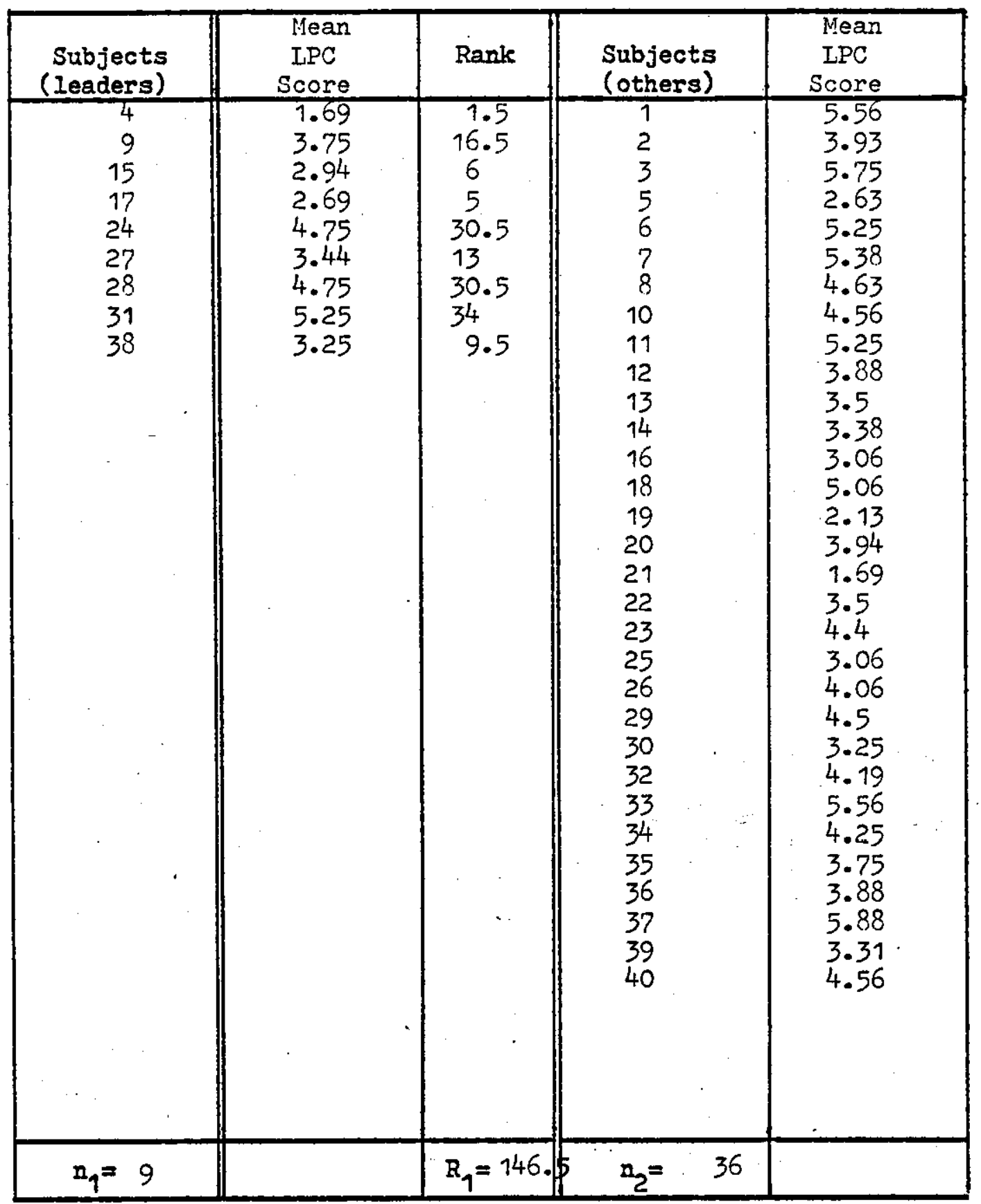

Null hypothesis $\left(\mathrm{H}_{0}\right)$ : Male socio-emotional leaders have the same IPC scores as other male subjects.

$\left(\mathrm{H}_{1}\right)$ : Male socio-emotional leaders have different IPC scores than other male subjects.

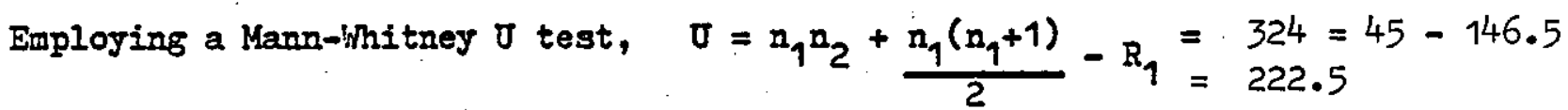
For $n_{2}$ larger than 20, $z=\frac{0-n_{1} n_{2} / 2}{\frac{\left(n_{1}\right)\left(n_{2}\right)\left(n_{1}+n_{2}+1\right)}{12}} \frac{60.5}{35.24}=1.72$

z 1.72 has atro-tailed probability under $\mathrm{H}_{\mathrm{O}}$ of $\mathrm{p} .085$. Region of rejection, $\mathrm{p} . \mathrm{C}$ Therefore $\mathrm{B}$ accepted. Male socio-emotional leaders have the same LPC scores as other male subjects. 
APPEIDIX XVII: Comparison of LPC Scores: Female Task Leaders and other Group Members

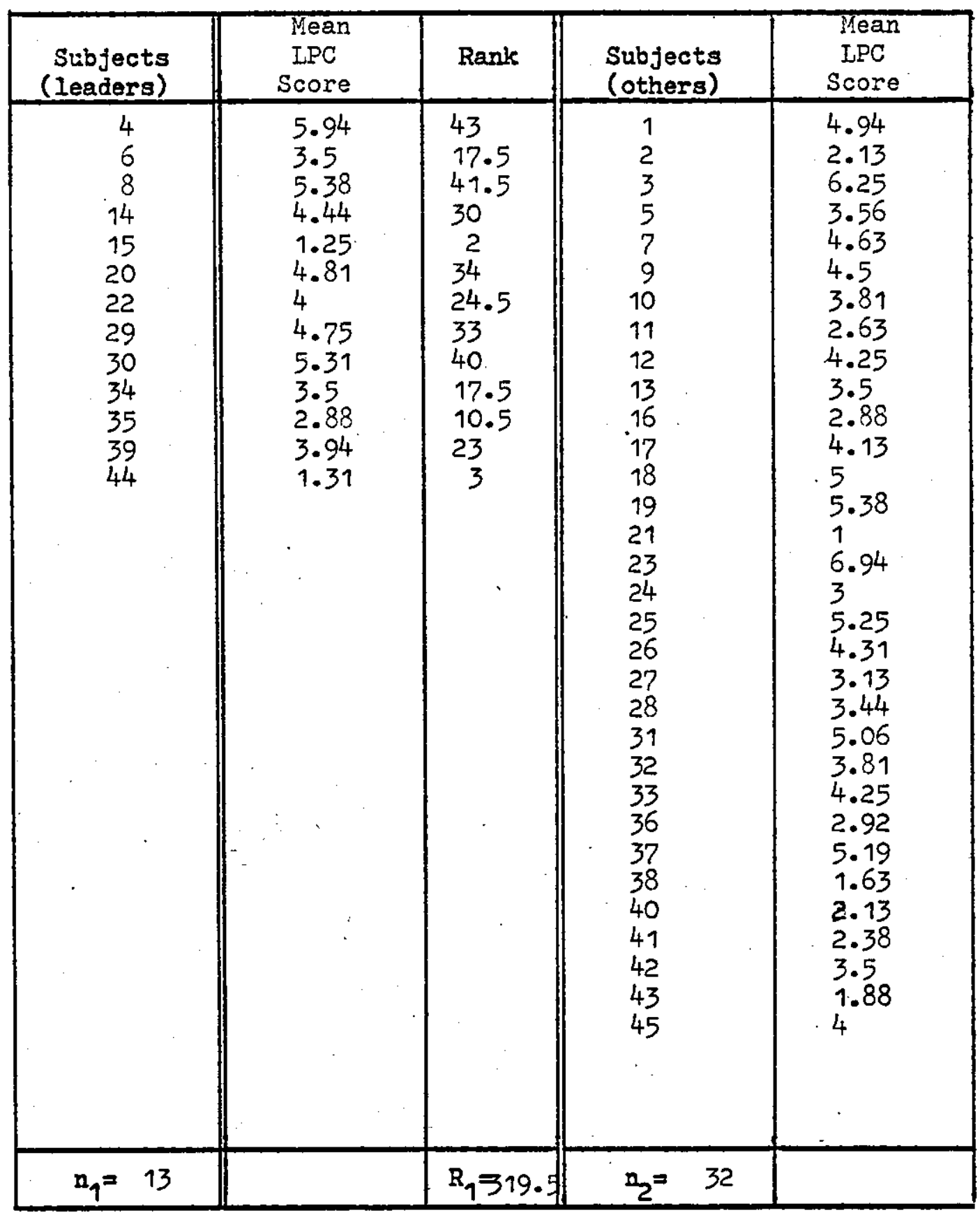

Null bypothesis $\left(H_{0}\right)$ : Female task leaders have the same IPC scores as other female subjects.

$\left(H_{q}\right)$ : Female task leaders have different LPC scores than other female subjects.

Employing a Mann-lhitney 0 test, $\quad \delta=n_{1} n_{2}+\frac{n_{1}\left(n_{1}+1\right)}{2}-R_{1}=\begin{aligned} & 416+91-319.5 \\ & 187.5\end{aligned}$

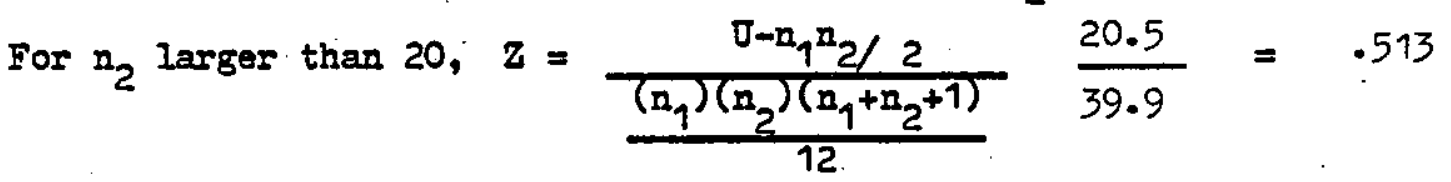

$z\rangle .513$ has a two-tailed probability under $\mathrm{H}_{0}$ of $\mathrm{p}\langle .61$. Region of rejection, $\mathrm{p}\rangle .0$ Therefore $\mathrm{H}_{0}$ accepted. Female task leaders have the same IPC scores as other female subjects. 


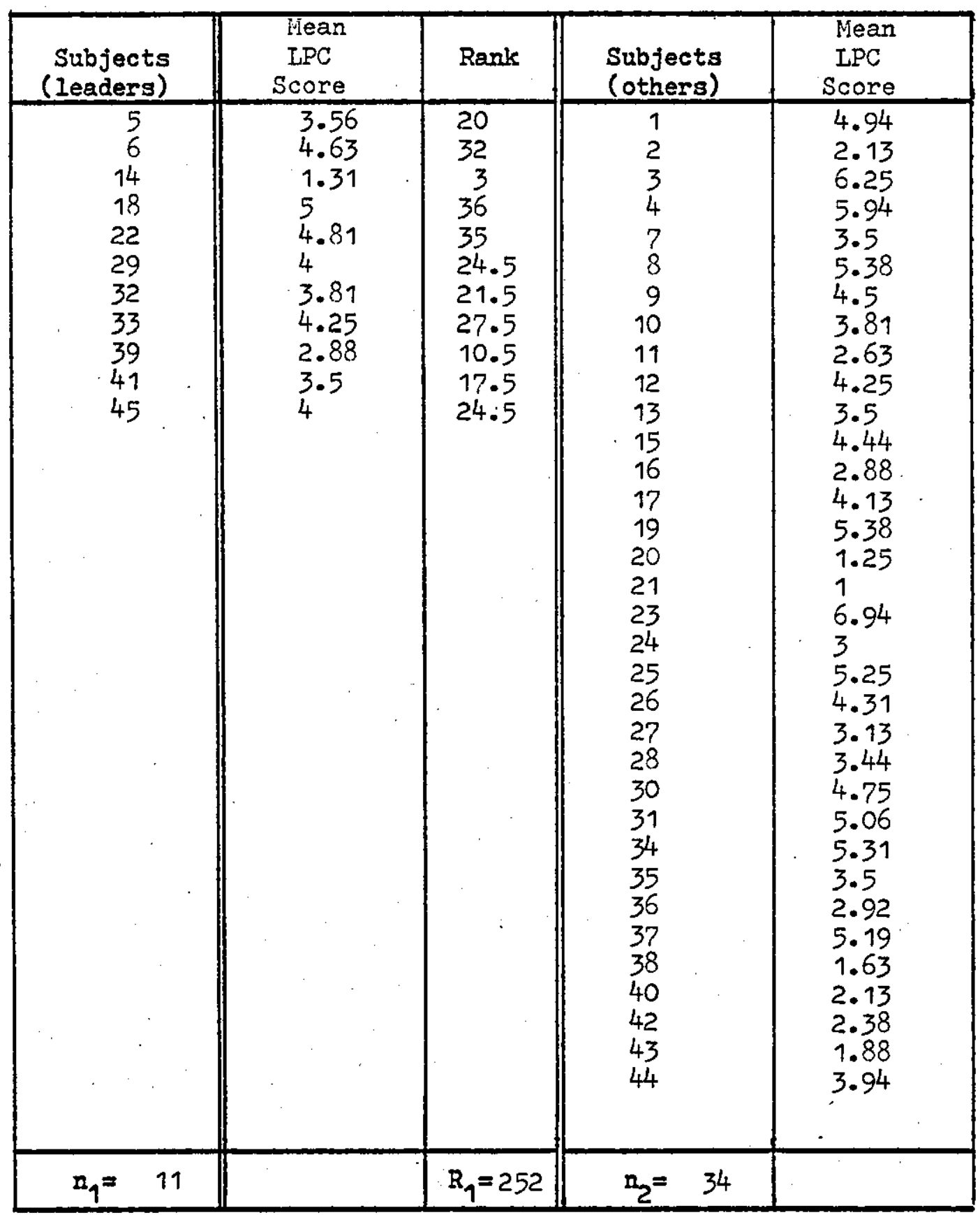

Null hypothesis $\left(\mathrm{H}_{\mathrm{O}}\right)$ : Female socio-emotional leaders have the same LPC scores as othe female subjects.

$\left(\mathrm{H}_{1}\right)$ : Female socio-emotional leaders have different LPC scores than other female subjects.

Employing a Mann-Whitney 0 test, $\quad \begin{aligned} \quad=n_{1} n_{2}+\frac{n_{1}\left(n_{1}+1\right)}{2}-R_{1} & =374+66-252 \\ & =188\end{aligned}$ For $n_{2}$ Iarger than $20, z=\frac{0-n_{1} n_{2} / 2}{\frac{\left(n_{1}\right)\left(n_{2}\right)\left(n_{1}+n_{2}+1\right)}{12}} \frac{1}{37.86}=.026$

Z .026. has atwo-tailed probability under $\mathrm{H}_{\mathrm{O}}$ of $\mathrm{p} .976$. Region of rejection, $\mathrm{p} .0$ Therefore $\mathbb{H}_{\mathrm{O}}$ accepted. Female socio-emotional leaders have the same LPC scores as other female subjects. 
APPEIDIX XIX: Comparison of Participation Rates: Male Task Leaders and other. Group Members

\begin{tabular}{|c|c|c|c|c|}
\hline $\begin{array}{l}\text { Subjects } \\
\text { (1eaders) }\end{array}$ & $\begin{array}{l}\text { Group } \\
\text { of Group } \\
\text { Responses }\end{array}$ & Rank & $\begin{array}{l}\text { Subjects } \\
\text { (others) }\end{array}$ & $\begin{array}{c}\% \\
\text { of Group } \\
\text { Responses }\end{array}$ \\
\hline $\begin{array}{r}1 \\
9 \\
11 \\
17 \\
24 \\
29 \\
31 \\
40\end{array}$ & $\begin{array}{l}45 \\
19 \\
30 \\
33 \\
21 \\
22 \\
46 \\
30\end{array}$ & $\begin{array}{c}2 \\
17.5 \\
5 \\
4 \\
13.5 \\
10.5 \\
1 \\
6\end{array}$ & $\begin{array}{r}2 \\
3 \\
4 \\
5 \\
6 \\
7 \\
8 \\
10 \\
12 \\
13 \\
14 \\
15 \\
16 \\
18 \\
19 \\
20 \\
21 \\
22 \\
23 \\
25 \\
26 \\
27 \\
28 \\
30 \\
32 \\
33 \\
34 \\
35 \\
36 \\
37 \\
38 \\
39\end{array}$ & $\begin{array}{l}10 \\
15 \\
13 \\
16 \\
23 \\
18 \\
16 \\
24 \\
13 \\
22 \\
21 \\
13 \\
18 \\
21 \\
12 \\
16 \\
15 \\
6 \\
17 \\
41 \\
15 \\
27 \\
20 \\
16 \\
13 \\
12 \\
15 \\
15 \\
21 \\
16 \\
19 \\
14\end{array}$ \\
\hline $\mathbf{n}_{\mathbf{j}}=8$ & & $R_{1}=59.5$ & $n_{2}=32$ & \\
\hline
\end{tabular}

Null hypothesis $\left(\mathrm{H}_{0}\right)$ : Nale task leaders have the same rate of participation as other male subjects.

$\left(\mathrm{H}_{1}\right)$ : Male task leaders have different rates of participation than other male subjects.

Employing a Mann-Whitney $\delta$ test, $\quad \begin{aligned} \quad=n_{1} n_{2}+\frac{n_{1}\left(n_{1}+1\right)}{2}-R_{1}= & 256+36-59.5 \\ & 232.5\end{aligned}$

For $n_{2}$ larger than 20, $z=\frac{\sigma-n_{1} n_{2} / 2}{\frac{\left(n_{1}\right)\left(n_{2}\right)\left(n_{1}+n_{2}+1\right)}{12}} \frac{104.5}{29.57}=3.53$

$z \geqslant 3.53$ has a two-tailed probability under $\mathrm{E}_{0}$ of $\mathrm{p}\langle .0004$. Region of rejection, $\mathrm{p}>0$ Therefore $\mathrm{H} O$ rejected, $\mathrm{H}$ accepted. Male task leaders have a higher rate of participation than other male subjects. 


\begin{tabular}{|c|c|c|c|c|}
\hline $\begin{array}{l}\text { Subjects } \\
\text { (leaders) }\end{array}$ & & Rank & $\begin{array}{l}\text { Subjects } \\
\text { (others) }\end{array}$ & \\
\hline $\begin{array}{r}4 \\
9 \\
15 \\
17 \\
24 \\
27 \\
28 \\
31 \\
38\end{array}$ & $\begin{array}{l}21 \\
46 \\
41 \\
45 \\
19 \\
27 \\
20 \\
33 \\
19\end{array}$ & $\begin{array}{l}27.5 \\
40 \\
38 \\
39 \\
23.5 \\
34 \\
25 \\
38 \\
23.5\end{array}$ & $\begin{array}{r}1 \\
2 \\
3 \\
5 \\
6 \\
7 \\
8 \\
10 \\
11 \\
12 \\
13 \\
14 \\
16 \\
18 \\
19 \\
20 \\
21 \\
22 \\
23 \\
25 \\
26 \\
29 \\
30 \\
32 \\
33 \\
34 \\
35 \\
36 \\
37 \\
39 \\
40\end{array}$ & $\begin{array}{r}10 \\
15 \\
13 \\
16 \\
23 \\
18 \\
16 \\
24 \\
30 \\
13 \\
22 \\
13 \\
18 \\
21 \\
12 \\
16 \\
21 \\
15 \\
6 \\
17 \\
15 \\
22 \\
16 \\
13 \\
12 \\
15 \\
15 \\
21 \\
16 \\
14 \\
30\end{array}$ \\
\hline$n_{1}=9$ & & $R_{1}=8$ & $n_{2}=31$ & \\
\hline
\end{tabular}

Null hypothesis $\left(H_{0}\right)$ : Male socio-emotional leaders have the same rate of participation as other male subjects.

$\left(\mathrm{H}_{1}\right)$ : Male socio-emotional leaders have different rates of participation than other male subjects.

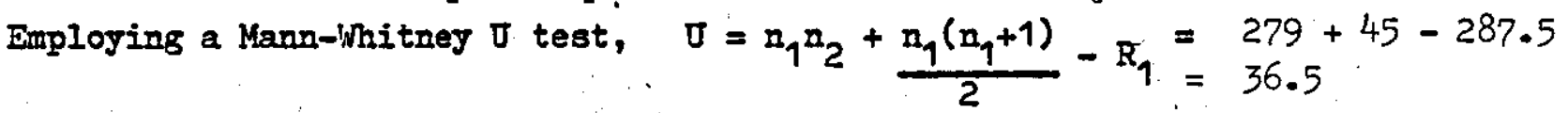

For $n_{2}$ larger than 20, $z=\frac{\frac{\delta-n_{1} n_{2} / 2}{\left(n_{1}\right)\left(n_{2}\right)\left(n_{1}+n_{2}+1\right)}}{12} \frac{103}{30.87}=3.34$

$\mathrm{Z} \geqslant 3.34$ has atwo-tailed probability under $\mathrm{H}_{0}$ of $\mathrm{p}<.001$. Region of rejection, $\mathrm{p}>0.0$ Therefore $\mathrm{H}_{\mathrm{O}}$ rejected, $\mathrm{H}_{j}$ accepted. Male socio-emotional leaders have a higher rate of participation than other male subjects. 


\begin{tabular}{|c|c|c|c|c|}
\hline $\begin{array}{c}\text { Subjects } \\
\text { (Ieaders) }\end{array}$ & $\begin{array}{c}c \% \\
\text { of Group } \\
\text { Responses }\end{array}$ & Rank & $\begin{array}{l}\text { Subjects } \\
\text { (others) }\end{array}$ & $\begin{array}{c}c / \\
\text { of Group } \\
\text { Resoonses }\end{array}$ \\
\hline $\begin{array}{c}4 \\
5 \\
8 \\
14 \\
15 \\
20 \\
22 \\
29 \\
30 \\
34 \\
35 \\
39 \\
44 \\
.\end{array}$ & $\begin{array}{l}25 \\
26 \\
27 \\
28 \\
26 \\
18 \\
12 \\
12 \\
23 \\
31 \\
24 \\
21 \\
33 \\
26\end{array}$ & $\begin{array}{c}13.5 \\
10 \\
6.5 \\
5 \\
10 \\
27.5 \\
40.5 \\
17.5 \\
3 \\
15.5 \\
21 \\
1 \\
10\end{array}$ & $\begin{array}{l}1 \\
2 \\
3 \\
5 \\
7 \\
9 \\
10 \\
11 \\
12 \\
13 \\
16 \\
17 \\
18 \\
19 \\
21 \\
23 \\
24 \\
25 \\
26 \\
27 \\
28 \\
31 \\
32 \\
33 \\
36 \\
37 \\
38 \\
40 \\
41 \\
42 \\
43 \\
45\end{array}$ & $\begin{array}{l}16 \\
13 \\
15 \\
32 \\
25 \\
12 \\
10 \\
23 \\
13 \\
10 \\
18 \\
22 \\
16 \\
26 \\
18 \\
21 \\
24 \\
26 \\
16 \\
15 \\
14 \\
.7 \\
29 \\
20 \\
14 \\
14 \\
14 \\
20 \\
27 \\
18 \\
8 \\
21\end{array}$ \\
\hline$n_{1}=13$ & & $R_{1}=181$ & $n_{2}=32$ & \\
\hline
\end{tabular}

Null hypothesis $\left(\mathrm{H}_{\mathrm{O}}\right)$ : Female task leaders have the same rate of participation as other female subjects.

$\left(\mathrm{H}_{1}\right)$ : Female task leaders have different rates of participation than other female subjects.

Employing a Mann-Whitney $\delta$ test, $U=n_{1} n_{2}+\frac{n_{1}\left(n_{1}+1\right)}{2}-R_{1}=416+91-181$

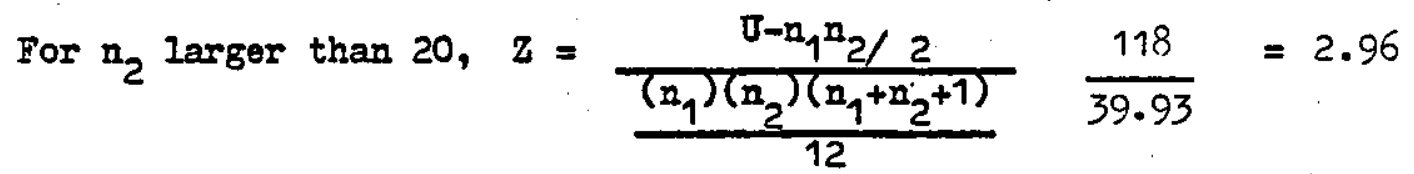

7) $\$ 2.96$ has atwo-tailed probability under $\mathrm{H}_{0}$ of $\mathrm{p}\langle .003$. Region of rejection, p $>$.0 Therefore $\mathrm{H} O$ rejected, $\mathrm{H}_{1}$ accepted. Female task leaders have higher rates of participation than other female subjects. 


\begin{tabular}{|c|c|c|c|c|c|}
\hline $\begin{array}{r}\text { Subjects } \\
\text { (leaders) } \\
\end{array}$ & . & Rank & $\begin{array}{l}\text { Subjects } \\
\text { (others) }\end{array}$ & & \\
\hline $\begin{array}{r}5 \\
6 \\
14 \\
18 \\
22 \\
29 \\
32 \\
33 \\
39 \\
41 \\
45\end{array}$ & $\begin{array}{l}32 \\
26 \\
28 \\
16 \\
12 \\
23 \\
29 \\
20 \\
33 \\
27 \\
21\end{array}$ & $\begin{array}{l}44 \\
36 \\
41 \\
15 \\
5.5 \\
28.9 \\
42 \\
22.5 \\
45 \\
39.5 \\
25\end{array}$ & $\begin{array}{r}1 \\
2 \\
3 \\
4 \\
7 \\
8 \\
9 \\
10 \\
11 \\
12 \\
13 \\
15 \\
16 \\
17 \\
19 \\
20 \\
21 \\
23 \\
24 \\
25 \\
26 \\
27 \\
28 \\
30 \\
31 \\
34 \\
35 \\
36 \\
37 \\
38 \\
40 \\
42 \\
43 \\
44\end{array}$ & $\begin{array}{r}16 \\
13 \\
15 \\
25 \\
25 \\
27 \\
12 \\
10 \\
23 \\
13 \\
10 \\
26 \\
18 \\
22 \\
26 \\
18 \\
18 \\
21 \\
24 \\
26 \\
16 \\
15 \\
14 \\
31 \\
7 \\
24 \\
21 \\
14 \\
14 \\
19 \\
20 \\
18 \\
8 \\
26\end{array}$ & $\therefore$ \\
\hline$n_{1}=11$ & & $R_{1}=339$ & $n_{2}=$ & & \\
\hline
\end{tabular}

Null hypothesis $\left(\mathbb{H}_{0}\right)$ : Female socio-emotional leaders have the same rate of participation as other female subjects.

$\left(B_{1}\right)$ : Female socio-emotional have different rates of participation as other female subjects.

Employing a Mann-Whitney $\delta$ test, $\quad U=n_{1} n_{2}+\frac{n_{1}\left(n_{1}+1\right)}{2}-R_{1}=374+66-339$

For $n_{2}$ larger than 20, $\mathbf{z}=\frac{\frac{\pi-n_{1} n_{2} / 2}{\left(n_{1}\right)\left(n_{2}\right)\left(n_{1}+n_{2}+1\right)}}{12} \frac{86}{37.86}=2.27$

2>2.27 has atwo-tailed probability under $\mathrm{H}_{0}$ of $\mathrm{p}<.023$. Region of rejection, $\mathrm{p}>.0$

Therefore $\mathrm{H}_{\mathrm{O}}$ rejected, $\mathrm{H}$, accepted. Female socio-emotional leaders have higher rates of articipation than other female subjects. 
APPENDIX XXIII: Comparison of Pre-emption Rates: Highest Participators and other Subjects, by group (males)

\begin{tabular}{|c|c|c|c|c|}
\hline $\begin{array}{c}\text { Subjects } \\
\text { (high part.) }\end{array}$ & $\begin{array}{l}\text { Pre-emption } \\
\text { rate }\end{array}$ & Rank & $\begin{array}{l}\text { Subjects } \\
\text { (others) }\end{array}$ & $\begin{array}{c}\text { Pre-emption } \\
\text { rate }\end{array}$ \\
\hline $\begin{array}{r}1 \\
9 \\
15 \\
17 \\
25 \\
27 \\
31 \\
40\end{array}$ & $\begin{array}{l}.391 \\
.391 \\
.926 \\
.563 \\
.611 \\
.833 \\
.177 \\
.2\end{array}$ & $\begin{array}{l}12.5 \\
12.5 \\
39 \\
27 \\
30 \\
37 \\
2 \\
3\end{array}$ & $\begin{array}{r}2 \\
3 \\
4 \\
5 \\
6 \\
7 \\
8 \\
10 \\
11 \\
12 \\
13 \\
14 \\
16 \\
18 \\
19 \\
20 \\
21 \\
22 \\
23 \\
24 \\
26 \\
28 \\
29 \\
30 \\
32 \\
33 \\
34 \\
35 \\
36 \\
37 \\
38 \\
39\end{array}$ & $\begin{array}{l}.429 \\
.482 \\
.75 \\
.5 \\
.355 \\
0 \\
.8 \\
.682 \\
.56 \\
.81 \\
1 \\
.348 \\
.4 \\
.889 \\
.36 \\
.357 \\
.375 \\
.579 \\
.464 \\
.222 \\
.6 \\
.346 \\
.444 \\
.55 \\
.5 \\
.526 \\
.348 \\
.731 \\
.444 \\
.615 \\
.5 \\
.4\end{array}$ \\
\hline$n_{1}=8$ & & $R_{1}=163$ & $n_{2}=32$ & \\
\hline
\end{tabular}

Null hypothesis $\left(\mathrm{H}_{\mathrm{O}}\right)$ : The rate of pre-emption for highest participators and other group members will be the same.

$\left(\mathrm{H}_{1}\right)$ : The rate of pre-emption for highest participators and other group members will differ.

Employing a Mann-Whitney 0 test, $\quad \delta=n_{1} n_{2}+\frac{n_{1}\left(n_{1}+1\right)}{2}-R_{1}=256+36-163$

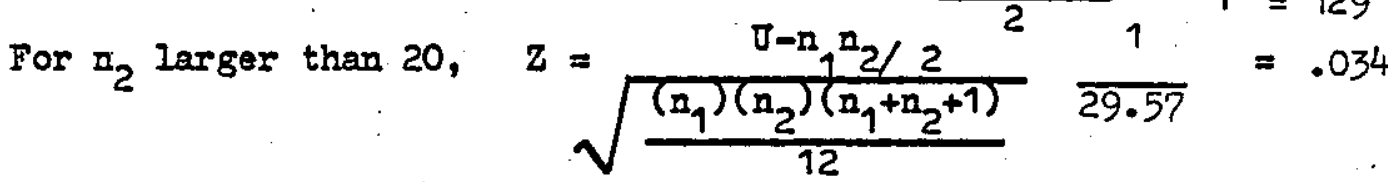

2).034has a two-tailed probability under $\mathrm{H}_{0}$ of $\mathrm{p}<.976$. Region of rejection, $\left.\mathrm{p}\right) .05$ Therefore, $\mathrm{H}_{\mathrm{O}}$ accepted. The rate of pre-emption for highest participators and other group members is the same. 
APPENDIX XXIV: Comparison of Pre-emption Rates: Highest Participators and Other Subjects, by group (females)

\begin{tabular}{|c|c|c|c|c|}
\hline $\begin{array}{c}\text { Subjects } \\
\text { (high part.) }\end{array}$ & $\begin{array}{l}\text { Pre-emption } \\
\text { rate }\end{array}$ & Rank & $\begin{array}{l}\text { Subjects } \\
\text { (others) }\end{array}$ & $\begin{array}{c}\text { Pre-emption } \\
\text { rate }\end{array}$ \\
\hline $\begin{array}{r}5 \\
6 \\
14 \\
19 \\
25 \\
30 \\
32 \\
39 \\
41\end{array}$ & $\begin{array}{l}.217 \\
.375 \\
.968 \\
.296 \\
.556 \\
.44 \\
.625 \\
.607 \\
.875\end{array}$ & $\begin{array}{r}6 \\
41 \\
43 \\
8 \\
27 \\
20 \\
33 \\
32 \\
40\end{array}$ & $\begin{array}{l}1 \\
2 \\
3 \\
4 \\
7 \\
8 \\
9 \\
10 \\
11 \\
12 \\
13 \\
15 \\
16 \\
17 \\
18 \\
20 \\
21 \\
22 \\
23 \\
24 \\
26 \\
27 \\
28 \\
29 \\
31 \\
33 \\
34 \\
35 \\
36 \\
37 \\
38 \\
40 \\
42 \\
43 \\
44\end{array}$ & $\begin{array}{l}.958 \\
.467 \\
.303 \\
.37 \\
0 \\
1 \\
.325 \\
.235 \\
.576 \\
.407 \\
.46 \\
1 \\
.094 \\
.72 \\
.5 \\
.583 \\
.818 \\
.571 \\
0 \\
.387 \\
.65 \\
.382 \\
.667 \\
.579 \\
.405 \\
.345 \\
.526 \\
.391 \\
.413 \\
0 \\
.3 \\
.118 \\
.714 \\
.385 \\
.5 \\
.476\end{array}$ \\
\hline $\mathfrak{n}_{1}=9$ & & $R_{1}=250$ & $n_{2}=36$ & \\
\hline
\end{tabular}

Null hypothesis $\left(H_{O}\right)$ : The rate of pre-emption for highest participators and other group members will be the same.

$\left(H_{1}\right)$ : The rate of pre-emption for highest participators and ather group members will differ.

Employing a Mann-Whitney $\delta$ test, $U=n_{1} n_{2}+\frac{n_{1}\left(n_{1}+1\right)}{2}-R_{1}=\begin{aligned} & 324+45-250 \\ & 119\end{aligned}$ For $n_{2}$ larger than 20, $\quad z=\frac{\delta-n_{1} n_{2} / 2}{\sqrt{\frac{\left(n_{1}\right)\left(n_{2}\right)\left(n_{1}+n_{2}+1\right)}{12}} \frac{43}{35.24}}=1.22$

$z \geqslant 1.2$ has a two-tailed probability under $H_{0}$ of $p<.222$. Region of rejection, $\left.p\right\rangle .05$. Therefore, $\mathbb{E}_{0}$ accepted. The rate of pre-emption for highest participators and other group members is the same. 


\section{CHOOSING A PRESIDENT}

\section{Background on Passmore University}

The University received its charter in 1967, having previously been labelled a College of Advanced Technology. The campus is situated on a large site, two miles outside Warnton and five miles from the sea. Warnton is a port of 200,000 population, with diverse industrial and maritime concerns. The University itself has 2500 undergraduate and 500 postgraduate students. The largest faculties are Engineering and Physical Sciences, with a rapidly growing Social Science and Management department.

Accommodation is available for 2000 students on campus, and this comprises both full board and self-catering halls.

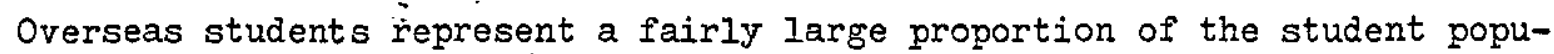
lation, approximately $35 \%$.

\section{The Students Union}

The Students Union is concerned with a host of activities which are provided for the benefit of all students. The Union is financed by Union Fees which are levied from all students ( $\$ 30$ per year). The Union employs over 40 staff in all and runs a travel bureau, several shops, two coffee bars, a newspaper, radio station plus hundreds of sports clubs and other societies.

The day to day running of the Union is operated by the Executive, who work from a somehwat overcrowded and outdated set of offices on the periphery of the campus.

\section{Structure of the Executive}

The executive consists of six members - four full time officers (President, Deputy President, Internal Affairs Vice President, and Treasurer) and two non-sabbatical officers (Secretary and External Affairs Vice President). The executive is elected annually at the campus wide general election, held in the Easter Term. On average, $25 \%$ of students vote at these elections.

The executive are directly responsible to two bodies - Union Council and Union General Meeting.

Council comprises elected representatives of University halls of residence, Out of Hall Students Association and Postgraduate students. The Council deals with the general running of the Union, in terms of day to day activity. The Union General Meeting is the chief decision making body of the Union, and any member of the Union may attend such a meeting to vote, speak or put a motion. At these meetings, the executive deliver reports of their activities since the last U.G.M. 
The major campaigns organised by the Union Executive at Passmore University at the present time are concerned with -

a) tuition fees - the fee increases and how this affects self-financed students (usually overseas students).

b) residential fees - the rise in hall fees over the past few years.

c) racialism - both on campus and in a more general setting.

\section{President}

The roles which a University Union President must fulfil are numerous. Primarily, he/she is head of the Union and is looked upon in many instances as a figurehead. In the event of serious trouble of any kind, it is the President who is directly responsible. However, in terms of the day to day running of the Union it is unlikely that the President's role will be easily distinguishable from other sabbatical officers. That is, ensuring the smooth running of the Union.

A considerable amount of his/her time is employed in personal contact with students, whilst the President is also expected to be able to address large meetings and entertain a number of dignitaries throughout the year.

The hours of work are flexible, but it is expected that he/she will be around the campus for considerable amounts of time during the year.

Any individual may only hold the post for a maximum of one year.

\section{$\underline{\text { TASKS }}$}

\section{INDIVIDUALIY}

Prepare your personal views on the characteristics you consider desirable in the person to be appointed as President. This involves, in essence, drawing up a "person specification" including such matters as age, sex, attitudes, abilities, activities, previous experience, etc.: You should be willing to offer these views when you come together as a group, and have sufficient belief to argue thereof.

\section{AS A GROUP}

After approximately 15 minutes, pool and discuss your ideas as to the specification for a Union President for Passmore University. Having reached consensus, after due consideration of all factors, nominate one of the group to act as spokesperson for a subsequent presentation of your ideas. (These should be jotted down in note form on the paper provided.). 


\section{GROUP QUESTIONNAIRE}

The following questions relate to the group's structure on the task which you have just completed.

Research has indicated that in any group, two styles of leadership may emerge and be identified - socio-emotional and task orientated.

1. The socio-emotional leader must generally be agreeable, conciliatory, and concerned about the members' well-being and personal feelings. This type of leader is most valuable to the group with regard to the maintenance of group cohesion and the general social welfare of the group.

2. The task leader is more concerned with the job at hand - he/she controls, shapes, directs and organises the group in carrying out a specific task. $\mathrm{He} /$ she is directly concerned with initiating structures and endeavouring to establish well-defined patterns of organisation, channels of communcation and methods of procedure.

These two elements of leadership behaviour may be dimensions of one individual's behaviour in the group, or it may be the case that two individuals emerge to fulfil either role.

With regard to this group, using the colour coding on the table in front of you, rank the members of the group in terms of

1. Value with regard to the maintenance of group cohesion and the social well-being of the group (socio-emotional leadership).

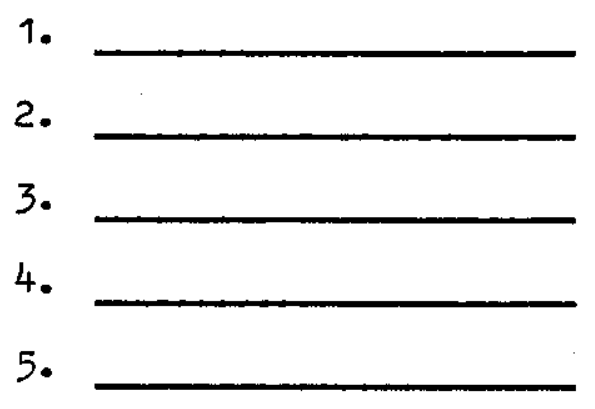

2. Value with regard to the initiation of structure and in the area directly related to the completion of the particular task (task leadership).

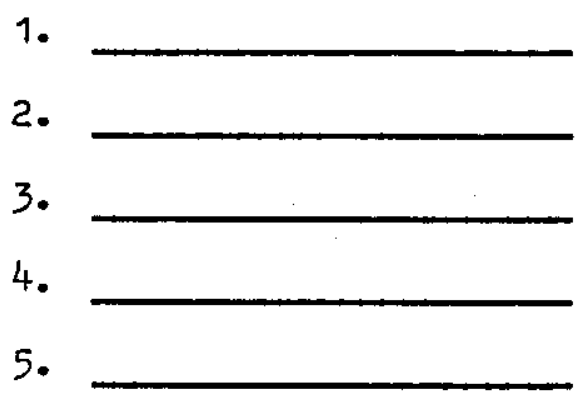


APPENDIX XXVII: (i) Summary of Game Behaviour, by subject (males).

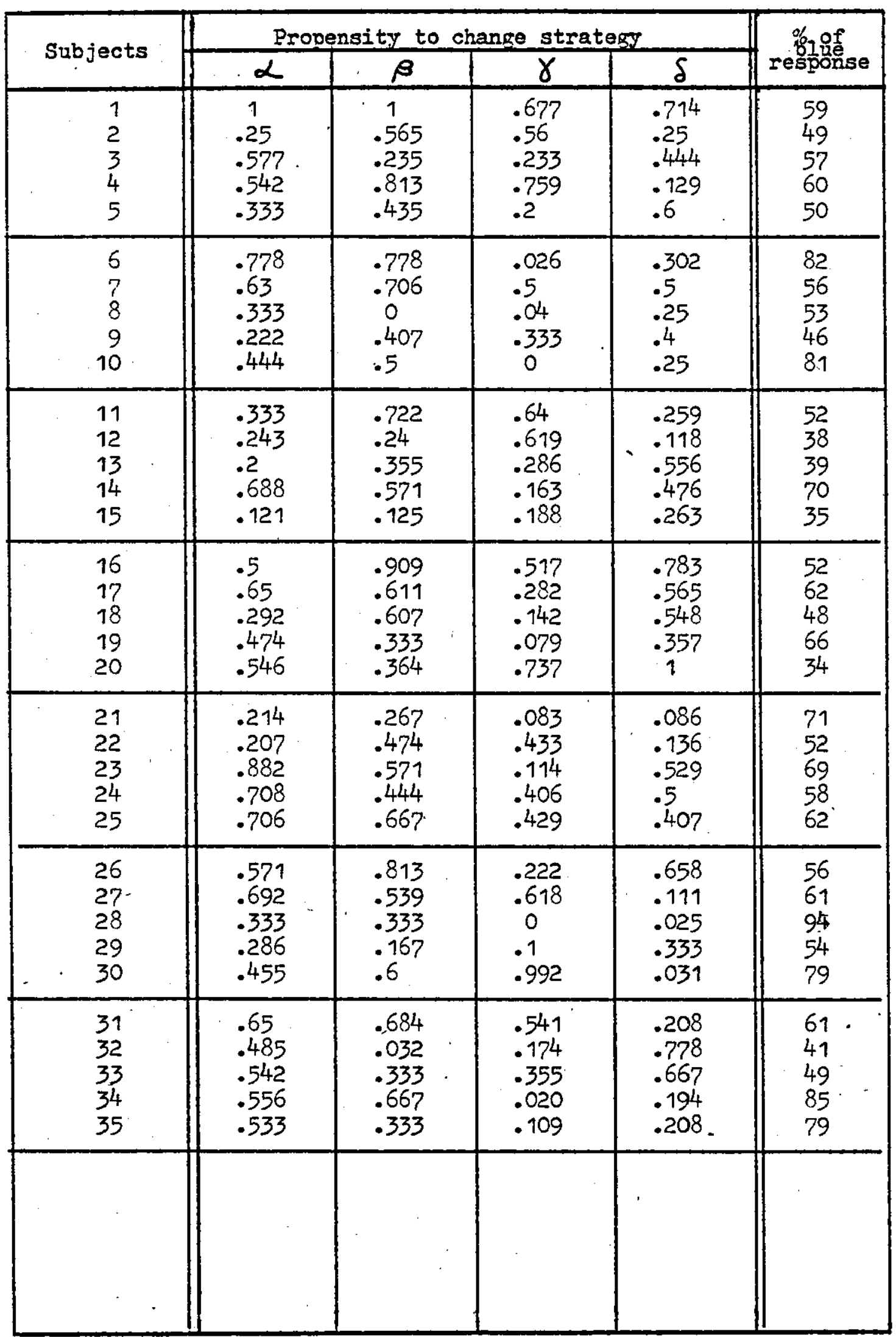


ADPENDIX XXVII: (ii) Summary of Game Behaviour, by subject (females)

\begin{tabular}{|c|c|c|c|c|c|}
\hline \multirow{2}{*}{ Subjects } & \multicolumn{4}{|c|}{ Propensity to change strategy } & \multirow{2}{*}{$\begin{array}{c}\text { of of } \\
\text { besponse }\end{array}$} \\
\hline & $\alpha$ & $\bar{\beta}$ & $\bar{\gamma}$ & $\delta$ & \\
\hline $\begin{array}{l}1 \\
2 \\
3 \\
4 \\
5\end{array}$ & $\begin{array}{l}.954 \\
.074 \\
.4 \\
.5 \\
.636\end{array}$ & $\begin{array}{l}.842 \\
.52 \\
.462 \\
.467 \\
.522\end{array}$ & $\begin{array}{l}.677 \\
.292 \\
.581 \\
.108 \\
.438\end{array}$ & $\begin{array}{l}.6 \\
.375 \\
.364 \\
.375 \\
.522\end{array}$ & $\begin{array}{l}59 \\
48 \\
42 \\
69 \\
45\end{array}$ \\
\hline $\begin{array}{r}6 \\
7 \\
8 \\
9 \\
10\end{array}$ & $\begin{array}{c}.441 \\
.382 \\
1 \\
.455 \\
.156\end{array}$ & $\begin{array}{l}.429 \\
.13 \\
1 \\
0 \\
.727\end{array}$ & $\begin{array}{l}.731 \\
.046 \\
.085 \\
.448 \\
.655\end{array}$ & $\begin{array}{l}.583 \\
.714 \\
.195 \\
.55 \\
.177\end{array}$ & $\begin{array}{l}38 \\
43 \\
88 \\
47 \\
46\end{array}$ \\
\hline $\begin{array}{l}11 \\
12 \\
13 \\
14 \\
15\end{array}$ & $\begin{array}{l}.833 \\
.667 \\
.1 \\
.205 \\
.5\end{array}$ & $\begin{array}{l}1 \\
.6 \\
.4 \\
.4 \\
.692\end{array}$ & $\begin{array}{l}.019 \\
.28 \\
.05 \\
.923 \\
.229\end{array}$ & $\begin{array}{l}.243 \\
.087 \\
.256 \\
.769 \\
.261\end{array}$ & $\begin{array}{l}90 \\
73 \\
85 \\
26 \\
71\end{array}$ \\
\hline $\begin{array}{l}16 \\
17 \\
18 \\
19 \\
20\end{array}$ & $\begin{array}{l}.857 \\
.364 \\
.522 \\
.539 \\
1\end{array}$ & $\begin{array}{c}.667 \\
0 \\
.357 \\
.167 \\
1\end{array}$ & $\begin{array}{l}.195 \\
0 \\
.133 \\
.03 \\
.22\end{array}$ & $\begin{array}{l}.364 \\
.114 \\
.895 \\
.696 \\
.316\end{array}$ & $\begin{array}{l}74 \\
80 \\
49 \\
56 \\
79\end{array}$ \\
\hline $\begin{array}{l}21 \\
22 \\
23 \\
24 \\
25\end{array}$ & $\begin{array}{l}.368 \\
.476 \\
.75 \\
.5 \\
.813\end{array}$ & $\begin{array}{l}.364 \\
.727 \\
.642 \\
.588 \\
.621\end{array}$ & $\begin{array}{l}.114 \\
.815 \\
.333 \\
.178 \\
.273\end{array}$ & $\begin{array}{l}.2 \\
.167 \\
.5 \\
.5 \\
.788\end{array}$ & $\begin{array}{l}70 \\
57 \\
62 \\
65 \\
55\end{array}$ \\
\hline $\begin{array}{l}26 \\
27 \\
28 \\
29 \\
30\end{array}$ & $\begin{array}{l}.5 \\
.225 \\
.29 \\
1 \\
.333\end{array}$ & $\begin{array}{l}.406 \\
.31 \\
.318 \\
.75 \\
.37\end{array}$ & $\begin{array}{l}.476 \\
.364 \\
.185 \\
.137 \\
.185\end{array}$ & $\begin{array}{l}.444 \\
.75 \\
.5 \\
.143 \\
.591\end{array}$ & $\begin{array}{l}48 \\
71 \\
47 \\
86 \\
49\end{array}$ \\
\hline $\begin{array}{l}31 \\
32 \\
33 \\
34 \\
35\end{array}$ & $\begin{array}{l}.857 \\
.128 \\
.8 \\
.546 \\
.333\end{array}$ & $\begin{array}{l}.462 \\
.0 \\
.444 \\
.222 \\
.546\end{array}$ & $\begin{array}{l}.046 \\
.2 \\
.057 \\
0 \\
.382\end{array}$ & $\begin{array}{l}.278 \\
.546 \\
.321 \\
.714 \\
.192\end{array}$ & $\begin{array}{l}80 \\
16 \\
81 \\
60 \\
60\end{array}$ \\
\hline $\begin{array}{l}36 \\
37 \\
38 \\
39 \\
40\end{array}$ & $\begin{array}{l}.184 \\
1 \\
.412 \\
.75 \\
.5\end{array}$ & $\begin{array}{l}.273 \\
.938 \\
.231 \\
.75 \\
.6\end{array}$ & $\begin{array}{l}.667 \\
.239 \\
.03 \\
.064 \\
.056\end{array}$ & $\begin{array}{l}.5 \\
.387 \\
.243 \\
.067 \\
.382\end{array}$ & $\begin{array}{l}29 \\
77 \\
70 \\
82 \\
70\end{array}$ \\
\hline $\begin{array}{l}41 \\
42 \\
43 \\
44 \\
45\end{array}$ & $\begin{array}{l}.366 \\
.438 \\
.474 \\
.923 \\
.364\end{array}$ & $\begin{array}{l}.057 \\
.25 \\
.643 \\
1 \\
.361\end{array}$ & $\begin{array}{l}.769 \\
.064 \\
.053 \\
.239 \\
.667\end{array}$ & $\begin{array}{l}.727 \\
.172 \\
.551 \\
.4 \\
.895\end{array}$ & $\begin{array}{l}24 \\
76 \\
67 \\
76 \\
31\end{array}$ \\
\hline $\begin{array}{l}46 \\
47 \\
48 \\
49 \\
50\end{array}$ & $\begin{array}{c}0 \\
.45 \\
.684 \\
.897 \\
.452 \\
\end{array}$ & $\begin{array}{l}0 \\
.286 \\
.2 \\
1 \\
.294 \\
\end{array}$ & $\begin{array}{l}0 \\
.154 \\
.033 \\
.697 \\
.714 \\
\end{array}$ & $\begin{array}{l}0 \\
.5 \\
.417 \\
.708 \\
.643 \\
\end{array}$ & $\begin{array}{r}100 \\
52 \\
66 \\
57 \\
35 \\
\end{array}$ \\
\hline $\begin{array}{l}51 \\
52 \\
53 \\
54 \\
55\end{array}$ & $\begin{array}{l}.75 \\
1 \\
.5 \\
.682 \\
.6\end{array}$ & $\begin{array}{l}0 \\
.556 \\
.474 \\
.278 \\
.286\end{array}$ & $\begin{array}{l}.019 \\
.162 \\
.111 \\
.083 \\
.039\end{array}$ & $\begin{array}{l}.023 \\
.724 \\
.531 \\
.5 \\
.156\end{array}$ & $\begin{array}{l}96 \\
66 \\
59 \\
60 \\
83\end{array}$ \\
\hline
\end{tabular}


APPENDIX XXVIII: (i) Blue Response over Trial Series, by subject (males)

\begin{tabular}{|c|c|c|c|c|c|c|c|c|c|c|}
\hline \multirow[t]{2}{*}{ Subjects } & \multicolumn{10}{|c|}{ Trials } \\
\hline & $1-10$ & $11-20$ & $21-30$ & $31-40$ & $41-50$ & $51-60$ & $61-70$ & $71-80$ & $81-90$ & $\sqrt{91-100}$ \\
\hline $\begin{array}{l}1 \\
2 \\
3 \\
4 \\
5\end{array}$ & $\begin{array}{r}10 \\
5 \\
4 \\
8 \\
7\end{array}$ & $\begin{array}{l}9 \\
5 \\
8 \\
5 \\
5\end{array}$ & $\begin{array}{l}5 \\
6 \\
4 \\
6 \\
8\end{array}$ & $\begin{array}{l}5 \\
6 \\
5 \\
5 \\
5\end{array}$ & $\begin{array}{l}5 \\
6 \\
4 \\
7 \\
4\end{array}$ & $\begin{array}{l}5 \\
7 \\
5 \\
5 \\
5\end{array}$ & $\begin{array}{l}5 \\
5 \\
7 \\
5 \\
6\end{array}$ & $\begin{array}{l}5 \\
5 \\
8 \\
6 \\
2\end{array}$ & $\begin{array}{l}5 \\
4 \\
5 \\
6 \\
4\end{array}$ & $\begin{array}{l}5 \\
4 \\
7 \\
6 \\
4\end{array}$ \\
\hline $\begin{array}{r}6 \\
7 \\
8 \\
9 \\
10\end{array}$ & $\begin{array}{l}8 \\
4 \\
? \\
4 \\
7\end{array}$ & $\begin{array}{r}9 \\
3 \\
10 \\
5 \\
6\end{array}$ & $\begin{array}{l}9 \\
6 \\
7 \\
8 . \\
7\end{array}$ & $\begin{array}{r}6 \\
6 \\
2 \\
3 \\
10\end{array}$ & $\begin{array}{l}9 \\
9 \\
4 \\
3 \\
8\end{array}$ & $\begin{array}{l}9 \\
3 \\
0 \\
2 \\
9\end{array}$ & $\begin{array}{l}7 \\
5 \\
9 \\
6 \\
8\end{array}$ & $\begin{array}{l}8 \\
3 \\
4 \\
3 \\
9\end{array}$ & $\begin{array}{l}7 \\
5 \\
6 \\
4 \\
7\end{array}$ & $\begin{array}{r}10 \\
7 \\
4 \\
8 \\
10\end{array}$ \\
\hline $\begin{array}{l}11 \\
12 \\
13 \\
14 \\
15\end{array}$ & $\begin{array}{r}5 \\
0 \\
3 \\
7 \\
10\end{array}$ & $\begin{array}{r}6 \\
1 \\
0 \\
6 \\
10\end{array}$ & $\begin{array}{l}8 \\
3 \\
3 \\
8 \\
4\end{array}$ & $\begin{array}{l}4 \\
7 \\
2 \\
8 \\
3\end{array}$ & $\begin{array}{l}3 \\
6 \\
2 \\
6 \\
0\end{array}$ & $\begin{array}{l}5 \\
5 \\
1 \\
5 \\
0\end{array}$ & $\begin{array}{l}6 \\
7 \\
4 \\
5 \\
0\end{array}$ & $\begin{array}{l}7 \\
7 \\
7 \\
8 \\
0\end{array}$ & $\begin{array}{l}3 \\
0 \\
9 \\
8 \\
2\end{array}$ & $\begin{array}{r}5 \\
2 \\
8 \\
8 \\
6 \\
6\end{array}$ \\
\hline $\begin{array}{l}16 \\
17 \\
18 \\
19 \\
20\end{array}$ & $\begin{array}{l}3 \\
9 \\
6 \\
3 \\
6\end{array}$ & $\begin{array}{l}4 \\
7 \\
4 \\
1 \\
3\end{array}$ & $\begin{array}{l}5 \\
6 \\
4 \\
3 \\
4\end{array}$ & $\begin{array}{l}5 \\
7 \\
5 \\
9 \\
4\end{array}$ & $\begin{array}{l}7 \\
5 \\
5 \\
9 \\
3\end{array}$ & $\begin{array}{l}6 \\
5 \\
2 \\
9 \\
3\end{array}$ & $\begin{array}{l}6 \\
6 \\
4 \\
8 \\
3\end{array}$ & $\begin{array}{l}4 \\
6 \\
7 \\
7 \\
2\end{array}$ & $\begin{array}{l}6 \\
5 \\
5 \\
8 \\
3\end{array}$ & $\begin{array}{l}6 \\
5 \\
6 \\
9 \\
3\end{array}$ \\
\hline $\begin{array}{l}21 \\
22 \\
23 \\
24 \\
25\end{array}$ & $\begin{array}{l}3 \\
5 \\
6 \\
5 \\
5\end{array}$ & $\begin{array}{l}4 \\
6 \\
8 \\
5 \\
7\end{array}$ & $\begin{array}{l}0 \\
6 \\
6 \\
6 \\
8\end{array}$ & $\begin{array}{l}4 \\
5 \\
8 \\
4 \\
6\end{array}$ & $\begin{array}{r}10 \\
7 \\
7 \\
4 \\
7\end{array}$ & $\begin{array}{r}10 \\
3 \\
6 \\
7 \\
5\end{array}$ & $\begin{array}{r}10 \\
3 \\
8 \\
8 \\
6\end{array}$ & $\begin{array}{r}10 \\
5 \\
7 \\
6 \\
4\end{array}$ & $\begin{array}{r}10 \\
5 \\
6 \\
7 \\
6\end{array}$ & $\begin{array}{r}10 \\
7 \\
7 \\
6 \\
8\end{array}$ \\
\hline $\begin{array}{l}26 \\
27 \\
28 \\
29 \\
30\end{array}$ & $\begin{array}{l}8 \\
7 \\
4 \\
7 \\
5\end{array}$ & $\begin{array}{r}8 \\
6 \\
10 \\
1 \\
6\end{array}$ & $\begin{array}{r}4 \\
6 \\
10 \\
2 \\
7\end{array}$ & $\begin{array}{r}4 \\
9 \\
10 \\
2 \\
5\end{array}$ & $\begin{array}{r}4 \\
4 \\
10 \\
10 \\
7\end{array}$ & $\begin{array}{r}4 \\
7 \\
10 \\
6 \\
10\end{array}$ & $\begin{array}{r}4 \\
5 \\
10 \\
6 \\
10\end{array}$ & $\begin{array}{r}9 \\
7 \\
10 \\
5 \\
10\end{array}$ & $\begin{array}{r}5 \\
4 \\
-10 \\
9 \\
10\end{array}$ & $\begin{array}{r}6 \\
6 \\
10 \\
6 \\
9\end{array}$ \\
\hline $\begin{array}{l}31 \\
32 \\
33 \\
34 \\
35\end{array}$ & $\begin{array}{l}4 \\
3 \\
6 \\
8 \\
5\end{array}$ & $\begin{array}{r}5 \\
3 \\
6 \\
10 \\
6\end{array}$ & $\begin{array}{l}8 \\
4 \\
5 \\
8 \\
5\end{array}$ & $\begin{array}{r}4 \\
5 \\
4 \\
10 \\
10\end{array}$ & $\begin{array}{r}6 \\
5 \\
4 \\
8 \\
10\end{array}$ & $\begin{array}{c}5 \\
2 \\
3 \\
6 \\
10\end{array}$ & $\begin{array}{c}8 \\
6 \\
4 \\
10 \\
10\end{array}$ & $\begin{array}{r}8 \\
2 \\
4 \\
7 \\
10\end{array}$ & $\begin{array}{l}5 \\
6 \\
7 \\
7 \\
4\end{array}$ & $\begin{array}{r}8 \\
5 \\
6 \\
10 \\
9\end{array}$ \\
\hline$\overline{\mathrm{x}}$ & 5.63 & 5.66 & 5.69 & 5.63 & 5.94 & 5.43 & 6.29 & 6.06 & 5.77 & 6.74 \\
\hline
\end{tabular}


APPENDIX XXVIII: (ij) Blue Responses over Trial Series, by subject (females)

\begin{tabular}{|c|c|c|c|c|c|c|c|c|c|c|}
\hline \multirow{2}{*}{ Subjects } & \multicolumn{10}{|c|}{ Trials } \\
\hline & $1-10$ & $11-20$ & $21-30$ & $31-4 c$ & $41-50$ & $51-60$ & $61-70$ & $71-80$ & $81-90$ & $91-100$ \\
\hline $\begin{array}{l}1 \\
2 \\
3 \\
4 \\
5\end{array}$ & $\begin{array}{l}6 \\
5 \\
4 \\
7 \\
7\end{array}$ & $\begin{array}{l}5 \\
8 \\
4 \\
4 \\
5\end{array}$ & $\begin{array}{l}6 \\
5 \\
4 \\
2 \\
5\end{array}$ & $\begin{array}{l}5 \\
5 \\
5 \\
3 \\
3\end{array}$ & $\begin{array}{l}5 \\
3 \\
4 \\
9 \\
5\end{array}$ & $\begin{array}{l}6 \\
6 \\
4 \\
9 \\
3\end{array}$ & $\begin{array}{r}7 \\
4 \\
3 \\
9 \\
10\end{array}$ & $\begin{array}{r}5 \\
4 \\
4 \\
10 \\
5\end{array}$ & $\begin{array}{l}8 \\
7 \\
5 \\
8 \\
6\end{array}$ & $\begin{array}{l}6 \\
1 \\
5 \\
8 \\
6\end{array}$ \\
\hline $\begin{array}{r}6 \\
? \\
8 \\
9 \\
10\end{array}$ & $\begin{array}{l}4 \\
2 \\
9 \\
8 \\
5\end{array}$ & $\begin{array}{l}3 \\
8 \\
7 \\
6 \\
3\end{array}$ & $\begin{array}{l}5 \\
5 \\
7 \\
5 \\
5\end{array}$ & $\begin{array}{l}0 \\
4 \\
7 \\
8 \\
7\end{array}$ & $\begin{array}{r}5 \\
2 \\
10 \\
7 \\
4\end{array}$ & $\begin{array}{r}4 \\
2 \\
10 \\
4 \\
4\end{array}$ & $\begin{array}{r}6 \\
5 \\
10 \\
4 \\
2\end{array}$ & $\begin{array}{r}3 \\
5 \\
10 \\
0 \\
5\end{array}$ & $\begin{array}{r}4 \\
6 \\
10 \\
3 \\
5\end{array}$ & $\begin{array}{l}4 \\
4 \\
9 \\
2 \\
6\end{array}$ \\
\hline $\begin{array}{l}11 \\
12 \\
13 \\
14 \\
15\end{array}$ & $\begin{array}{r}10 \\
4 \\
8 \\
4 \\
7\end{array}$ & $\begin{array}{l}9 \\
6 \\
4 \\
2 \\
5\end{array}$ & $\begin{array}{r}10 \\
7 \\
5 \\
2 \\
7\end{array}$ & $\begin{array}{l}7 \\
6 \\
7 \\
3 \\
5\end{array}$ & $\begin{array}{r}9 \\
9 \\
10 \\
2 \\
8\end{array}$ & $\begin{array}{l}9 \\
9 \\
6 \\
3 \\
7\end{array}$ & $\begin{array}{r}9 \\
7 \\
10 \\
3 \\
9\end{array}$ & $\begin{array}{r}10 \\
8 \\
8 \\
2 \\
9\end{array}$ & $\begin{array}{r}9 \\
8 \\
10 \\
3 \\
6\end{array}$ & $\begin{array}{r}8 \\
9 \\
10 \\
2 \\
8\end{array}$ \\
\hline $\begin{array}{l}16 \\
17 \\
18 \\
19 \\
20\end{array}$ & $\begin{array}{r}7 \\
10 \\
4 \\
7 \\
8\end{array}$ & $\begin{array}{r}.6 \\
10 \\
6 \\
2 \\
7\end{array}$ & $\begin{array}{r}7 \\
10 \\
5 \\
1 \\
6\end{array}$ & $\begin{array}{l}7 \\
8 \\
5 \\
5 \\
8\end{array}$ & $\begin{array}{l}8 \\
2 \\
2 \\
3 \\
7\end{array}$ & $\begin{array}{r}8 \\
10 \\
6 \\
7 \\
8\end{array}$ & $\begin{array}{l}9 \\
3 \\
6 \\
6 \\
7\end{array}$ & $\begin{array}{r}7 \\
7 \\
2 \\
7 \\
10\end{array}$ & $\begin{array}{r}7 \\
10 \\
3 \\
8 \\
9\end{array}$ & $\begin{array}{r}9 \\
10 \\
10 \\
10 \\
9\end{array}$ \\
\hline $\begin{array}{l}21 \\
22 \\
23 \\
24 \\
25\end{array}$ & $\begin{array}{l}6 \\
6 \\
7 \\
2 \\
7\end{array}$ & $\begin{array}{l}7 \\
7 \\
6 \\
3 \\
4\end{array}$ & $\begin{array}{l}8 \\
5 \\
6 \\
4 \\
6\end{array}$ & $\begin{array}{l}6 \\
5 \\
6 \\
5 \\
7\end{array}$ & $\begin{array}{l}9 \\
7 \\
6 \\
7 \\
6\end{array}$ & $\begin{array}{l}7 \\
5 \\
7 \\
6 \\
6\end{array}$ & $\begin{array}{l}6 \\
7 \\
7 \\
9 \\
4\end{array}$ & $\begin{array}{r}6 \\
8 \\
6 \\
10 \\
7\end{array}$ & $\begin{array}{l}9 \\
7 \\
6 \\
9 \\
4\end{array}$ & $\begin{array}{r}10 \\
6 \\
8 \\
10 \\
4\end{array}$ \\
\hline $\begin{array}{l}26 \\
27 \\
28 \\
29 \\
30\end{array}$ & $\begin{array}{l}6 \\
4 \\
5 \\
6 \\
5\end{array}$ & $\begin{array}{r}6 \\
4 \\
2 \\
10 \\
5\end{array}$ & $\begin{array}{l}5 \\
3 \\
2 \\
7 \\
5\end{array}$ & $\begin{array}{l}1 \\
1 \\
6 \\
8 \\
3\end{array}$ & $\begin{array}{l}6 \\
3 \\
6 \\
8 \\
2\end{array}$ & $\begin{array}{l}5 \\
5 \\
6 \\
8 \\
3\end{array}$ & $\begin{array}{r}8 \\
4 \\
2 \\
10 \\
3\end{array}$ & $\begin{array}{r}2 \\
4 \\
2 \\
10 \\
4\end{array}$ & $\begin{array}{r}4 \\
3 \\
6 \\
10 \\
10\end{array}$ & $\begin{array}{r}5 \\
0 \\
10 \\
9 \\
8\end{array}$ \\
\hline $\begin{array}{l}31 \\
32 \\
33 \\
34 . \\
35\end{array}$ & $\begin{array}{l}7 \\
8 \\
9 \\
6 \\
6\end{array}$ & $\begin{array}{l}7 \\
2 \\
8 \\
6 \\
6\end{array}$ & $\begin{array}{l}4 \\
2 \\
5 \\
8 \\
6\end{array}$ & $\begin{array}{l}9 \\
0 \\
9 \\
6 \\
5\end{array}$ & $\begin{array}{r}10 \\
0 \\
9 \\
4 \\
5\end{array}$ & $\begin{array}{l}8 \\
0 \\
9 \\
3 \\
8\end{array}$ & $\begin{array}{l}6 \\
0 \\
5 \\
8 \\
7\end{array}$ & $\begin{array}{r}10 \\
0 \\
10 \\
7 \\
6\end{array}$ & $\begin{array}{r}10 \\
3 \\
7 \\
6 \\
7\end{array}$ & $\begin{array}{r}10 \\
1 \\
10 \\
6 \\
5\end{array}$ \\
\hline $\begin{array}{l}36 \\
37 \\
38 \\
39 \\
40\end{array}$ & $\begin{array}{l}5 \\
8 \\
7 \\
5 \\
8 .\end{array}$ & $\begin{array}{l}2 \\
8 \\
4 \\
8 \\
6\end{array}$ & $\begin{array}{l}5 \\
8 \\
7 \\
9 \\
8\end{array}$ & $\begin{array}{r}4 \\
9 \\
5 \\
10 \\
3\end{array}$ & $\begin{array}{r}5 \\
6 \\
3 \\
10 \\
7\end{array}$ & $\begin{array}{r}3 \\
6 \\
10 \\
10 \\
6\end{array}$ & $\begin{array}{r}4 \\
9 \\
10 \\
10 \\
8\end{array}$ & $\begin{array}{r}0 \\
8 \\
8 \\
10 \\
7\end{array}$ & $\begin{array}{r}1 \\
7 \\
8 \\
10 \\
8\end{array}$ & $\begin{array}{r}1 \\
8 \\
8 \\
10 \\
9\end{array}$ \\
\hline $\begin{array}{l}41 \\
42 \\
43 \\
44 \\
45\end{array}$ & $\begin{array}{l}3 \\
0 \\
8 \\
8 \\
5\end{array}$ & $\begin{array}{l}2 \\
6 \\
6 \\
5 \\
3\end{array}$ & $\begin{array}{l}2 \\
6 \\
6 \\
5 \\
3\end{array}$ & $\begin{array}{l}1 \\
8 \\
7 \\
9 \\
5\end{array}$ & $\begin{array}{r}4 \\
10 \\
6 \\
8 \\
3\end{array}$ & $\begin{array}{l}3 \\
9 \\
6 \\
6 \\
3\end{array}$ & $\begin{array}{r}1 \\
10 \\
5 \\
7 \\
1\end{array}$ & $\begin{array}{l}1 \\
9 \\
7 \\
9 \\
3\end{array}$ & $\begin{array}{r}2 \\
9 \\
9 \\
10 \\
2\end{array}$ & $\begin{array}{r}4 \\
9 \\
7 \\
10 \\
3\end{array}$ \\
\hline $\begin{array}{l}46 \\
47 \\
48 \\
49 \\
50 \\
\end{array}$ & $\begin{array}{r}10 \\
5 \\
6 \\
5 \\
4\end{array}$ & $\begin{array}{r}10 \\
7 \\
4 \\
5 \\
3\end{array}$ & $\begin{array}{r}10 \\
5 \\
5 \\
4 \\
5\end{array}$ & $\begin{array}{r}10 \\
4 \\
9 \\
5 \\
6\end{array}$ & $\begin{array}{r}10 \\
5 \\
4 \\
6 \\
6\end{array}$ & $\begin{array}{r}10 \\
5 \\
4 \\
5 \\
2\end{array}$ & $\begin{array}{r}10 \\
2 \\
5 \\
6 \\
1\end{array}$ & $\begin{array}{c}10 \\
8 \\
9 \\
6 \\
4\end{array}$ & $\begin{array}{r}10 \\
7 \\
10 \\
10 \\
3\end{array}$ & $\begin{array}{r}10 \\
4 \\
10 \\
5 \\
1\end{array}$ \\
\hline $\begin{array}{l}51 \\
52 \\
53 \\
55 \\
55\end{array}$ & $\begin{array}{l}6 \\
7 \\
6 \\
8 \\
8\end{array}$ & $\begin{array}{r}10 \\
7 \\
6 \\
8 \\
8\end{array}$ & $\begin{array}{r}10 \\
8 \\
7 \\
6\end{array}$ & $\begin{array}{r}10 \\
9 \\
6 \\
5 \\
10\end{array}$ & $\begin{array}{r}10 \\
5 \\
6 \\
5 \\
10\end{array}$ & $\begin{array}{r}10 \\
5 \\
4 \\
5 \\
5\end{array}$ & $\begin{array}{r}10 \\
8 \\
7 \\
18\end{array}$ & $\begin{array}{r}10 \\
6 \\
6 \\
6 \\
8\end{array}$ & $\begin{array}{r}10 \\
5 \\
6 \\
5\end{array}$ & $\begin{array}{r}10 \\
6 \\
5 \\
3\end{array}$ \\
\hline $\bar{x}$ & 6.13 & 5.62 & 5.76 & 5.82 & 6.02 & 5.96 & 6.33 & 6.33 & 6.87 & 6.71 \\
\hline
\end{tabular}


APPENDIX XXIX: (i) Leadership Nominations, by subject (males)

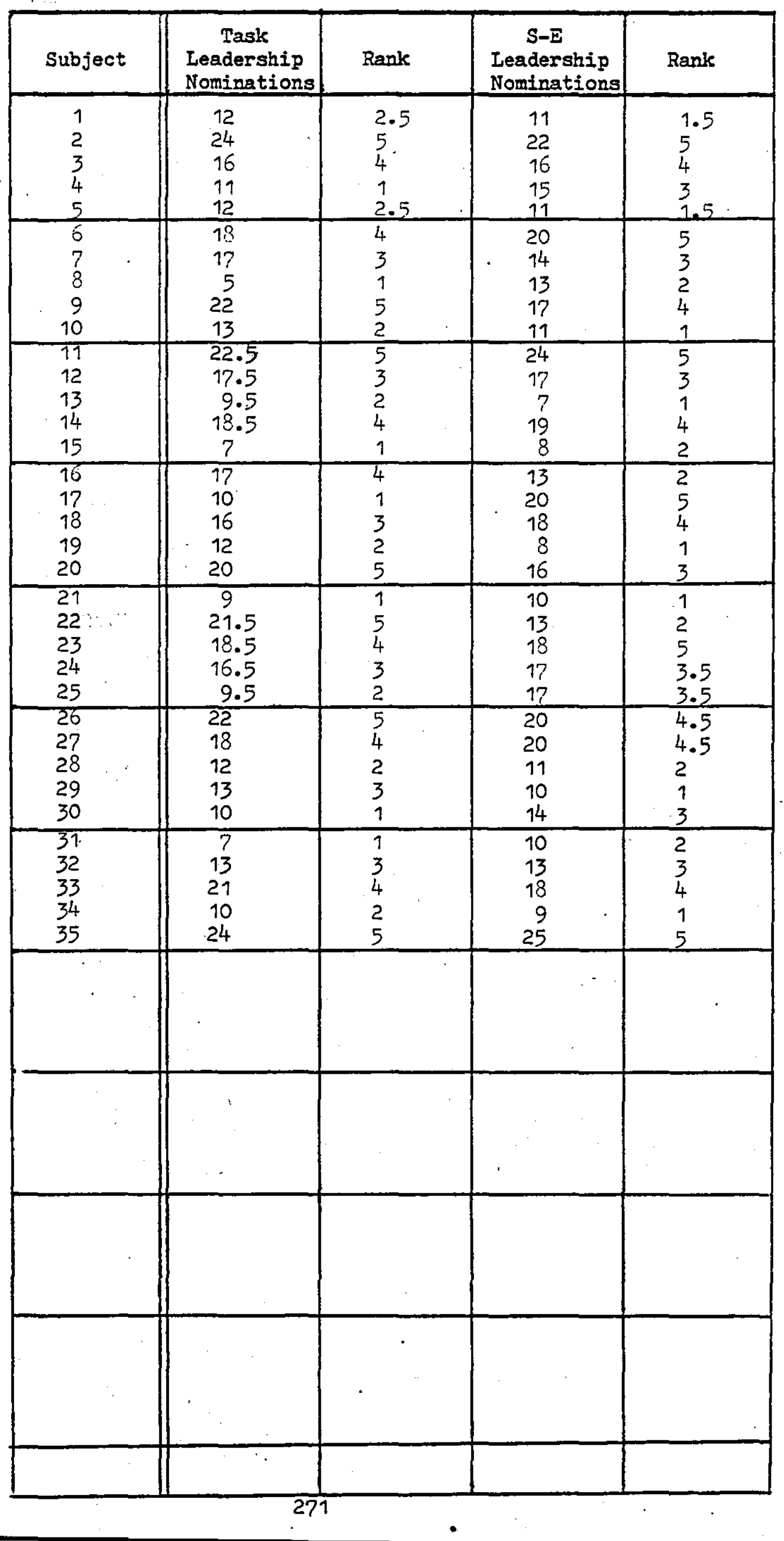


APPLWDIX XXIX: (ii) Leadership Nominations, by subject (females)

\begin{tabular}{|c|c|c|c|c|}
\hline Subject & $\begin{array}{l}\text { Task } \\
\text { Leadership } \\
\text { Nominations }\end{array}$ & Rank & $\begin{array}{l}\text { S-E } \\
\text { Leadership } \\
\text { Nominations } \\
\end{array}$ & Rank \\
\hline $\begin{array}{l}1 \\
2 \\
3 \\
4 \\
5\end{array}$ & $\begin{array}{r}14 \\
11 \\
6 \\
22 \\
22 \\
\end{array}$ & $\begin{array}{l}3 \\
2 \\
1 \\
4.5 \\
4.5\end{array}$ & $\begin{array}{r}13 \\
7 \\
13 \\
21 \\
2 \\
\end{array}$ & $\begin{array}{l}2.5 \\
1 \\
2.5 \\
4.5 \\
4.5\end{array}$ \\
\hline $\begin{array}{r}6 \\
7 \\
8 \\
9 \\
10\end{array}$ & $\begin{array}{l}10 \\
12 \\
18 \\
24 \\
11\end{array}$ & $\begin{array}{l}1 \\
3 \\
4 \\
5 \\
2 \\
\end{array}$ & $\begin{array}{r}16 \\
14 \\
15 \\
23 \\
7\end{array}$ & $\begin{array}{l}4 \\
2 \\
3 \\
5 \\
1\end{array}$ \\
\hline $\begin{array}{l}11 \\
12 \\
13 \\
14 \\
15\end{array}$ & $\begin{array}{r}18 \\
6 \\
17 \\
25 \\
9\end{array}$ & $\begin{array}{l}4 \\
1 \\
3 \\
5 \\
2\end{array}$ & $\begin{array}{r}14 \\
18 \\
6 \\
24 \\
10\end{array}$ & $\begin{array}{l}3 \\
4 \\
1 \\
5 \\
2\end{array}$ \\
\hline $\begin{array}{l}16 \\
17 \\
18 \\
19 \\
20\end{array}$ & $\begin{array}{r}24 \\
8 \\
16 \\
17 \\
10 \\
\end{array}$ & $\begin{array}{l}5 \\
1 \\
3 \\
4 \\
2\end{array}$ & $\begin{array}{r}22 \\
7 \\
20 \\
18 \\
8 \\
\end{array}$ & $\begin{array}{l}5 \\
1 \\
4 \\
3 \\
2 \\
\end{array}$ \\
\hline $\begin{array}{l}21 \\
22 \\
23 \\
24 \\
25\end{array}$ & $\begin{array}{l}19.5 \\
17 \\
12 \\
5 \\
21.5\end{array}$ & $\begin{array}{l}4 \\
3 \\
2 \\
1 \\
5\end{array}$ & $\begin{array}{r}19 \\
17 \\
10 \\
7 \\
22\end{array}$ & $\begin{array}{l}4 \\
3 \\
2 \\
1 \\
5\end{array}$ \\
\hline $\begin{array}{l}26 \\
27 \\
28 \\
29 \\
30 \\
\end{array}$ & $\begin{array}{r}16 \\
17 \\
9 \\
12 \\
21 \\
\end{array}$ & $\begin{array}{l}3 \\
4 \\
1 \\
2 \\
5 \\
\end{array}$ & $\begin{array}{r}19 \\
14 \\
5 \\
16 \\
21 \\
\end{array}$ & $\begin{array}{l}4 \\
2 \\
1 \\
3 \\
5 \\
\end{array}$ \\
\hline $\begin{array}{l}31 \\
32 \\
33 \\
34 \\
35 \\
\end{array}$ & $\begin{array}{c}20.5 \\
7 \\
24 \\
8 \\
15.5 \\
\end{array}$ & $\begin{array}{l}4 \\
1 \\
5 \\
2 \\
3 \\
\end{array}$ & $\begin{array}{l}16 \\
15 \\
20 \\
12 \\
12 \\
\end{array}$ & $\begin{array}{l}4 \\
3 \\
5 \\
1.5 \\
1.5 \\
\end{array}$ \\
\hline $\begin{array}{l}36 \\
37 \\
38 \\
39 \\
40\end{array}$ & $\begin{array}{r}15 \\
18 \\
23 \\
5 \\
14 \\
\end{array}$ & $\begin{array}{l}3 \\
4 \\
5 \\
1 \\
2 \\
\end{array}$ & $\begin{array}{r}13 \\
21 \\
21 \\
13 \\
2\end{array}$ & $\begin{array}{l}2.5 \\
4.5 \\
4.5 \\
2.5 \\
1\end{array}$ \\
\hline $\begin{array}{l}41 \\
42 \\
43 \\
44 \\
45\end{array}$ & $\begin{array}{l}21 \\
12 \\
15 \\
17 \\
10 \\
\end{array}$ & $\begin{array}{l}5 \\
2 \\
3 \\
4 \\
1\end{array}$ & $\begin{array}{r}25 \\
10 \\
15 \\
17 \\
8\end{array}$ & $\begin{array}{l}5 \\
2 \\
3 \\
4 \\
1\end{array}$ \\
\hline $\begin{array}{l}46 \\
47 \\
48 \\
49 \\
50 \\
\end{array}$ & $\begin{array}{r}8 \\
7 \\
23 \\
22 \\
15 \\
\end{array}$ & $\begin{array}{l}2 \\
1 \\
5 \\
4 \\
3 \\
\end{array}$ & $\begin{array}{l}11 \\
13 \\
20 \\
19 \\
12 \\
\end{array}$ & $\begin{array}{l}1 \\
3 \\
5 \\
4 \\
2 \\
\end{array}$ \\
\hline $\begin{array}{l}51 \\
52 \\
53 \\
54 \\
55\end{array}$ & $\begin{array}{r}18 \\
7 \\
13 \\
18 \\
19\end{array}$ & $\begin{array}{l}3.5 \\
1 \\
2 \\
3.5 \\
5\end{array}$ & $\begin{array}{l}20 \\
11 \\
15 \\
12 \\
17\end{array}$ & $\begin{array}{r}5 \\
1 \\
3 \\
2 \\
-4\end{array}$ \\
\hline
\end{tabular}


APPLIDIX XXX: Comparison of Pre-emption Rates, bj sex

\begin{tabular}{|c|c|c|c|c|c|c|c|c|c|}
\hline $\begin{array}{c}\text { Male } \\
\text { Subjects }\end{array}$ & & Ranik & $\begin{array}{c}\text { Male } \\
\text { Subjects }\end{array}$ & & Rank & $\begin{array}{r}\text { Female } \\
\text { subjects }\end{array}$ & & \begin{tabular}{|r|} 
Female \\
Subjects
\end{tabular} & \\
\hline $\begin{array}{l}1 \\
2 \\
3 \\
4 \\
5\end{array}$ & $\begin{array}{c}1 \\
.25 \\
.577 \\
.542 \\
.333\end{array}$ & $\begin{array}{l}4 \\
77 \\
33 \\
39 \\
70.5\end{array}$ & $\begin{array}{l}26 \\
27 \\
28 \\
29 \\
30\end{array}$ & $\begin{array}{l}.571 \\
.692 \\
.333 \\
.286 \\
.455\end{array}$ & $\begin{array}{l}34 \\
23 \\
70 . \\
76 \\
54\end{array}$ & $\begin{array}{l}1 \\
2 \\
3 \\
4 \\
5\end{array}$ & $\begin{array}{l}.955 \\
.074 \\
.4 \\
.5 \\
.636\end{array}$ & $\begin{array}{l}31 \\
32 \\
33 \\
34 \\
35\end{array}$ & $\begin{array}{l}.857 \\
.128 \\
.8 \\
.546 \\
.333\end{array}$ \\
\hline $\begin{array}{r}6 \\
7 \\
8 \\
9 \\
10\end{array}$ & $\begin{array}{l}.778 \\
.63 \\
.333 \\
.222 \\
.444\end{array}$ & $\begin{array}{l}17 \\
31 \\
70.5 \\
80 \\
58 \\
\end{array}$ & $\begin{array}{l}31 \\
32 \\
33 \\
34 \\
35 \\
\end{array}$ & $\begin{array}{l}.65 \\
.485 \\
.542 \\
.556 \\
.533 \\
\end{array}$ & $\begin{array}{l}29 \\
51 \\
38 \\
35 \\
41 \\
\end{array}$ & $\begin{array}{r}6 \\
7 \\
8 \\
9 \\
10 \\
\end{array}$ & $\begin{array}{l}.441 \\
.382 \\
1 \\
.454 \\
.156 \\
\end{array}$ & $\begin{array}{l}36 \\
37 \\
38 \\
39 \\
40 \\
\end{array}$ & $\begin{array}{l}.184 \\
1 \\
.412 \\
.75 \\
.5 \\
\end{array}$ \\
\hline $\begin{array}{l}11 \\
12 \\
13 \\
14 \\
15\end{array}$ & $\begin{array}{l}.333 \\
.243 \\
.2 \\
.688 \\
.121\end{array}$ & $\begin{array}{l}70.5 \\
78 \\
84 \\
25 \\
88\end{array}$ & & & & $\begin{array}{l}11 \\
12 \\
13 \\
14 \\
15\end{array}$ & $\begin{array}{l}.833 \\
.667 \\
1 \\
.205 \\
.5\end{array}$ & $\begin{array}{l}41 \\
42 \\
43 \\
44 \\
45\end{array}$ & $\begin{array}{l}.366 \\
.438 \\
.474 \\
.923 \\
.364\end{array}$ \\
\hline $\begin{array}{l}16 \\
17 \\
18 \\
19 \\
20\end{array}$ & $\begin{array}{l}.5 \\
.65 \\
.292 \\
.474 \\
.546\end{array}$ & $\begin{array}{l}45 \\
28 \\
74 \\
52.5 \\
36.5\end{array}$ & & & & $\begin{array}{l}16 \\
17 \\
18 \\
19 \\
20\end{array}$ & $\begin{array}{c}.857 \\
.364 \\
.522 \\
.539 \\
1\end{array}$ & $\begin{array}{l}46 \\
47 \\
48 \\
49 \\
50\end{array}$ & $\begin{array}{l}.0 \\
.45 \\
.684 \\
.897 \\
.452\end{array}$ \\
\hline $\begin{array}{l}21 \\
22 \\
23 \\
24 \\
25\end{array}$ & $\begin{array}{l}.214 \\
.207 \\
.382 \\
.708 \\
.706\end{array}$ & $\begin{array}{l}81 \\
82 \\
11 \\
22 \\
21 \\
\end{array}$ & & & & $\begin{array}{l}21 \\
22 \\
23 \\
24 \\
25 \\
\end{array}$ & $\begin{array}{l}.368 \\
.476 \\
.75 \\
.5 \\
.813 \\
\end{array}$ & $\begin{array}{l}51 \\
52 \\
53 \\
54 \\
55\end{array}$ & $\begin{array}{l}.75 \\
1 \\
.5 \\
.682 \\
.6 \\
\end{array}$ \\
\hline . & & & & & & $\begin{array}{l}26 \\
27 \\
28 \\
29\end{array}$ & $\begin{array}{l}.5 \\
.225 \\
.29 \\
1\end{array}$ & & \\
\hline & & & & & & 30 & .333 & $n_{2}=55$ & \\
\hline
\end{tabular}

Null Hypothesis $\left(\mathrm{H}_{0}\right)$ : Sex does not have an influence on rate of pre-emption. $\left(\mathrm{H}_{1}\right)$ : Sex does have an influence on rate of pre-emption.

Employing a Mann-Whitney $\delta$ test, $\begin{aligned} \delta=n_{1} n_{2}+\frac{n_{1}\left(n_{1}+1\right)}{2}-R_{1} & =1925+630-1720 \\ & =835\end{aligned}$ For $n_{2}$ larger than $20, z=\frac{\delta-n_{1} n_{2} / 2}{\sqrt{\frac{\left(n_{1}\right)\left(n_{2}\right)\left(n_{1}+n_{2}+1\right)}{12}} \frac{127.5}{120.82}}=1.06$

$z>1.06$ has a two-tailed probability under $\mathrm{H}_{0}$ of $p<.299$. Region of rejection, p) .05.

Therefore, $\mathrm{H}_{0}$ accepted. Sex does not have an influence on rate of pre-emption. 
APPENDIX XXXI: Comparison of Pre-emption Rates: Male Socio-emotional Leaders and other Group Members

\begin{tabular}{|c|c|c|c|c|}
\hline $\begin{array}{c}\text { Subjects } \\
\text { (leaders) }\end{array}$ & $\begin{array}{l}\text { Pre-emption } \\
\text { rate }\end{array}$ & Rank & $\begin{array}{l}\text { Subjects } \\
\text { (others) }\end{array}$ & $\begin{array}{l}\text { Pre-emption } \\
\text { rate }\end{array}$ \\
\hline $\begin{array}{c}1 \\
5 \\
10 \\
13 \\
19 \\
21 \\
29 \\
34\end{array}$ & $\begin{array}{l}1 \\
.333 \\
.444 \\
.2 \\
.474 \\
.214 \\
.286 \\
.556\end{array}$ & $\begin{array}{c}35 \\
12.5 \\
14 \\
2 \\
16 \\
4 \\
8 \\
23\end{array}$ & $\begin{array}{r}2 \\
3 \\
4 \\
6 \\
7 \\
8 \\
9 \\
11 \\
12 \\
14 \\
15 \\
16 \\
17 \\
18 \\
20 \\
22 \\
23 \\
24 \\
25 \\
26 \\
27 \\
28 \\
30 \\
31 \\
32 \\
33 \\
35\end{array}$ & $\begin{array}{l}.25 \\
.577 \\
.542 \\
.778 \\
.63 \\
.333 \\
.222 \\
.333 \\
.243 \\
.688 \\
.121 \\
.5 \\
.65 \\
.292 \\
.546 \\
.207 \\
.882 \\
.708 \\
.706 \\
.571 \\
.692 \\
.333 \\
.455 \\
.65 \\
.485 \\
.542 \\
.533\end{array}$ \\
\hline $\mathbf{x}_{1}=8$ & , & $1=114$. & $n_{2}=27$ & \\
\hline
\end{tabular}

Null Hypothesis $\left(\mathrm{H}_{\mathrm{O}}\right)$ : Male socio-emotional leaders have the same rate of pre-emption as other male subjects.

$\left(B_{1}\right)$ : Male socio-emotional leaders have lower rates of pre-emption than other male subjects.

Employing a Mann-Whitney $\delta$ test, $\delta=n_{1} n_{2}+\frac{n_{1}\left(n_{1}+1\right)}{2}-R_{1}=216+36-114.5$

For $n_{2}$ larger than $20, \quad z=\frac{J-n_{1} n_{2} / 2}{\sqrt{\frac{\left(n_{1}\right)\left(n_{2}\right)\left(n_{1}+n_{2}+1\right)}{12}} \frac{39.5}{25.46}}=1.55$

Z) 1.5 has a one-tailed probability under $\mathrm{H}_{0}$ of $\mathrm{p}\langle .06$. Region of rejection,p $>.05$

Therefore, $\mathrm{H}_{\mathrm{O}}$ accepted at the $5 \%$ level, but rejected as the $7 \%$ level. 
APPENDIX XXXII: Comparison of Pre-emption Rates: Male Task Leaders and other Groip Members

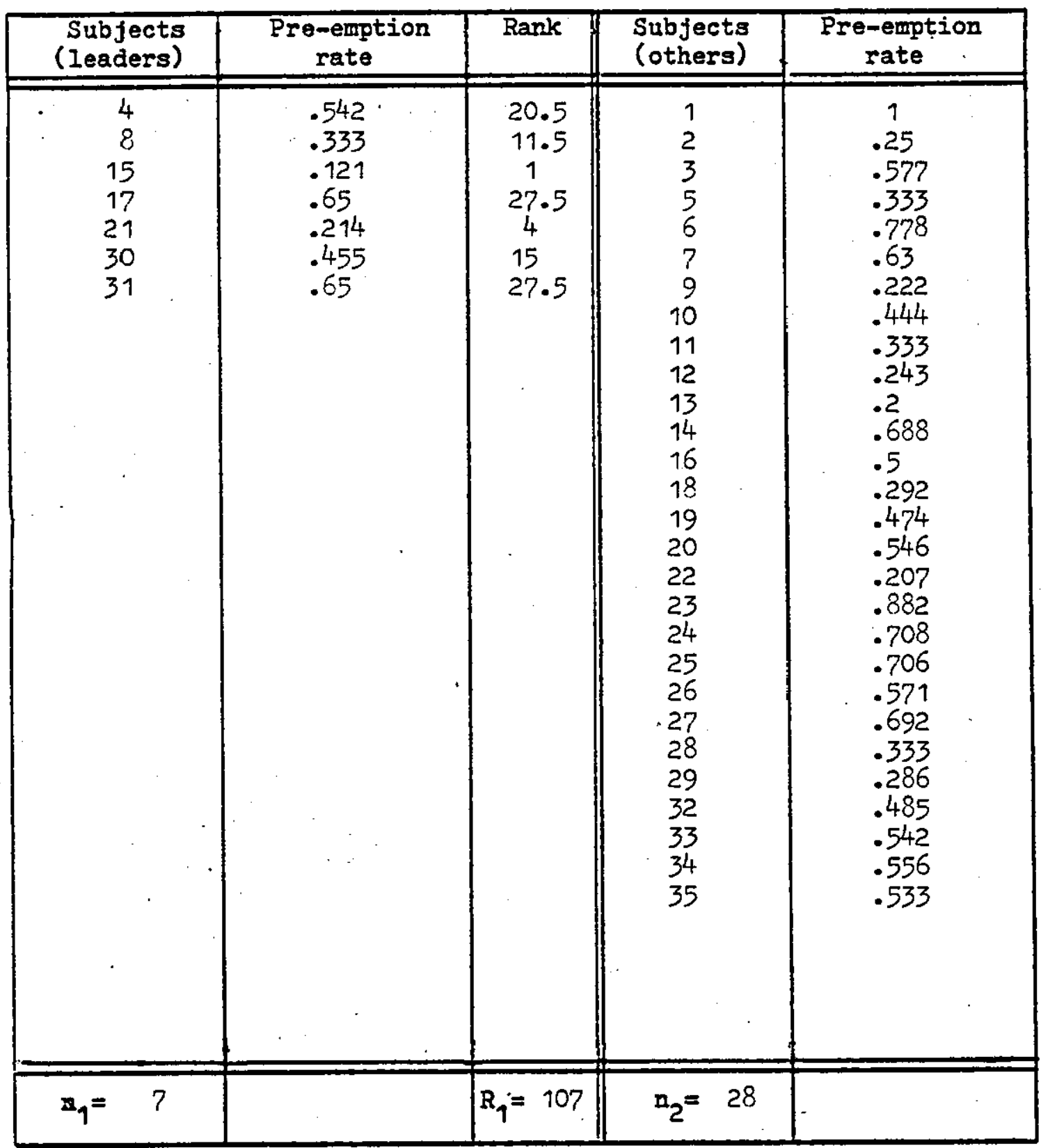

Null Hypothesis $\left(\mathrm{H}_{\mathrm{O}}\right)$ : Male task leaders have the same rate of pre-emption as other $\left(H_{1}\right)$ : Male task leaders have lower rates of pre-emption than other

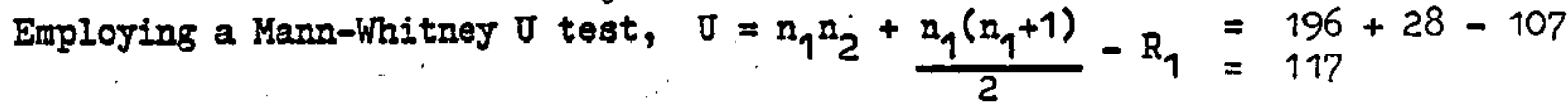

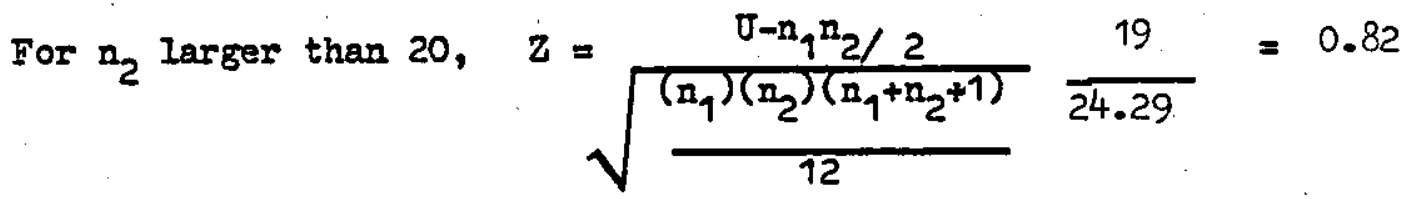

z) :82 has a one-tailed probability under $\mathrm{H}_{0}$ of $\mathrm{p}<.206$. Region of rejection,p $>.05$

Therefore, $\mathrm{H}_{0}$ accepted. Male task leaders have the same rate of pre-emption as other male subjects. 


\begin{tabular}{|c|c|c|c|c|c|c|}
\hline $\begin{array}{l}\text { Subjects } \\
\text { (Ieaders) }\end{array}$ & $\begin{array}{l}\text { Pre-emption } \\
\text { rate }\end{array}$ & Rank & $\begin{array}{l}\text { Subjects } \\
\text { (others) }\end{array}$ & $\begin{array}{l}\text { Pre-emption } \\
\text { rate }\end{array}$ & $\begin{array}{l}\text { Subjects } \\
\text { (others) }\end{array}$ & $\begin{array}{c}\text { Pre-emptio } \\
\text { rate }\end{array}$ \\
\hline $\begin{array}{r}2 \\
10 \\
13 \\
16 \\
24 \\
28 \\
34 \\
35 \\
40 \\
45 \\
46 \\
52\end{array}$ & $\begin{array}{l}.074 \\
.156 \\
1 \\
.364 \\
.5 \\
.29 \\
.546 \\
.333 \\
.5 \\
.364 \\
0 \\
1\end{array}$ & $\begin{array}{c}2 \\
4 \\
52.5 \\
11.5 \\
27.5 \\
8 \\
33 \\
9.5 \\
27.5 \\
11.5 \\
-1 \\
52.5\end{array}$ & $\begin{array}{l}1 \\
3 \\
4 \\
5 \\
6 \\
7 \\
8 \\
9 \\
11 \\
12 \\
14 \\
15 \\
17 \\
18 \\
19 \\
20 \\
21 \\
22 \\
23 \\
25 \\
26 \\
27 \\
29 \\
30\end{array}$ & $\begin{array}{l}.954 \\
.4 \\
.5 \\
.636 \\
.441 \\
.382 \\
1 \\
.455 \\
.833 \\
.677 \\
.205 \\
.5 \\
.364 \\
.522 \\
.539 \\
1 \\
.368 \\
.476 \\
.75 \\
.813 \\
.5 \\
.225 \\
.1 \\
.333\end{array}$ & $\begin{array}{l}31 \\
32 \\
33 \\
36 \\
37 \\
38 \\
39 \\
41 \\
42 \\
43 \\
44 \\
47 \\
48 \\
49 \\
50 \\
51 \\
53 \\
54 \\
55\end{array}$ & $\begin{array}{l}.857 \\
.128 \\
.8 \\
.184 \\
1 \\
.412 \\
.75 \\
.366 \\
.438 \\
.474 \\
.923 \\
.45 \\
.684 \\
.897 \\
.452 \\
.75 \\
.5 \\
.682 \\
.6\end{array}$ \\
\hline$n_{1}=12$ & & $R_{124}$ & & & $\mathbf{n}_{2}=$ & \\
\hline
\end{tabular}

Null Hypothesis $\left(B_{0}\right)$ : Female socio-emotional leaders have the same rate of pre-e ption as other female subjects.

$\left(H_{1}\right)$ : Female socio-emotional leaders have lower rates of pre-emption than other female subjects.

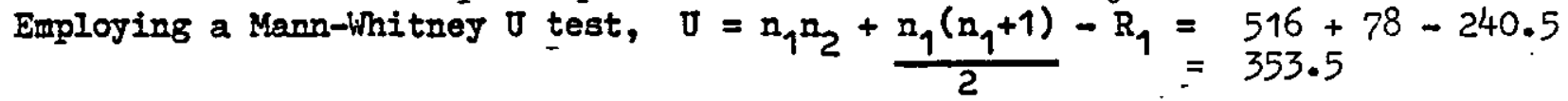

For $n_{2}$ larger than 20, $z=\frac{\delta-n_{1} n_{2} / 2}{\sqrt{\frac{\left(n_{1}\right)\left(n_{2}\right)\left(n_{1}+n_{2}+1\right)}{12}} \frac{95.5}{49.07}}=1.946$

$z \geqslant 1.95$ has a one-tailed probability under $\mathrm{H}_{0}$ of $\mathrm{p}<.026$.

Region of rejection, $p>05$.

Therefore, $\mathrm{H}_{0}$ rejected, $\mathrm{H}_{1}$ accepted. Female socio-emotional leaders have lower rates of pre-emption than other female subjects. 


\begin{tabular}{|c|c|c|c|c|c|c|}
\hline $\begin{array}{l}\text { Subjects } \\
\text { (Ieaders) }\end{array}$ & $\begin{array}{l}\text { Pre-emption } \\
\text { rate }\end{array}$ & Rank & $\begin{array}{l}\text { Subjects } \\
\text { (others) } \\
\end{array}$ & $\begin{array}{c}\text { Pre-emption } \\
\text { rate }\end{array}$ & $\begin{array}{l}\text { Subjects } \\
\text { (others) }\end{array}$ & $\begin{array}{c}\text { Bre-emptic } \\
\text { rate }\end{array}$ \\
\hline $\begin{array}{r}3 \\
6 \\
12 \\
17 \\
24 \\
28 \\
32 \\
39 \\
45 \\
47 \\
52\end{array}$ & $\begin{array}{l}.4 \\
.441 \\
.667 \\
.364 \\
.5 \\
.29 \\
.128 \\
.75 \\
.364 \\
.45 \\
1\end{array}$ & $\begin{array}{l}16 \\
19 \\
36 \\
11.5 \\
27.5 \\
8 \\
3 \\
40 \\
12 \\
20 \\
52.5\end{array}$ & $\begin{array}{r}1 \\
2 \\
4 \\
5 \\
7 \\
8 \\
9 \\
10 \\
11 \\
13 \\
14 \\
15 \\
16 \\
18 \\
19 \\
20 \\
21 \\
22 \\
23 \\
25 \\
26 \\
27 \\
29 \\
30\end{array}$ & $\begin{array}{l}.954 \\
.074 \\
.5 \\
.636 \\
.382 \\
1 \\
.455 \\
.156 \\
.833 \\
1 \\
.205 \\
.5 \\
.857 \\
.522 \\
.539 \\
1 \\
.368 \\
.476 \\
.75 \\
.813 \\
.5 \\
.225 \\
1 \\
.333\end{array}$ & $\begin{array}{l}31 \\
33 \\
34 \\
35 \\
36 \\
37 \\
38 \\
40 \\
41 \\
42 \\
43 \\
44 \\
46 \\
48 \\
49 \\
50 \\
51 \\
53 \\
54 \\
55\end{array}$ & $\begin{array}{l}.357 \\
.8 \\
.546 \\
.333 \\
.184 \\
1 \\
.412 \\
.5 \\
.366 \\
.438 \\
.474 \\
.923 \\
0 \\
.684 \\
.897 \\
.452 \\
.75 \\
.5 \\
.682 \\
.6\end{array}$ \\
\hline$n_{1}=11$ & & $R_{2135}=$ & & & $n_{2}=44$ & \\
\hline
\end{tabular}

Null Hypothesis $\left(\mathrm{H}_{\mathrm{O}}\right)$ : Female task leaders have the same rate of pre-emption
as other female subjects.

$\left(H_{1}\right)$ : Female task leaders have lower rates of pre-emption than other female subjects.

Employing a Mann-Whitney $\delta$ test, $\begin{aligned} \delta=n_{1} n_{2}+\frac{n_{1}\left(n_{1}+1\right)}{2}-R_{1} & =484+66-235.5 \\ & =314.5\end{aligned}$

For $n_{2}$ larger than 20, $z=\frac{\delta-n_{1} n_{2} / 2}{\sqrt{\frac{\left(n_{1}\right)\left(n_{2}\right)\left(n_{1}+n_{2}+1\right)}{12}} \frac{72.5}{47.53}}=1.525$

z) 1.53 has a one-tailed probability under $\mathrm{B}_{0}$ of $\mathrm{p}<.063$.

Region of rejection, p).05.

Therefore, $\mathrm{H}_{\mathrm{O}}$ accepted at $5 \%$ level, but rejected at $7 \%$ level. 
There is a row of five houses each painted a different colour. Five people of different nationalities live in these five houses. Each person keeps his own peculiar type of pet; drinks his own distinctive type of drink; and each smokes a brand of cigarette different from that of any of his neighbours.

The following are the items of information you are given:

1. There are five houses

2. The Norwegian lives in the first house

3. The Englishman lives in the red house

4. Kools are smoked in the yellow house.

5. The Japanese smokes Parliaments

6. Milk is drunk in the middle house

7. The Old Gold smoker keeps snails

8. Coffee is drunk in the green house

9. The man who smokes Chesterfields lives next to the house with the fox

10. The Norwegian lives next to the blue house

11. The Spaniard has a dog

12. The Lucky Strike smoker drinks orange juice

13. The Ukranian drinks tea

14. Kools are smoked in the house next to the house with the horse

15. The green house is on the right of the ivory house

WHO drinks water?

WHO owns the zebra? 
APPENDIX XXXVI: (i) Summary of Game Behaviour, by subject (males)

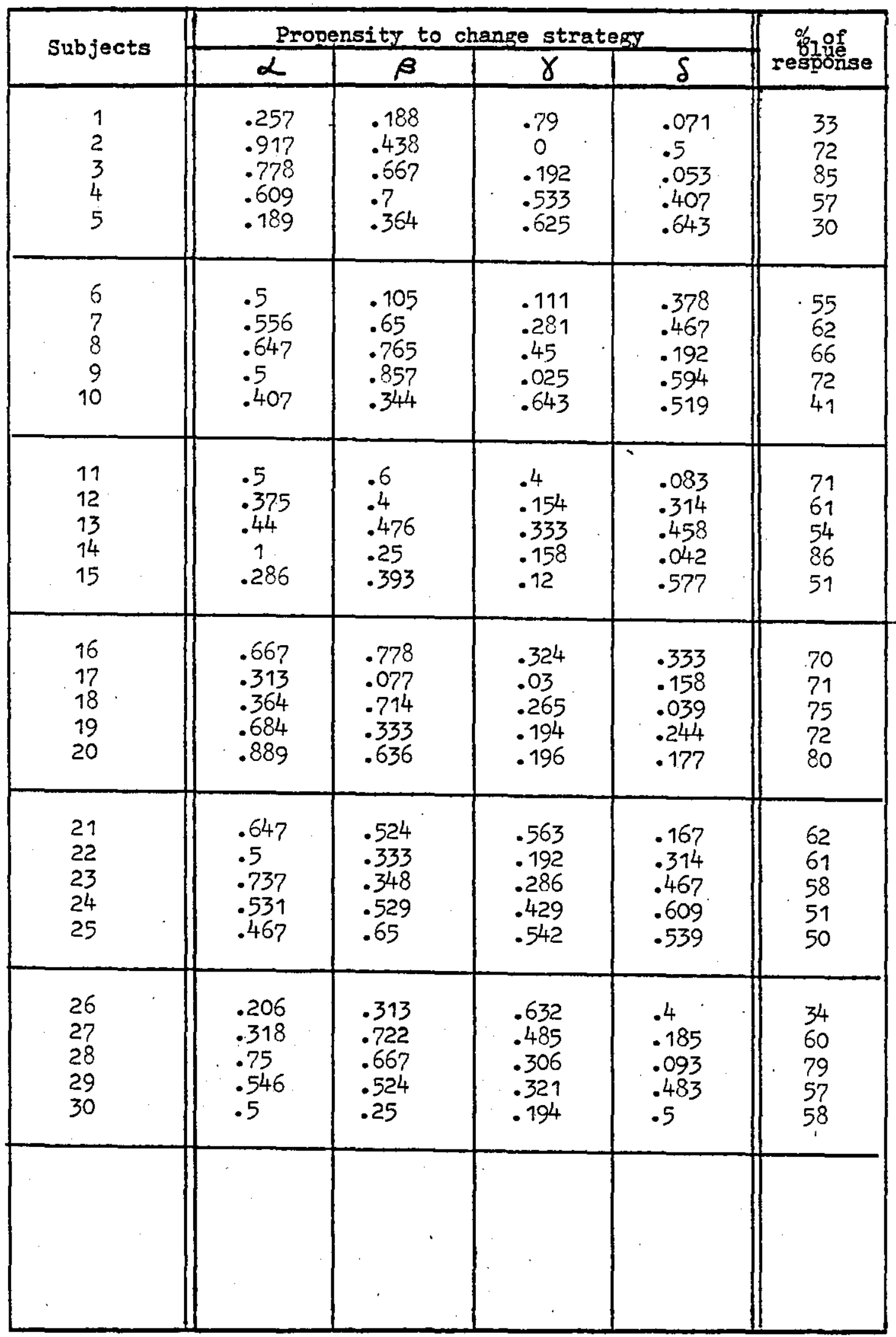


APPENDIX XXXVI: (ii) Summary of Game Behaviour, by subject (female)

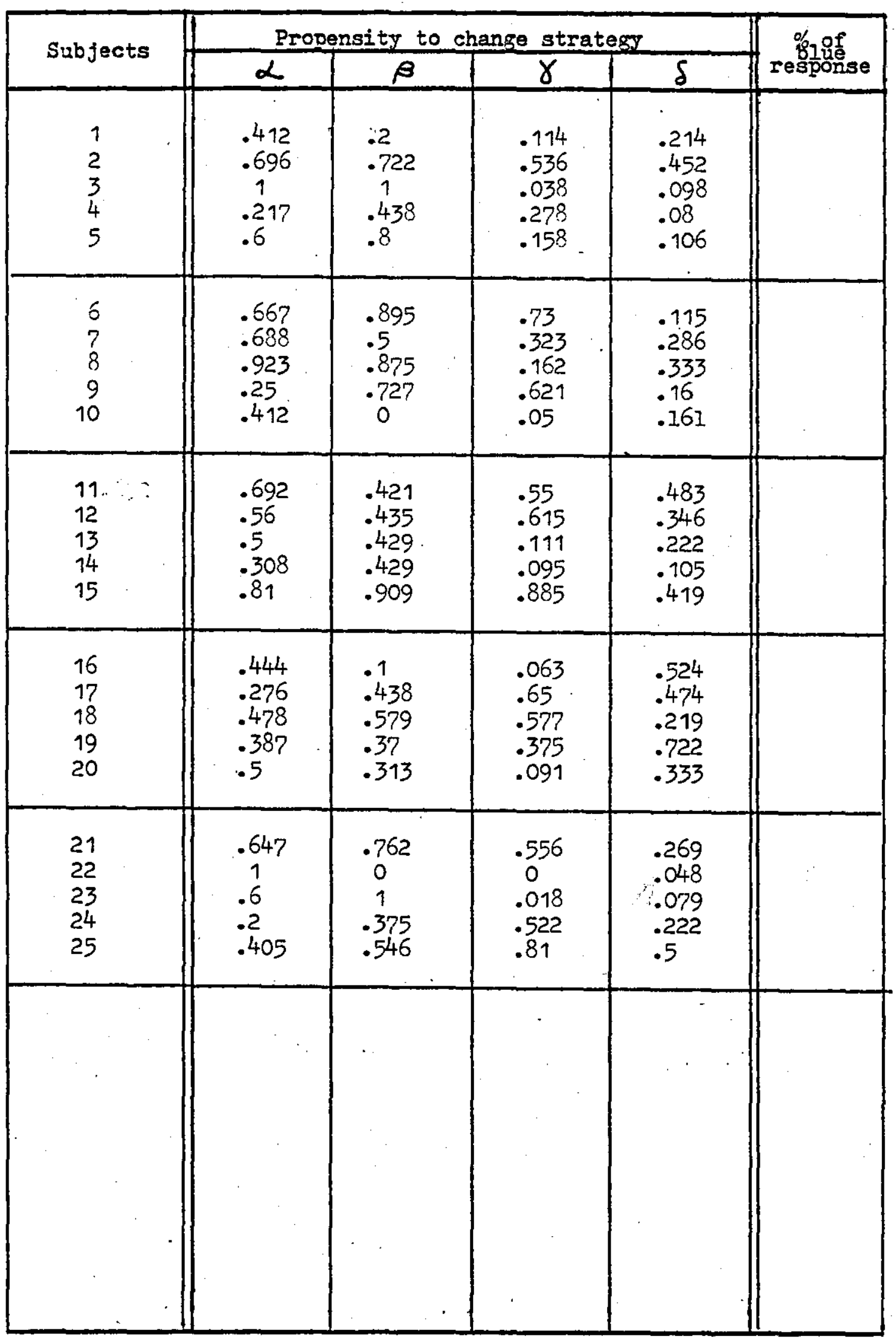


APEIDIX XXXVII: (i) BIue Response over Trial Series, by subject (males)

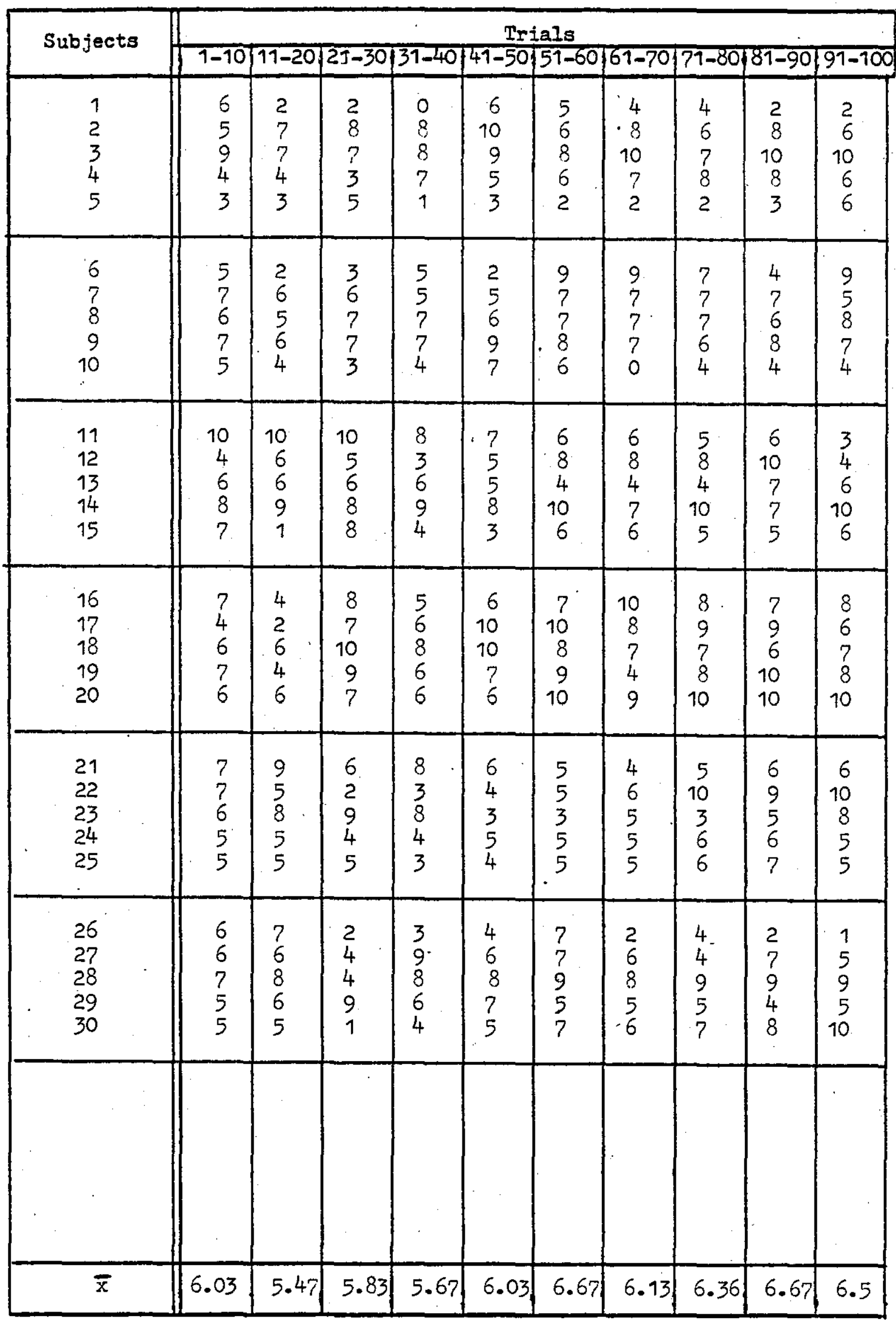


APPFIDIX XXXIII: (ii) BIue Response over Trial Series, by subject (females)

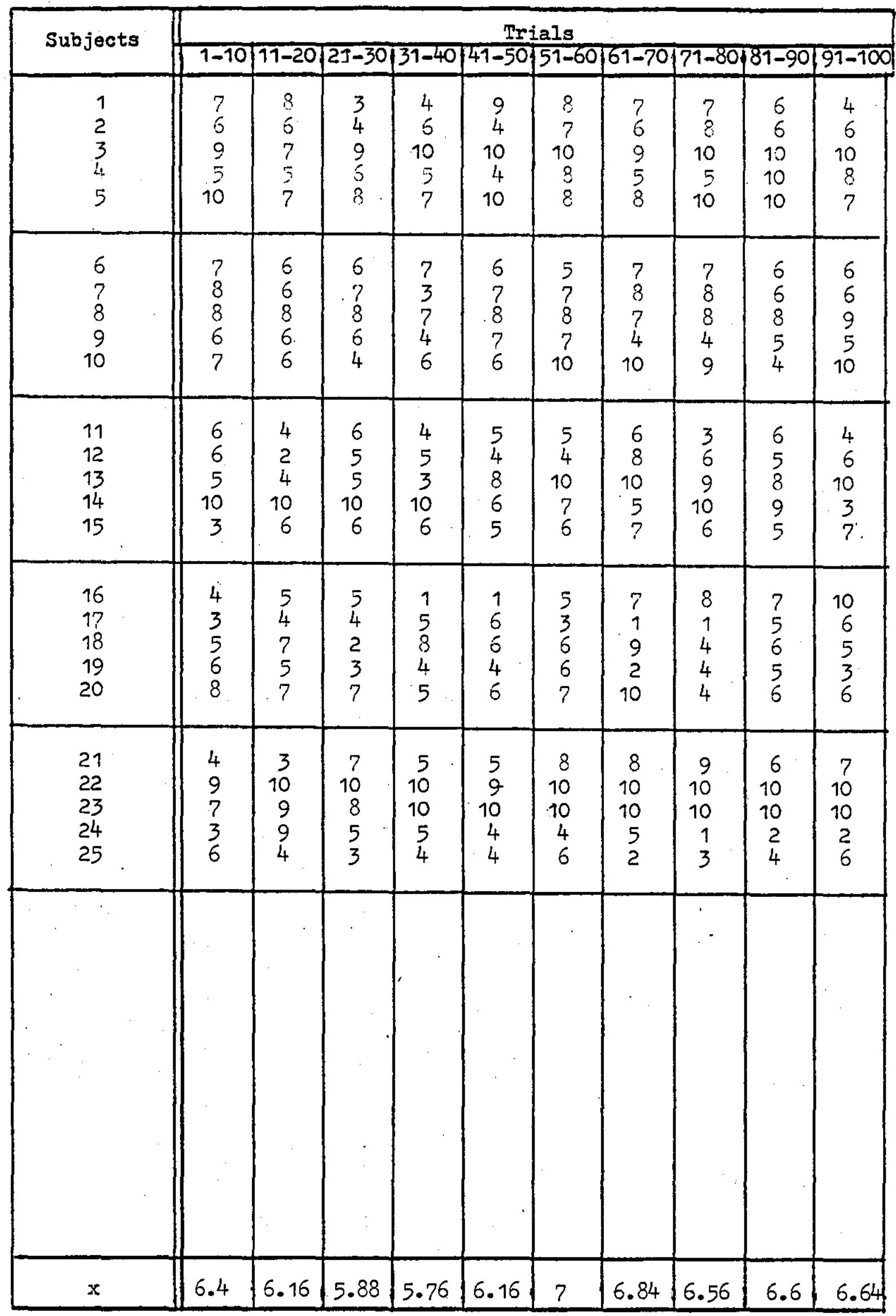


(i) Leadership Nominations, by subject (males)

\begin{tabular}{|c|c|c|c|c|}
\hline Subject & $\begin{array}{l}\quad \text { Task } \\
\text { Leadership } \\
\text { Nominations }\end{array}$ & Rank & $\begin{array}{l}\quad \text { S-E } \\
\text { Leadership } \\
\text { Nominations }\end{array}$ & Rank \\
\hline $\begin{array}{l}1 \\
2 \\
3 \\
4 \\
5\end{array}$ & $\begin{array}{r}13 \\
5 \\
14 \\
18 \\
25\end{array}$ & $\begin{array}{l}2 \\
1 \\
3: \\
4 \\
5\end{array}$ & $\begin{array}{r}7 \\
16 \\
17 \\
15 \\
20\end{array}$ & $\begin{array}{l}1 \\
3 \\
4 \\
2 \\
5\end{array}$ \\
\hline $\begin{array}{r}6 \\
7 \\
8 \\
9 \\
10\end{array}$ & $\begin{array}{r}20 \\
8 \\
8 \\
16 \\
23\end{array}$ & $\begin{array}{l}4 \\
1.5 \\
1.5 \\
3 \\
5\end{array}$ & $\begin{array}{l}12 \cdot 5 \\
14.5 \\
12 \cdot 5 \\
16 \\
16.5\end{array}$ & $\begin{array}{l}1.5 \\
3 \\
1.5 \\
4 \\
5\end{array}$ \\
\hline $\begin{array}{l}11 \\
12 \\
13 \\
14 \\
15\end{array}$ & $\begin{array}{r}15 \\
7 \\
13 \\
23 \\
17 i\end{array}$ & $\begin{array}{l}3 \\
1 \\
2 \\
5 \\
4\end{array}$ & $\begin{array}{r}17 \\
15 \\
9 \\
20 \\
14\end{array}$ & $\begin{array}{l}4 \\
3 \\
1 \\
5 \\
2\end{array}$ \\
\hline $\begin{array}{l}16 \\
17 \\
18 \\
19 \\
20\end{array}$ & $\begin{array}{r}19 \\
13 \\
6 \\
17 \\
20\end{array}$ & $\begin{array}{l}4 \\
2 \\
1 \\
3 \\
5\end{array}$ & $\begin{array}{r}12 \\
9 \\
14 \\
22 \\
18\end{array}$ & $\begin{array}{l}2 \\
1 \\
3 \\
5 \\
4\end{array}$ \\
\hline $\begin{array}{l}21 \\
22 \\
23 \\
24 \\
25 \\
\end{array}$ & $\begin{array}{r}18 \\
18 \\
9 \\
13 \\
17 \\
\end{array}$ & $\begin{array}{l}4.5 \\
4.5 \\
1 \\
2 \\
3 \\
\end{array}$ & $\begin{array}{r}20 \\
20 \\
11 \\
8 \\
16 \\
\end{array}$ & $\begin{array}{l}4.5 \\
4.5 \\
2 \\
1 \\
3 \\
\end{array}$ \\
\hline $\begin{array}{l}26 \\
27 \\
28 \\
29 \\
30\end{array}$ & $\begin{array}{r}19 \\
13 \\
6 \\
22 \\
15\end{array}$ & $\begin{array}{l}4 \\
2 \\
1 \\
5 \\
3\end{array}$ & $\begin{array}{l}12 \\
11 \\
14 \\
22 \\
16\end{array}$ & $\begin{array}{l}2 \\
1 \\
3- \\
5 \\
4\end{array}$ \\
\hline
\end{tabular}


APPEMIX XXXVIII: (ii) Leadership Nominations, by subject (females)

\begin{tabular}{|c|c|c|c|c|}
\hline Subject & $\begin{array}{l}\text { Task } \\
\text { Leadership } \\
\text { Nominations } \\
\end{array}$ & Rank & $\begin{array}{l}\quad S-E \\
\text { Leadership } \\
\text { Nominations } \\
\end{array}$ & Rank \\
\hline $\begin{array}{l}1 \\
2 \\
3 \\
4 \\
5\end{array}$ & $\begin{array}{r}13 \\
8 \\
10 \\
19 \\
25\end{array}$ & $\begin{array}{l}3 \\
1 \\
2 \\
4 \\
5\end{array}$ & $\begin{array}{r}15 \\
14 \\
8 \\
15 \\
23\end{array}$ & $\begin{array}{l}3.5 \\
2 \\
1 \\
3.5 \\
5\end{array}$ \\
\hline $\begin{array}{r}6 \\
7 \\
8 \\
9 \\
10\end{array}$ & $\begin{array}{r}19 \\
18 \\
8 \\
8 \\
22\end{array}$ & $\begin{array}{l}4 \\
3 \\
1.5 \\
1.5 \\
5\end{array}$ & $\begin{array}{r}24 \\
18 \\
17 \\
7 \\
9\end{array}$ & $\begin{array}{l}5 \\
4 \\
3 \\
1 \\
2\end{array}$ \\
\hline $\begin{array}{l}11 \\
12 \\
13 \\
14 \\
15\end{array}$ & $\begin{array}{r}9 \\
17 \\
18 \\
23 \\
8\end{array}$ & $\begin{array}{l}2 \\
4 \\
3 \\
5 \\
1\end{array}$ & $\begin{array}{r}8 \\
14 \\
18 \\
18 \\
17 \\
\end{array}$ & $\begin{array}{l}1 \\
2 \\
4.5 \\
4.5 \\
3 \\
\end{array}$ \\
\hline $\begin{array}{l}16 \\
17 \\
18 \\
19 \\
20 \\
\end{array}$ & $\begin{array}{r}21 \\
15 \\
10 \\
20 \\
9 \\
\end{array}$ & $\begin{array}{l}5 \\
3 \\
2 \\
4 \\
1 \\
\end{array}$ & $\begin{array}{r}17.5 \\
14.5 \\
9 \\
18.5 \\
15.5 \\
\end{array}$ & $\begin{array}{l}4 \\
2 \\
1 \\
5 \\
3 \\
\end{array}$ \\
\hline $\begin{array}{l}21 \\
22 \\
23 \\
24 \\
25\end{array}$ & $\begin{array}{r}6 \\
13 \\
24 \\
17 \\
15\end{array}$ & $\begin{array}{l}1 \\
2 \\
5 \\
4 \\
3\end{array}$ & $\begin{array}{r}9 \\
13 \\
24 \\
20 \\
9\end{array}$ & $\begin{array}{l}1.5 \\
3 \\
5 \\
4 \\
1.5\end{array}$ \\
\hline & & & & $\cdot$ \\
\hline
\end{tabular}


APPENDIX XXXIX: Comparison of Pre-emption Rate: Male Task Leaders and other Group Members

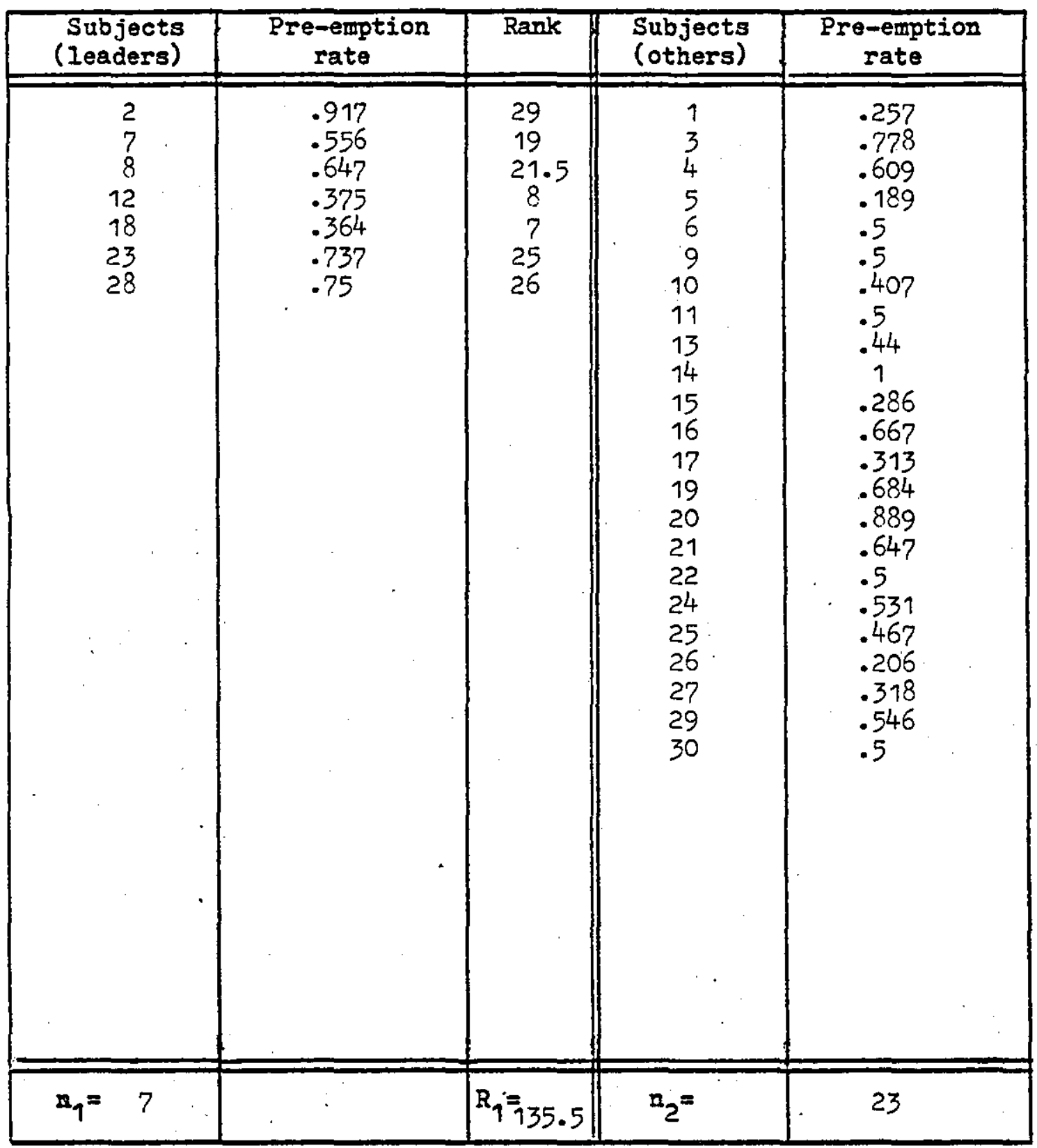

Null Hypothesis $\left(\mathrm{H}_{\mathrm{O}}\right)$ : Male task leaders have the same rate of pre-emption as other male subjects.

$\left(\mathbb{H}_{1}\right)$ : Male task leaders have higher rates of pre-emption than other male subjects.

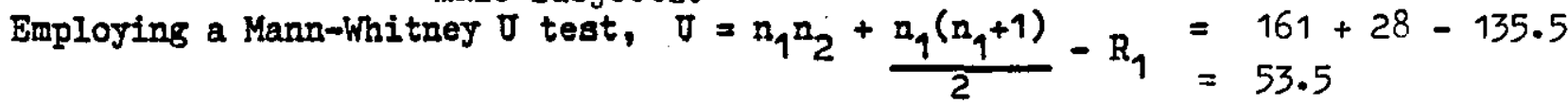

For $\mathrm{n}_{2}$ larger than 20, $\quad \mathrm{z}=\frac{\delta-\mathrm{n}_{1} \mathrm{n}_{2} / 2}{\sqrt{\frac{\left(\mathrm{n}_{1}\right)\left(\mathrm{n}_{2}\right)\left(\mathrm{n}_{1}+\mathrm{n}_{2}+1\right)}{12}} \frac{27}{20.39}}=1.32$

z) 1.32 has a one-tailed probability under $\mathrm{H}_{0}$ of $\mathrm{p}<.093$. Region of rejection, $>.05$

Therefore, $\mathrm{H}_{\mathrm{O}}$ accepted at $5 \%$ level, but rejected at $10 \%$ level. 


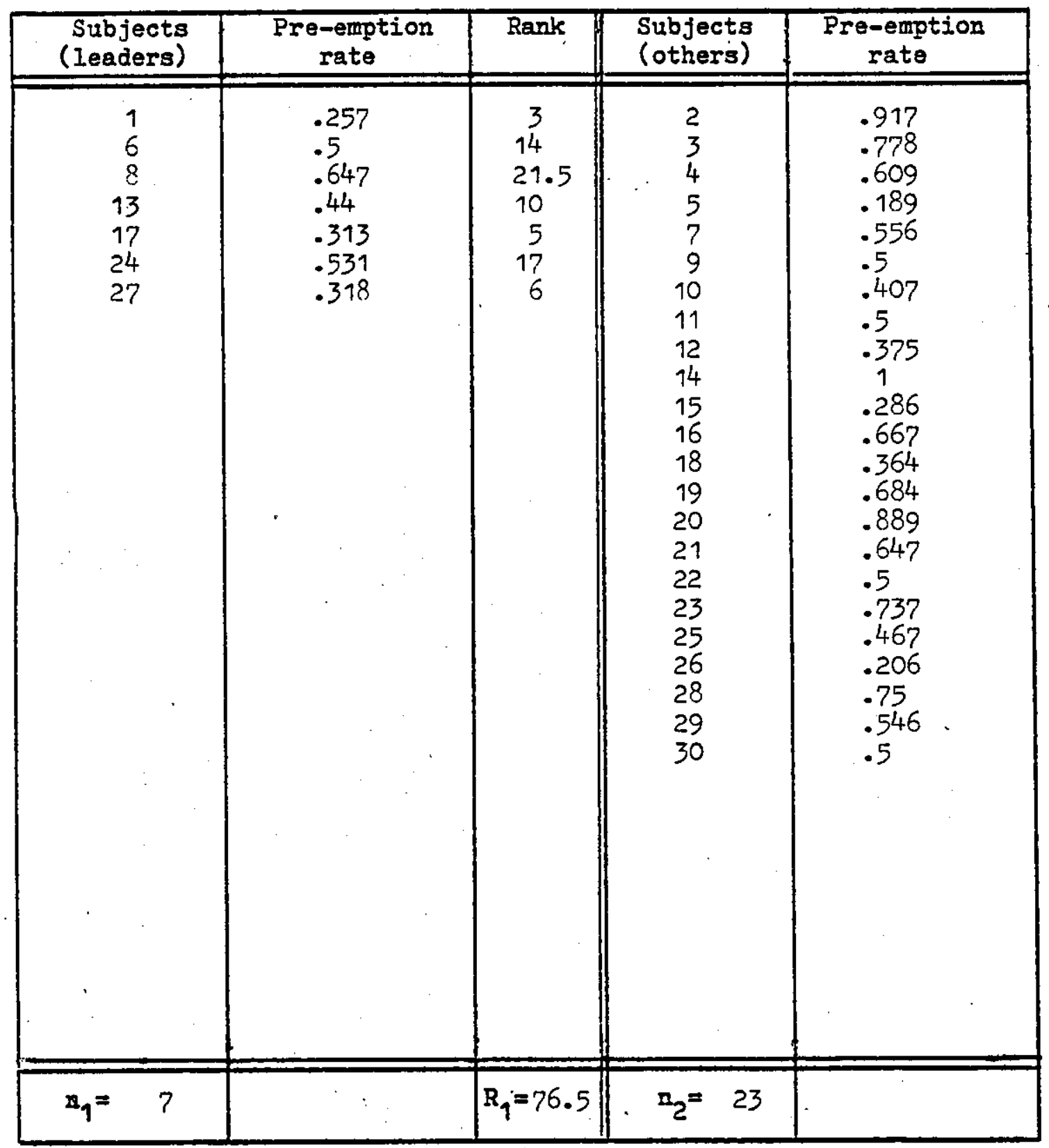

Null Eypothesis $\left(H_{0}\right)$ : Male socio-emotional leaders have the same rate of pre-emption as other male subjects.

$\left(\mathrm{H}_{1}\right)$ : Male socio-emotional leaders have higher rates of pre-emption than other male subjects.

Employing a Mann-Whitney $\delta$ test, $\dot{\delta}=n_{1} n_{2}+\frac{n_{1}\left(n_{1}+1\right)}{2}-R_{1}=\begin{aligned} & 161+28-76.5 \\ & 112.5\end{aligned}$ For $n_{2}$ larger than 20, $\quad z=\frac{\delta-n_{1} n_{2} / 2}{\sqrt{\frac{\left(n_{1}\right)\left(n_{2}\right)\left(n_{1}+n_{2}+1\right)}{12}} \frac{32}{20.39}}=1.57$

z) 1.5 Thas a one-tailed probability under $\mathrm{H}_{0}$ of $\mathrm{p}<.058$. Region of rejection, $p>05$ Therefore, $\mathrm{H}_{0}$ accepted at the $5 \%$ level, but rejected at $7 \%$ level. 
APPENDIX XII: Comparison of Pre-emption Rate: Female Task Leaders and other Group Members

\begin{tabular}{|c|c|c|c|c|c|}
\hline $\begin{array}{l}\text { Subjects } \\
\text { (leaders) }\end{array}$ & $\begin{array}{l}\text { Pre-emption } \\
\text { rate }\end{array}$ & Rank & $\begin{array}{l}\text { Subjects } \\
\text { (others) }\end{array}$ & $\begin{array}{l}\text { Pre-emption } \\
\text { rate }\end{array}$ & Rank \\
\hline $\begin{array}{r}2 \\
8 \\
9 \\
15 \\
20 \\
21\end{array}$ & $\begin{array}{l}.696 \\
.923 \\
.25 \\
.81 \\
.5 \\
.647\end{array}$ & $\begin{array}{l}21 \\
23 \\
3 \\
22 \\
12.5 \\
17\end{array}$ & $\begin{array}{r}1 \\
3 \\
4 \\
5 \\
6 \\
7 \\
10 \\
11 \\
12 \\
13 \\
14 \\
16 \\
17 \\
18 \\
19 \\
22 \\
23 \\
24 \\
25\end{array}$ & $\begin{array}{l}.412 \\
1 \\
.217 \\
.6 \\
.667 \\
.688 \\
.412 \\
.692 \\
.56 \\
.5 \\
.308 \\
.444 \\
.276 \\
.478 \\
.387 \\
1 \\
.6 \\
.2 \\
.405\end{array}$ & $\begin{array}{c}8.5 \\
24.5 \\
2 \\
15.5 \\
18 \\
19 \\
8.5 \\
20 \\
14 \\
12.5 \\
5 \\
10 \\
4 \\
11 \\
6 \\
24.5 \\
15.5 \\
1 \\
7\end{array}$ \\
\hline$n_{1}=6$ & & $R_{1}=98.5$ & $\mathfrak{n}_{2}=\quad 19$ & & $R_{2}=2 i$ \\
\hline
\end{tabular}

Null Hypothesis $\left(\mathrm{H}_{0}\right)$ : Female task leaders have the same rate of pre-emption as other group members.

$\left(H_{1}\right)$ : Female task leaders have higher rates of pre-emption than other group members.

Imploying a Mann-ihitney U test, $\begin{aligned} & \sigma=n_{1} n_{2}+\frac{n_{1}\left(n_{1}+1\right)}{2}-R_{1}=114=21-98.5 \\ & =36.5\end{aligned}$ $n_{1}=6, n_{2}=19, U=36.5$. Critical value of $U=30$, at $5 \%$ level of signif. Therefore, $\mathrm{H}_{0}$ accepted. Female task leaders have the same rate of pre-emption as other group members. 


\begin{tabular}{|c|c|c|c|c|c|}
\hline $\begin{array}{l}\text { Subjects } \\
\text { (leaders) }\end{array}$ & $\begin{array}{l}\text { Pre-emption } \\
\text { rate }\end{array}$ & Rank & $\begin{array}{l}\text { Subjects } \\
\text { (others) }\end{array}$ & $\begin{array}{l}\text { Pre-emption } \\
\text { rate }\end{array}$ & Rank \\
\hline $\begin{array}{r}3 \\
9 \\
11 \\
18 \\
21 \\
25\end{array}$ & $\begin{array}{l}1 \\
.25 \\
.692 \\
.478 \\
.647 \\
.405\end{array}$ & $\begin{array}{c}24.5 \\
3 \\
20 \\
11 \\
17 \\
7\end{array}$ & $\begin{array}{r}1 \\
2 \\
4 \\
5 \\
6 \\
7 \\
8 \\
10 \\
12 \\
13 \\
14 \\
15 \\
16 \\
17 \\
19 \\
20 \\
22 \\
23 \\
24\end{array}$ & $\begin{array}{l}.412 \\
.696 \\
.217 \\
.6 \\
.667 \\
.688 \\
.923 \\
.412 \\
.56 \\
.5 \\
.308 \\
.81 \\
.444 \\
.276 \\
.387 \\
.5 \\
1 \\
.6 \\
.2\end{array}$ & $\begin{array}{c}8.5 \\
21 \\
2 \\
15.5 \\
18 \\
19 \\
23 \\
8.5 \\
14 \\
12.5 \\
5 \\
22 \\
10 \\
4 \\
6 \\
12.5 \\
24.5 \\
15.5 \\
1\end{array}$ \\
\hline$n_{1}=6$ & & $\mathbf{R}_{\mathbf{1}}=82$. & $n_{2}=19$ & & $\mathrm{R}_{2}=2^{2}$ \\
\hline
\end{tabular}

Null Eypothesis $\left(H_{0}\right)$ : Female socio-emotional leaders have the same rate of pre-emption as other group members.

$\left(H_{1}\right)$ : Female socio-emotional leaders have higher rates of pre-emption than other group members.

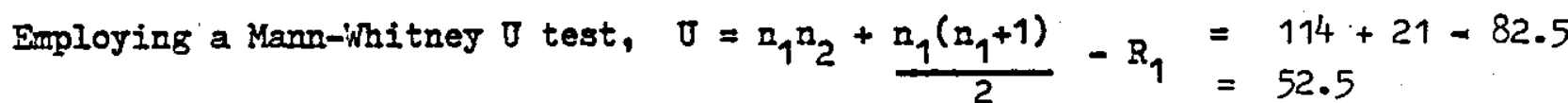
$n_{1}=6, n_{2}=19, J=82.5$ Critical value of $U=30$, at $\%$ level of signif.

Therefore, $\mathrm{H}$ accepted, Female socio-emotional leaders have the same rate of pre-emption as other group members: 
APPENDIX XIIII: Group Problem: Investigation Three

Imagine yourselves in the role of a think tank, brought together to look at the problems of energy and energy conservation in the 1980's. Discuss freely what you consider the most promising areas for development in the coming decade. You may if you wish jot down your ideas on the wall board behind you and be prepared to present a summary of your discussion on my return in 30 minutes. 
APPENDIX XLIV: (i) Summary of Game Behaviour, by subject (males)

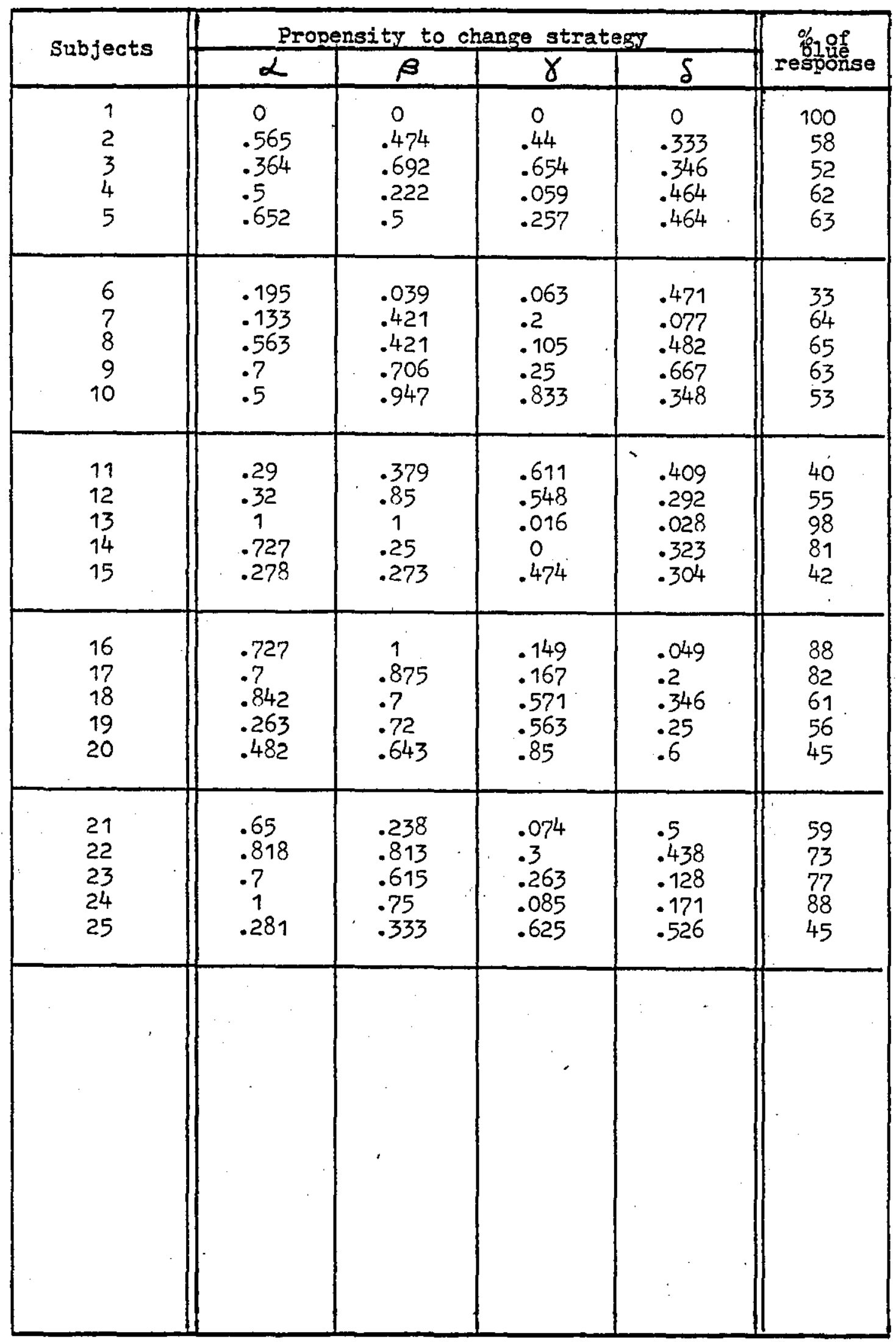


APPENDIX XIIV: (ii) Summary of Game Behaviour, by subject (females)

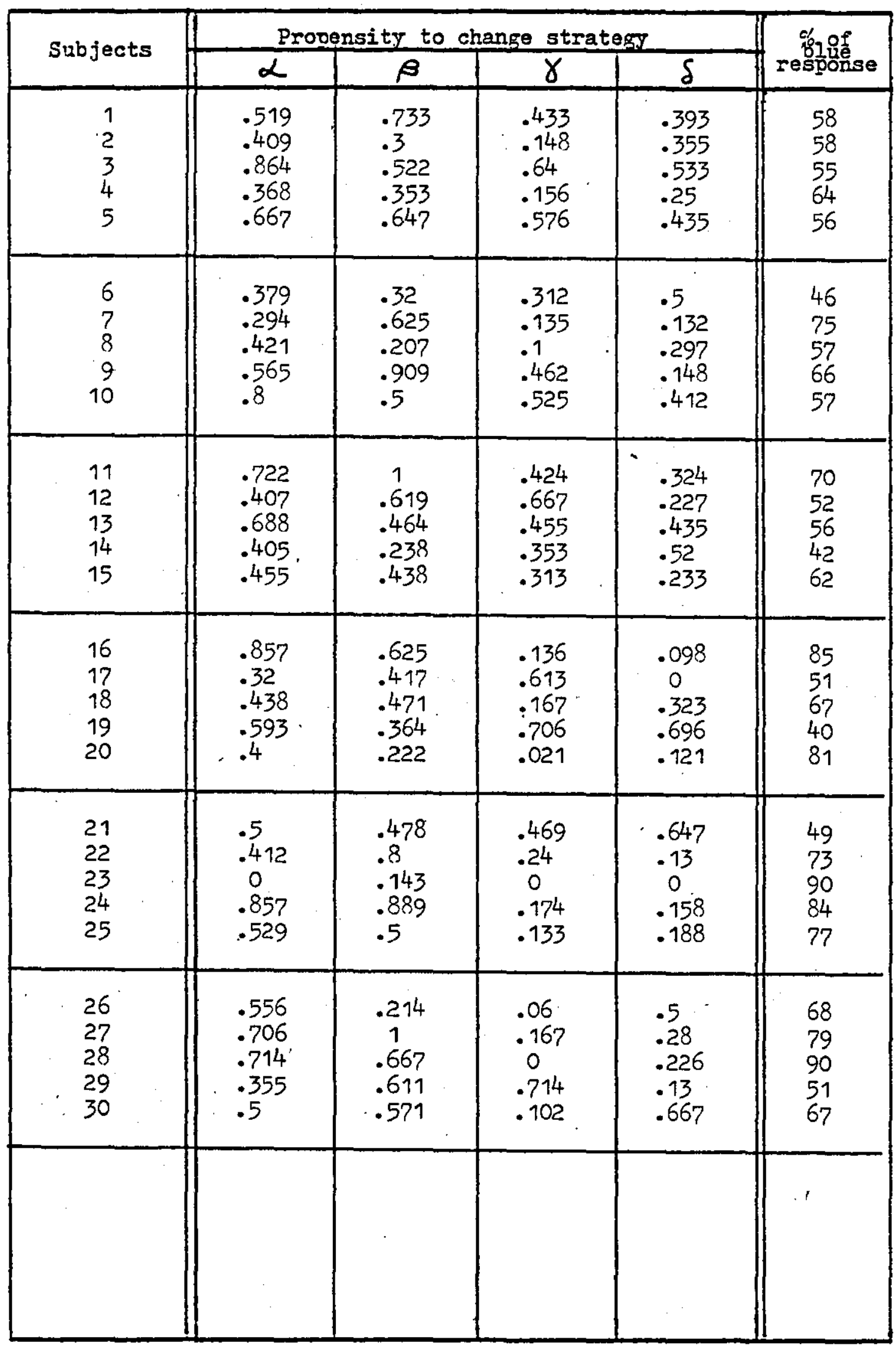


APPENDIX XIV: (i) BIue Response over Trial Series, by subject (males)

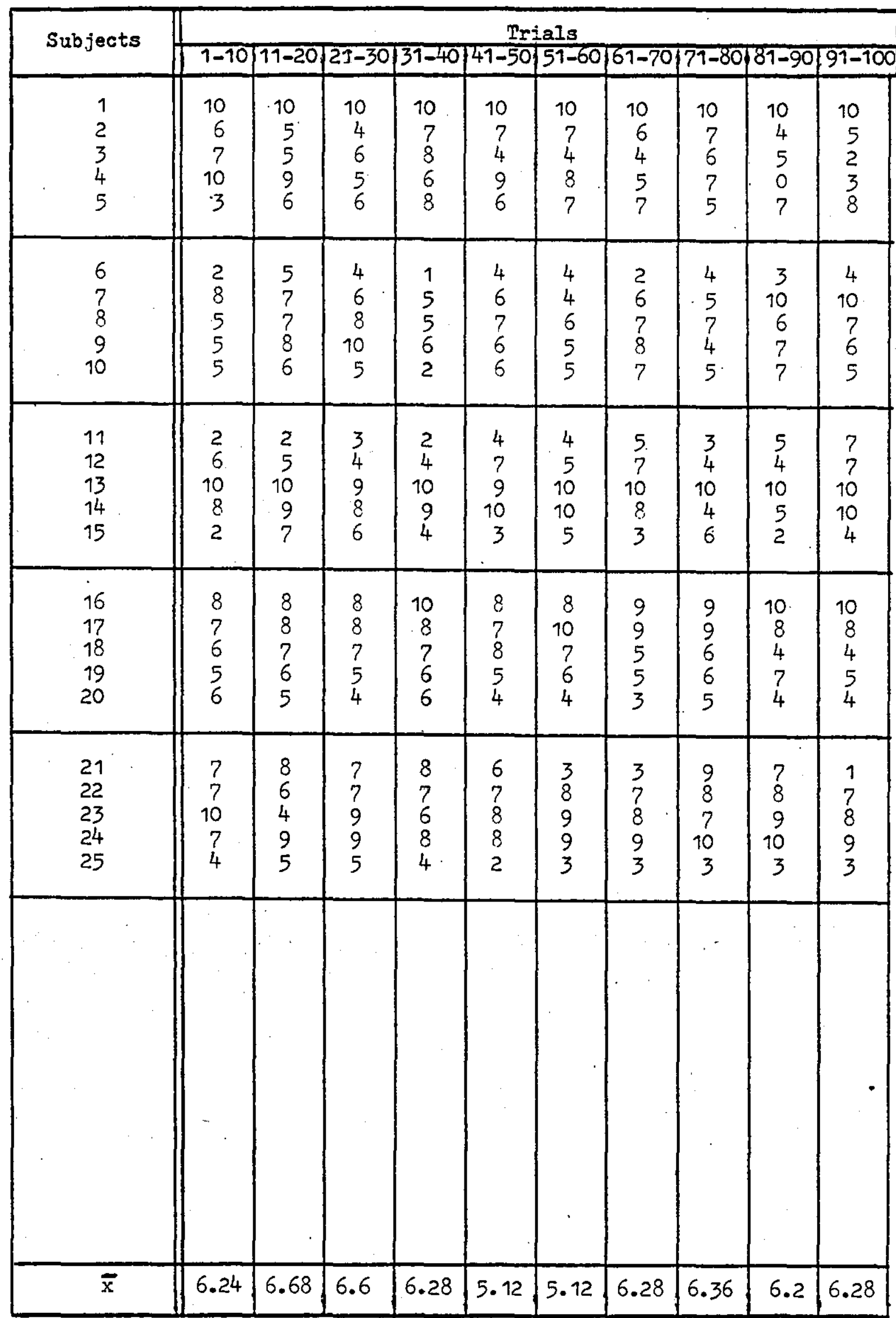


APPENDIX XLi: (ii) Blue Responses over Trial Series, by subject, (females)

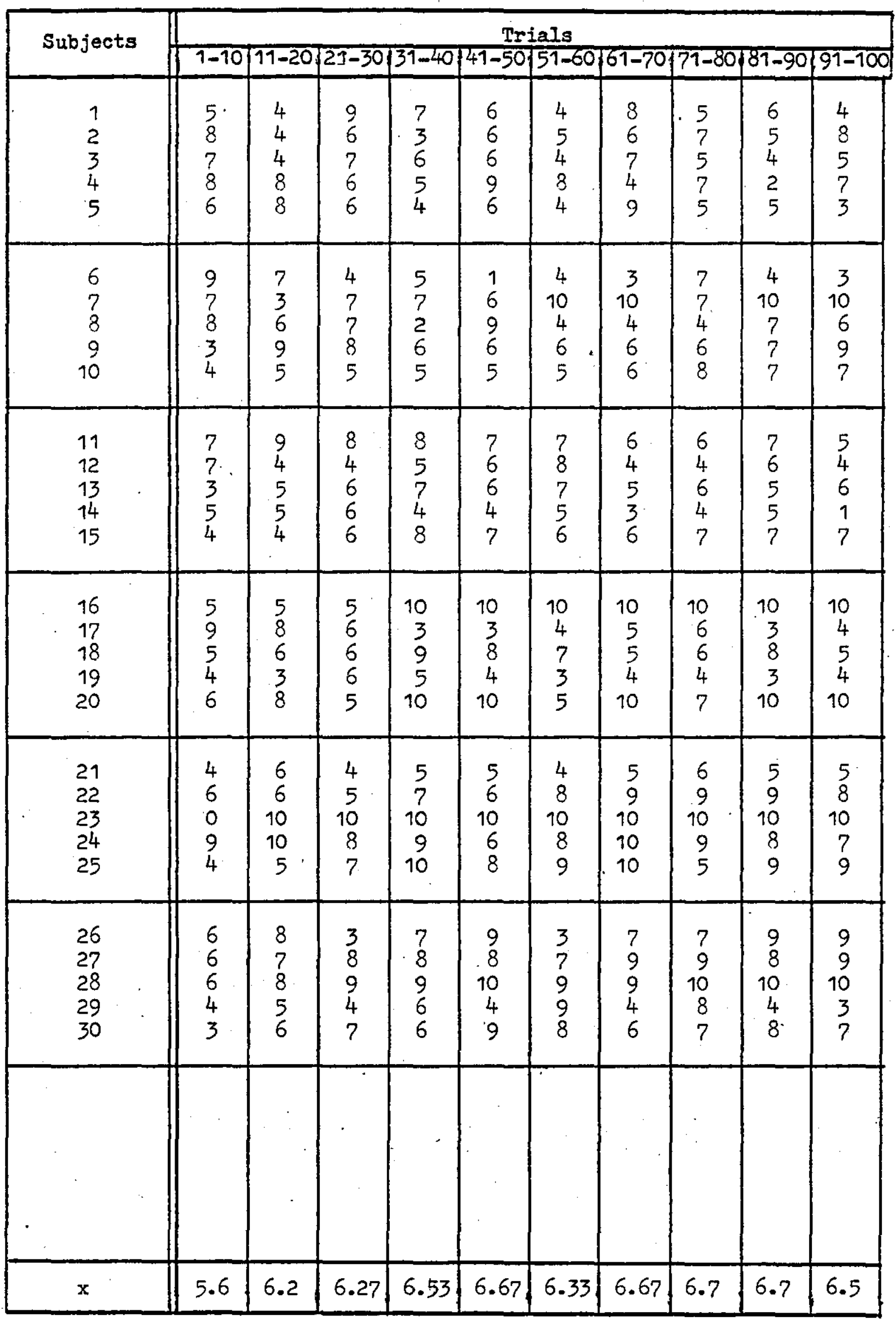


APPENDIX XLVI: (i) Leadership Nominations, by subject (males)

\begin{tabular}{|c|c|c|c|c|}
\hline Subject & $\begin{array}{l}\text { Task } \\
\text { Leadership } \\
\text { Nominations }\end{array}$ & Rank & $\begin{array}{l}\quad \text { S-E } \\
\text { Leadership } \\
\text { Nominations } \\
\end{array}$ & Rank \\
\hline $\begin{array}{l}1 \\
2 \\
3 \\
4 \\
5\end{array}$ & $\begin{array}{r}12 \\
20 \\
13 \\
25 \\
5\end{array}$ & $\begin{array}{l}2 \\
4 \\
3 \\
5 \\
1\end{array}$ & $\begin{array}{r}11 \\
18 \\
14 \\
25 \\
7\end{array}$ & $\begin{array}{l}2 \\
4 \\
3 \\
5 \\
1\end{array}$ \\
\hline $\begin{array}{r}6 \\
7 \\
8 \\
9 \\
10\end{array}$ & $\begin{array}{c}24 \\
21 \\
9.5 \\
10.5 \\
10\end{array}$ & $\begin{array}{l}5 \\
4 \\
1 \\
3 \\
2\end{array}$ & $\begin{array}{r}19 \\
16 \\
7 \\
21 \\
21\end{array}$ & $\begin{array}{l}3 \\
2 \\
1 \\
4.5 \\
4.5\end{array}$ \\
\hline $\begin{array}{l}11 \\
12 \\
13 \\
14 \\
15 \\
\end{array}$ & $\begin{array}{r}12 \\
22 \\
8 \\
14 \\
19 \\
\end{array}$ & $\begin{array}{l}2 \\
5 \\
1 \\
3 \\
4\end{array}$ & $\begin{array}{r}15 \\
22 \\
14 \\
7 \\
17\end{array}$ & $\begin{array}{l}3 \\
5 \\
2 \\
1 \\
4\end{array}$ \\
\hline $\begin{array}{l}16 \\
17 \\
18 \\
19 \\
20 \\
\end{array}$ & $\begin{array}{r}8 \\
19 \\
23 \\
7 \\
18 \\
\end{array}$ & $\begin{array}{l}2 \\
4 \\
5 \\
1 \\
3 \\
\end{array}$ & $\begin{array}{r}12 \\
14 \\
24 \\
8 \\
17 \\
\end{array}$ & $\begin{array}{l}2 \\
3 \\
5 \\
1 \\
4 \\
\end{array}$ \\
\hline $\begin{array}{l}21 \\
22 \\
23 \\
24 \\
25 \\
\end{array}$ & $\begin{array}{r}17 \\
17 \\
7 \\
9 \\
25 \\
\end{array}$ & $\begin{array}{l}3.5 \\
3.5 \\
1 \\
2 \\
5\end{array}$ & $\begin{array}{l}19 \\
14 \\
12.5 \\
13.5 \\
16\end{array}$ & $\begin{array}{l}5 \\
3 \\
1 \\
2 \\
4 \\
\end{array}$ \\
\hline & & & & - \\
\hline
\end{tabular}


APPENDIX XIVI: (ii) Leadership Nominations, by subject (females)

\begin{tabular}{|c|c|c|c|c|}
\hline Subject & $\begin{array}{l}\text { Task } \\
\text { Leadership } \\
\text { Nominations } \\
\end{array}$ & Rank & $\begin{array}{l}\quad S-E \\
\text { Leadership } \\
\text { Nominations }\end{array}$ & Rank \\
\hline $\begin{array}{l}1 \\
2 \\
3 \\
4 \\
5 .\end{array}$ & $\begin{array}{r}18 \\
12 \\
9 \\
21 \\
15\end{array}$ & $\begin{array}{l}4 \\
2 \\
1 \\
5 \\
3\end{array}$ & $\begin{array}{r}16 \\
20 \\
9 \\
20 \\
10\end{array}$ & $\begin{array}{l}3 \\
4.5 \\
1 \\
4.5 \\
2\end{array}$ \\
\hline $\begin{array}{r}6 \\
7 \\
8 \\
9 \\
10\end{array}$ & $\begin{array}{l}22 \\
11.5 \\
23 \\
9 \\
9.5\end{array}$ & $\begin{array}{l}4 \\
3 \\
5 \\
1 \\
2\end{array}$ & $\begin{array}{c}16.5 \\
9 \\
20.5 \\
9 \\
20\end{array}$ & $\begin{array}{l}3 \\
1.5 \\
5 \\
1.5 \\
4\end{array}$ \\
\hline $\begin{array}{l}11 \\
12 \\
13 \\
14 \\
15\end{array}$ & $\begin{array}{r}14 \\
8 \\
12 \\
25 \\
16\end{array}$ & $\begin{array}{l}3 \\
1 \\
2 \\
5 \\
4\end{array}$ & $\begin{array}{r}14 \\
7 \\
12 \\
25 \\
17\end{array}$ & $\begin{array}{l}3 \\
1 \\
2 \\
5 \\
4\end{array}$ \\
\hline $\begin{array}{l}16 \\
17 \\
18 \\
19 \\
20\end{array}$ & $\begin{array}{c}15 \\
15.5 \\
24.5 \\
5 \\
15\end{array}$ & $\begin{array}{l}2.5 \\
4 \\
5 \\
1 \\
2.5\end{array}$ & $\begin{array}{l}13 \\
14 \\
22 \\
12 \\
14\end{array}$ & $\begin{array}{l}2 \\
3.5 \\
5 \\
1 \\
3.5\end{array}$ \\
\hline $\begin{array}{l}21 \\
22 \\
23 \\
24 \\
25\end{array}$ & $\begin{array}{r}25 \\
15 \\
7 \\
11 \\
17\end{array}$ & $\begin{array}{l}5 \\
3 \\
1 \\
2 \\
4\end{array}$ & $\begin{array}{l}25 \\
11 \\
11 \\
12 \\
16\end{array}$ & $\begin{array}{l}5 \\
1.5 \\
1.5 \\
3 \\
4\end{array}$ \\
\hline $\begin{array}{l}26 \\
27 \\
28 \\
29 \\
30\end{array}$ & $\begin{array}{r}22 \\
8 \\
8 \\
20 \\
17\end{array}$ & $\begin{array}{l}5 \\
1.5 \\
1.5 \\
4 \\
3\end{array}$ & $\begin{array}{r}24 \\
7 \\
12 \\
18 \\
14\end{array}$ & $\begin{array}{l}5 \\
1 \\
2 \\
4 \\
3\end{array}$ \\
\hline
\end{tabular}


APDENDIX XLVII: Comparison of Pre-emption Rates: Male Task Leaders and other Group Members

\begin{tabular}{|c|c|c|c|c|c|}
\hline $\begin{array}{l}\text { Subjects } \\
\text { (Ieaders) }\end{array}$ & $\begin{array}{l}\text { Pre-emption } \\
\text { rate }\end{array}$ & Rank & $\begin{array}{l}\text { Subjects } \\
\text { (others) }\end{array}$ & $\begin{array}{l}\text { Pre-emption } \\
\text { rate }\end{array}$ & Rank \\
\hline $\begin{array}{r}5 \\
8 \\
13 \\
19 \\
23\end{array}$ & $\begin{array}{l}.652 \\
.563 \\
1 \\
.263 \\
.7 \\
.\end{array}$ & $\begin{array}{c}16 \\
13.5 \\
24.5 \\
4 \\
18\end{array}$ & $\begin{array}{r}1 \\
2 \\
3 \\
4 \\
6 \\
7 \\
9 \\
10 \\
11 \\
12 \\
14 \\
15 \\
16 \\
17 \\
18 \\
20 \\
21 \\
22 \\
24 \\
25 \\
\end{array}$ & $\begin{array}{l}.0 \\
.563 \\
.364 \\
.5 \\
.195 \\
.133 \\
.7 \\
.5 \\
.29 \\
.32 \\
.727 \\
.278 \\
.727 \\
.7 \\
.842 \\
.482 \\
.65 \\
.818 \\
1 \\
.333\end{array}$ & $\begin{array}{c}1 \\
13.5 \\
9 \\
11.5 \\
3 \\
2 \\
18 \\
11.5 \\
7 \\
8 \\
20.5 \\
5 \\
20.5 \\
18 \\
23 \\
10 \\
15 \\
22 \\
24.5 \\
6 \\
\end{array}$ \\
\hline$n_{1}=5$ & & $R_{1}=76$ & $n_{2}=20$ & & $R_{2}=243$ \\
\hline
\end{tabular}

Null Eypothesis $\left(H_{0}\right)$ : Male task leaders have the same rate of pre-emption as other group members.

$\left(\mathrm{H}_{1}\right)$ : Male task leaders have higher rates of pre-emption than other group members.

Employing a Mann-Whitney U test, $\quad \sigma=n_{1} n_{2}+\frac{n_{1}\left(n_{1}+1\right)}{2}-R_{1}=100+15-76$ $\mathrm{n}_{1}=5, \mathrm{n}_{2}=20, \mathrm{~J}=39$. Critical value of $\mathrm{J}=25$, at $5 \%$ level of signif. Therefore, $\mathrm{H}_{0}$ accepted, Male task leaders have the same rate of pre-emption as other group members. 


\begin{tabular}{|c|c|c|c|c|c|}
\hline $\begin{array}{l}\text { Subjects } \\
\text { (leaders) }\end{array}$ & $\begin{array}{l}\text { Pre-emption } \\
\text { rate }\end{array}$ & Rank & $\begin{array}{l}\text { Subjects } \\
\text { (others) }\end{array}$ & $\begin{array}{l}\text { Pre-emption } \\
\text { rate }\end{array}$ & Rank \\
\hline $\begin{array}{r}5 \\
8 \\
14 \\
19 \\
23\end{array}$ & $\begin{array}{l}.652 \\
.563 \\
.72 \\
.263 \\
.7\end{array}$ & $\begin{array}{c}16 \\
13.5 \\
20.5 \\
4 \\
18\end{array}$ & $\begin{array}{r}1 \\
2 \\
3 \\
4 \\
6 \\
7 \\
9 \\
10 \\
11 \\
12 \\
13 \\
15 \\
16 \\
17 \\
18 \\
20 \\
21 \\
22 \\
24 \\
25\end{array}$ & $\begin{array}{l}0 \\
.563 \\
.364 \\
.5 \\
.195 \\
.133 \\
.7 \\
.5 \\
.29 \\
.32 \\
.1 \\
.278 \\
.727 \\
.7 \\
.842 \\
.482 \\
.65 \\
.818 \\
1 \\
.333\end{array}$ & $\begin{array}{c}1 \\
13.5 \\
9 \\
11.5 \\
3 \\
2 \\
18 \\
11.5 \\
7 \\
8 \\
24.5 \\
5 \\
20.5 \\
18 \\
23 \\
10 \\
15 \\
22 \\
24.5 \\
6\end{array}$ \\
\hline$n_{1}=5$ & & $R_{1}=72$ & $n_{2}=20$ & & $R_{2}=247$ \\
\hline
\end{tabular}

Null Eypothesis $\left(\mathrm{H}_{\mathrm{O}}\right)$ : Male socio-emotional leaders have the same rate of pre-emption as other group members.

$\left(\mathrm{H}_{1}\right)$ : Male socio-emotional leaders have higher rates of pre-emption than other group members.

Employing a Mann-Whitney $\delta$ test, $\sigma=n_{1} n_{2}+\frac{n_{1}\left(n_{1}+1\right)}{2}-R_{1}=100+15-72$ $n_{1}=5, n_{2}=20,0=43$. Critical value of $U=25$, at $5 \%$ level of signif. Therefore, Ho accepted, Male socio-emotional leaders have the same rate of pre-emption as other group members. 


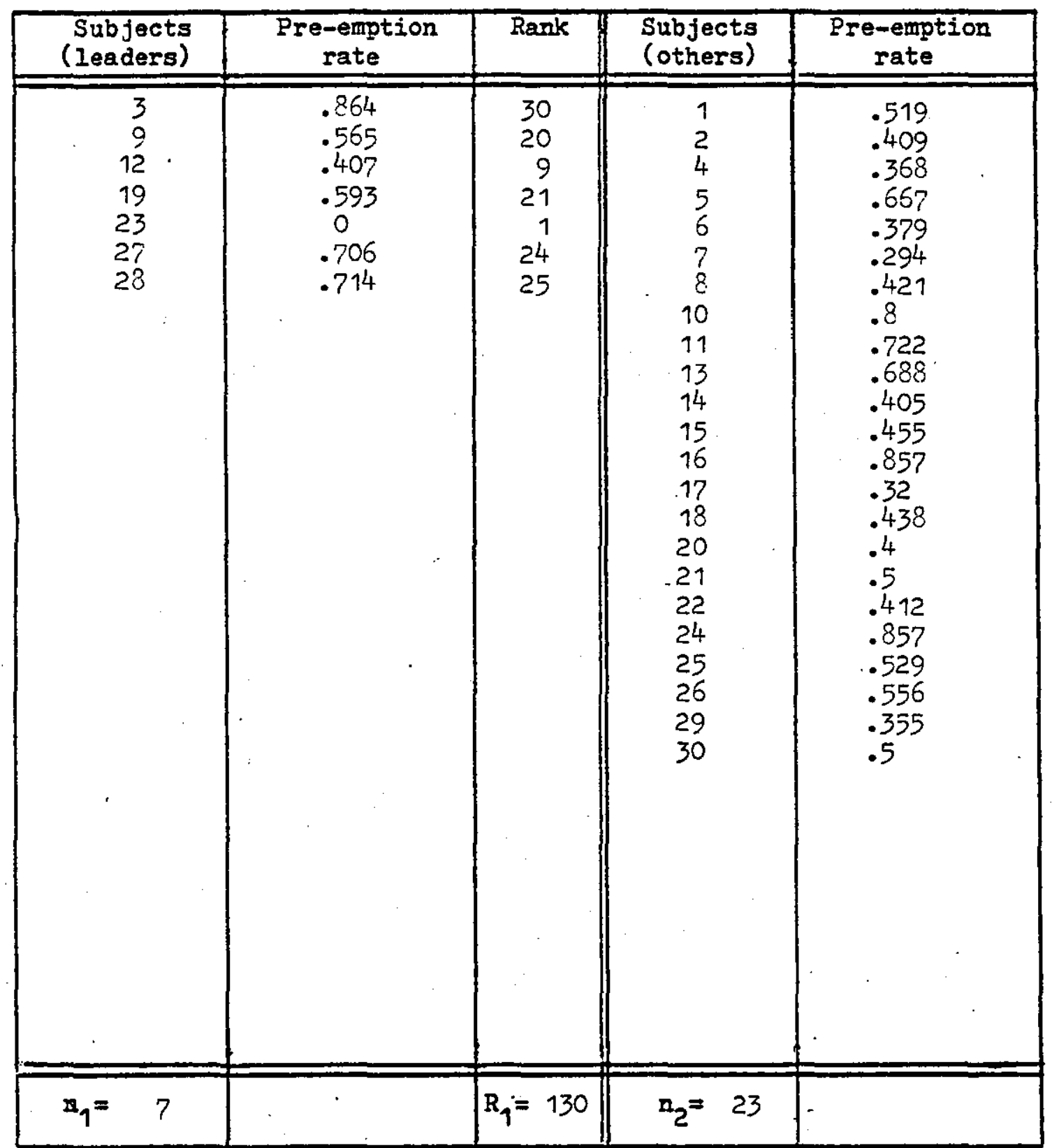

Null Bypothesis $\left(\mathrm{H}_{\mathrm{O}}\right)$ : Female task leaders have the same rate of prememption as other group members.

$\left(\mathrm{H}_{1}\right)$ : . Female task leaders have higher rates of pre-emption than other group members.

Employing a Mann-Whitney $\delta$ test, $\quad J=n_{1} n_{2}+\frac{n_{1}\left(n_{1}+1\right)}{2}-R_{1}=161+28-130$ For $n_{2}$ larger than 20, $\quad z=\frac{\nabla-n_{1} n_{2} / 2}{\sqrt{\frac{\left(n_{1}\right)\left(n_{2}\right)\left(n_{1}+n_{2}+1\right)}{12}}} \frac{21.5}{20.39}=1.05$

z) 1.05 has a one-tailed probability under $\mathrm{B}_{0}$ of $\mathrm{p}<.147$. Region of rejection, $\left.\mathrm{p}\right\rangle .09$ Therefore, $\mathrm{H}_{\mathrm{O}}$ accepted. Female task leaders have the same rate of pre-emption as other task leaders. 


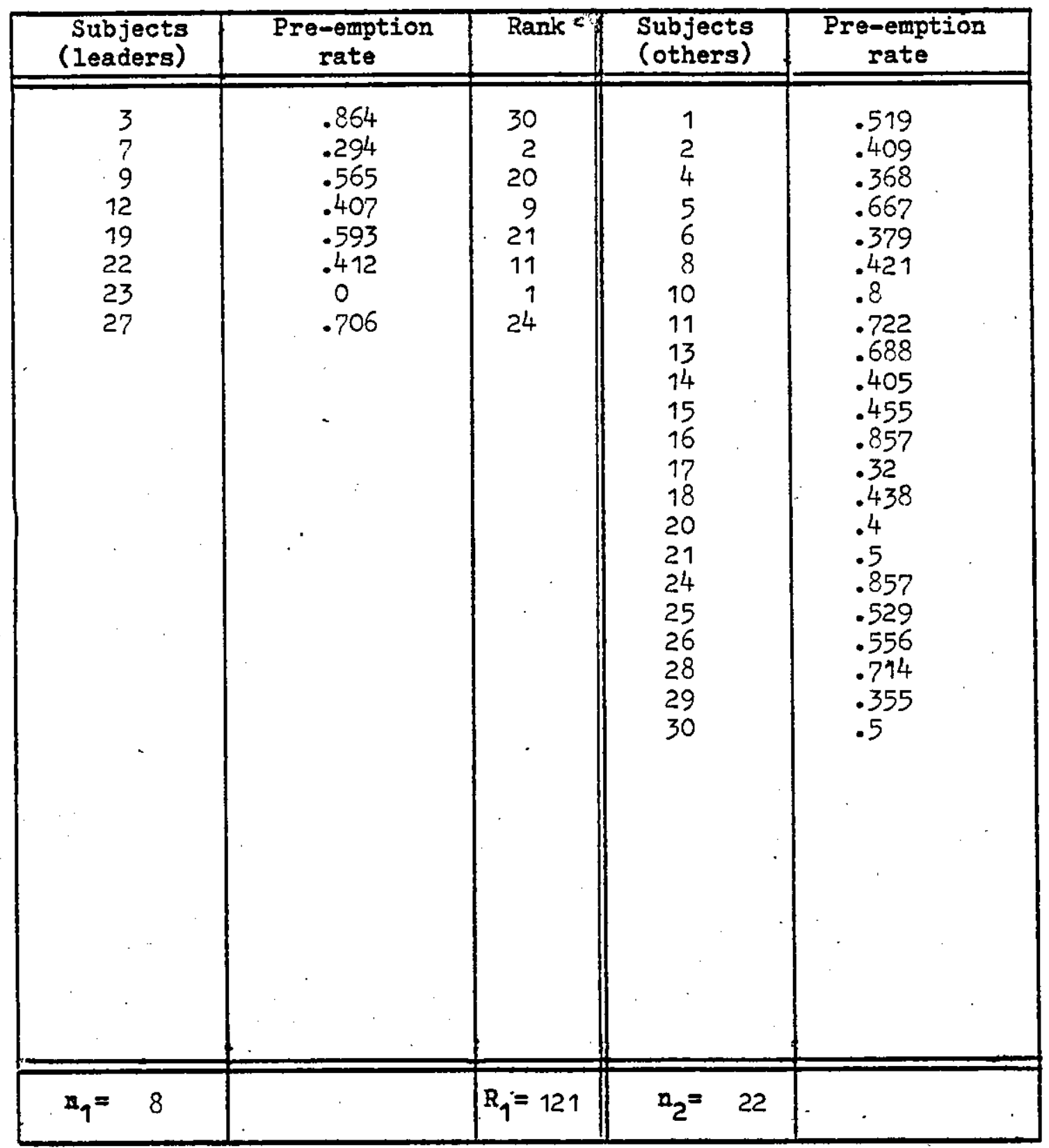
Null Hypothesis $\left(H_{O}\right):$ Female socio-emotional leaders have the same rate of
pre-emption as other group members.

$\left(\mathrm{H}_{1}\right)$ : Female socio-emotional leaders have higher rates of pre-emption than other group members.

Employing a Mann-Whitney 0 test, $\delta=n_{1} n_{2}+\frac{n_{1}\left(n_{1}+1\right)}{2}-R_{1}=176+36-118$ For $n_{2}$ larger than 20, $\quad=\sqrt{\frac{\delta-n_{1} n_{2} / 2}{\frac{\left(n_{1}\right)\left(n_{2}\right)\left(n_{1}+n_{2}+1\right)}{12}} \frac{36}{21.32}}=.281$

z) .281 has a one-tailed probability under $\mathrm{H}_{0}$ of $\mathrm{p}<.39$. Region of rejection, $>.05$

Therefore, $\mathrm{H}_{\mathrm{O}}$ accepted. Female socio-emotional leaders have the same rate of pre-emption as other group members. 
